\title{
Arsenic Removal from Industrial Wastewater by Photo-oxidation
}

by

\section{Liang Zou}

B. Eng. in Water and Wastewater Engineering

Suzhou Institute of Urban Construction and Environmental Protection

\author{
A thesis submitted to the \\ Faculty of Graduate Studies and Research \\ in partial fulfillment of the requirements \\ for the degree of \\ Master of Applied Science \\ Ottawa-Carleton Institute for Civil and Environmental Engineering \\ Carleton University \\ Ottawa, Ontario, Canada
}

May, 2007

(c) Copyright

2007, Liang Zou 


$\begin{array}{ll}\begin{array}{l}\text { Library and } \\ \text { Archives Canada }\end{array} & \begin{array}{l}\text { Bibliothèque et } \\ \text { Archives Canada }\end{array} \\ \begin{array}{l}\text { Published Heritage } \\ \text { Branch }\end{array} & \begin{array}{l}\text { Direction du } \\ \text { Patrimoine de l'édition }\end{array} \\ \begin{array}{l}\text { 395 Wellington Street } \\ \text { Ottawa ON K1A 0N4 }\end{array} & \begin{array}{l}\text { 395, rue Wellington } \\ \text { Ottana ON K1A ON4 } \\ \text { Canada Oa }\end{array}\end{array}$

Your file Votre référence ISBN: 978-0-494-27006-6 Ourfile Notre référence ISBN: 978-0-494-27006-6

NOTICE:

The author has granted a nonexclusive license allowing Library and Archives Canada to reproduce, publish, archive, preserve, conserve, communicate to the public by telecommunication or on the Internet, loan, distribute and sell theses worldwide, for commercial or noncommercial purposes, in microform, paper, electronic and/or any other formats.

The author retains copyright ownership and moral rights in this thesis. Neither the thesis nor substantial extracts from it may be printed or otherwise reproduced without the author's permission.
AVIS:

L'auteur a accordé une licence non exclusive permettant à la Bibliothèque et Archives Canada de reproduire, publier, archiver, sauvegarder, conserver, transmettre au public par télécommunication ou par l'Internet, prêter, distribuer et vendre des thèses partout dans le monde, à des fins commerciales ou autres, sur support microforme, papier, électronique et/ou autres formats.

L'auteur conserve la propriété du droit d'auteur et des droits moraux qui protège cette thèse. $\mathrm{Ni}$ la thèse ni des extraits substantiels de celle-ci ne doivent être imprimés ou autrement reproduits sans son autorisation.
In compliance with the Canadian

Privacy Act some supporting forms may have been removed from this thesis.

While these forms may be included in the document page count, their removal does not represent any loss of content from the thesis.
Conformément à la loi canadienne sur la protection de la vie privée, quelques formulaires secondaires ont été enlevés de cette thèse.

Bien que ces formulaires aient inclus dans la pagination, il n'y aura aucun contenu manquant. 


\begin{abstract}
Arsenic is a naturally occurring chemical found in the earth's crust, which when released into drinking water supplies can be hazardous to humans and must be removed. Most arsenic removal or remediation technologies require that the arsenic be in the oxidized form as arsenate when it is much easier to remove by many of the technologies currently available. Hence this investigation was directed towards developing a process for the efficient oxidation of arsenite to arsenate. The photochemical oxidation is one such process that had not been adequately investigated in the past and it is the objective of this work to evaluate this.

A detailed study was conducted on the Direct Photolysis (DP) and the Advanced Oxidation Processes (AOP) employing hydrogen peroxide $\left(\mathrm{H}_{2} \mathrm{O}_{2}\right)$ as the homogeneous photo-oxidizer for the oxidation of arsenite to arsenate. The effects of many operating parameters were evaluated for both these photochemical processes. The AOP is found to be much more effective than DP for the economic and effective conversion of arsenite to arsenate and the process can be developed for further use as a preoxidation step for many of the established arsenate removal technologies such as Ion Exchange, Membrane Separation etc. It is found that Dissolved Oxygen (DO) in the case of DP and the $\mathrm{H}_{2} \mathrm{O}_{2}$ /Arsenic ratio in the case of AOP are the most important parameters that dictate the feasibility and efficiency of arsenite oxidation.

The kinetic studies were conducted in a batch reactor and in a custom-modified recirculating batch reactor and the results were analyzed to establish the probable reaction order and rate constants. Reaction schemes are postulated to indicate the most probable mechanism for the overall photo-oxidation reactions.
\end{abstract}




\section{ACKNOWLEDGEMENT}

I wish to express my deep gratitude and admiration for my supervisor, Professor Sampat Sridhar, Department of Civil and Environmental Engineering, Carleton University. Along the way, not only has he provided me unwavering support and guidance in the development of this thesis, but he has also taught me the additional lessons on critical thinking and organization, which I will carry forward in my academic and personal life. Without the intellectual instructions and patient correction from Professor Sridhar, I would not have completed the thesis for my Master's degree.

I also would like to thank Dr. Doug Gould and Dr. David Koren of CANMET, Natural Resources Canada (NRCan), for their generous help all through the research work and for the materials and laboratory support provided for my project. I would like to thank Mr. M. Pawlak of the Analytical Science Group, NRCan and Dr. S. Cathum of SAIC for giving me the required training on arsenic speciation and analytical methods. Thanks are also extended to Mr. J. Kawaja, Ms. L. Lortie, Mr. P. Bédard, Ms. L. Morin and Ms. S. Rowsome in NRCan, and to Ms. M. Tudoret-Chow of Carleton University for their assistance during the progress of this work. I would like to thank the Department Chair, Professor G. A. Hartley, and the Associate Chair, Professor S. Sivathayalan for their administrative help and assistance.

I am deeply grateful to my friends Zhe-Cheng Jin, Dan Shu, Chen Wang, for their invaluable encouragement and endless help on my thesis writing.

Last but not the least, I would like to especially thank my wife, Xiu-Juan Xia, for her understanding, emotional support and encouragement during the past two years. 


\section{TABLE OF CONTENTS}

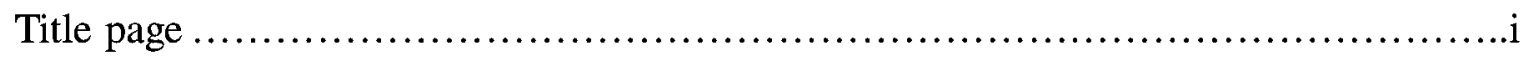

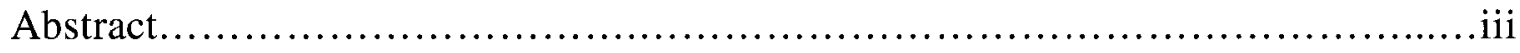

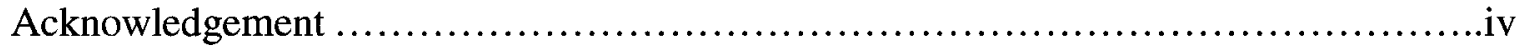

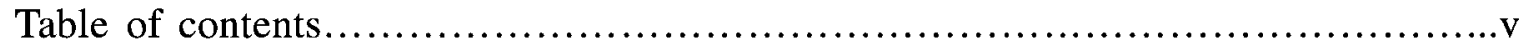

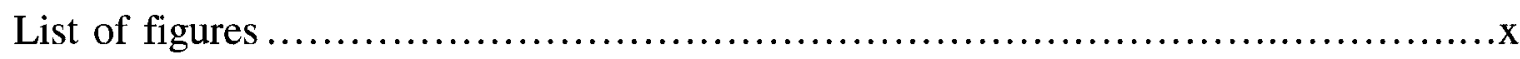

List of tables...............................................................

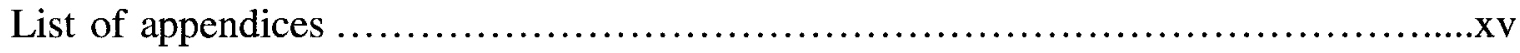

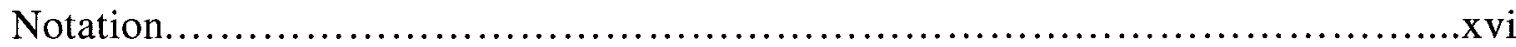

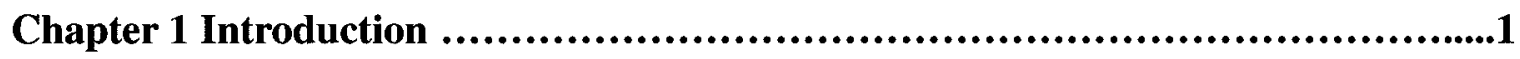

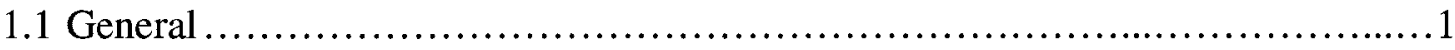

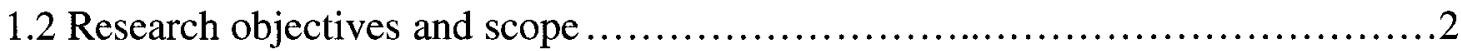

1.3 Organization of the thesis...................................................

Chapter 2 Background review........................................................5

2.1 Arsenic in the environment - sources and distribution......................... 5

2.2 Basic chemistry of arsenic in water.......................................... 6

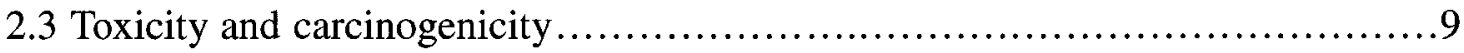

2.4 Environmental impact ................................................ 11

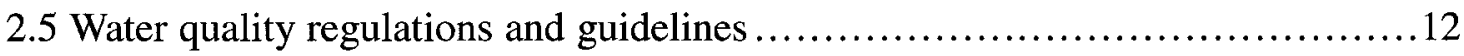

2.5.1 Drinking water quality guidelines for arsenic............................. 12

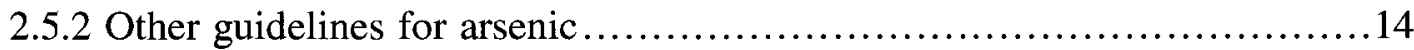

2.6 Review of removal technologies........................................ 14

2.6.1 Precipitation/coprecipitation ..................................... 15

2.6.2 Adsorption/ ion exchange........................................ 16

2.6.3 Membrane filtration............................................... 17

2.7 Pre-oxidation of As(III) to As(V) ...................................... 19 
2.8 Need for new As(III) oxidation technologies..................................21

2.8.1 Limitations of existing As(III) oxidation technologies.......................21

2.8 .2 Need for new technology ............................................23

Chapter 3 Review of photochemistry and photooxidation of arsenic..................24

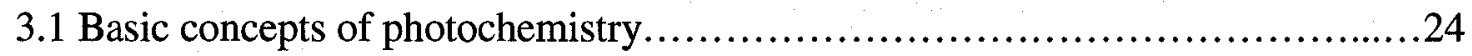

3.1.1 Electromagnetic radiation and energy ....................................24

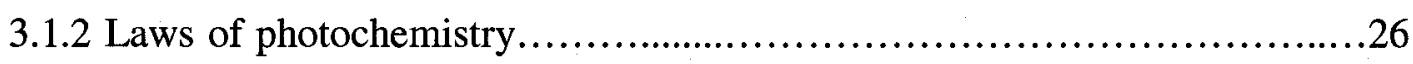

3.1.2.1 First law of photochemistry .....................................26

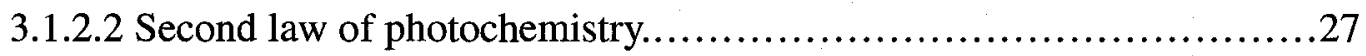

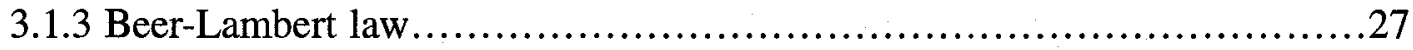

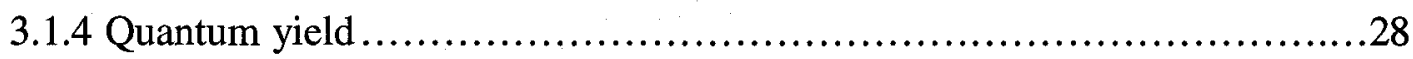

3.1.5 Comparison of photochemical and thermochemical reactions................29

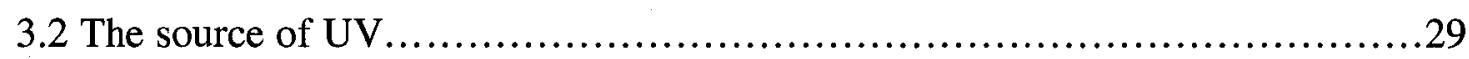

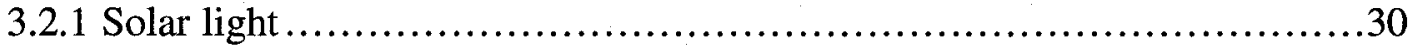

3.2.2 Mercury UV lamp..................................................... 30

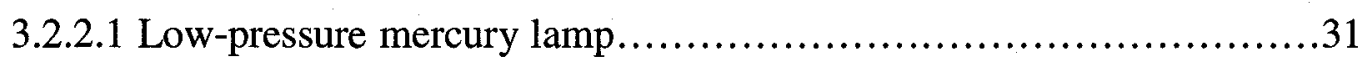

3.2.2.2 Medium-pressure mercury lamp................................... 31

3.2.2.3 High-pressure mercury lamp ...................................... 32

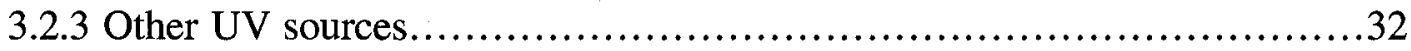

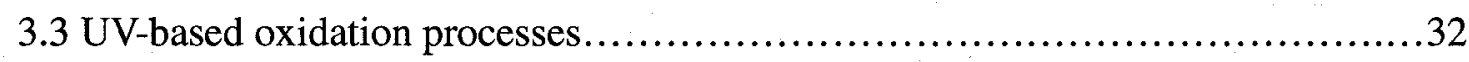

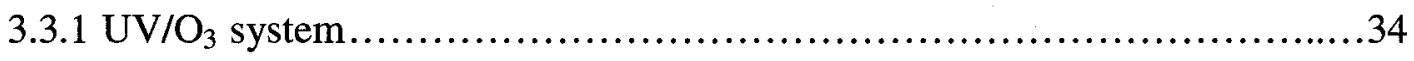

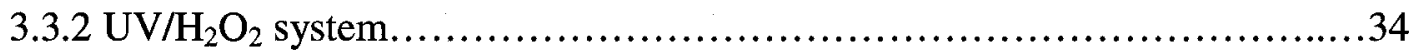

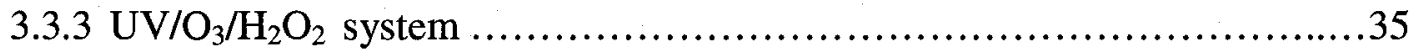

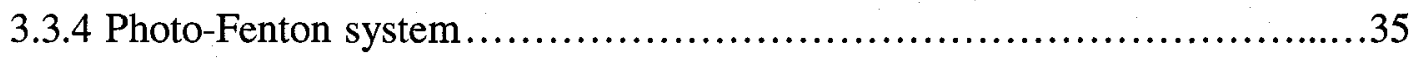

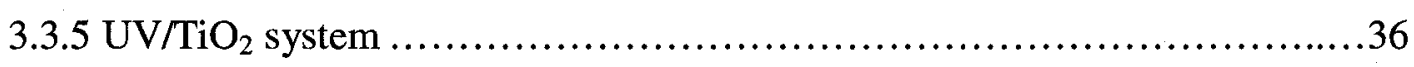

3.4 Summary of the previous work on photooxidation of As(III) ....................37

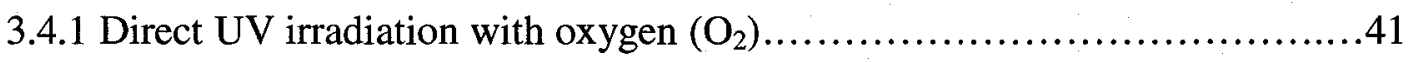

3.4.2 Hydrogen peroxide $\left(\mathrm{H}_{2} \mathrm{O}_{2}\right)$ as the oxidant.............................41

3.4.3 Iron compounds as the catalyst ...........................................41

3.4.4 Sulfite as the oxidant/inducer.............................................43 
3.4.5 Humic acid as the oxidant ................................................44

3.4.6 Activated carbon as the heterogeneous catalyst...............................44

$3.4 .7 \mathrm{TiO}_{2}$ as the heterogeneous catalyst......................................44

3.5 Mechanism of UV-based As(III) oxidation..................................45

3.6 Justification for the current work..........................................47

Chapter 4 Experimental details....................................................50

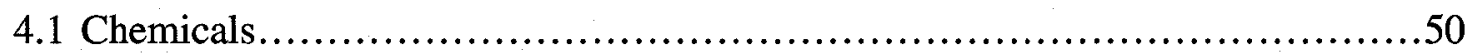

4.2 Equipment and apparatus.............................................50

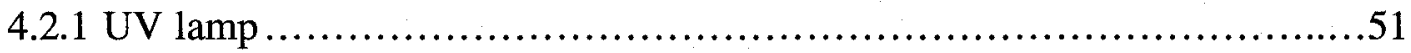

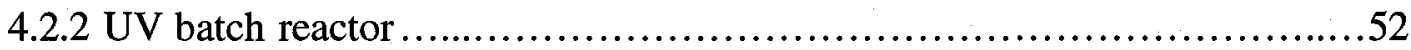

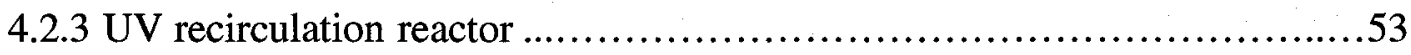

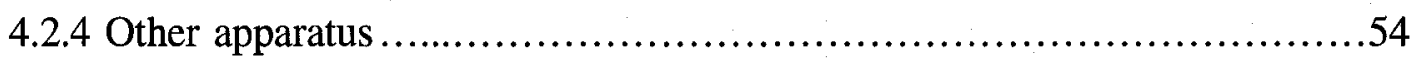

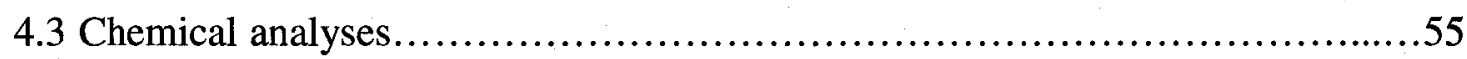

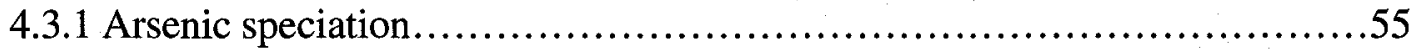

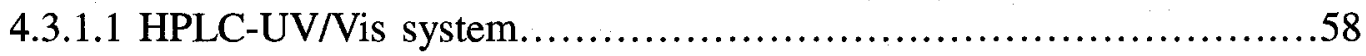

4.3.1.2 HPLC-HG-AAS system.........................................6

4.3.1.3 CSE-HPLC-DAD system........................................61

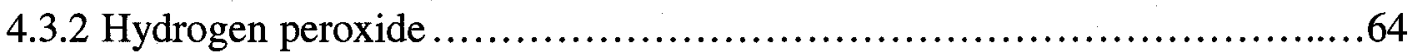

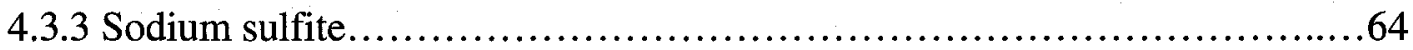

4.4 Sample stability, preservation and pretreatment..............................65

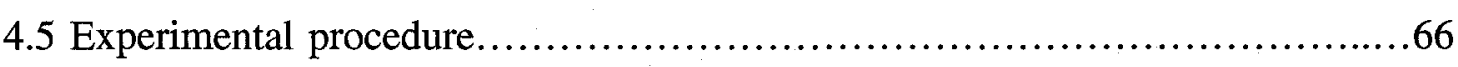

4.5.1 Experimental arrangement ............................................66

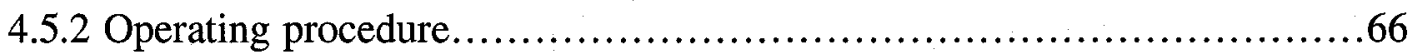

4.5.2.1 Safe handling and waste disposal ..................................66

4.5.2.2 Batch reactor................................................... 67

4.5.2.3 Recirculation reactor........................................68

4.5.3 Parameter control...................................................69

4.5.3.1 Initial As(III) concentration.....................................69

4.5.3.2 Initial $\mathrm{H}_{2} \mathrm{O}_{2}$ concentration ......................................69

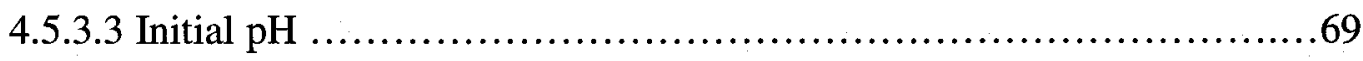


4.5.3.4 DO concentration ............................................... 70

4.5.3.4 Mixing efficiency ............................................. 70

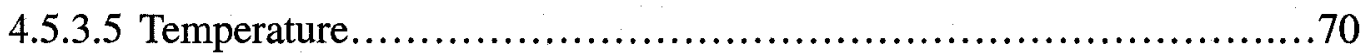

4.5.4 Evaluation of the experimental reproducibility.............................71

Chapter 5 Results and discussion..................................................72

5.1 Absorption spectra of $\mathrm{As}(\mathrm{III})$ and hydrogen peroxide........................72

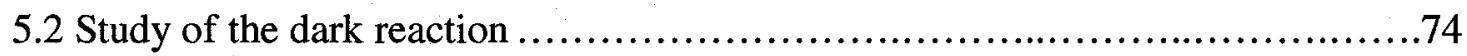

5.3 Direct photolysis .................................................. 74

5.3.1 Direct photolysis in the batch reactor.................................. 74

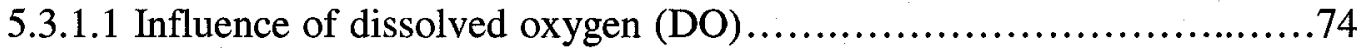

5.3.1.2 Effect of initial As(III) concentration...............................83

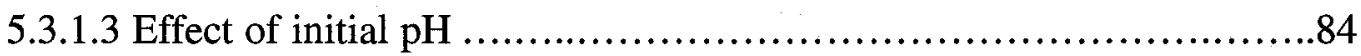

5.3.2 Direct photolysis in the recirculation reactor.............................89

5.3.2.1 Effect of recycle rate...........................................91

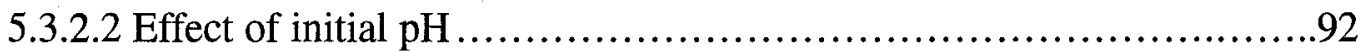

5.3.2.3 Effect of initial As(III) concentration .............................93

5.3 .3 Kinetics of direct photolysis......................................94

5.3.3.1 Rate equation and reaction order................................94

5.3.3.2 Reaction mechanism.......................................... 101

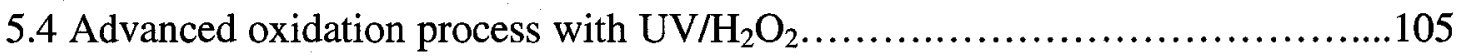

5.4.1 Dark reaction experiment.......................................... 106

$5.4 .2 \mathrm{AOP}$ in the batch reactor........................................ 107

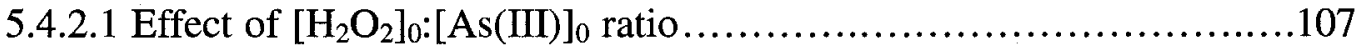

5.4.2.2 Influence of dissolved oxygen.................................... 111

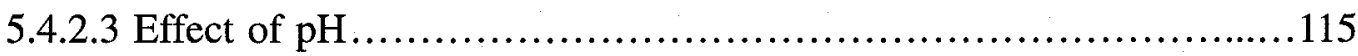

5.4.2.4 Effect of initial As(III) concentration..............................119

5.4.3 AOP in the recirculation reactor..................................... 120

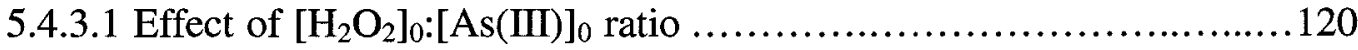

5.4.3.2 Effect of recycle rate........................................... 121

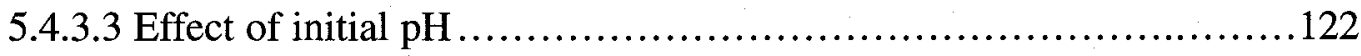

viii 
5.4.3.4 Effect of initial As(III) concentration ............................123

5.4.4 Kinetics of the $\mathrm{H}_{2} \mathrm{O}_{2} / \mathrm{UV}$ process.................................. 124

5.4 .4 .1 Rate equation and reaction order............................... 124

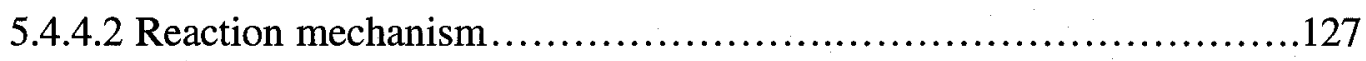

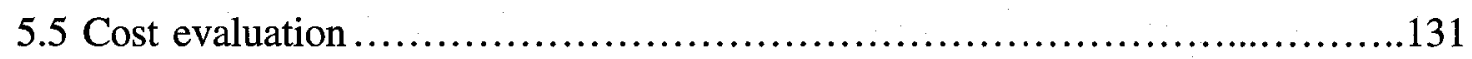

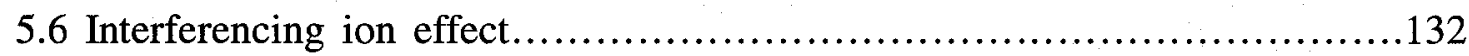

5.6.1 Batch reactor................................................... 133

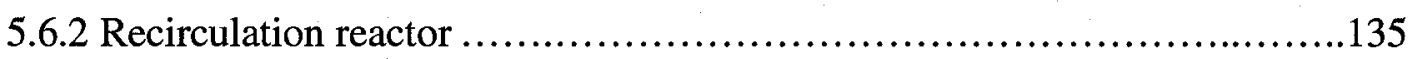

Chapter 6 Conclusion and recommendations.....................................138

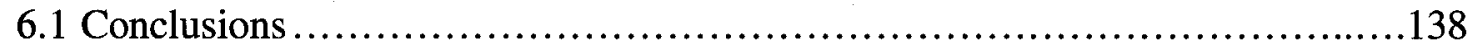

6.2 Recommendations............................................. 142

References................................................................................144

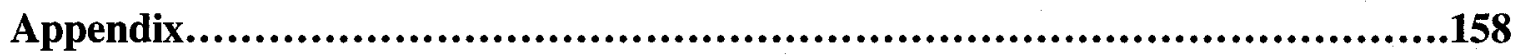




\section{LIST OF FIGURES}

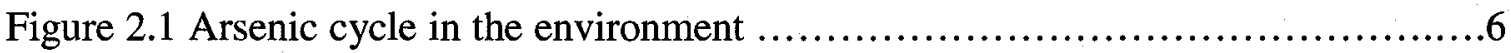

Figure 2.2 (a) Arsenite and (b) arsenate speciation as a function of $\mathrm{pH}$.................

Figure 2.3 Eh-pH diagrams of As-O-H system $\ldots \ldots \ldots \ldots \ldots \ldots \ldots \ldots \ldots \ldots \ldots \ldots \ldots \ldots$

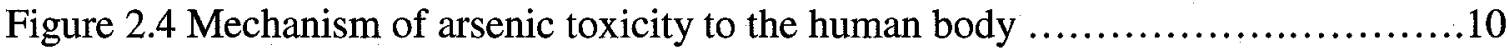

Figure 2.5 Distribution of documented world problem with arsenic in groundwater .... 12

Figure 2.6 Classification of membranes and the relative size of materials subject to

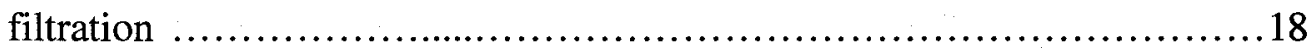

Figure 3.1 Electromagnetic-photon spectrum.......................................

Figure 4.1 Energy distribution of $1 \mathrm{~kW}$ Rayox ${ }^{\circledR}$ Sentinel $^{\mathrm{TM}}$ medium-pressure mercury

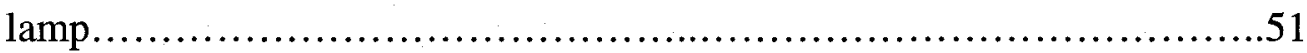

Figure 4.2 The front view (left) and rear view (right) of the UV batch reactor...........53

Figure 4.3 The establishment of the UV recirculation reactor........................54

Figure 4.4 Procedures for arsenic speciation in different matrixes....................56

Figure 4.5 The schematic of HPLC-UV/Vis system............................59

Figure 4.6 The schematic of HPLC-HG-AAS system..........................60

Figure 4.7 The procedure of chelation-solvent extraction...........................63

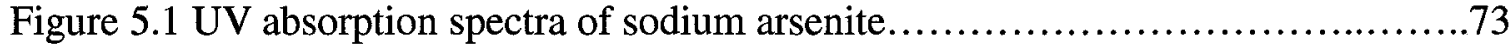

Figure 5.2 UV absorption spectra of hydrogen peroxide............................... 73

Figure 5.3 As (III) concentration as a function of irradiation time in direct photolysis under oxic and near-anoxic conditions...............................76

Figure 5.4 As (V) concentration as a function of irradiation time in direct photolysis under oxic and near-anoxic conditions

.76

Figure 5.5 DO as a function of irradiation time in direct photolysis under oxic and nearanoxic conditions

Figure $5.6 \mathrm{pH}$ as a function of irradiation time in direct photolysis under oxic and nearanoxic conditions..................................................... 77

Figure 5.7 Measured Eh-pH diagram in direct photolysis under oxic and near-anoxic conditions.... 
Figure 5.8 As (III) and DO concentrations as a function of irradiation time in direct photolysis under different DO concentrations.

Figure $5.9 \mathrm{As}$ (III) concentrations as a function of irradiation time in direct photolysis under different initial As(III) concentrations.

Figure 5.10 As (III) concentration as a function of irradiation time in direct photolysis under different initial $\mathrm{pH}$. . .85

Figure 5.11 DO concentration as a function of irradiation time in direct photolysis under different initial $\mathrm{pH}$.

Figure $5.12 \mathrm{pH}$ as a function of irradiation time in direct photolysis under different initial $\mathrm{pH}$ . .86

Figure 5.13 Measured Eh-pH diagram in direct photolysis under different initial $\mathrm{pH}$

Figure 5.14 Production of As (V) and $\mathrm{H}^{+}$as a function of irradiation time in direct

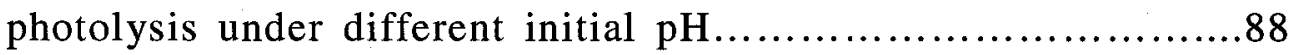

Figure 5.15 Schematic diagram of the recirculation reactor system. .90

Figure 5.16 As(III) concentration as a function of irradiation time in the recirculation reactor in direct photolysis at different recycle rates

Figure $5.17 \mathrm{As}(\mathrm{III})$ concentration as a function of irradiation time in the recirculation reactor in direct photolysis under different initial $\mathrm{pH}$. . .93

Figure $5.18 \mathrm{As}$ (III) concentration as a function of irradiation time in the recirculation system in direct photolysis under different initial As(III) concentration.....94

Figure 5.19 Evaluation of zero-order model with respect to the As(III) concentration .96

Figure 5.20 As(III) concentration as a function of irradiation time in AOP under different $\left[\mathrm{H}_{2} \mathrm{O}_{2}\right]_{0}:[\mathrm{As}(\mathrm{III})]_{0}$ ratios 108

Figure 5.21 $\mathrm{As}(\mathrm{V})$ concentration as a function of irradiation time in AOP under different $\left[\mathrm{H}_{2} \mathrm{O}_{2}\right]_{0}:[\mathrm{As}(\mathrm{III})]_{0}$ ratios .108

Figure 5.22 DO concentration as a function of irradiation time in AOP under different $\left[\mathrm{H}_{2} \mathrm{O}_{2}\right]_{0}:[\mathrm{As}(\mathrm{III})]_{0}$ ratios 109

Figure $5.23 \mathrm{pH}$ as a function of irradiation time in AOP under different $\left[\mathrm{H}_{2} \mathrm{O}_{2}\right]_{0}:[\mathrm{As}(\mathrm{III})]_{0}$ ratios. 
Figure 5.24 Measured Eh-pH diagram in AOP under different $\left[\mathrm{H}_{2} \mathrm{O}_{2}\right]_{0}:[\mathrm{As}(\mathrm{III})]_{0}$ ratios.

Figure 5.25 As(III) and DO concentrations as a function of irradiation time in AOP under different DO conditions with $\left[\mathrm{H}_{2} \mathrm{O}_{2}\right]_{0}:[\mathrm{As}(\mathrm{III})]_{0}=1: 1$

Figure 5.26 As(III) and DO concentrations as a function of irradiation time in AOP under

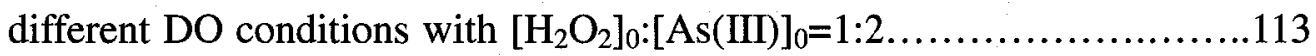

Figure 5.27 As(III) and DO concentrations as a function of irradiation time in AOP under different DO conditions with $\left[\mathrm{H}_{2} \mathrm{O}_{2}\right]_{0}:[\mathrm{As}(\mathrm{III})]_{0}=1: 4$

Figure 5.28 As (III) concentration as a function of irradiation time in AOP under different initial $\mathrm{pH}$. 116

Figure 5.29 DO concentration as a function of irradiation time in AOP under different initial $\mathrm{pH}$ 116

Figure $5.30 \mathrm{pH}$ as a function of irradiation time in AOP under different initial $\mathrm{pH}$

Figure 5.31 Measured Eh-pH diagram in AOP under different initial $\mathrm{pH}$.

Figure 5.32 As(III) concentration as a function of irradiation time in AOP under different initial As(III) concentration

Figure 5.33 As(III) concentration as a function of irradiation time in the recirculation reactor in $\mathrm{AOP}$ under different $\left[\mathrm{H}_{2} \mathrm{O}_{2}\right]_{0}:[\mathrm{As}(\mathrm{IIII})]_{0}$ ratios.

Figure 5.34 As(III) concentration as a function of irradiation time in the recirculation reactor in $\mathrm{AOP}$ under different recycle rates

Figure 5.35 As(III) concentration as a function of irradiation time in the recirculation reactor in $\mathrm{AOP}$ under different initial $\mathrm{pH}$.

Figure 5.36 As(III) concentration as a function of irradiation time in the recirculation reactor in AOP under different initial As(III) concentrations.

Figure 5.37 As(III) concentration as a function of irradiation time in the batch reactor in direct photolysis in the presence of different interfering ions.

Figure $5.38 \mathrm{As}(\mathrm{III})$ concentration as a function of irradiation time in the batch reactor in $\mathrm{AOP}$ in the presence of different interfering ions 134

Figure 5.39 $\mathrm{As}(\mathrm{III})$ concentration as a function of irradiation time in the recirculation reactor in direct photolysis in the presence of different interfering ions...136 
Figure 5.40 As(III) concentration as a function of irradiation time in recirculation reactor in $\mathrm{AOP}$ in the presence of different interfering ions.......................136 


\section{LIST OF TABLES}

Table 2.1 History of U.S. standards for arsenic in drinking water.....................13

Table 2.2 Summary of Canadian guidelines for arsenic..............................14

Table 2.3 Summary of reaction schemes of oxidizing As(III) by different oxidants.......21

Table 3.1 Relative oxidation power of common oxidants............................33

Table 3.2 Summary of experimental conditions of the As(III) photooxidation processes...................................................... 39

Table 3.3 List of reactions involved in photolysis of As(III) .......................46

Table 5.1 Molar ratio of $\left[\mathrm{H}^{+}\right]$and $[\mathrm{As}(\mathrm{V})]$ in the final solution in direct photolysis process......................................................... 88

Table 5.2 Arsenic species under different initial $\mathrm{pH}$ conditions.......................89

Table 5.3 Rate constants from different rate models at different DO conditions..........98

Table 5.4 Initial reaction rates at different initial As(III) concentration conditions........98

Table 5.5 Summary of the performance comparison between the batch reactor and the recirculation reactor in direct photolysis process.........................101

Table 5.6 Proposed reactions of As(III) oxidation in direct photolysis process...........105

Table 5.7 Maximum percentage conversion of As(III) by $\mathrm{H}_{2} \mathrm{O}_{2}$ in dark reaction........ 107

Table 5.8 Molar ratio of $\left[\mathrm{H}^{+}\right]$and $[\mathrm{As}(\mathrm{V})]$ in the final solution in AOP...........118

Table 5.9 Summary of the performance comparison between the batch reactor and the recirculation reactor in AOP.........................................127

Table 5.10 Proposed reactions of As(III) oxidation in AOP.....................130

Table 5.11 Cost evaluation in different photooxidation processes and reactor modes...........................................................

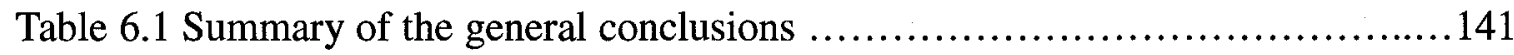




\section{LIST OF APPENDICES}

Appendix A. List of chemicals................................................. 158

Appendix B. Calibration curve of arsenic speciation by HPLC-UV/Vis.................159

Appendix C. Calibration curve of arsenic speciation by HPLC-HG-AAS.................160

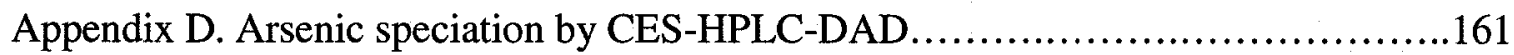

Appendix E. Determination of S(IV) by HPLC-UV/Vis........................... 162

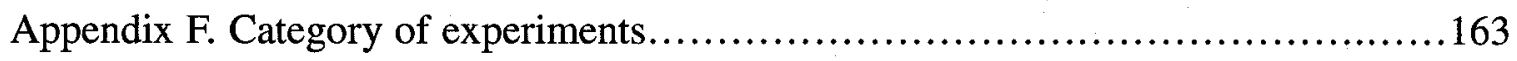

Appendix G: Verification of reproducibility of results...............................168

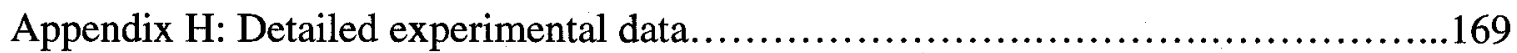




\section{NOTATION}

\section{Symbols}

A

A

A*

[A]

$[\mathrm{A}]_{0}$

$c$

$c$

E

E

$\mathrm{E}_{\mathrm{L}}$

$h$

I

$\mathrm{I}_{0}$

$k, k_{i}$

$l$

$\mathrm{nm}$

Q

$\mathrm{t}$

$\mathrm{T}$

V

\section{Greek letters}

$\alpha$

$\mathcal{\varepsilon}$

$\lambda$

$\phi$

$\Phi$

$v$ absorbance of the medium, dimensionless

a molecule of reactant

an electronically excited state of a reactant molecule

molar concentration of the reactant, $\mathrm{mol} \cdot \mathrm{L}^{-1}(\mathrm{M})$

initial concentration of the reactant, $\mathrm{mol} \cdot \mathrm{L}^{-1}$

velocity of light, $\mathrm{m} \cdot \mathrm{s}^{-1}$

molar concentration of the medium, $\mathrm{mol} \cdot \mathrm{L}^{-1}$

activation energy, $\mathrm{kcal} \cdot \mathrm{mol}^{-1}$

energy of quantum, $\mathrm{J}$

energy output of lamp, $J$

Plank's constant $\left(6.626 \times 10^{-34} \mathrm{~J} \cdot \mathrm{s}\right)$

intensity of transmitted light (Einstein $\cdot \mathrm{s}^{-1} \cdot \mathrm{cm}^{-2}$ )

intensity of the incident monochromatic light (Einstein $\left.\cdot \mathrm{s}^{-1} \cdot \mathrm{cm}^{-2}\right)$

rate constant, $\mathrm{M}^{1-\mathrm{n}} \cdot \mathrm{s}^{-1}$

path length penetrated by the incident light, $\mathrm{cm}$

nanometer, unit of wavelength

recirculation rate, $\mathrm{m}^{3} \cdot \mathrm{s}^{-1}$

irradiation time, hour

temperature, ${ }^{\circ} \mathrm{K}$

volume of the tank, $\mathrm{m}^{3}$

molar absorption coefficient, $\mathrm{cm}^{2} \cdot \mathrm{mol}^{-1}$

molar extinction coefficient $\left(\mathrm{M}^{-1} \cdot \mathrm{cm}^{-1}\right)$

wavelength of light, $\mathrm{m}$

quantum yield, mol Einstein $^{-1}$

overall quantum yield, mol. Einstein ${ }^{-1}$

frequency of light radiation, $\mathrm{cm} \cdot \mathrm{s}^{-1}$ 


\section{Abbreviations}

AOP

DI

DO

DP

GPM

UV
Advanced Oxidation Processes

Deionized

Dissolved Oxygen

Direct Photolysis

US gallons per minute

Ultraviolet

xvii 


\section{CHAPTER 1. INTRODUCTION}

\subsection{General}

Arsenic is a common, ubiquitous, naturally occurring element widely distributed in the earth's crust in the form of several arsenic compounds. Environmental contamination results when the arsenic is released by natural geologic events such as volcanic activity and soil and rock erosion. Anthropogenic activities that release arsenic include industrial processes such as mining, smelting and the production of paints, metals, soaps, dyes, drugs, semi-conductors, wood preservatives and many other consumer products. Arsenic is transported in the environment by groundwater and surface water systems and can impact human health by the ingestion of such water supplies. In recent years, high concentrations of arsenic have been found in the groundwater of Bangladesh, Vietnam and western United States and in many other parts of the world, to the extent, it is now regarded as a global issue. The human health impact due to ingestion of arsenic could be quite severe, as arsenic is known to cause skin lesions and cancers of the brain, liver, kidney and stomach (Smith et al., 1992). Chronic exposure may lead to a variety of symptoms including cardiovascular disease, diabetes and other skin ailments. In view of these wide-ranging health impacts, the World health Organization (WHO) has established a new standard for arsenic in drinking water of $10 \mu \mathrm{g} / \mathrm{L}(10 \mathrm{ppb})$. The USEPA and the European Union have adopted the new standard replacing the old standard of $50 \mu \mathrm{g} / \mathrm{L}$. Such trends in regulatory standards for drinking water have also raised corresponding 
demands for more stringent regulations for industrial wastewater discharges containing arsenic. To comply with such projected standards for industrial effluents in the future, it is imperative that new technology is developed whereby more efficient and economic removal of arsenic from industrial wastewaters such as acid mine waters, tailings and other industrial effluents can be achieved.

Arsenic mainly exists in water as arsenite (As(III)) and arsenate (As(V)). Many established technologies are effective for As(V) treatment, typically, chemical precipitation/coprecipitation, ion exchange, adsorption, and membrane separation. For most of the arsenic removal processes, a pre-oxidation step of converting As(III) to As(V) is required. Chlorine, permanganate, ozone, and some commercial products (such as Filox- $\mathrm{R}^{\mathrm{TM}}$ ) have proven to be the effective oxidants for As(III) oxidation (Office of Water, 2003). However, those oxidants have drawbacks such as the formation of by-products, difficulty in storage and handling, as well as processing requirements. Therefore, researchers endeavor to explore some innovative technologies that can yield high oxidation efficiency, low operating cost and preferably no by-products.

\subsection{Research Objectives and Scope}

Pervious research indicates that ultraviolet (UV) irradiation combined with certain oxidants or catalysts could be a potential substitute for the chemical As(III) oxidation processes. However, its applicability to the industry has not been fully explored yet. The mechanism for the oxidation of As(III) to As(V) by UV irradiation has not been 
delineated.

The objective of this research is to develop an UV-based oxidation process for As(III) oxidation and investigate the process feasibility. Specifically, the research work included: planning experimental protocol; standardizing sampling procedures; developing and establishing chemical analytical methods; assembling, commissioning and operating of UV reactors in the batch mode and the recirculation mode; selecting and comparing the performance of oxidants for arsenic oxidation; monitoring the variation of several parameters during the process, such as $\mathrm{pH}, \mathrm{Eh}$, dissolved oxygen, $\mathrm{As}(\mathrm{III}), \mathrm{As}(\mathrm{V})$, total arsenic etc.; studying the effects of various operating parameters and determining the optimum operating conditions; and finally, delineating the reaction kinetics and the probable reaction mechanism.

\subsection{Organization of the Thesis}

The rest of this thesis is comprised of the following five chapters:

Chapter 2 provides an overview of arsenic in the environment, such as, the source, species and distribution, basic chemistry, environmental and health impact, regulations and guidelines, available removal and oxidation technologies etc.

Chapter 3 introduces the general concept of photochemistry and UV-based oxidation processes. It also summarizes the current research on UV-based arsenic oxidation processes.

Chapter 4 describes the experimental details, including the process scheme, 
experimental planning, apparatus, chemicals and materials used, sample handling and analytical procedures.

Chapter 5 presents the experimental data and results obtained, analysis of the data and the hypothesized probable reaction mechanism and kinetic models.

Chapter 6 presents conclusions and recommendations. 


\section{CHAPTER 2. BACKGROUND REVIEW}

\subsection{Arsenic in the Environment - Sources and Distribution}

Arsenic, the name derived from the Greek word arsenikon, ranks the $20^{\text {th }}$ most abundant element in the earth's crust, the $14^{\text {th }}$ in the seawater and the $12^{\text {th }}$ in the human body (National Research Council of Canada, 1978; Eisler, 1988). The average content of arsenic in the continental crust is approximately $1 \sim 2 \mathrm{mg} \cdot \mathrm{kg}^{-1}$ (Greenwood and Earnshaw, 1984).

Situated in the Group 15 (former Group V) of the Periodic Table, arsenic is a semimetallic element (Cox, 2004). In the environment, arsenic can exist in the oxidation state of $-3,0,+3$ and +5 . It occurs in nature over 200 different mineral forms, including elemental arsenic, arsenates, arsenites, sulfides, sulfosalts, arsenides, oxides, silicates and organic forms (Smedley and Kinniburgh, 2002).

The source of arsenic is either natural or anthropogenic processes. Volcanic activities and weathering of rock are two of the main natural processes. Other natural occurrences, such as atmospheric deposition and forest fires, also contribute to arsenic in the environment (Smith et al., 2003). Mining activities are the major anthropogenic sources of arsenic. Arsenic coexists with many minerals, such as gold, silver, sulfur etc., and is a byproduct during alloying and smelting processes. Abandoned equipment, such as mining bearings, acid mining drainages, mining waste and mill tailings could also contain high concentration of arsenic. Wood preservation is the major consumption of arsenic products. 
According to U.S. Geological Survey, more than $90 \%$ of the consumption of arsenic trioxide, the major form of consumed arsenic, is used for the wood preservation as the product of chromated copper arsenate (CCA) (Brooks, 2007). Meanwhile, anthropogenic activities also stimulate the geochemical cycling of arsenic, in which biological activities play a significant role of transforming arsenic to different states and interacting with organic compounds. Figure 2.1 presents the transport and distribution of arsenic in the environment.

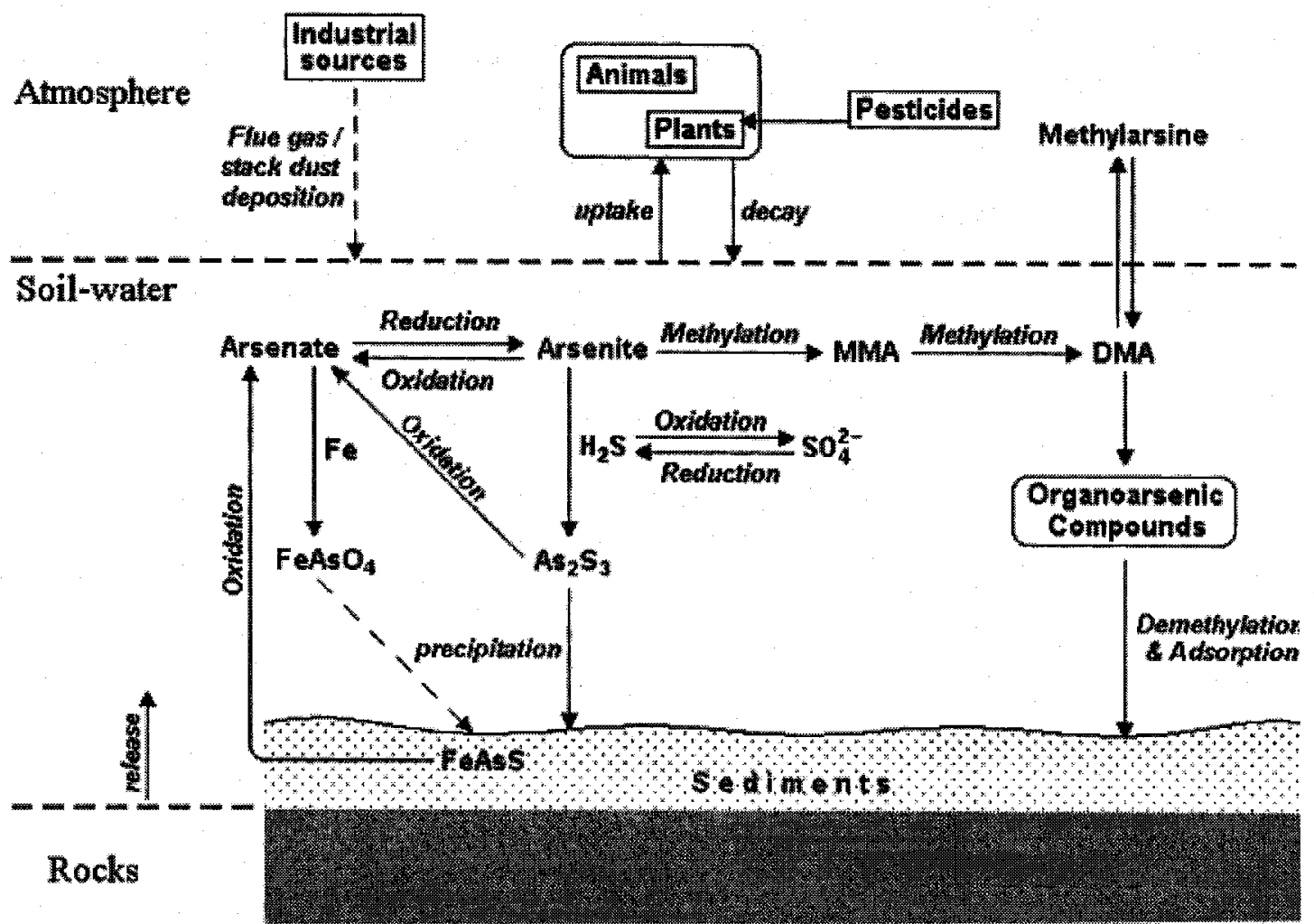

Figure 2.1 Arsenic cycle in the environment (Roy and Saha, 2002)

\subsection{Basic Chemistry of Arsenic in Water}

In natural waters, arsenic is mostly found in inorganic As(III) and As(V). The 
species of $\mathrm{As}(\mathrm{III})$ and $\mathrm{As}(\mathrm{V})$ are controlled by the redox potential (Eh) and $\mathrm{pH}$ in the aquatic environment. The distribution of arsenic species as a function of $\mathrm{pH}$ for both arsenite (As(III)) and arsenate (As(V)) are shown in Figure 2.2. Under oxidizing conditions (corresponding to high Eh values), $\mathrm{As}(\mathrm{V})$ is the dominant form. At $\mathrm{pH}$ values below 2.2, $\mathrm{As}(\mathrm{V})$ appears as $\mathrm{H}_{3} \mathrm{AsO}_{4}$; in the $\mathrm{pH}$ range from 2.2 to $11.5, \mathrm{H}_{2} \mathrm{AsO}_{4}{ }^{-}$and $\mathrm{HAsO}_{4}{ }^{2-}$ are the dominant species. $\mathrm{AsO}_{4}{ }^{3-}$ may be present in extremely alkaline conditions. Under reducing conditions (corresponding to low Eh values), arsenic is found in the form of $\mathrm{As}(\mathrm{III}) . \mathrm{H}_{3} \mathrm{AsO}_{3}$ is the dominant species of $\mathrm{As}$ (III) below $\mathrm{pH}$ 9.2. At higher pH values, $\mathrm{H}_{3} \mathrm{AsO}_{3}$ dissociates to $\mathrm{H}_{2} \mathrm{AsO}_{3}{ }^{-}, \mathrm{HAsO}_{3}{ }^{2-}$ and $\mathrm{AsO}_{3}{ }^{2-}$ (Bissen and Frimmel, 2003).
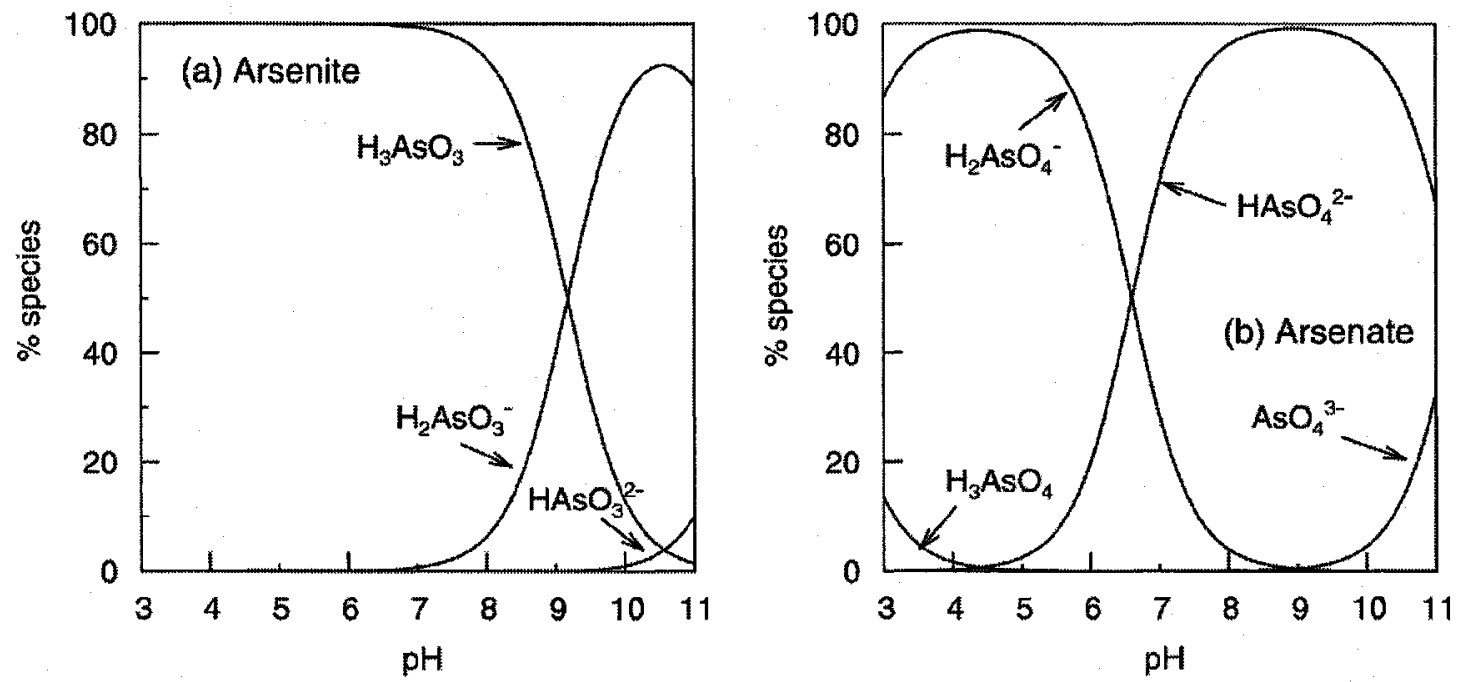

Figure 2.2 (a) Arsenite and (b) arsenate speciation as a function of $\mathrm{pH}$ (ionic strength of about $0.01 \mathrm{M})$. Redox conditions have been chosen such that the indicated oxidation state dominates the speciation in both cases (Smedley and Kinniburgh, 2002)

Typically the Eh-pH diagrams depict the geochemical behavior of dominant arsenic species in the aqueous environment. Most of the Eh-pH diagrams were adopted from the 
comprehensive studies of Pourbaix (1974) and Brookins (1988). The latest Eh-pH diagrams were revised and extended by Vink (1996), in which the equilibrium activity of $\mathrm{H}_{3} \mathrm{AsO}_{3}$ was taken into account. The Eh-pH diagram of As-O-H system is shown in Figure 2.3. The range of $\mathrm{Eh}$ and $\mathrm{pH}$ values for each arsenic species may shift in the presence of sulfuric and ferric compounds due to the formation of arsenopyrite (FeAsS) and sulfides ( $\left.\mathrm{AsS}, \mathrm{As}_{2} \mathrm{~S}_{3}\right)$.

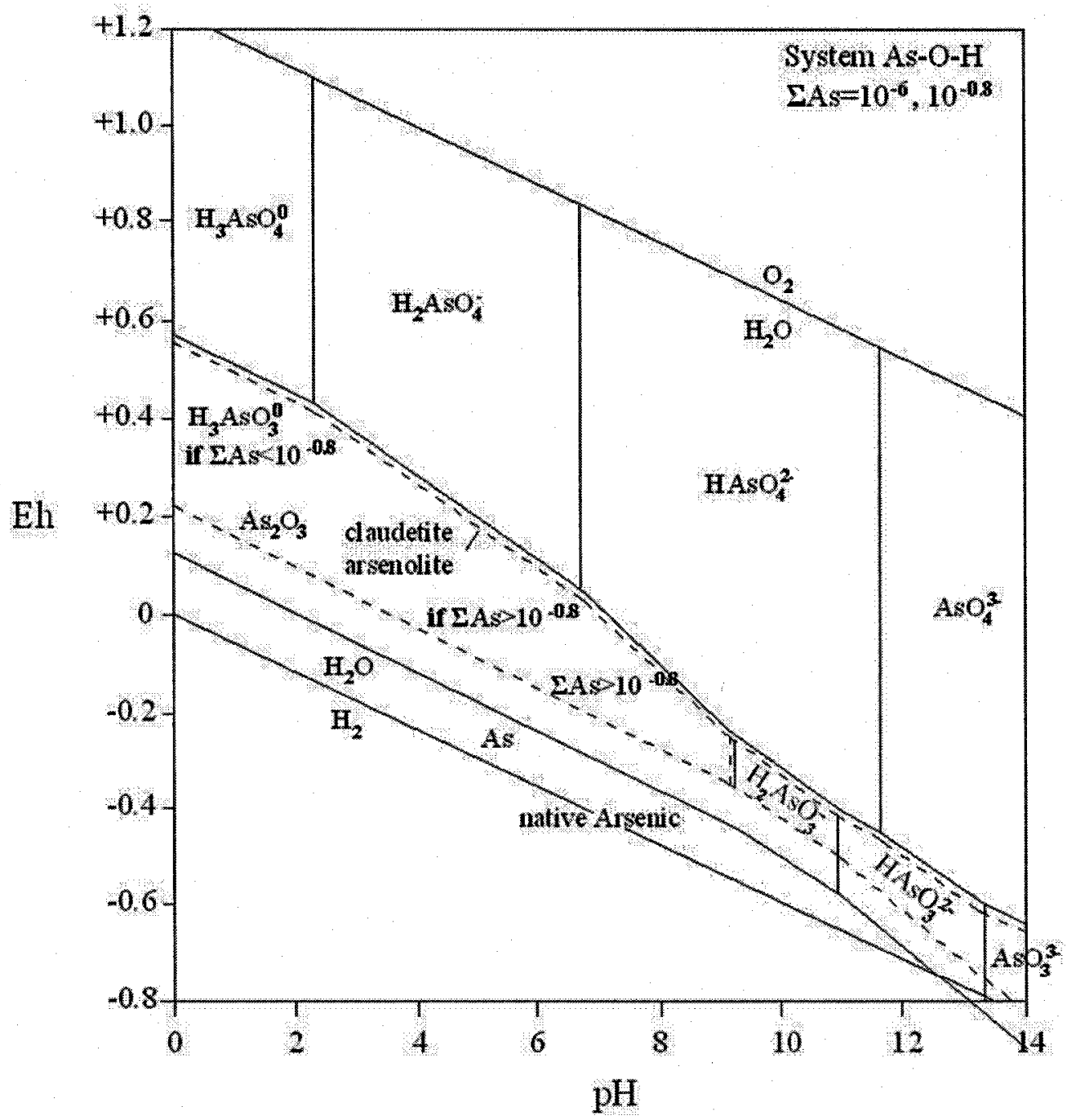

Figure 2.3 Eh-pH diagrams of As-O-H system (Vink, 1996) 


\subsection{Toxicity and Carcinogenicity}

Arsenic is known as the "king of poisons". The toxicity of arsenic is related to the form of arsenic compounds. Traditionally inorganic arsenicals were considered to be more toxic than organic forms. However, recent research indicated that methylated arsenicals may be more toxic than arsenate. The toxicity of arsenicals follows in a descending order as: inorganic $\mathrm{As}(\mathrm{III})>$ methylarsine oxide $\left(\mathrm{MMAO}^{\mathrm{III}}\right)>$ complex of dimethylarsinous acid with glutathione $\left(\mathrm{DMA}^{\mathrm{III}} \mathrm{GS}\right)>\operatorname{dimethylarsinic}$ acid $\left(\mathrm{DMA}^{\mathrm{V}}\right)>$ methylarsonic acid $\left(\mathrm{MMA}^{\mathrm{V}}\right)>$ inorganic As(V) (Vega et al., 2001). This approximate toxicity ranking clearly indicates that $\mathrm{As}(\mathrm{V})$ is much less toxic than $\mathrm{As}(\mathrm{III})$ and hence the preferred oxidation of $\mathrm{As}(\mathrm{III})$ to $\mathrm{As}(\mathrm{V})$ as a first step in arsenic elimination.

The drinking water containing arsenic can cause health problems. The symptoms are determined by the dose and the duration of arsenic exposure. Acute arsenic poisoning can cause vomiting, muscle cramps, circulatory disorders etc., and even death at fatal dose. Chronic exposure to arsenic can cause the diseases in skin, cardiovascular, nervous, hepatic, hematological endocrine and renal systems (Hughes, 2002).

Arsenic-induced cancer was first observed by Jonathan Hutchinson in 1888 (Meharg, 2005). However, the observation didn't bring concerns to the public until the late 1980 s. In 1988 the U.S. Environmental Protection Agency (EPA) rated arsenic a class A human carcinogen on the basis of the epidemiological study carried out in Taiwan in 1960s. In recent years, chronic exposure to arsenic at low doses was of great concern because of numerous evidences on its potential carcinogenicity (Schoen et al., 2004). According to 
the National Academy of Sciences (NAS) of the USA (2001), even at arsenic level as low as $3 \mu \mathrm{g} / \mathrm{L}$ in the drinking water, people still could be at a lifetime risk of cancer.

The toxic mode of arsenic is that it inhibits cellular respiration by interacting with sulphhydryl groups of proteins and enzymes, and substituting phosphorus during ATP production (Mandal and Suzuki, 2002). The detailed processes are shown in Figure 2.4 below. However, the mechanisms of carcinogenic action for arsenic are still uncertain. Several modes were proposed: oxidative stress, disruption of DNA methylation, inhibition of DNA repair enzymes, chromosomal damage, modulation of signal transduction pathways, and amplification of gene transcription (Tapio and Grosche, 2006). Those modes indicate that arsenic plays a role as a cocarcinogen or an inducer of carcinogenesis (Tchounwou et al., 2003).

A

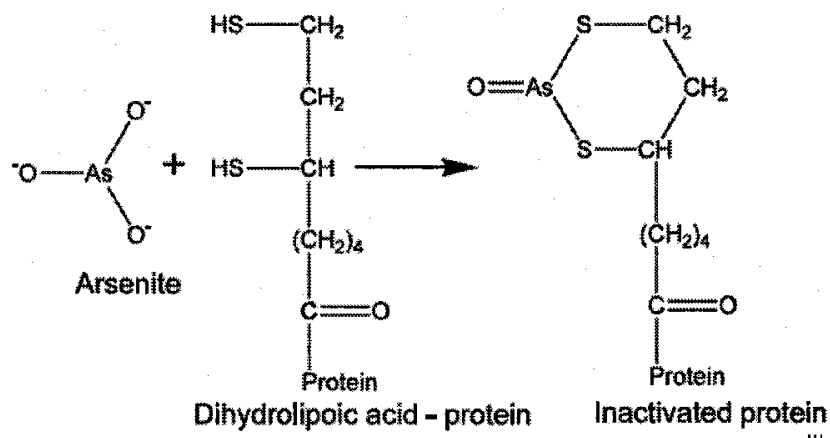
complex with iAs

B
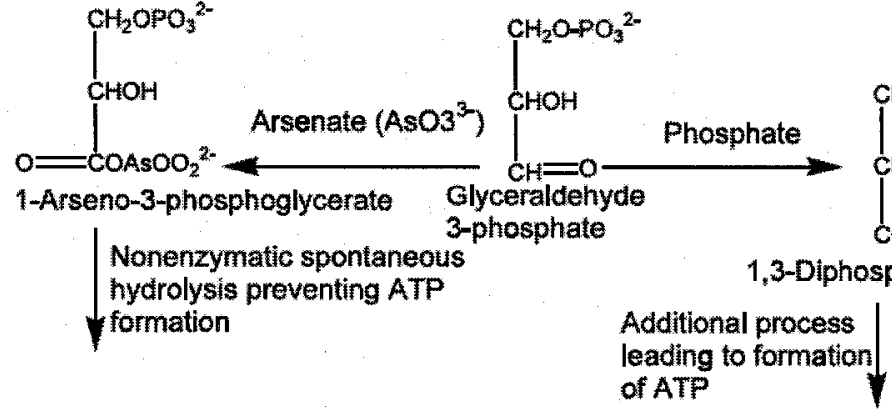

Figure 2.4 Mechanism of arsenic toxicity to the human body (Mandal and Suzuki, 2002) 


\subsection{Environmental Impact}

Naturally arsenic-enriched groundwater is a significant global problem for the safety of drinking water resources. In the mid-1900s, the mass poisoning in the Bengal Delta was revealed to be a cause of arsenic contamination in the well water. It brought a great concern on geologically related arsenic problems. Nowadays, it is estimated that globally over 100 million people, or $1.5 \%$ of the planet's population, are living in areas containing dangerous levels of arsenic in the drinking water (Meharg, 2005).

In addition, mining activities also could bring severe arsenic contamination to the groundwater. Arsenic contamination or arsenic-related diseases caused by mining operations have been identified in countries such as Thailand, South Africa, Zimbabwe, England, and the USA (Smedley and Kinniburgh, 2002). The distribution of world's arsenic-enriched aquifers and mining contaminated regions is shown in Figure 2.5. 


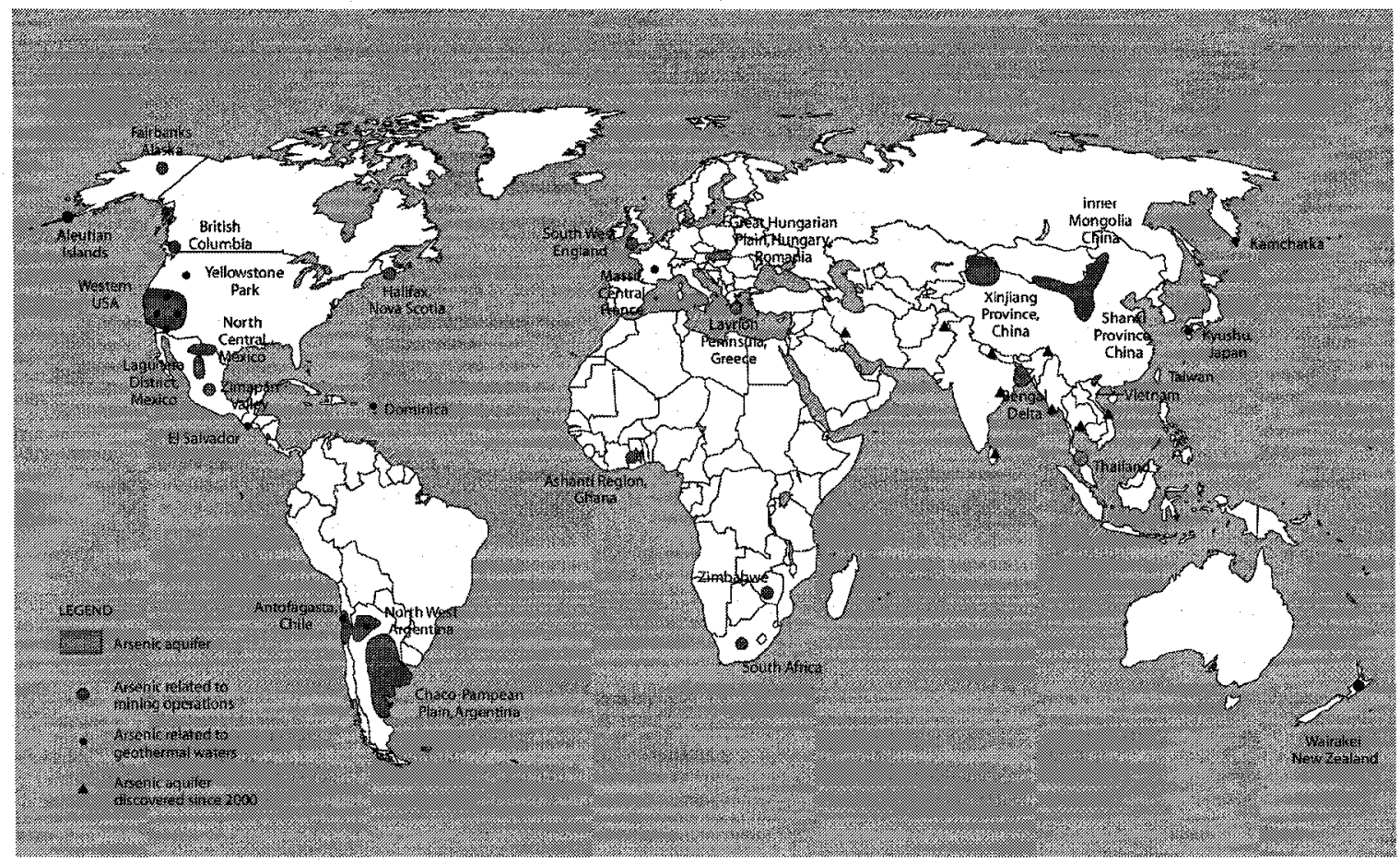

Figure 2.5 Distribution of documented world problem with arsenic in groundwater (Meharg, 2005)

In Canada, the levels of arsenic in drinking water are usually less than $5 \mu \mathrm{g} / \mathrm{L}$. The arsenic contamination is mainly from the incineration of fossil fuels, mining industries, and agricultural uses etc (Health Canada, 2006).

\subsection{Water Quality Regulations and Guidelines}

\subsubsection{Drinking Water Quality Guidelines for Arsenic}

Drinking water is the major pathway of arsenic poisoning. The first arsenic standard for drinking water of $50 \mu \mathrm{g} / \mathrm{L}$ was established in the early twentieth century. This standard was determined arbitrarily by dividing a safe acute arsenic dose of $1000 \mu \mathrm{g} / \mathrm{L}$ by the number of 20 (Meharg, 2005). It was considered 'safe' for over half century and is still widely applied in many developing countries.

In developed countries, more stringent arsenic standards were demanded for the 
safety of public health based on the evidence of arsenic-cancer relationship. European

Union in 1998 constituted the standard of arsenic $10 \mu \mathrm{g} / \mathrm{L}$ in drinking water (Council of the European Union, 1998). In USA, the setting of new arsenic standard in drinking water experienced an extraordinarily protracted process as shown in Table 2.1. The debates were on the uncertainties in epidemiological studies, the threshold dose for carcinogenic effects, and the feasibility of current removal technologies and analytical methods. Health Canada in 1999 established the interim guideline of $25 \mu \mathrm{g} / \mathrm{L}$ for arsenic in drinking water, and in 2006 a new guideline of $10 \mu \mathrm{g} / \mathrm{L}$ has come into effect (Health Canada, 1999; Health Canada, 2006).

Table 2.1 History of U.S. standards for arsenic in drinking water (Smith et al., 2002)

\begin{tabular}{ll}
\hline \hline 1942 & USPHS sets an interim drinking water standard of $50 \mu \mathrm{g} / \mathrm{L}$ \\
1962 & USPHS identifies $10 \mu \mathrm{g} / \mathrm{L}$ as the goal \\
1975 & EPA adopts the interim standard of $50 \mu \mathrm{g} / \mathrm{L}$ set by the USPHS in 1942 \\
1986 & Congress directs EPA to revise the standard by 1989 \\
1988 & EPA estimates that the ingestion of $50 \mu \mathrm{g} / \mathrm{L}$ results in a skin cancer risk of 1 in 400 \\
1992 & Internal cancer risk estimated to be 1.3 per 100 persons at $50 \mu \mathrm{g} / \mathrm{L}$ \\
1993 & World Health Organization recommends lowering arsenic in drinking water to $10 \mu \mathrm{g} / \mathrm{L}$ \\
1996 & Congress directs the EPA to propose a new drinking water standard by January 2000 \\
1999 & NRC estimates cancer mortality risks to be about 1 in 100 at $50 \mu g / L$ \\
2000 & EPA proposes a standard of $5 \mu \mathrm{g} / \mathrm{L}$ and requests comment on 3,10, and $20 \mu \mathrm{g} / \mathrm{L}$ \\
2001 & (January) Clinton EPA lowers the standard to $10 \mu \mathrm{g} / \mathrm{L}$ \\
2001 & (March) Bush EPA delays lowering the standard \\
2001 & (September) New NRC report concludes that EPA underestimated cancer risks \\
2001 & (October) EPA announces it will adopt the standard of $10 \mu \mathrm{g} / \mathrm{L}$ \\
2002 & (February) The effective date for new standard of $10 \mu \mathrm{g} / \mathrm{L}$ \\
2006 & (January) Compliance date for the new arsenic standard \\
\hline \hline
\end{tabular}




\subsubsection{Other Guidelines for Arsenic}

Besides drinking water guidelines, some countries also specify arsenic guidelines and regulations for various purposes. In Canada, those guidelines and regulations are covered by Canadian Water Quality Guidelines for the Protection of Aquatic Life (Canadian Council of Ministers of the Environment, 2006), and Canadian Water Quality Guidelines for the Protection of Agricultural Water Uses (Canadian Council of Ministers of the Environment, 2005), and Metal Mining Effluent Regulations (Department of Justice Canada, 2007). A summary of those guidelines is shown in Table 2.2.

Table 2.2 Summary of Canadian guidelines for arsenic

\begin{tabular}{lc}
\hline \hline \multicolumn{1}{c}{ Purposes } & Recommended Guidelines $(\mu \mathrm{g} / \mathrm{L})$ \\
\hline \hline Freshwater Aquatic Life & 5.0 \\
Marine Aquatic Life & 12.5 \\
Irrigation & 100 \\
Livestock Water & 12 \\
Mining Effluent & $500^{*}$ \\
\hline \hline
\end{tabular}

${ }^{*}$ Maximum Authorized Monthly Arithmetic Mean Concentration

\subsection{Review of Removal Technologies}

As mentioned in the previous chapter, there are numerous technologies available for the treatment of arsenic-contaminated water. Precipitation/coprecipitation, adsorption, ion exchange, and membrane filtration are the most common arsenic removal technologies. The principles, merits and drawbacks of the application of these technologies are briefly reviewed. 


\subsubsection{Precipitation/Coprecipitation}

Precipitation/coprecipitation is one of the most widely used methods to treat arsenic contaminated water. Dissolved arsenic contaminants can be chemically transformed into an insoluble solid and directly separated from water by precipitation or be adsorbed onto the certain precipitated species and removed from water by clarification or filtration.

Iron precipitation is successfully used in the arsenic removal processes. Ferric oxyhydroxide in the $\mathrm{Fe}(\mathrm{III})$-containing solution can react with arsenic ions and form insoluble $\mathrm{AsO}_{4} \cdot \mathrm{FeO}(\mathrm{OH})(\mathrm{H} 2 \mathrm{O})_{1+\mathrm{x}}$ or $\mathrm{AsO}_{3} \cdot \mathrm{FeO}(\mathrm{OH})(\mathrm{H} 2 \mathrm{O})_{1+\mathrm{x}}$ (arsenical ferrihydrite) complexes. Iron precipitation is less affected by the $\mathrm{pH}$, but a $\mathrm{pH}$ range of $4 \sim 7$ is preferred to obtain the optimal arsenic removal efficiency. However, this method presents much lower removal efficiency for As(III) than As(V). Hence, pre-oxidation of As(III) to As $(\mathrm{V})$ is preferred. The high iron consumption is a potential disadvantage of this method. A Fe/As molar ratio above 3 was recommended due to the consideration of the stability of arsenical ferrihydrite (Riveros et al., 2001).

Aluminum precipitation and lime softening are also the alternatives. These methods are sensitive to the variation of $\mathrm{pH}$. For the effective removal of arsenic, the $\mathrm{pH}$ below 7.0 and the $\mathrm{pH}$ above 10.5 are required for aluminum precipitation and lime softening respectively (Kartinen and Martin, 1995). The pre-oxidation of As(III) is also required for the treatment of As(III)-contaminated water. 


\subsubsection{Adsorption/ Ion Exchange}

Arsenic removal by adsorption is a process in which the molecules or particles of arsenic contaminants are bound to the surface of adsorbents, and then removed by the process of separating the adsorbents from treated waters. Ion exchange is a special case of adsorption, in which ions in the aqueous solution are swapped with similarly charged ions in the immobile solid resin phase. The removal efficiency of adsorption/ ion exchange is mainly affected by the type of adsorbents/resin, $\mathrm{pH}$ and the competition of other ions in the solution.

The Activated Alumina (AA) has been popularly used in the adsorption process for arsenic removal. The optimum $\mathrm{pH}$ range was established to be 5.5-6.0 (Kartinen and Martin, 1995). The selectivity of AA adsorption follows the sequence as (Office of Water, 2000):

$$
\mathrm{OH}^{-}>\mathrm{H}_{2} \mathrm{AsO}_{4}^{-}>\mathrm{Si}(\mathrm{OH})_{3} \mathrm{O}^{-}>\mathrm{F}^{-}>\mathrm{HSeO}^{3-}>\mathrm{TOC}^{-} \mathrm{SO}^{2-}>\mathrm{H}_{3} \mathrm{AsO}_{3}
$$

Strong-base anion exchange resins (SBA) in either chloride or hydroxide form can be used for the arsenic removal in the ion exchange system. The optimal operating $\mathrm{pH}$ of these resins is in the range of 6.5 to 9.0 (Office of Water, 2003). The sequence of exchange affinity is similar to the selectivity of AA adsorption, but it follows a different pattern (Office of Research and Development, 2000):

$$
\begin{gathered}
\mathrm{HCrO}^{4-}>\mathrm{CrO}_{4}{ }^{2-}>\mathrm{ClO}^{4-}>\mathrm{SeO}_{4}{ }^{2-}>\mathrm{SO}_{4}{ }^{2-}>\mathrm{NO}^{3-}>\mathrm{Br}^{-}>\left(\mathrm{HPO}_{4}{ }^{2-}, \mathrm{HAsO}_{4}{ }^{2-}, \mathrm{SeO}_{3}{ }^{2-}\right. \\
\left.\mathrm{CO}_{3}{ }^{2-}\right)>\mathrm{CN}^{-}>\mathrm{NO}^{2-}>\mathrm{Cl}^{-}>\left(\mathrm{H}_{2} \mathrm{PO}_{4}^{-}, \mathrm{H}_{2} \mathrm{AsO}_{4}^{-}, \mathrm{HCO}_{3}{ }^{-}\right)>\mathrm{OH}^{-}>\mathrm{CH}_{3} \mathrm{COO}^{-}>\mathrm{F}^{-}
\end{gathered}
$$

The sequences of AA adsorption selectivity and the ion exchange affinity above 
show the poor selectivity/exchange affinity to the As(III). It is because of the neutral molecular charge of $\mathrm{H}_{3} \mathrm{AsO}_{3}$ at $\mathrm{pH}$ levels below 9.2. Therefore, a pre-oxidation of $\mathrm{As}(\mathrm{III})$ to $\mathrm{As}(\mathrm{V})$ is required.

Besides, suspended solids in the water can degrade the performance of adsorption media and exchange resin. Furthermore, the competition of sulfate and the formation of the arsenical ferrihydrite complexes in the presence of $\mathrm{Fe}(\mathrm{III})$ can also deteriorate the arsenic removal efficiency in the ion exchange process.

\subsubsection{Membrane Filtration}

Arsenic can also be directly removed by membrane filtration. Membrane filtration has the distinctive advantages compared to the other arsenic removal technologies. It is less affected by the variation of chemical composition and $\mathrm{pH}$ in the untreated water, and usually no chemical addition is required.

The performance of membrane filtration, to a great extent, is determined by the type of membrane. Based on the range of pore size of the membrane, the membrane filtration can be classified as: microfiltration (MF), ultrafiltration (UF), nanofiltration (NF) and reverse osmosis (RO). The pore size of the membrane and the size of materials subject to filtration are shown in Figure 2.6. Usually microfiltration (MF) and ultrafiltration (UF) are operated under a pressure of 10-30 psi. Nanofiltration (NF) and reverse osmosis (RO) are operated under high-pressure from 75 to 250 psi, or even higher (Letterman, 1999). 


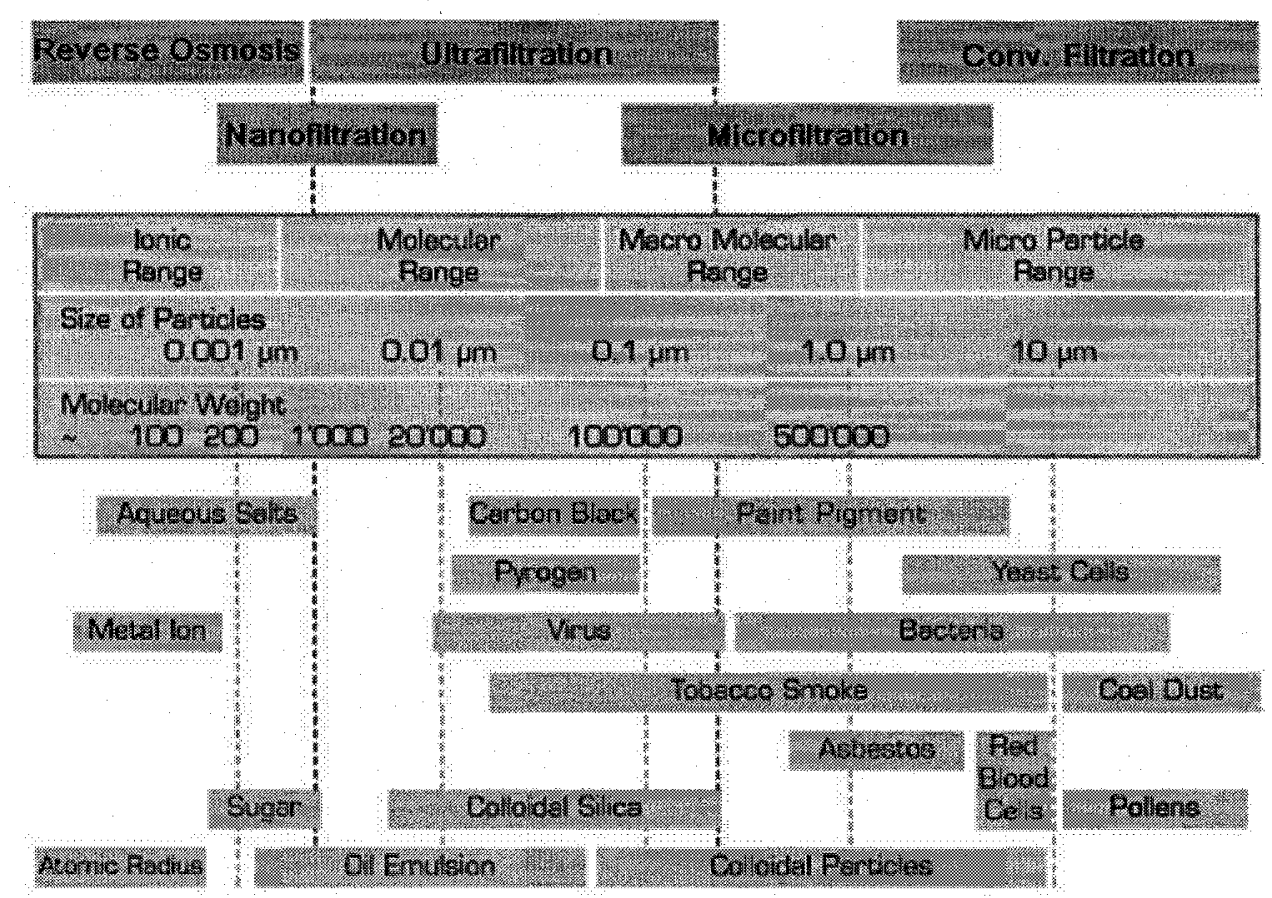

Figure 2.6 Classification of membranes and the relative size of materials subject to filtration (Adapted from http://www.christwater.com/EN/ProductsServices /ProcessesTechnologies/ Filtration/Filtration.htm)

Nanofiltration (NF) and reverse osmosis (RO) covering the size range of 'Metal Ion', in which dissolved arsenic occurs, are applicable for the arsenic removal. As(V) removal efficiencies of $60 \sim 100 \%$ for nanofiltration (NF) and $96 \sim 100 \%$ for reverse osmosis (RO) have been reported in the literature (Office of Solid waste and Emergency Response, 2002). However the removal efficiency for As(III) is much lower than those obtained for $\mathrm{As}(\mathrm{V})$. This is because the As(III) generally has a smaller molecule size than As(V), thus it can be less effectively captured by the membrane ( $\mathrm{Ng}$ et al., 2004). Once again, the pre-oxidation of $\mathrm{As}(\mathrm{III})$ to $\mathrm{As}(\mathrm{V})$ would enhance the efficiency of the membrane filtration process.

The main drawbacks of membrane processes are the high costs of membranes, the 
high operating pressures and the consequent safety consideration, especially for the nanofiltration (NF) and reverse osmosis (RO) systems.

\subsection{Pre-oxidation of As(III) to $\mathrm{As}(\mathrm{V})$}

As discussed in the previous section, most of the arsenic removal technologies require the pre-oxidation process of converting $\mathrm{As}(\mathrm{III})$ to $\mathrm{As}(\mathrm{V})$ for achieving optimal performance. Oxygen, hydrogen peroxide, Fenton's reagent, chlorine dioxide, monochloramine, chlorine, manganese compounds and ozone, are potential oxidants.

The oxidation of As(III) by either air or pure oxygen is very slow. Kim and Nriagu (2000) observed that in the continuous purging of groundwater containing 46 and $62 \mu \mathrm{g} / \mathrm{L}$ of initial As(III) with air and pure oxygen over 5 days, only $54 \%$ and $57 \%$ of As(III) were oxidized respectively. However, in the presence of activated carbon as catalyst, the oxidation rate can be significantly improved. $90 \%$ of the initial $40 \mu \mathrm{g} / \mathrm{L}$ As(III) was oxidized by oxygen within $20 \sim 30$ minutes in the presence of $5 \sim 10 \mathrm{~g} / \mathrm{L}$ of activated carbon (Bissen and Frimmel, 2003). Solid Phase Oxidants (Filox-R ${ }^{\mathrm{TM}}$ ), a granular manganese dioxide media, also can catalytically oxidize As(III) to As(V) using dissolved oxygen in the water. The laboratory study indicated that over $98.7 \%$ As(III) was converted to As(V) within 1.5 minutes by Filox-R ${ }^{\mathrm{TM}}$ (Ganesh and Clifford, 2001).

The oxidation of As(III) by hydrogen peroxide was found to be highly pH-dependent (Pettine et al., 1999). At pH above 10.3, As(III) can be oxidized to As(V) rapidly. However, at $\mathrm{pH}$ below 4.9, the oxidation is almost quenched. Also the As(III) 
oxidation percentage is affected by the molar ratio of $\mathrm{H}_{2} \mathrm{O}_{2} / \mathrm{As}(\mathrm{III})$. Yang et al. (1999) indicated that under $\mathrm{pH} 9.0$, only $50 \%$ of $\mathrm{As}(\mathrm{III})$ was oxidized at the theoretical $\mathrm{H}_{2} \mathrm{O}_{2} / \mathrm{As}(\mathrm{III})$ molar ratio of $1: 1$. To completely oxidize $\mathrm{As}(\mathrm{III})$, excessive $\mathrm{H}_{2} \mathrm{O}_{2}$ with a $\mathrm{H}_{2} \mathrm{O}_{2} / \mathrm{As}(\mathrm{III})$ molar ratio of $4: 1$ was required. The addition of $\mathrm{Fe}(\mathrm{II})$ with $\mathrm{H}_{2} \mathrm{O}_{2}$, known as Fenton' reagent, can significantly increase the oxidation efficiency. But the efficiency is dependent on the molar ratio of $\mathrm{Fe}(\mathrm{II}) / \mathrm{H}_{2} \mathrm{O}_{2} / \mathrm{As}(\mathrm{III})$. Driehaus and Jekel (1993) recommended an optimal $\mathrm{Fe}(\mathrm{III}) / \mathrm{H}_{2} \mathrm{O}_{2} / \mathrm{As}$ (III) ratio of 10:5:1. However, interfering compounds in the contaminated water and improper mixing could degrade the oxidation efficiency. Thus the operation and control of $\mathrm{Fe}(\mathrm{II}) / \mathrm{H}_{2} \mathrm{O}_{2} / \mathrm{As}(\mathrm{III})$ ratio during the process will be very difficult.

Ghurye and Clifford (2001) carried out a very specific investigation on As(III) oxidation by different oxidants. Their study indicated that chlorine dioxide and monochloramine presented low efficiencies for As(III) oxidation. However, chlorine and permanganate were highly effective in the $\mathrm{pH}$ range of $6.3 \sim 8.3$. The oxidation of arsenic can be completed in less than 1 minute. Ozone can also rapidly oxidize As(III) in the pH range of 6.3 8.3. However, the oxidation rates were significantly reduced in the presence of sulphide or total organic carbon (TOC). These observations were consistent with the results presented in other papers (Kim and Nriagu, 2000; Frank and Clifford, 1986; Dodd et al., 2006). A summary of reaction schemes that have been suggested for the different oxidants is presented in Table 2.3 . 
Table 2.3 Summary of reaction schemes of oxidizing As(III) by different oxidants

\begin{tabular}{|c|c|c|}
\hline No. & Oxidants & Reactions \\
\hline R2-1 & Oxygen & $2 \mathrm{H}_{3} \mathrm{AsO}_{3}+\mathrm{O}_{2}(a q) \rightarrow 2 \mathrm{H}_{2} \mathrm{AsO}_{4}^{-}+2 \mathrm{H}^{+}$ \\
\hline \multirow{2}{*}{ R2-2 } & Hydrogen & $\mathrm{H}_{3} \mathrm{AsO}_{3}+\mathrm{H}_{2} \mathrm{O}_{2} \rightarrow \mathrm{HAsO}_{4}^{2-}+2 \mathrm{H}^{+}+\mathrm{H}_{2} \mathrm{O}$ \\
\hline & Peroxide & $\mathrm{H}_{2} \mathrm{AsO}_{3}^{-}+\mathrm{H}_{2} \mathrm{O}_{2} \rightarrow \mathrm{HAsO}_{4}^{2-}+\mathrm{H}^{+}+\mathrm{H}_{2} \mathrm{O}$ \\
\hline \multirow{2}{*}{ R2-3 } & Fenton' Regent & $\mathrm{Fe}^{2+}+\mathrm{H}_{2} \mathrm{O}_{2} \rightarrow \mathrm{Fe}(\mathrm{III}) \mathrm{OH}^{2+}+\mathrm{OH}$ \\
\hline & & $\mathrm{H}_{3} \mathrm{AsO}_{3}+2 \mathrm{OH} \cdot \rightarrow \mathrm{H}_{2} \mathrm{AsO}_{4}^{-}+\mathrm{H}^{+}+\mathrm{H}_{2} \mathrm{O}$ \\
\hline \multirow{2}{*}{ R2-4 } & Chlorine dioxide & $\mathrm{H}_{3} \mathrm{AsO}_{3}+2 \mathrm{ClO}_{2}+\mathrm{H}_{2} \mathrm{O} \rightarrow \mathrm{H}_{2} \mathrm{AsO}_{4}^{-}+2 \mathrm{ClO}_{2}^{-}+3 \mathrm{H}^{+}$ \\
\hline & & $5 \mathrm{H}_{3} \mathrm{AsO}_{3}+2 \mathrm{ClO}_{2}+\mathrm{H}_{2} \mathrm{O} \rightarrow 5 \mathrm{H}_{2} \mathrm{AsO}_{4}^{-}+2 \mathrm{ClO}_{2}^{-}+7 \mathrm{H}^{+}$ \\
\hline R2-5 & Monochloramine & $\mathrm{H}_{3} \mathrm{AsO}_{3}+\mathrm{NH}_{2} \mathrm{Cl}+\mathrm{H}_{2} \mathrm{O} \rightarrow \mathrm{HAsO}_{4}^{2-}+\mathrm{NH}_{4}^{+}+\mathrm{Cl}^{-}+2 \mathrm{H}^{+}$ \\
\hline \multirow{2}{*}{ R2-6 } & & $\mathrm{Cl}_{2}+\mathrm{H}_{2} \mathrm{O} \rightarrow \mathrm{HCl}+\mathrm{HOCl}$ \\
\hline & Chlorine & $\mathrm{H}_{3} \mathrm{AsO}_{3}+\mathrm{OCl}^{-} \rightarrow \mathrm{H}_{2} \mathrm{AsO}_{4}^{-}+\mathrm{H}^{+}+\mathrm{Cl}^{-}$ \\
\hline R2-7 & Permanganate & $3 \mathrm{H}_{3} \mathrm{AsO}_{3}+2 \mathrm{MnO}_{4}^{-} \rightarrow 3 \mathrm{H}_{2} \mathrm{AsO}_{4}^{-}+2 \mathrm{MnO}_{2}+\mathrm{H}_{2} \mathrm{O}$ \\
\hline R2-8 & Ozone & $\mathrm{H}_{3} \mathrm{AsO}_{3}+\mathrm{O}_{3} \rightarrow \mathrm{H}_{2} \mathrm{AsO}_{4}^{-}+\mathrm{H}^{+}+\mathrm{O}_{2}$ \\
\hline
\end{tabular}

\subsection{Need for New As(III) Oxidation Technologies}

\subsubsection{Limitations of Existing As(III) Oxidation Technologies}

Oxygen, chlorine dioxide and monochloramine are not very effective for As(III) oxidation. Hydrogen peroxide is effective at high $\mathrm{pH}$, but the high $\mathrm{pH}$ dependence limits its industrial application. Fenton' reagent is an option, but there are operational difficulties in process control.

Some reagents, such as ozone, chlorine, permanganate and Filox $-\mathrm{R}^{\mathrm{TM}}$ present high oxidation efficiency to the As(III). But those reagents also have their drawbacks. 
Ozone is a very effective reagent. But it could be interfered by sulphide and TOC. It is not stable and decomposes very fast at high temperature and $\mathrm{pH}$ above 10 . The high operating and maintaining costs are also the limitations.

Chlorine has long been used in the disinfection process for the water treatment. However, in recent years, there are serious concerns on the application of chlorine and the formation of chlorination disinfection byproducts (DBPs), which are considered to be potential carcinogens. Furthermore, chlorine could damage the membrane material and requires special handling and storage.

Permanganate, a very corrosive and powerful oxidizing powder, is difficult to handle. It stains everything purple, including water. Also the manganese particulates formed in the oxidation process need to be removed by an additional follow-up filtration.

The oxidation of As(III) using Filox-R ${ }^{\mathrm{TM}}$ needs to maintain high dissolved oxygen (DO) concentration in the water or extend the empty bed contact time to eliminate the potential interferences, such as iron, manganese, hydrogen sulfide. Besides, routine backwashing is required.

Some new technologies using iron compounds, such as Fe (0) (zero-valent iron) (Kanel et al., 2005), Fe(II) (ferrous) (Bisceglia et al., 2003) and Fe (VI) (ferrate) (Lee et al, 2003) have been put forward recently. Those technologies have the potential advantages on follow-up precipitation and filtration processes. But they may not be compatible with the other arsenic removal processes, such as ion-exchange. 


\subsubsection{Need for New Technology}

In view of the limitations of the existing As(III) oxidation technologies above, there is a demand for new technology that has high oxidation efficiency, low cost, high process reliability, and tolerance to fluctuations in the composition of the untreated water.

UV-based oxidation processes can be a viable alternative. These processes have quite a few advantages for industrial application. Firstly, UV itself can generate very high energy to excite the molecules in the solution and induce certain reactions. In the presence of hydrogen peroxide, it can generate $\cdot \mathrm{OH}$ radicals, which are very powerful oxidants. So the oxidation efficiency of these processes is usually higher than conventional thermochemical processes. Secondly, in the UV-based oxidation processes, the consumption of chemicals can be reduced substantially and sometimes can be totally eliminated, and thus any potential secondary waste can be avoided. Thirdly, the UV-based oxidation processes are easy to operate. The potential advantage of high resistance to $\mathrm{pH}$ fluctuation can further simplify the operation process. Fourthly, these processes are temperature independent.

This research is mainly directed towards industrial wastewater remediation, specifically, to develop a UV-based As (III) oxidation process and evaluate its feasibility for industrial applications. A detailed review of prior work in this area is presented and discussed in the next chapter. 


\section{CHAPTER 3. REVIEW OF PHOTOCHEMISTRY AND PHOTOOXIDATION OF ARSENIC}

The main subject of this study is to investigate the oxidation of As(III) to As(V) in the presence of UV irradiation. In this process, the UV rays are employed to effect photochemical reactions. The basic concepts and theories of photochemistry are introduced for the better understanding of the theoretical background and main principles of the study. Current UV technologies, past research studies and applications on As(III) oxidation processes are reviewed.

\subsection{Basic Concepts of Photochemistry}

\subsubsection{Electromagnetic Radiation and Energy}

Light has long been recognized as a form of energy. However, the theoretical debate on the particle property and the wave property of light has lasted for centuries. Modern theory indicated that light has the wave-particle duality, and defined light as the electromagnetic radiation, a form of energy that is transported by the movement of photons as a self-propagating transverse oscillating wave.

Electromagnetic radiation has the properties of frequency, wavelength, and propagation speed. The relationship of those properties can be expressed as equation $(3-1)$ :

$$
\lambda=\frac{c}{v}
$$

in which, $c$ is the propagation speed, a constant of $2.998 \times 10^{8} \mathrm{~m} / \mathrm{s}$ in the vacuum; $v$ is 
the frequency $\left(s^{-1}\right)$ and $\lambda$ is the wavelength $(m)$. Distinguished by the wavelength or frequency, electromagnetic radiation can be generally classified as radio waves, microwaves, infrared radiation, visible light, ultraviolet radiation, $\mathrm{X}$ rays, and gamma radiation.

The energy of electromagnetic radiation can be quantified as the energy of each photon. The Planck's quantum theory describes the relationship of the photon energy with the properties of electromagnetic radiation, shown as equation (3-2):

$$
E=h v=h c / \lambda
$$

in which, $h$ is the Plank's constant $\left(6.626 \times 10^{-34} \mathrm{~J} \cdot \mathrm{s}\right)$, and $E$ is the quantized energy of the photons $(J)$. Generally, the irradiance of electromagnetic radiation energy is described by one mole of photons with the unit of 'Einstein'. An Einstein can be calculated by multiplying the energy of one photon by the Avogadro's number of $6.0225 \times 10^{23}$, shown in equation (3-3):

$$
\text { Energyof one Einstein }=6.0225 \times 10^{23} \times(h c / \lambda)=1.196 \times 10^{8} / \lambda
$$

in which, $6.0225 \times 10^{23}$ is the Avogadro's number, the energy is in the unit of $J$.

The energy and sources of the photons at different frequency and wavelength ranges are shown in Figure 3.1. 


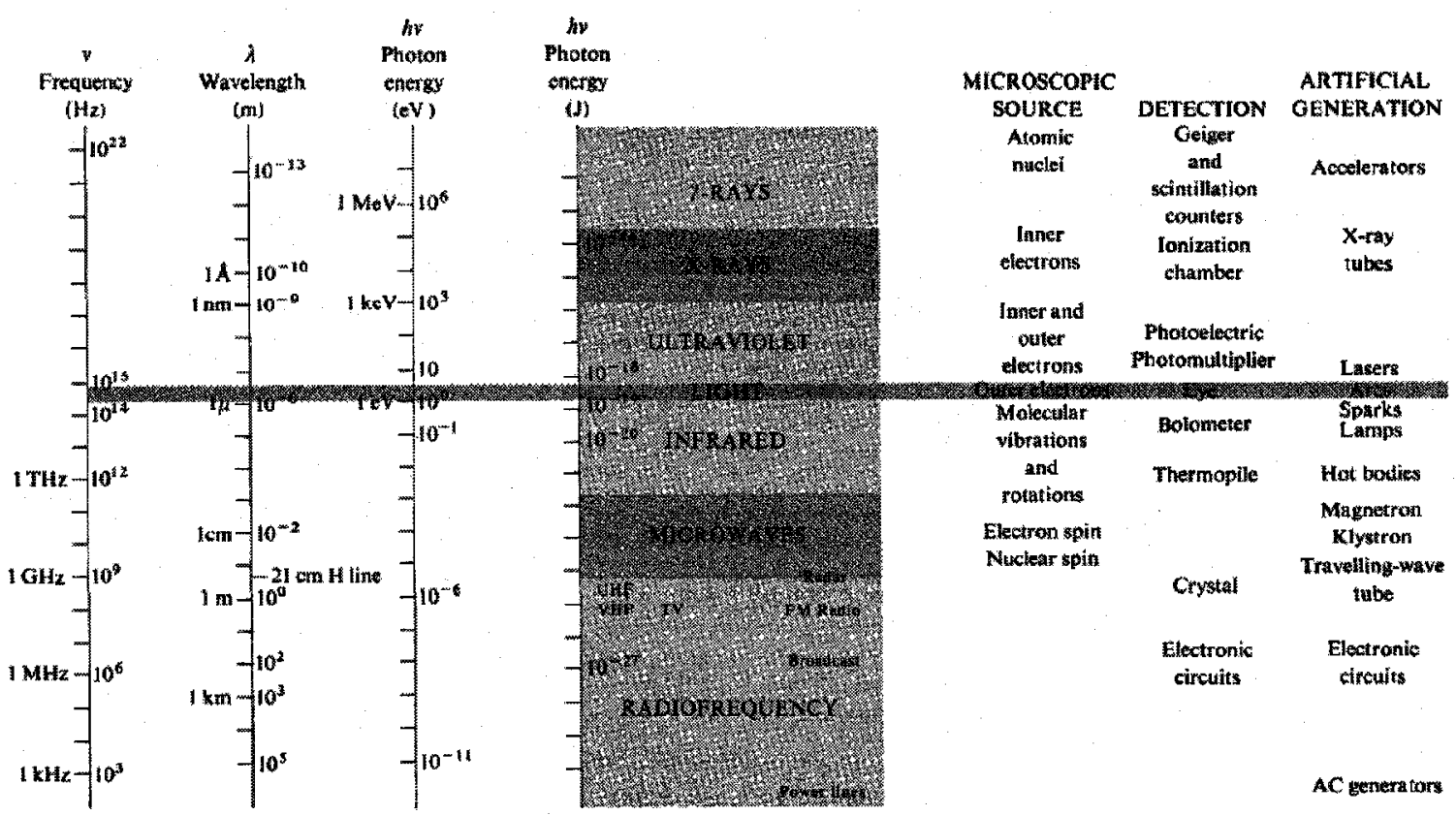

Figure 3.1 Electromagnetic-photon spectrum (Retrieved from: http://langley.atmos.colostate.edu /at622/notes/at622_sp06_sec1.pdf)

\subsubsection{Laws of Photochemistry}

Photochemistry is the study of chemical changes that are driven by light absorption. Calvert and Pitts (1966) laid out two basic laws of photochemistry: the Grotthus-Draper Law and the Stark-Einstein Law.

\subsubsection{First Law of Photochemistry}

Grotthus-Draper Law, known as the first law of photochemistry, states that only the light that is absorbed by a molecule can be effective in producing photochemical change in the molecule. This law indicates that the emission spectrum of the light, the absorption spectra for the photolyzed materials, the absorption spectrum of the applicable media (e.g. glass tubes), and the intensity of light absorbed by the reactants are potential factors to the photochemical reactions. 


\subsubsection{Second Law of Photochemistry}

Stark-Einstein Law, known as the second law of photochemistry, states that for every photon of radiation that is absorbed, only one molecule is activated for a photochemical reaction. Stark-Einstein Law is also called as photochemical equivalence law or photoequivalence law.

In photochemical processes, there are two distinct steps: the absorption of light by a reactant (called primary process) and the subsequent chemical reactions (called secondary processes). The Stark-Einstein Law usually only applies to the primary process of photochemical reactions. However if secondary processes follow, in which no absorption of light is required, those reactions do not obey the Stark-Einstein Law.

\subsubsection{Beer-Lambert Law}

As mentioned above, the key of photochemical reactions is that the light is absorbed by the chemicals. The absorption of light energy and its relationship with the concentration of absorbing chemicals can be described by the Beer-Lambert law. It states that for a parallel beam of monochromatic radiation passing through a homogeneous solution the absorbance is proportional to the product of the concentration and path length. The general Beer-Lambert law is usually written as equation (3-4):

$$
A=\log _{10}\left(I_{0} / I\right)=\varepsilon \cdot c \cdot l
$$

in which, $A$ is the absorbance of the chemical in solution (no units); $I$ is the intensity of transmitted light (Einstein $\left.\mathrm{s}^{-1} \cdot \mathrm{cm}^{-2}\right) ; I_{0}$ is the intensity of the incident monochromatic 
light (Einstein $\left.\cdot \mathrm{s}^{-1} \cdot \mathrm{cm}^{-2}\right) ; c$ is the molar concentration of chemical $(M) ; l$ is the path length penetrated by the incident light $(\mathrm{cm}) ; \varepsilon$ is the molar extinction coefficient $\left(M^{-1} \mathrm{~cm}^{-1}\right)$. It is a function of wavelength and the nature of the chemicals.

\subsubsection{Quantum Yield}

The efficiency of the photochemical process can be measured by the quantum yield. Based on the steps of photochemical process mentioned above, the quantum yield can be defined as primary quantum yield and overall quantum yield.

Primary quantum yield $(\phi)$ describes the efficiency of primary process. It can be defined as the molecules of reactant consumed per photon absorbed. In other words, it indicates the percentage of absorbed photons that has been utilized in the photochemical process over all the absorbed photons. Thus the value of primary quantum yield will not exceed 1.

The overall quantum yield ( $\Phi$ ) describes the efficiency of overall photochemical process, including primary process and subsequent non-photochemical processes. It can be defined as the molecules of reactant decomposed or product formed per photon absorbed. If chain reactions occur in the secondary processes, the overall quantum yield could be greater than primary quantum yield. The overall quantum yield can be expressed as:

$$
\Phi=\frac{d[x] / d t}{n}
$$

in which, $\Phi$ is the overall quantum yield (mol-Einstein $\left.{ }^{-1}\right) ; d[x] / d t$ is the rate of 
change of a measurable quantity, $x ; n$ is the absorbed photon per unit time (McNaught and Wilkinson, 1997).

\subsubsection{Comparison of Photochemical and Thermochemical Reactions}

Compared with thermochemical reactions, there are two distinct advantages of photochemical reactions: better selectivity and high molecular reactivity.

In thermochemical reactions, the energy is broadly distributed; while in photochemical reactions, the energy can be selected and distributed in a narrow range by changing the wavelength of the radiation. By this way, it is possible to selectively excite a molecule to different excited states under different radiation wavelengths. Thus for the chemical reaction with several pathways, the reaction can be controlled under the preferable route and the side reactions can be significantly reduced.

In thermochemical reactions, some reactions are difficult to be carried out or can only occur under high temperature and high-pressure conditions. In photochemical reactions, the selected radiation can stimulate the reactivity of molecules by providing high energy under natural conditions.

Due to the advantages of photochemical reactions, photochemical processes have broad applications in polymer, pharmaceutical, petroleum, and environmental industries.

\subsection{The source of $U V$}

For the environmental industry, UV irradiation is one of the most popularly applied 
photochemical technologies in the fields of surface, water and air disinfection, photodegradation of organic pollutants, and detoxification of inorganic contaminants.

The UV spectrum can be subdivided into three categories. Considering the effects of UV exposure on human health, the UV radiation refers to the wavelength in the $100 \sim 400$ $\mathrm{nm}$ range, and is usually categorized as: UVA $(320 \sim 400 \mathrm{~nm}), \mathrm{UVB}(290 \sim 320 \mathrm{~nm})$ and UVC (200 290 nm) (Diffey, 2002).

\subsubsection{Solar Light}

The solar light is the natural source of UV. When the electromagnetic radiation given off by the sun reaches the earth, it will be attenuated by the earth's atmosphere. All the UVC and the large portion of UVB are naturally absorbed by the ozone layer in the atmosphere. And 99\% of the ultraviolet radiation that reaches the earth's surface is UVA. The industrial application of natural UV source is limited due to the low efficiency and the uncertainty of climate. Usually solar-simulated artificial light sources are required to supplement the solar radiation.

\subsubsection{Mercury UV Lamp}

Due to the advantages of high volatility and low ionization potential, mercury is widely chosen as the substance of gas-discharge lamp to produce UV radiation. The mercury UV lamp consists of a sealed quartz tube and two electrodes at the ends. The tube is filled with inert gas and contains a small dose of mercury within the tube. When a very high voltage is applied to the electrodes, the mercury can be vaporized by the ignited 
arc and generates UV light by the excited $\mathrm{Hg}$ atoms. According to the pressure within the tube, the mercury UV lamp can be classified as: low-pressure mercury lamp, medium-pressure mercury lamp, and high-pressure mercury lamp.

\subsubsection{Low-pressure Mercury Lamp}

Low-pressure mercury lamp has the internal lamp pressure below atmospheric $\left(10^{-3} \sim 10^{-2}\right.$ torr $)$. It primarily emits two wavelengths at $253.7 \mathrm{~nm}$ and $184.9 \mathrm{~nm}$. Usually low-pressure lamp is considered as monochromatic, since $90 \%$ of the light is in the wavelength range centered at $253.7 \mathrm{~nm}$. A typical low-pressure mercury lamp has a power input in the range $20 \sim 120$ watts, and a long lifetime range of $4000 \sim 8000$ hours (Philips, 1983). The drawbacks of this type of lamp are the low intensity output and low treatment efficiency under the wavelength range below $240 \mathrm{~nm}$.

\subsubsection{Medium-pressure Mercury Lamp}

Medium-pressure mercury lamp has the internal lamp pressure near atmospheric $\left(10^{2} \sim 10^{4}\right.$ torr). It emits a discrete spectrum covering a wide range of $U V$, visible and $\mathbb{R}$ regions. A typical medium-pressure lamp has a power input in the range of $250 \sim 30,000$ watts, and a long lifetime range of 1000 4000 hours. The operating temperature of the tube is typically $600 \sim 800^{\circ} \mathrm{C}$ and usually a water-cooling system is required. It is more efficient than the low-pressure lamp for many photochemical applications due to the broad emission spectrum and high intensity output. However, the medium-pressure lamp is usually more costly than the low-pressure lamp and its efficiency in the range of 200 300 nm is only 5 20\% (Philips, 1983). 


\subsubsection{High-pressure Mercury Lamp}

High-pressure mercury lamp has a much higher internal lamp pressure (above $6 \times 10^{4}$ torr) and emits a higher intensity of the UV light than the low and medium-pressure lamps (McNaught and Wilkinson, 1997). The arc core temperature of this type of lamp can be as high as $7000^{\circ} \mathrm{C}$ (Lawer, 2004). Its emission spectrum appears more continuous in the wavelength range of $200 \sim 1400 \mathrm{~nm}$. However, high-pressure mercury lamp could be hazardous due to its high temperature, high internal pressure and intense short-wavelength radiation. It is also costlier.

\subsubsection{Other UV Sources}

Besides mercury UV lamps, metal halide lamps, medium or high-pressure Xenon lamps and electrodeless lamps are also commercially available as the sources of UV irradiation.

\subsection{UV-based Oxidation Processes}

UV-based oxidation processes can be classified as Direct Photolysis (DP) and Advanced Oxidation Process (AOP). Direct Photolysis is a process in which the reactant itself absorbs UV energy and directly decomposes without the assistance of any oxidants or catalysts. Many organic contaminants can absorb the UV radiation in the range of 200 300 nm and decompose by Direct Photolysis. However, Direct Photolysis presents low efficiency for most of the contaminants. So the addition of oxidants or catalysts in the 
UV processes, referred to as AOP, is usually required.

AOP is defined by Glaze et al. (1987) as "near ambient temperature and pressure water treatment processes which involve the generation of hydroxyl radicals in sufficient quantity to effect water purification". Hydroxyl radical $(\mathrm{OH} \cdot)$ is a short-lived and extremely powerful oxidant. Its relative oxidation power is next only to fluorine gas, as shown in Table 3.1. OH. attacks and reacts with the molecules of the contaminant at a very high reaction rate. The reaction rate of $\mathrm{OH} \cdot$ is typically $10^{6}$ to $10^{9}$ times faster than the corresponding rate for ozone.

Table 3.1 Relative oxidation power of common oxidants

\begin{tabular}{l|cc}
\hline \multicolumn{1}{c|}{ Oxidant } & $\begin{array}{c}\text { Oxidation Potential } \\
\text { (Volts) }\end{array}$ & $\begin{array}{c}\text { Relative Oxidation } \\
\text { Power }\left(\mathbf{C l}_{2}=\mathbf{1 . 0}\right)\end{array}$ \\
\hline Fluorine $\left(\mathrm{F}_{2}\right)$ & 3.0 & 2.23 \\
Hydroxyl radical $(\mathrm{OH} \cdot)$ & 2.8 & 2.06 \\
Oxygen Radical $\left(\mathrm{O}_{2}^{-} \cdot\right)$ & 2.4 & 1.78 \\
Ozone $\left(\mathrm{O}_{3}\right)$ & 2.1 & 1.50 \\
Hydrogen peroxide $\left(\mathrm{H}_{2} \mathrm{O}_{2}\right)$ & 1.8 & 1.31 \\
Potassium Permanganate $\left(\mathrm{KMnO}_{4}\right)$ & 1.7 & 1.24 \\
Chlorine Dioxide $\left(\mathrm{ClO}_{2}\right)$ & 1.6 & 1.15 \\
Oxygen $\left(\mathrm{O}_{2}\right)$ & 1.2 & 0.86 \\
Bromine $\left(\mathrm{Br}_{2}\right)$ & 1.1 & 0.80 \\
lodine $\left(\mathrm{I}_{2}\right)$ & 0.8 & 0.54 \\
\hline \hline
\end{tabular}

The generation of $\mathrm{OH} \cdot$ can be achieved by several UV processes, including $\mathrm{UV} / \mathrm{O}_{3}$ system, $\mathrm{UV} / \mathrm{H}_{2} \mathrm{O}_{2}$ system, $\mathrm{UV} / \mathrm{O}_{3} / \mathrm{H}_{2} \mathrm{O}_{2}$ system, Photo-Fenton system and $\mathrm{UV} / \mathrm{TiO}_{2}$ system. The following is a brief introduction to these AOP systems. 


\subsubsection{UV/O $/$ System}

Under the irradiation of $\mathrm{UV}$, Ozone $\left(\mathrm{O}_{3}\right)$ can produce hydrogen peroxide $\left(\mathrm{H}_{2} \mathrm{O}_{2}\right)$ as the intermediate and then decompose to $\mathrm{OH} \cdot$ :

$$
\begin{gathered}
\mathrm{O}_{3} \stackrel{h v<310 \mathrm{~nm}}{\longrightarrow} \mathrm{O}_{2}+\mathrm{O}\left({ }^{1} \mathrm{D}\right) \\
O\left({ }^{1} \mathrm{D}\right)+\mathrm{H}_{2} \mathrm{O} \rightarrow \mathrm{H}_{2} \mathrm{O}_{2} \rightarrow 2 \mathrm{OH}
\end{gathered}
$$

in which $O\left({ }^{1} D\right)$ is the singlet oxygen atom. $\mathrm{O}_{3}$ has a very high molecular absorptivity. At UV wavelength of $254 \mathrm{~nm}$, the extinction coefficient $\varepsilon$ of $\mathrm{O}_{3}$ is as high as 3300 $M^{1} \cdot \mathrm{cm}^{-1}$

\subsection{2 $\mathrm{UV} / \mathrm{H}_{2} \mathrm{O}_{2}$ System}

Hydroxyl radical $(\mathrm{OH} \cdot)$ can be formed by the Direct Photolysis of hydrogen peroxide $\left(\mathrm{H}_{2} \mathrm{O}_{2}\right)$ :

$$
\mathrm{H}_{2} \mathrm{O}_{2} \stackrel{h v}{\longrightarrow} 2 \mathrm{OH}
$$

In alkaline conditions, $\mathrm{H}_{2} \mathrm{O}_{2}$ can decompose to $\mathrm{HO}_{2}{ }^{-}$, and produce $\mathrm{OH} \cdot$ by reaction (R3-5):

$$
\begin{aligned}
& \mathrm{H}_{2} \mathrm{O}_{2} \Leftrightarrow \mathrm{HO}_{2}^{-}+\mathrm{H}^{+} \\
& \mathrm{HO}_{2}^{-} \stackrel{h v}{\longrightarrow} \mathrm{OH} \cdot+\mathrm{O}^{-}
\end{aligned}
$$

The molecular absorptivity of $\mathrm{H}_{2} \mathrm{O}_{2}$ is much lower than $\mathrm{O}_{3}$. At UV wavelength of $254 \mathrm{~nm}$, the extinction coefficient $\varepsilon$ of $\mathrm{H}_{2} \mathrm{O}_{2}$ is only $18.2 \mathrm{M}^{-1} \mathrm{~cm}^{-1}$. But with the increase of $\mathrm{pH}$, the $\mathrm{OH} \cdot$ yield rate increases. The increase of $\mathrm{HO}_{2}^{-}$in alkaline conditions might contribute to the increase of $\mathrm{OH} \cdot$ yield since it has higher extinction coefficient 
$\left(\varepsilon_{254 n m}=240 M^{-1} \cdot \mathrm{cm}^{-1}\right)$ than $\mathrm{H}_{2} \mathrm{O}_{2}$ (Legrini et al., 1993).

\subsubsection{UV/O $\mathrm{O}_{3} / \mathrm{H}_{2} \mathrm{O}_{2}$ System}

Under dark conditions, $\mathrm{O}_{3}$ can react with $\mathrm{H}_{2} \mathrm{O}_{2}$ to produce $\mathrm{OH} \cdot$. The yield of $\mathrm{OH} \cdot$ can be significantly improved in the presence of UV radiation. The possible pathways of the generation of $\mathrm{OH} \cdot$ are shown below (Legrini et al., 1993):

$$
\begin{gathered}
\mathrm{H}_{2} \mathrm{O}_{2}+\mathrm{H}_{2} \mathrm{O} \Leftrightarrow \mathrm{H}_{3} \mathrm{O}^{+}+\mathrm{HO}_{2}^{-} \\
\mathrm{O}_{3}+\mathrm{H}_{2} \mathrm{O}_{2} \rightarrow \mathrm{O}_{2}+\mathrm{OH} \cdot+\mathrm{HO}_{2} \\
\mathrm{O}_{3}+\mathrm{HO}_{2}^{-} \rightarrow \mathrm{O}_{2}+\mathrm{OH} \cdot+\mathrm{O}_{2}^{-} \\
\mathrm{O}_{3}+\mathrm{O}_{2}^{-} \cdot \rightarrow \mathrm{O}_{2}+\mathrm{O}_{3}^{-} \\
\mathrm{O}_{3}^{-}+\mathrm{H}_{2} \mathrm{O} \rightarrow \mathrm{O}_{2}+\mathrm{OH} \cdot+\mathrm{OH}^{-}
\end{gathered}
$$

\subsubsection{Photo-Fenton System}

The addition of ferrous $\left(\mathrm{Fe}^{2+}\right)$ or ferric $\left(\mathrm{Fe}^{3+}\right)$ ions to the $\mathrm{UV} / \mathrm{H}_{2} \mathrm{O}_{2}$ system is called Photo-Fenton oxidation. $\mathrm{Fe}^{2+}$ can react with $\mathrm{H}_{2} \mathrm{O}_{2}$ to produce $\mathrm{OH} \cdot$, known as the Fenton reaction. $\mathrm{Fe}^{3+}$ forms $\mathrm{Fe}(\mathrm{OH})^{2+}$ complex at acidic conditions. The latter decomposes to $\mathrm{Fe}^{2+}$ and generates $\mathrm{OH} \cdot$ under the UV irradiation. $\mathrm{Fe}(\mathrm{OH})^{2+}$ complex has very high molecular absorptivity, with the extinction coefficients of $\varepsilon_{208 \mathrm{~nm}}=4300 \mathrm{M}^{-1} \cdot \mathrm{cm}^{-1}$ and $\varepsilon_{300 n m}=1985 M^{-1} \cdot \mathrm{cm}^{-1}$ (Pozdnyakov et al., 2000). So the yield of $\mathrm{OH} \cdot$ from the $\mathrm{Fe}(\mathrm{OH})^{2+}$ complex is very high. The generated $\mathrm{Fe}^{2+}$ can further react with $\mathrm{H}_{2} \mathrm{O}_{2}$ to generate $\mathrm{OH} \cdot$ and $\mathrm{Fe}^{3+}$.

The reaction scheme shown from reactions (R3-11) to (R3-13) indicates that 
$\mathrm{Fe}^{3+} / \mathrm{Fe}^{2+}$ plays the role of homogenous catalyst in the $\mathrm{UV} / \mathrm{H}_{2} \mathrm{O}_{2}$ system, which stimulates the generation of $\mathrm{OH}$.

$$
\begin{gathered}
\mathrm{Fe}^{3+}+\mathrm{H}_{2} \mathrm{O} \rightarrow \mathrm{Fe}(\mathrm{OH})^{2+}+\mathrm{H}^{+} \\
\mathrm{Fe}(\mathrm{OH})^{2+} \stackrel{h v}{\longrightarrow} \mathrm{Fe}^{2+}+\mathrm{OH} \\
\mathrm{Fe}^{2+}+\mathrm{H}_{2} \mathrm{O}_{2} \rightarrow \mathrm{Fe}^{3+}+\mathrm{OH}^{-}+\mathrm{OH}
\end{gathered}
$$

Ferrioxalate $\left(\left[\mathrm{Fe}\left(\mathrm{C}_{2} \mathrm{O}_{4}\right)_{3}\right]^{3-}\right)$, a widely used chemical actinometer, can also be used to produce $\mathrm{OH} \cdot$ following the steps below (Kocar and Inskeep, 2003). $\left[\mathrm{Fe}\left(\mathrm{C}_{2} \mathrm{O}_{4}\right)_{3}\right]^{3-}$ decomposes to $\mathrm{Fe}^{2+}$ and $\mathrm{C}_{2} \mathrm{O}_{4}^{-}$. under $\mathrm{UV}$ irradiation in the wavelength range of $250 \sim 450$ $\mathrm{nm}$. The former can produce $\mathrm{OH} \cdot$ in the presence of $\mathrm{H}_{2} \mathrm{O}_{2}$ as mentioned above. The latter can form superoxide radical $\left(\mathrm{O}_{2}^{-} \cdot\right)$ by reactions (R3-15) and (R3-16). The formation of $\mathrm{H}_{2} \mathrm{O}_{2}$ in the ferrioxalate system can be described as in reactions (R3-17) and (3-18). The $\mathrm{OH} \cdot$ can then be produced by the decomposition of $\mathrm{H}_{2} \mathrm{O}_{2}$ or Fenton reaction.

$$
\begin{gathered}
\mathrm{Fe}\left(\mathrm{C}_{2} \mathrm{O}_{4}\right)_{3}^{3-} \stackrel{h v}{\longrightarrow} \mathrm{Fe}^{2+}+2 \mathrm{C}_{2} \mathrm{O}_{4}^{2-}+\mathrm{C}_{2} \mathrm{O}_{4}^{-} \cdot \\
\mathrm{C}_{2} \mathrm{O}_{4}^{-} \cdot \rightarrow \mathrm{CO}_{2}^{-}+\mathrm{CO}_{2} \\
\mathrm{CO}_{2}^{-} \cdot+\mathrm{O}_{2} \rightarrow \mathrm{O}_{2}^{-} \cdot+\mathrm{CO}_{2} \\
\mathrm{O}_{2}^{-} \cdot+\mathrm{H}^{+} \rightarrow \mathrm{HO}_{2} \\
2 \mathrm{HO}_{2} \cdot \rightarrow \mathrm{H}_{2} \mathrm{O}_{2}+\mathrm{O}_{2}
\end{gathered}
$$

\subsubsection{UV/TiO 2 System}

Titanium dioxide $\left(\mathrm{TiO}_{2}\right)$ is the most widely used heterogeneous photocatalyst due to its effective long-wavelength UV absorbance and chemical inertness. The photocatalysis 
occurs when reactants are adsorbed by the $\mathrm{TiO}_{2}$ particles.

As a semiconductor, there is a band gap between the valence band and the conduction band with the energy of $\Delta \mathrm{E}_{\mathrm{bg}}$ in the surface of $\mathrm{TiO}_{2}$ particles. Under UV irradiation, the absorbed photons with the energy equal to or greater than $\Delta \mathrm{E}_{\mathrm{bg}}$ can promote the electrons to move from the valence band to the conduction band. This process generates an excited electron (e) in the conduction band and a positively charged hole in the valence band $\left(\mathrm{h}^{+}\right)$. The $\mathrm{O}_{2}{ }^{-}$and $\mathrm{OH} \cdot$ can be produced from the oxygen and the water by the reaction below (Munter, 2001). $\mathrm{TiO}_{2}$ can also enhance the decomposition of $\mathrm{H}_{2} \mathrm{O}_{2}$ as shown in reaction (R3-23).

$$
\begin{gathered}
\mathrm{TiO}_{2} \stackrel{h v}{\longrightarrow} \mathrm{TiO}_{2}\left(e^{-}+h^{+}\right) \\
\mathrm{TiO}_{2}\left(e^{-}\right)+\mathrm{O}_{2} \rightarrow \mathrm{TiO}_{2}+\mathrm{O}_{2}^{-} \\
\mathrm{TiO}_{2}\left(h^{+}\right)+\mathrm{OH}^{-}(\mathrm{ad}) \rightarrow \mathrm{TiO}_{2}+\mathrm{OH} \cdot(\mathrm{ad}) \\
\mathrm{TiO}_{2}\left(h^{+}\right)+\mathrm{H}_{2} \mathrm{O}(\mathrm{ad}) \rightarrow \mathrm{TiO}_{2}+\mathrm{OH} \cdot(\mathrm{ad})+\mathrm{H}^{+} \\
\mathrm{TiO}_{2}\left(e^{-}\right)+\mathrm{H}_{2} \mathrm{O}_{2} \rightarrow \mathrm{TiO}_{2}+\mathrm{OH}^{-}+\mathrm{OH}
\end{gathered}
$$

The major advantage of $\mathrm{UV} / \mathrm{TiO}_{2}$ system is that it can be operated in the UV-A wavelength range with solar radiation.

\subsection{Summary of the Previous Work on Photooxidation of As(III)}

Number of studies on As(III) oxidation by UV-based oxidation processes were published in the literature. These studies covered the homogeneous processes of using oxygen, hydrogen peroxide, iron compounds, sodium sulfite, and humic acid, and the 
heterogeneous catalytic processes of using activated carbon and titanium dioxide $\left(\mathrm{TiO}_{2}\right)$. A summary of the experimental conditions for these As(III) oxidation processes is listed in Table 3.2. 
Table 3.2 Summary of experimental conditions of the As(III) photooxidation processes

\begin{tabular}{|c|c|c|c|c|c|}
\hline Ref. & {$[\mathrm{As}(\mathrm{III})]_{0}$} & Oxidant/Catalyst & $\begin{array}{c}\mathrm{pH} \\
\text { range }\end{array}$ & $\mathrm{O}_{2}$ Condition & UV Source \\
\hline $\begin{array}{c}\text { Gottschalk et al. } \\
\text { (1992) }\end{array}$ & $0.534 \mu \mathrm{M}$ & Activated Carbon: $1 \sim 10 \mathrm{~g} / \mathrm{L}$ & $6 \sim 10$ & Not mentioned & $\begin{array}{l}\text { Low-pressure Lamp, 15Watts } \\
\text { High-pressure Lamp, } 700 \text { Watts }\end{array}$ \\
\hline Khoe et al.(1997) & $0.067 \sim 3.337 \mathrm{mM}$ & $\mathrm{Fe}(1 \mathrm{I}): 1.325 \mathrm{mM}$ & $1 \sim 3$ & $40 \mathrm{mg} / \mathrm{L}$ & Low-pressure Lamp, 15Watts \\
\hline $\begin{array}{l}\text { Emett \& Khoe } \\
\text { (2001) }\end{array}$ & $2.002 \mathrm{mM}$ & $\mathrm{Fe}(111): 5.014 \mathrm{mM}$ & $1.5 \sim 3$ & $0 \sim 7.0 \mathrm{mg} / \mathrm{L}$ & $13.3 \mu \mathrm{E} / \mathrm{L}$ near UV light \\
\hline Zaw \&Emett (2002) & $0.053 \sim 0.133 \mathrm{mM}$ & $\begin{array}{l}\mathrm{Fe}(\mathrm{III}): \\
0.448 \sim 3.402 \mathrm{mM}\end{array}$ & $1.5-3$ & Air sparged & $\begin{array}{c}\text { Sunlight \& Low-pressure Lamp, } \\
3 \text { Watts/L }\end{array}$ \\
\hline $\begin{array}{l}\text { Kocar\& Inskeep } \\
\text { (2003) }\end{array}$ & $0.001 \sim 13.50 \mathrm{mM}$ & $\begin{array}{l}\mathrm{Fe}(\mathrm{III}): 18 \mu \mathrm{M} \\
\text { Oxalate: } 1 \mathrm{mM}\end{array}$ & $3 \sim 7$ & Not required & $\begin{array}{l}\text { Quartz Tungsten Halogen lamp } \\
\qquad \begin{array}{c}(300-500 \mathrm{~nm}) \\
250 \mathrm{~W}\end{array}\end{array}$ \\
\hline Hug et al.(2001) & $6.647 \mu \mathrm{M}$ & $\begin{array}{l}\text { Total } \mathrm{Fe}(\mathrm{III}) \& \mathrm{Fe}(\mathrm{II}) \text { : } \\
1.074-89.534 \mu \mathrm{M} \\
\text { Citrate: } 50 \mu \mathrm{M}\end{array}$ & $6.5 \sim 8$ & Not required & $\begin{array}{l}\text { Solar UV simulator (UV-A), } \\
\qquad 90 \mathrm{~W} / \mathrm{m}^{2}\end{array}$ \\
\hline Khoe et al.(1998) & $1.7 \mathrm{~L}, 0.006 \mathrm{mM}$ & $\begin{array}{l}\mathrm{Na}_{2} \mathrm{SO}_{3}: 0.032 \sim 0.095 \mathrm{mM} \\
\mathrm{Na}_{2} \mathrm{SO}_{3}: 0.032 \sim 0.095 \mathrm{mM} \\
0.016 \mathrm{mM} / \mathrm{L} / \mathrm{min}\end{array}$ & 9 & ait $(2.5 \mathrm{~L} / \mathrm{min})$ & Low-pressure Lamp, $11 \mathrm{~mW} / \mathrm{cm}^{2}$ \\
\hline Khoe et al.(2005) & $1.7 \mathrm{~L}, 0.006 \mathrm{mM}$ & $\begin{array}{l}\mathrm{SO}_{2}(\mathrm{~g}): 0.02 \mathrm{~L} / \mathrm{min} \\
\mathrm{Na}_{2} \mathrm{~S}_{2} \mathrm{O}_{3}: 0.006 \sim 0.037 \mathrm{mM} \\
\mathrm{Na}_{2} \mathrm{~S}_{4} \mathrm{O}_{6}: 0.007 \mathrm{mM} / \mathrm{L} / \mathrm{min}\end{array}$ & $6.5 \sim 9$ & air (2.5L/min) & Low-pressure Lamp, 15Watts \\
\hline $\begin{array}{l}\text { Ganesh\& Clifford } \\
\text { (2001) }\end{array}$ & $1 \mathrm{~L}, 0.66 \mu \mathrm{M}$ & $\mathrm{Na}_{2} \mathrm{SO}_{3}: 7.934 \mu \mathrm{M}$ & 8.3 & Air saturated & Low-pressure Lamp, $32 \mathrm{~mW} / \mathrm{cm}^{2}$ \\
\hline $\begin{array}{l}\text { Buschmann et } \\
\text { al.(2005) }\end{array}$ & $0.40 \mu \mathrm{M}$ & $\begin{array}{l}\text { Humic Acid (from } \\
\text { Suwannee River): } 5 \mathrm{mg} / \mathrm{L}\end{array}$ & $4 \sim 8$ & Not required & $\begin{array}{c}\text { Medium- pressure lamp, } \\
700 \text { Watts }\end{array}$ \\
\hline
\end{tabular}


Table 3.2 Summary of experimental conditions of the As(III) photooxidation processes (Continued)

\begin{tabular}{|c|c|c|c|c|c|}
\hline Ref. & {$[\mathrm{As}(I I I)]_{0}$} & Oxidant/Catalyst & $\begin{array}{c}\mathrm{pH} \\
\text { range }\end{array}$ & $\mathrm{O}_{2}$ Condition & UV Source \\
\hline Yang et al. (1999) & $525 \mu \mathrm{M}$ & $\begin{array}{l}\mathrm{H}_{2} \mathrm{O}_{2}: 131.25 \sim 1050 \mu \mathrm{M} \\
\mathrm{TIO}_{2}: 2 \mathrm{~g} / \mathrm{L}, \mathrm{P} 25\end{array}$ & 9 & Nitrogen \& Air sparged & $\begin{array}{l}\text { Medium-pressure lamp, } \\
\text { 400Watts }\end{array}$ \\
\hline Bissen et al. (2001) & $0.67 \sim 135 \mu \mathrm{M}$ & $\begin{array}{l}\mathrm{TiO}_{2} \\
0.001 \sim 0.05 \mathrm{~g} / \mathrm{L}, \mathrm{P} 25\end{array}$ & $5 \sim 9$ & Air saturated & $\begin{array}{c}\text { Solar UV simulator (UV-A) \& } \\
\text { 1000W Xe arc lamp }\end{array}$ \\
\hline Lee \&Choi (2002) & $500 \mu \mathrm{M}$ & $\mathrm{TiO}_{2}: 1.5 \mathrm{~g} / \mathrm{L}, \mathrm{P} 25$ & $3 \sim 9$ & $\begin{array}{c}\text { Nitrogen sparged \& Air } \\
\text { saturated }\end{array}$ & $\begin{array}{c}\text { Xe arc lamp }(>300 \mathrm{~nm}) \\
\text { 300Watts }\end{array}$ \\
\hline Jayaweera et al.(2003) & $1330 \mu \mathrm{M}$ & $\mathrm{TiO}_{2}: 0.25 \sim 2.5 \mathrm{~g} / \mathrm{L}, \mathrm{BDH}$ & $1 \sim 13$ & Air saturated & $\begin{array}{l}\text { Sunlight } \& 250 \text { Watts } \\
\text { Medium-pressure lamp }\end{array}$ \\
\hline Ryu\&Choi(2004) & $500 \mu M$ & $\mathrm{TiO}_{2}: 0.5 \mathrm{~g} / \mathrm{L}, \mathrm{P} 25$ & $3 \sim 9$ & $\begin{array}{c}\text { Nitrogen sparged \& Air } \\
\text { saturated }\end{array}$ & $\begin{array}{c}\text { Xe arc lamp }(>300 \mathrm{~nm}) \\
\text { 300Watts }\end{array}$ \\
\hline Dutta et al. (2005) & $40-333 \mu \mathrm{M}$ & $\begin{array}{l}\mathrm{TiO}_{2}: 0.01 \sim 0.1 \mathrm{~g} / \mathrm{L} \\
\text { Hombikat UV100 }\end{array}$ & $3 \sim 9$ & $\begin{array}{c}\text { Nitrogen sparged \& Air } \\
\text { saturated }\end{array}$ & $\begin{array}{l}\text { High-pressure lamp }(365 \mathrm{~nm}) \text {, } \\
\qquad 125 \text { Watts }\end{array}$ \\
\hline Xu et al.(2005) & $13.4 \mu \mathrm{M}$ & $\mathrm{TiO}_{2}: 0.1 \sim 1.0 \mathrm{~g} / \mathrm{L}, \mathrm{P} 25$ & - & $\begin{array}{c}\text { Argon sparged \& Air } \\
\text { saturated }\end{array}$ & $\begin{array}{l}\text { Low-pressure lamp }(350 \mathrm{~nm}) \\
1.5 \sim 5.0 \mu \mathrm{E} / \mathrm{min} / \mathrm{cm}^{2}\end{array}$ \\
\hline Pena et al.(2005) & $26.7 \mu \mathrm{M}$ & $\begin{array}{l}\mathrm{TiO}_{2}: \\
0.2 \mathrm{~g} / \mathrm{L}, \text { nanocrystalline }\end{array}$ & 7 & Air saturated & Sunlight \\
\hline Ferguson et al.(2005) & $0.1-89 \mu \mathrm{M}$ & $\mathrm{TiO}_{2}: 0.05 \sim 0.2 \mathrm{~g} / \mathrm{L}, \mathrm{P} 25$ & 6.3 & $\begin{array}{c}\text { Nitrogen sparged \& Air } \\
\text { saturated }\end{array}$ & $\begin{array}{l}\text { Low-pressure UV lamp } \\
\qquad(365 \mathrm{~nm}), 8 \text { Watts }\end{array}$ \\
\hline Yoon\&Lee(2005) & $100 \mu \mathrm{M}$ & $\mathrm{TiO}_{2}: 10 \mathrm{~g} / \mathrm{L}, \mathrm{P} 25$ & $3-7$ & $\begin{array}{c}\text { Nitrogen sparged \& Air } \\
\text { saturated }\end{array}$ & $\begin{array}{l}\text { Low-pressure UV lamp } \\
\text { (254nm and } 352 \mathrm{~nm}), 4 \text { Watts }\end{array}$ \\
\hline
\end{tabular}




\subsubsection{Direct UV Irradiation with Oxygen $\left(\mathrm{O}_{2}\right)$}

Gottschalk et al. (1992) compared the performance of low-pressure and high-pressure mercury lamps to the oxidation of $\mathrm{As}(\mathrm{III})$ in the presence of $\mathrm{O}_{2}$. The results indicated that low-pressure lamp is not effective for the As(III) oxidation, whereas high-pressure lamp presented high oxidation efficiency. $90 \%$ of $20 \mathrm{~mL} 0.534 \mu \mathrm{M}$ As(III) were oxidized within 30 90 $\mathrm{s}$ in the $\mathrm{pH}$ range of $6 \sim 10$. With the increase of $\mathrm{pH}$ from 8 to 10 , the reaction constant was clearly enhanced.

\subsubsection{Hydrogen Peroxide $\left(\mathrm{H}_{2} \mathrm{O}_{2}\right)$ as the Oxidant}

As discussed in the previous chapter, under dark conditions the complete oxidation of $\mathrm{As}(\mathrm{III})$ by $\mathrm{H}_{2} \mathrm{O}_{2}$ requires the addition of excess $\mathrm{H}_{2} \mathrm{O}_{2}$ and alkaline condition with $\mathrm{pH}$ above 10.3. Yang et al. (1999) indicated that in the presence of UV light, the consumption of $\mathrm{H}_{2} \mathrm{O}_{2}$ can be significantly reduced. At a $\mathrm{H}_{2} \mathrm{O}_{2}$ : As(III) ratio of $1: 4$, air saturated 0.525 $\mathrm{mM}$ As(III) solution can be completely oxidized to $\mathrm{As}(\mathrm{V})$ within 10 minutes at $\mathrm{pH} 9$ under the UV irradiation.

\subsubsection{Iron Compounds as the Catalyst}

Khoe et al. (1997) studied oxidation of As(III) using Fe(II) as the catalyst. The results showed that under UV irradiation, $0.067 \mathrm{mM}$ As(III) can be completely oxidized within 15 minutes in the presence of $1.325 \mathrm{mM} \mathrm{Fe}$ (II) and with the oxygen sparging. The study also showed that under the conditions of low oxygen concentration, only small amounts of As(III) can be removed even in the presence of Fe(II) and UV irradiation. It 
indicated that oxygen plays an important role in the As(III) oxidation process.

Emett \& Khoe (2001) and Zaw \& Emett (2002) further investigated the oxidation of As(III) in the presence of Fe(III). Emett and Khoe (2001) indicated that $2.002 \mathrm{mM}$ air saturated As(III) solution can be oxidized to $\mathrm{As}(\mathrm{V})$ within 30 minutes in the presence of $5.014 \mathrm{mM}$ Fe(III) under the irradiation of $254 \mathrm{~nm}$ UV. The Fe(II) was produced during the oxidation process. Under de-aerated conditions, the oxidation of As(III) also occurred but the oxidation rate was much slower than aerated conditions. However, at the dissolved oxygen (DO) concentration above $7.0 \mathrm{mg} / \mathrm{L}$, no significant effect of oxygen to the As(III) oxidation rate was observed. Operating below $\mathrm{pH} 4.0$ was preferred due to the instability of $\mathrm{Fe}$ (II) at $\mathrm{pH}$ above 4.0. The study also indicated that the addition of chloride $\left(\mathrm{Cl}^{-}\right)$increased the $\mathrm{As}(\mathrm{III})$ oxidation rate, while the addition of sulfate $\left(\mathrm{SO}_{4}{ }^{2-}\right)$ had an adverse effect.

Zaw and Emett (2002) compared the As(III) oxidation efficiency by Fe(III) under sunlight and UV lamp. The results indicated that in the $\mathrm{pH}$ range of $1.5 \sim 3.0$, initial 0.113 $\mathrm{mM}$ As(III) can be completely oxidized to As(V) in the presence of $3.402 \mathrm{mM}$ Fe(III) within 6 hours of sunlight $\left(1.5 \sim 4 \mathrm{~mW} / \mathrm{cm}^{2}\right)$ irradiation. Under the irradiation of $3 \mathrm{watts} / \mathrm{L}$ UV (254 nm) light, complete oxidation of $0.053 \mathrm{mM}$ As(III) was achieved within 5 minutes by adding $0.448 \mathrm{mM}$ Fe(III). It also indicated that the addition of hydrochloric acid can increase the As(III) oxidation rate.

The oxidation of As(III) by ferrioxalate under UV irradiation was observed. The oxidation of $\mathrm{As}(\mathrm{III})$ by ferrioxalate solutions was found to be $\mathrm{pH}$ dependent. With the 
decrease of $\mathrm{pH}$, the rates of $\mathrm{As}(\mathrm{III})$ oxidation increased. At optimal $\mathrm{pH}$ of $3.0,17.4 \mu \mathrm{M}$ As(III) can be completely oxidized in the solution with $18 \mu \mathrm{M} \mathrm{Fe}(\mathrm{III})$ and $1 \mathrm{mM}$ oxalate within 30 minutes (Kocar and Inskeep, 2003).

Adding citrate into $\mathrm{As}$ (III)/ Fe(II) \&Fe(III) solution under UV-A irradiation was also found to be an effective way to accelerate the $\mathrm{As}$ (III) oxidation rate. $6.647 \mu \mathrm{M}$ As(III) with $36 \mu \mathrm{M}$ Fe can be completely oxidized to As(V) within 1 hour in the presence of 50 $\mu \mathrm{M}$ citrate at $\mathrm{pH} 7.0 \sim 7.3$ (Hug, et al, 2001).

\subsubsection{Sulfite as the Oxidant/Inducer}

Khoe et al. (1998) developed the method of oxidizing of As(III) under the UV irradiation at $254 \mathrm{~nm}$ and sparging with air in the presence of sodium sulfite. A more extensive investigation was carried out to compare the performance of different sulfur compounds: sodium sulfite $\left(\mathrm{Na}_{2} \mathrm{SO}_{3}\right)$, sodium thiosulfate $\left(\mathrm{Na}_{2} \mathrm{~S}_{2} \mathrm{O}_{3}\right)$, sodium tetrathionate $\left(\mathrm{Na}_{2} \mathrm{~S}_{4} \mathrm{O}_{6}\right)$, and sulfur dioxide $\left(\mathrm{SO}_{2}\right.$ gas) (Khoe et al., 2005). The results indicated that sulfur dioxide and sodium sulfite presented better oxidation efficiency. With the increase of sulfite dose, the oxidation rate increased. The optimum $\mathrm{pH}$ for oxidation is at neutral or alkaline conditions. For the consideration of $\mathrm{As}(\mathrm{V})$ removal in the follow-up processes (such as ion-exchange material), the recommended dissolved sulfite was no more than $0.198 \mathrm{mM}$. The effectiveness of sodium sulfite was verified by Ganesh \& Clifford (2001). In the presence of $7.934 \mu \mathrm{M}$ sodium sulfite, air saturated $0.667 \mu \mathrm{M}$ As(III) solution was completely oxidized within 1 minute under the irradiation of $254 \mathrm{~nm}$ UV light (Ganesh 
and Clifford, 2001). However, the experiment was carried out at very low As(III) concentration and with the small volume of $1 \mathrm{~L}$. The application of the method at higher As(III) concentration and larger volume was not evaluated. According to the molar ratio of sulfite/As(V) in the experiment, the consumption of sulfite in the actual application would be very costly.

\subsubsection{Humic Acid as the Oxidant}

Buschmann et al. (2005) investigated the As(III) oxidation by humic acid under the irradiation of UV-A light. The results showed that the oxidation rate of As(III) was significantly improved by the addition of humic acid and the increase of $\mathrm{pH}$ from 4.0 to 8.0. Addition of $\mathrm{Fe}(\mathrm{III})$ was demonstrated to enhance $\mathrm{As}(\mathrm{III})$ oxidation rate.

\subsubsection{Activated Carbon as the Heterogeneous Catalyst}

Gottschalk et al. (1992) investigated the As(III) oxidation using activated carbon as the catalyst under $254 \mathrm{~nm}$ UV irradiation. The results showed that $90 \% 0.534 \mu \mathrm{M} \mathrm{As}$ (III) was oxidized within 25 minutes in the presence of $5 \mathrm{~g} / \mathrm{L}$ activated carbon at $\mathrm{pH} 8.5$. It also indicated that the oxidation rate was improved by increasing either activated carbon concentration or the $\mathrm{pH}$.

\subsection{7 $\mathrm{TiO}_{2}$ as the Heterogeneous Catalyst}

In recent years, the application of $\mathrm{TiO}_{2}$ to $\mathrm{As}$ (III) oxidation has gained attention due to its adsorption and oxidation capabilities. The studies showed that in the presence of 
$\mathrm{TiO}_{2}$, the As(III) oxidation rate can be significantly improved. $40 \mu \mathrm{M}$ air saturated As(III) can be completely oxidized within 15 minutes at $\mathrm{pH} 9$ (Bissen et al., 2001). The oxidation rate was insensitive to the $\mathrm{pH}$ in the range of $3 \sim 9$ but enhanced with the increase of $\mathrm{TiO}_{2} / \mathrm{As}(\mathrm{III})$ ratio (Lee and Choi, 2002; Ryu and Choi, 2004; Dutta, et al, 2005; Xu, et al. 2005). Besides, sufficient DO in the solution was also indicated to be a crucial factor to the As(III) oxidation (Ryu and Choi, 2004).

\subsection{Mechanism of UV-based As(III) Oxidation}

Numerous reactions involved in the photolysis of As(III) have been published in the literature. Most of them are based on the fundamental study by Kläning et al. (1989). Kläning proposed the pathway of As(III) oxidation with the following steps: As(III) is first oxidized to the intermediate As(IV), and then As(IV) is further oxidized to the final product of As(V). A list of reactions based on Kläning's hypothesis is shown in Table 3.3. However, this hypothesis of photolytic As(III) oxidation was not further confirmed in the recent literature mainly because the intermediate As(IV) could not be detected by current analytical methods. 
Table 3.3 List of reactions involved in photolysis of As(III)

\begin{tabular}{|c|c|c|c|}
\hline No. & Reactions & Rate Constant & Reference \\
\hline \multicolumn{4}{|c|}{ As(III) Oxidation } \\
\hline R3-24 & $A s^{(I I I)}(O H)_{3} \stackrel{h v}{\longrightarrow} A s^{(I V)}(O H)_{4}$ & Unknown & Dutta et al. 2005 \\
\hline $\mathrm{R} 3-25$ & $\begin{array}{l}\mathrm{As}^{(\mathrm{III})}(\mathrm{OH})_{2} \mathrm{O}^{-}+\mathrm{CO}_{3} \cdot \cdot^{-}+2 \mathrm{OH}^{-} \rightarrow \\
\mathrm{As}^{(I V)} \mathrm{O}_{3}^{2-}+\mathrm{CO}_{3}^{2-}+2 \mathrm{H}_{2} \mathrm{O}\end{array}$ & $k=1.1 \times 10^{8} \mathrm{M}^{-1} \mathrm{~s}^{-1}$ & Kläning et al. 1989 \\
\hline R3-26 & $A s^{(I I I)}(\mathrm{OH})_{3}+\mathrm{H}_{2} \mathrm{O}_{2} \rightarrow A s^{(I V)}(\mathrm{OH})_{4}+2 O \mathrm{H}^{-}$ & $\begin{array}{c}\mathrm{k}=5.5 \times 10^{-3} \mathrm{M}^{-1} \mathrm{~s}^{-1} \\
(\mathrm{pH} \mathrm{7.5})\end{array}$ & Dutta et al. 2005 \\
\hline R3-27 & $\begin{array}{l}A s^{(I I I)}(\mathrm{OH})_{3}+\mathrm{O}_{2} \cdot \cdot^{-}+\mathrm{H}_{2} \mathrm{O}+\mathrm{H}^{+} \rightarrow \\
A s^{(I V)}(\mathrm{OH})_{3}+\mathrm{H}_{2} \mathrm{O}_{2}\end{array}$ & $k=3 \times 10^{6} \mathrm{M}^{-1} \mathrm{~s}^{-1}$ & Kläning et al. 1989 \\
\hline R3-28 & $A s^{(I I I)}(\mathrm{OH})_{3}+\mathrm{OH} \cdot \rightarrow A s^{(I V)}(\mathrm{OH})_{4}$ & $\mathrm{k}=8.5 \times 10^{9} \mathrm{M}^{-1} \mathrm{~s}^{-1}$ & Kläning et al. 1989 \\
\hline \multicolumn{4}{|c|}{ As(IV) Oxidation and Equilibria } \\
\hline R3-29 & $A s^{(I V)}(O H)_{4} \Leftrightarrow H A s^{(I V)} O_{3}^{-}+H^{+}+H_{2} O$ & $\mathrm{pK}=3.64$ & Kläning et al. 1989 \\
\hline R3-30 & $A s^{(I V)}(O H)_{4} \Leftrightarrow A s(O H)_{3} O^{-}+H^{+}$ & $\mathrm{pK}=7.26$ & Kläning et al. 1989 \\
\hline R3-31 & $H A s^{(I V)} O_{3}^{-} \Leftrightarrow A s^{(I V)} O_{3}^{2-}+H^{+}$ & $\mathrm{pK}=7.57$ & Kläning et al. 1989 \\
\hline R3-32 & $A s(O H)_{3} O^{-} \Leftrightarrow H A s^{(I V)} O_{3}^{-}+H_{2} O$ & $\begin{array}{c}\mathrm{K}=4 \times 10^{3} \\
\text { (base-catalyzed) }\end{array}$ & Kläning et al. 1989 \\
\hline R3-33 & $A s^{(I V)}(\mathrm{OH})_{4} \rightarrow A s(I I I)+A s(V)$ & $\mathrm{k}=8.4 \times 10^{8} \mathrm{M}^{-1} \mathrm{~s}^{-1}$ & Kläning et al. 1989 \\
\hline R3-34 & $A s^{(I V)}(O H)_{4}+H A s^{(I V)} O_{3}^{-} \rightarrow A s(I I I)+A s(V)$ & $\mathrm{k}=2.0 \times 10^{9} \mathrm{M}^{-1} \mathrm{~s}^{-1}$ & Kläning et al. 1989 \\
\hline R3-35 & $2 H A s^{(I V)} O_{3}^{-} \rightarrow A s(I I I)+A s(V)$ & $\mathrm{k}=4.5 \times 10^{8} \mathrm{M}^{-1} \mathrm{~s}^{-1}$ & Kläning et al. 1989 \\
\hline R3-36 & $2 A s^{(I V)} O_{3}^{2-} \rightarrow A s(I I I)+A s(V)$ & $\mathrm{k}=1.9 \times 10^{7} \mathrm{M}^{-1} \mathrm{~s}^{-1}$ & Kläning et al. 1989 \\
\hline R3-37 & $H A s^{(I V)} O_{3}^{-}+A s^{(I V)} O_{3}^{2-} \rightarrow A s(I I I)+A s(V)$ & $\mathrm{k}=4.8 \times 10^{8} \mathrm{M}^{-1} \mathrm{~s}^{-1}$ & Kläning et al. 1989 \\
\hline R3-38 & $A s^{(V)}(\mathrm{OH})_{4}+\mathrm{O}_{2} \rightarrow A s(\mathrm{~V})+\mathrm{HO}_{2} \cdot / \mathrm{O}_{2} .^{-}$ & $\mathrm{k}=1.4 \times 10^{9} \mathrm{M}^{-1} \mathrm{~s}^{-1}$ & Kläning et al. 1989 \\
\hline R3-39 & $A s(\mathrm{OH})_{3} \mathrm{O}^{-}+\mathrm{O}_{2} \rightarrow A s(\mathrm{~V})+\mathrm{O}_{2}$ & $k=1.1 \times 10^{9} \mathrm{M}^{-1} \mathrm{~s}^{-1}$ & Kläning et al. 1989 \\
\hline R3-40 & $H A s^{(I V)} \mathrm{O}_{3}^{-}+\mathrm{O}_{2} \rightarrow A s(I V)-\mathrm{O}_{2}^{-}$ & $\mathrm{k} \approx 10^{9} \mathrm{M}^{-1} \mathrm{~s}^{-1}$ & Kläning et al. 1989 \\
\hline $\mathrm{R} 3-41$ & $H A s^{(I V)} O_{3}^{-}+O_{2} \rightarrow A s(I V)-O_{2}^{-}$ & $\mathrm{k}=1.4 \times 10^{9} \mathrm{M}^{-1} \mathrm{~s}^{-1}$ & Kläning et al. 1989 \\
\hline R3-42 & $A s(I V)-O_{2} \stackrel{H^{+}}{\longrightarrow} A s(V)+H O_{2} \cdot / O_{2} \cdot-$ & $\mathrm{k} \approx 10^{10} \mathrm{M}^{-1} \mathrm{~s}^{-1}$ & Kläning et al. 1989 \\
\hline R3-43 & $A s(I V)-O_{2} \stackrel{O H^{-}}{\longrightarrow} A s(V)+O_{2} \cdot-$ & $\mathrm{k}=3.1 \times 10^{4} \mathrm{M}^{-1} \mathrm{~s}^{-1}$ & Kläning et al. 1989 \\
\hline
\end{tabular}

In many papers, $\mathrm{OH} \cdot$ was suggested to be the dominant oxidant of As(III) oxidation

(Khoe et al., 1997; Emett and Khoe, 2001). However, the evaluation of the role of OH· by adding the 2-propanol as an $\mathrm{OH} \cdot$ scavenger led to different conclusions. In UV/

ferrioxalate process, Kocar \& Inskeep (2003) found significant decrease in oxidation rate 
in the presence of 2-propanol and concluded that $\mathrm{OH} \cdot$ plays an important role on As(III) oxidation. The same scavenger used in the UV/ Fe/Citrate process showed that no significant effect of oxidation rate was observed in the presence of $\mathrm{OH}$. scavenger and the conclusion was made that $\mathrm{OH} \cdot$ might not be a key oxidant to the $\mathrm{As}(\mathrm{III})$ oxidation process (Hug et al., 2001). In UV/Humic acid process, the As(III) oxidation was suggested by the excited triplet states and/or phenoxyl radicals in the system (Buschmann, et al, 2001).

However, there is a considerable debate on the reaction mechanism on the As(III) oxidation by $\mathrm{UV} / \mathrm{TiO}_{2}$ process. Dutta et al. (2005) and Xu et al. (2005) hypothesized that $\mathrm{OH} \cdot$ radicals play significant role in the As(III) oxidation process. In contrast, Lee \& Choi (2002) and Ryu \& Choi (2004) have suggested the possible role of superoxide. Jayaweera et al. (2003) and Yoon \& Lee (2005) also proposed the As(III) oxidation by valence band holes.

\subsection{Justification for the Current Work}

In this study, we investigated the feasibility of a UV-based As(III) oxidation process that would have the advantages of high oxidation efficiency, a process unaffected or less affected by the compositional variation of incoming wastewater, universal applicability over a wide range, less by-products, low cost, and easy operation. Two critical factors investigated are: 1) Selection of proper oxidants/catalysts; 2) Determination of optimal parameters for As(III) oxidation process. A secondary objective is to delineate the possible reaction scheme. 
The UV-based As(III) oxidation processes by different oxidants/catalysts were reviewed in this study. The use of iron compounds as a photoabsorber is favored because the product of ferric hydroxide precipitate in the As(III) photooxidation process is an excellent adsorbent for the As(V) removal in the follow-up precipitation/ coprecipitation or adsorption processes. However, ferrihydrite complexes could impair the efficiency of resin in ion-exchange system and it also could increase the particle loading in membrane system. Hence additional process is required prior to the arsenic removal in these systems.

The patented method of using sulfite for photooxidation of As(III) is applicable to water treatment system at low As(III) concentration. However excessive dose of sulfite is usually required to achieve the complete oxidation of As(III). Besides, the by-product of sulfate could compete with arsenic in the ion-exchange system.

Humic acid could be an alternative. However, the variation of organic composition in the humic acid could affect the performance of As(III) oxidation. Also, the humic substances could deteriorate the water quality.

Even though activated carbon and $\mathrm{TiO}_{2}$ presented great potential to the $\mathrm{As}$ (III) oxidation and arsenic removal, as a suspended powder, they are difficult to handle and recycle. The application of other AOPs, such as $\mathrm{UV} / \mathrm{O}_{3}$ system and $\mathrm{UV} / \mathrm{O}_{3} / \mathrm{H}_{2} \mathrm{O}_{2}$ system, to the As(III) oxidation has not been explored yet. However, the use of $\mathrm{O}_{3}$ needs specific storage and handling, and generally results in increased costs.

Hydrogen peroxide was indicated to be highly efficient for As(III) oxidation under 
UV irradiation. Water and oxygen, the potential by-products of hydrogen peroxide, would not pose any harm in the treated water and any further processing. Besides, the performance of $\mathrm{As}(\mathrm{III})$ oxidation in the $\mathrm{UV} / \mathrm{H}_{2} \mathrm{O}_{2}$ system has not been fully investigated. In this study, consequently, hydrogen peroxide is chosen as the oxidant for the detailed study in two types of reactors.

Many studies in previous work were limited to very small scale at extremely low concentration of As(III) and no detailed investigations of parameters over a wide range were carried out. In this study, the processes were investigated at a much larger scale (30L batch reactor and $60 \mathrm{~L}$ recirculation reactor) and at a much higher concentration range of As (III) with the monitoring of multiple parameters, such as $\mathrm{DO}, \mathrm{pH}$ and Eh. Consequently, greater confidence can be attributed to the results of this study that will be used to determine the feasibility of its industrial application.

The reaction scheme for As(III) oxidation under UV irradiation has remained unresolved and some conflicting results are presented in the literature. Hopefully the results of this study would lead to a better understanding of the As(III) oxidation mechanism. 


\section{CHAPTER 4. EXPERIMENTAL DETAILS}

In this chapter, the details of the experiment are discussed. The chemicals and equipment used in this study are presented. The analytical and sample preservation methods are explained. The experimental procedure and arrangement are also described.

\subsection{Chemicals}

The chemicals in this study were used for different purposes, such as the preparation of synthetic arsenic wastewater, evaluation of the process interference and sample analysis and preservation. The chemicals and their application are listed in Appendix A. All the chemicals meet ACS grades.

The deionized (DI) water used for the synthesis of arsenic wastewater was produced by the Reverse Osmosis System located in the building of the Booth Street Complex of Natural Resources Canada (NRCan). The DI water with a resistivity of $18.2 \mathrm{M} \Omega \cdot \mathrm{cm}$ was prepared by Barnstead Nanopure II ® water system for analytical purposes.

\subsection{Equipment and Apparatus}

In this study, medium-pressure mercury lamp was chosen as the source of UV radiation, due to its a) advantages of broader wavelength range, over low-pressure lamps and b) lower energy consumption over high-pressure lamps. Two different reactor systems were used: UV batch reactor and UV recirculation reactor. Peripheral instrumentation and other apparatus were also used for the measurement of $\mathrm{pH}, \mathrm{DO}$ and 
Eh etc.

\subsubsection{UV Lamp}

$1 \mathrm{~kW}$ Rayox ${ }^{\circledR}$ Sentinel $^{\mathrm{TM}}$ medium-pressure UV lamp was used in this study. The Rayox $^{\circledR}$ lamp has a total length of $20 \mathrm{~cm}$ and arc length of $8.0 \mathrm{~cm}$. At the operating condition of 250 volts and 4.5 amps, the energy distribution of Rayox lamp in the wavelength range of $200 \sim 300 \mathrm{~nm}$ is shown in Figure 4.1. The total energy output in this wavelength range is 173.00 watts, which is more than $15 \%$ of total energy output of the lamp. As can be seen from Figure 4.1, two peaks appear at about $220 \mathrm{~nm}$ and $257 \mathrm{~nm}$ and with energies of 10.72 watts and 24.62 watts respectively.

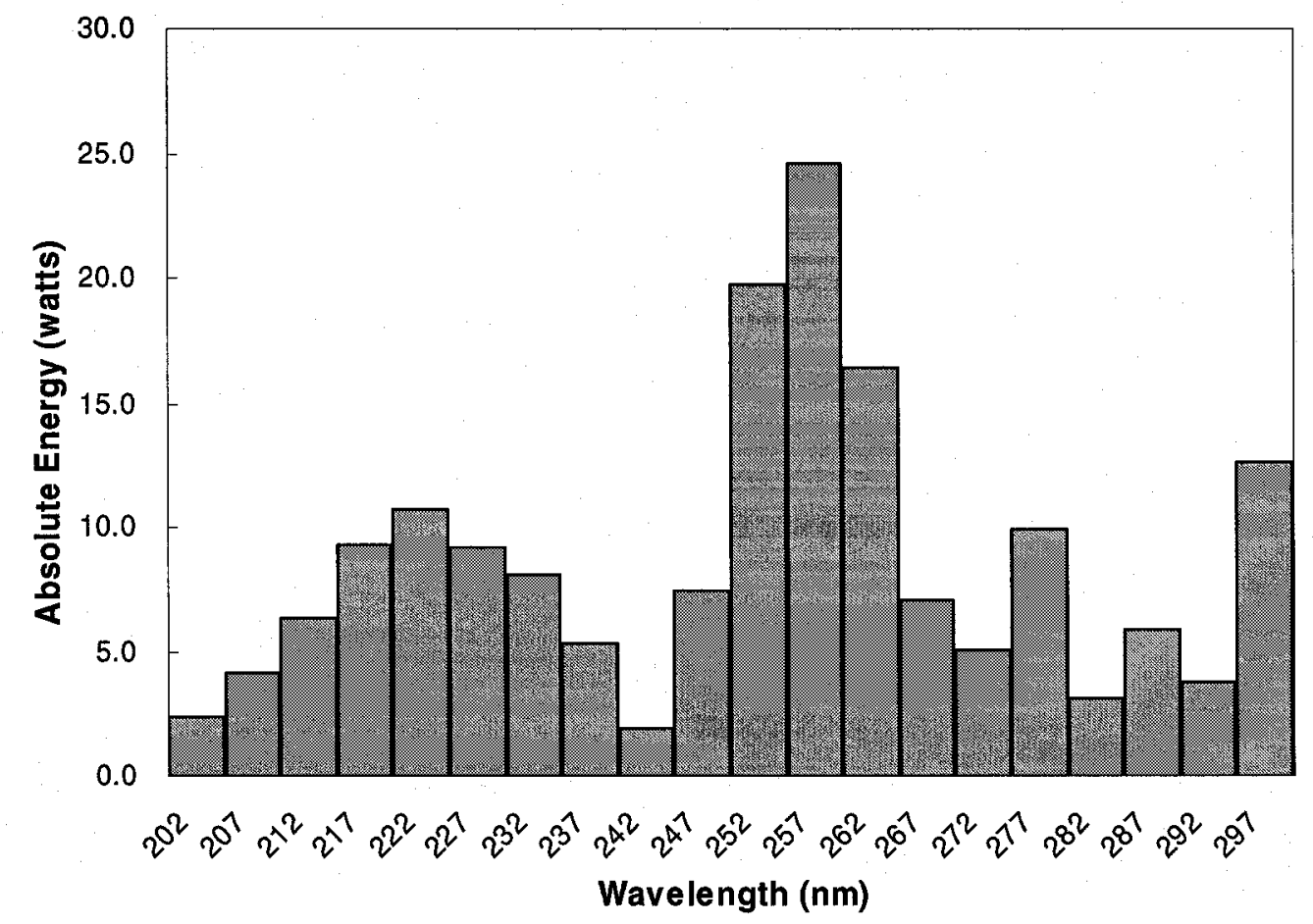

Figure 4.1 Energy distribution of $1 \mathrm{~kW}$ Rayox ${ }^{\circledR}$ Sentinel ${ }^{\mathrm{TM}}$ medium-pressure mercury lamp 


\subsubsection{UV Batch Reactor}

The batch reactor is a Rayox Advanced Oxidation System supplied by the Calgon Carbon Oxidation Technologies in Markham, Ontario, Canada. The reactor is shown in Figure 4.2. The main part of the system is a stainless steel cylinder with an internal diameter $\times$ height of $36 \mathrm{~cm} \times 50 \mathrm{~cm}$ and a capacity of $40 \mathrm{~L}$. The Rayox ${ }^{\circledR} \mathrm{UV}$ lamp is mounted in the centre of the cylinder and separated from the water by a quartz sleeve. The reactor is also equipped with some accessories, including a $\mathrm{pH}$ probe, temperature sensor, timer, mixer, cooling water loop, quartz sleeve wiper, and UV light shutter. The synthetic wastewater and reagents can be fed from the ports on the top of the tank. The samples can be collected at the sampling port located on the side of the tank.

The lamp was operated at the operating condition as mentioned in section 4.2.1. The light intensity in the wavelength range of 200 to $500 \mathrm{~nm}$ was $6.45 \pm 0.16 \times 10^{-4}$ Einstein/s (Yang, 1998). The UV dose applied for a 30L reactor volume and 1 hour reaction time was $33.33 \mathrm{kWh} / \mathrm{m}^{3}$. 

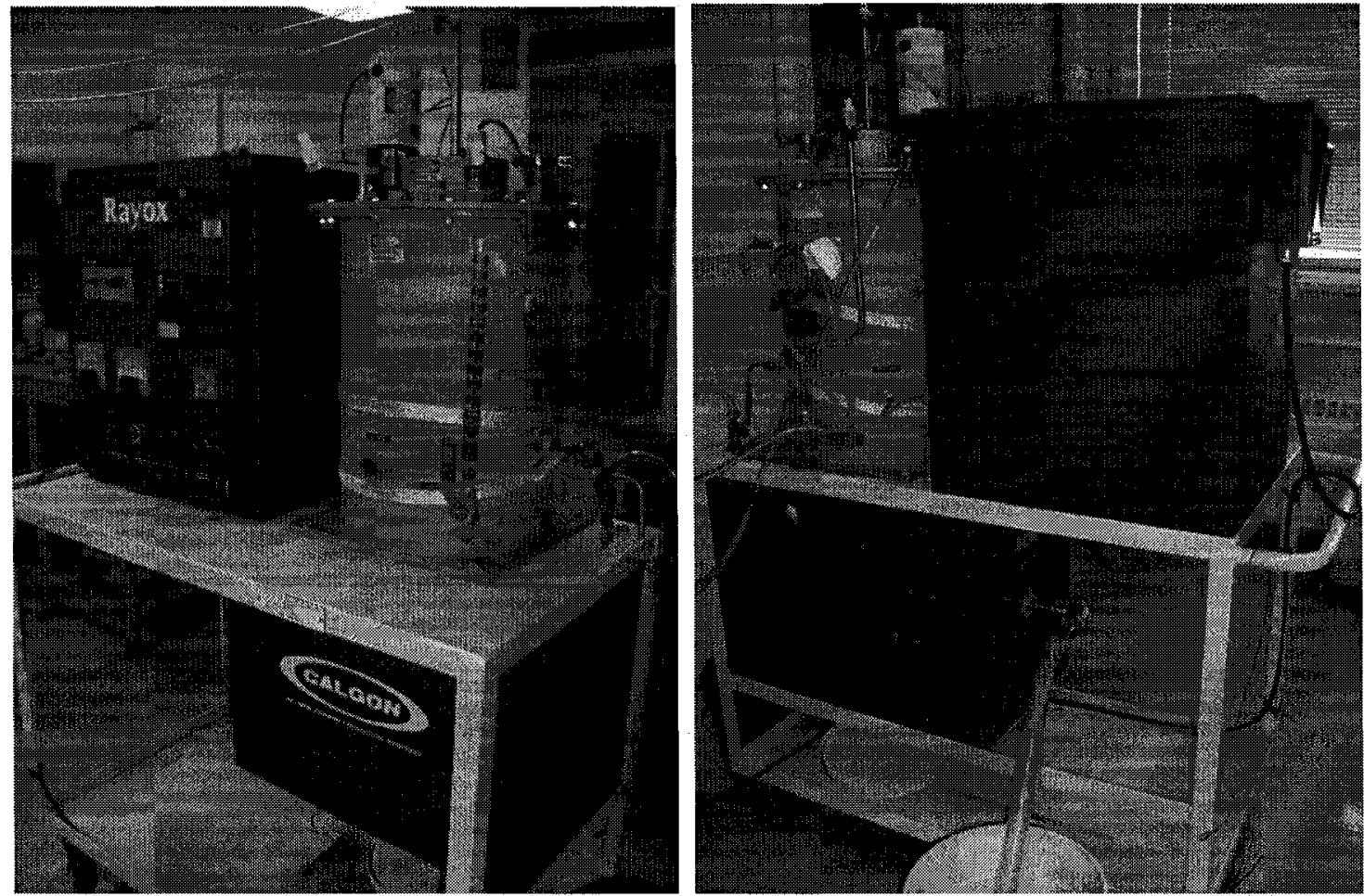

Figure 4.2 The front view (left) and rear view (right) of the UV batch reactor

\subsubsection{UV Recirculation Reactor}

The UV recirculation reactor is a modified system based on the UV batch reactor (Sridhar et al., 2000). The recirculation is established by combining the UV batch reactor above with a $25 \mathrm{~L}$ recycle tank unit, shown in Figure 4.3 . The upper side of the recycle tank is connected with the batch reactor by a flexible stainless steel hose with a diameter of $5.08 \mathrm{~cm}$. The lower side is a discharge line connected with the drain of the batch reactor via a centrifugal pump. The pump can recycle the wastewater with a maximum flowrate of 27 GPM $\left(1.70 \times 10^{-3} \mathrm{~m}^{3} / \mathrm{s}\right)$. The recycling rate can be adjusted by a manual flow control valve and monitored by the control panel. 


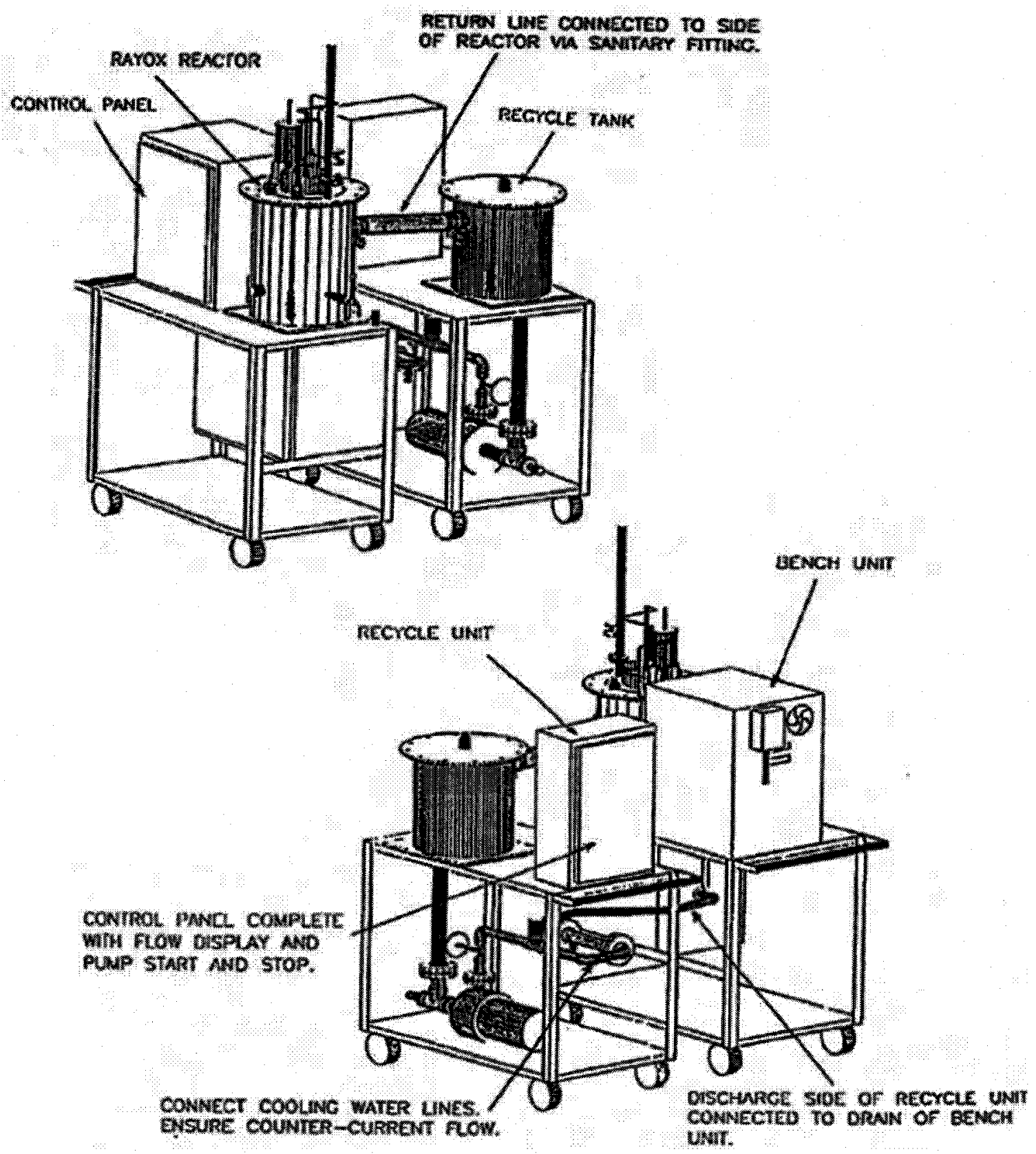

Figure 4.3 The establishment of the UV recirculation reactor

\subsubsection{Other Apparatus}

Fisher Scientific Accumet ${ }^{\circledR}$ AR40 DO meter equipped with YSI 5906 BOD Probe $( \pm 0.1 \mathrm{mg} / \mathrm{L})$, Fisher Scientific Accumet ${ }^{\circledR}$ model $15 \mathrm{pH}$ Meter $( \pm 0.05)$, and WTW SenTix ${ }^{\circledR}$ MultiLine P4 Universal Pocket Meter with SenTix ${ }^{\circledR}$ ORP probe $( \pm 5 \mathrm{mV})$ were 
used to measure the on-site $\mathrm{DO}, \mathrm{pH}$ and Eh values in the samples respectively.

\subsection{Chemical Analyses}

\subsubsection{Arsenic Speciation}

Separation and identification of the arsenic species at different oxidation states is called arsenic speciation. A variety of techniques have been proposed for the arsenic speciation. The most popular analytical methods used for arsenic speciation are based on a combination of a powerful separation process with an adequate element-specific detector. Figure 4.4 presents a general procedure for arsenic speciation in different matrices.

The methods used for separation and pre-concentration are solvent extraction, precipitation and co-precipitation, ion-exchange chromatography (IEC), gas chromatography (GC), supercritical fluid chromatography (SFC) (Laintz et al., 1997), capillary electrophoresis (CE) and high performance liquid chromatography (HPLC). The commonly used detection techniques include ultraviolet spectrometry (UV/vis) (Morin et al., 1997), electrochemical methods (EQ) (Boucher et al., 1996), hydride generation atomic absorption (HG-AAS) (Manning and Martens, 1997), graphite furnace - AAS (GF-AAS) (Do et al., 2001), hydride generation-atomic fluorescence spectrometry (HG-AFS) (Simon et al., 2004), inductively coupled plasma - atomic emission spectrometry (ICP-AES) (Le et al., 1994), inductively coupled plasma-mass spectrometry (ICP-MS) (Ochsenkiihn-Petropulu et al., 1995), electrothermal-AAS (ETAAS) 
(Slaveykova et al., 1996), X-ray spectrometry (Elteren et al., 1989), neutron activation analysis (NAA) (Šlejkovec et al., 1993), atomic fluorescence spectrometry (AFS) (Woller et al., 1995), capillary electrophoresis (CE) (Schlegel et al., 1996), polarographic techniques (Buldini et al., 1980), cathodic stripping voltammetry (CSV) and anodic stripping voltammetry (ASV) (Munoz et al., 2005), and microlithographic fabricated arrays (Tomeik et al., 1997).

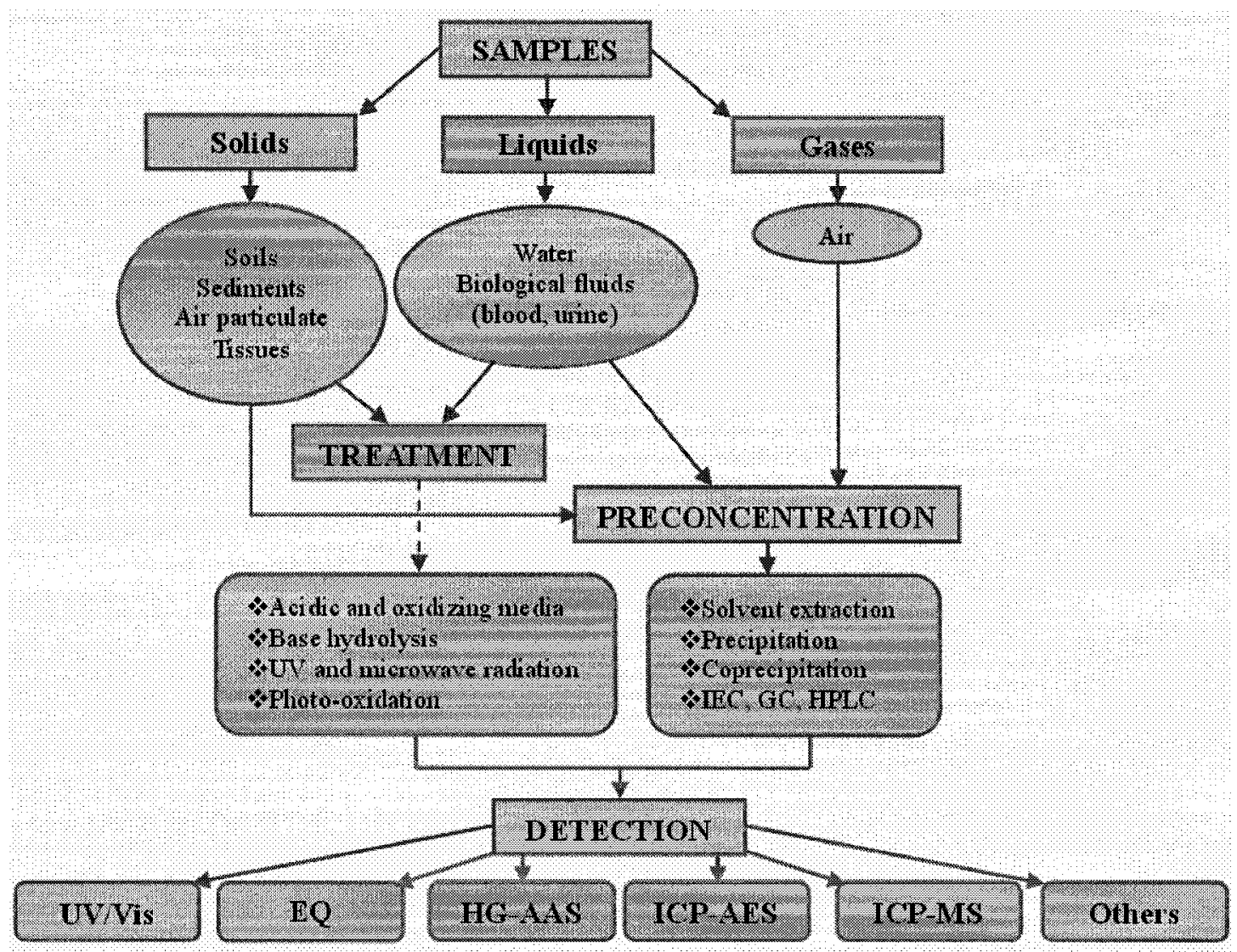

Figure 4.4 Procedures for arsenic speciation in different matrixes (Burguera and Burguera, 1997)

The most common separation techniques for arsenic speciation are GC and HPLC.

GC has very high resolving power; however it generally requires a derivatisation step to produce volatile species, which is not always feasible. Compared to GC, HPLC has 
universal applicability to most of the inorganic and organic compounds, and it is popularly used for separating arsenic species. According to the chemical structure and charge of the arsenic species, different types of HPLC columns were applied: Ion-pair Chromatography (IP-HPLC), Reversed-phase Chromatography (RP-HPLC), Ion-exchange (IE) or ion-exclusion chromatography (SE-HPLC). IP-HPLC columns have been applied to routine analysis of neutral and ionic arsenic species. The elution order is independent of the column substrate, but the effective resolution of arsenic species relies on the parameters, such as ion-pair reagent, flow rate, ionic strength, especially the $\mathrm{pH}$ of the mobile phase (Do et al., 2001). RP-HPLC columns are favored for samples with severe matrix interferences and $\mathrm{pH}$ effects, but the elution order in this type of column is sensitive to the change of eluent composition (Guerin et al., 1999). IE-HPLC columns have poorer selectivity compared to the other HPLC columns, but they have higher buffering capacity and are stable under a wide range of $\mathrm{pH}$ values. A combination of two or more HPLC columns also can be applied to improve the separation capability and shorten the analysis time.

Another advantage of HPLC is that the separated compounds eluted from the column can be easily collected for further separation, concentration and detection by another analytical technique. For example, HPLC-HG-AAS and HPLC-ICP-MS are popularly used for arsenic analysis at ultra trace levels because of their high detection sensitivity. The absolute detection limits (DL) of arsenic by HPLC-HG-AAS and HPLC-ICP-MS are up to $0.07 \mathrm{ng}$ and $0.0022 \mathrm{ng}$ respectively (Terlecka, 2005). HG has 
the advantage of eliminating spectral and chemical interferences from sample matrix, but it can only be directly applied to several arsenic species due to the limitation on forming arsine $\left(\mathrm{AsH}_{3}\right)$, and further decomposition techniques are generally required. ICP-MS offers high sensitivity and multi-element capability, but the most severe limitation of ICP-MS is the isobaric interference on the elemental arsenic signals originating from Argon and/or the sample matrix. The expenses of purchasing and running the ICP-MS equipment are also costly for many environmental analytical laboratories.

Literature surveys indicated the diversity of analytical techniques for the detection and speciation of arsenic. However, when it comes to the specific project or application, the merits and demerits of the optional methods should to be considered with respect to the scope of the study and also the available analytical systems in the laboratory. In this study, three types of arsenic speciation methods were evaluated: HPLC-UV/Vis system, HPLC-HG-AAS system and chelation solvent extraction-HPLC- Diode Array Detector (CSE-HPLC-DAD) system.

\subsubsection{HPLC-UV/Vis System}

The HPLC-UV/Vis system was established at NRCan. It was equipped with Dionex ${ }^{\circledR}$ eluent degas module, Dionex ${ }^{\circledR}$ Advanced Gradient Pump (AGP), Dionex ${ }^{\circledR}$ automated sampler, Inert High-Pressure Valve (IHPV), Dionex® Ion Pac ICE-AS1 Ion-exclusion column $(9 \times 250 \mathrm{~mm})$, and Linear TM UVIS 200 Detector, shown in Figure

4.5. The AGP pumps $0.01 \mathrm{M} \mathrm{H}_{3} \mathrm{PO}_{4}$ eluent at the flowrate of $0.6 \mathrm{~mL} / \mathrm{min}$ through the HPLC column by a high-pressure pump. The chromatographic process begins when the 
$10 \mu \mathrm{L}$ sample is mixed with eluent by IHPV and injected onto the top of the column by the autosampler. Separation of components occurs as the analytes and mobile phase are pumped through the column. Eventually, each component elutes from the column as a narrow band and is recorded as a peak at detection wavelength of $193.7 \mathrm{~nm}$ when it is passing from sample cell to UV detector.

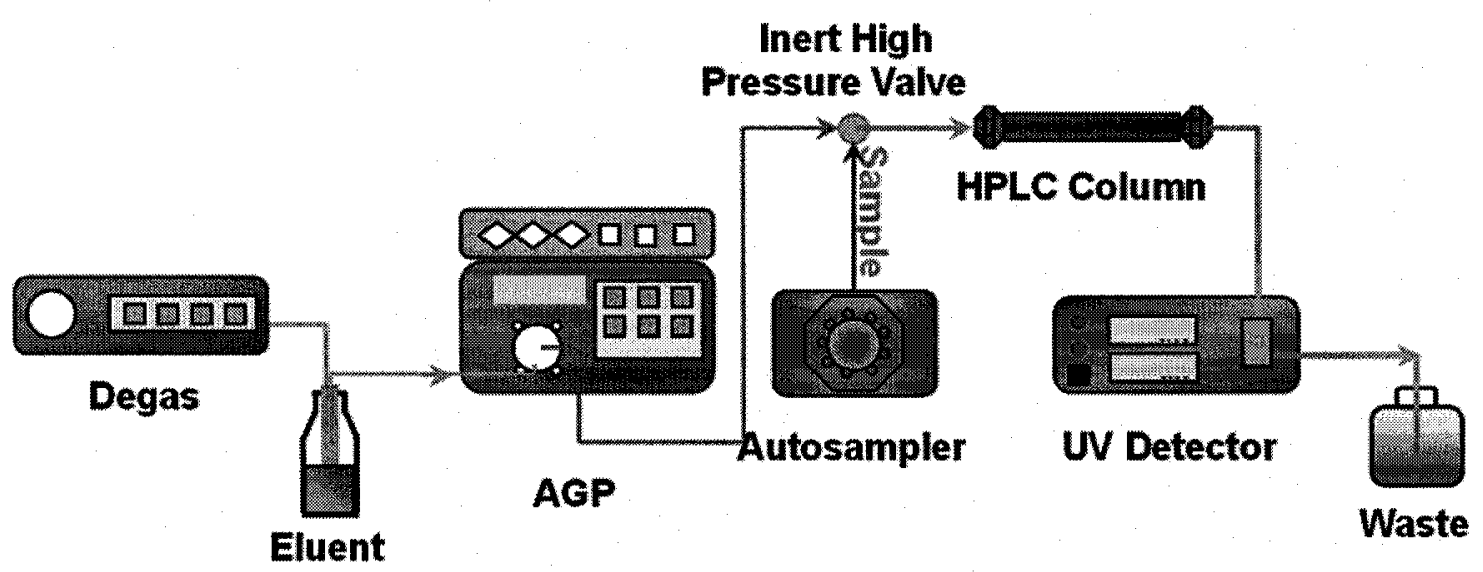

Figure 4.5 The schematic of HPLC-UV/Vis system

The AGP, autosampler, IHPV and the UV detector are controlled and communicated by the computer with the PeakNet 5.1 Chromatography Workstation Software through an Advanced Computer Interface (ACI). The data are collected to the computer and post-processed by the software.

This method has an established detection limit of $0.5 \mathrm{mg} / \mathrm{L}$ arsenic. The calibration curve in the range of $0.5 \sim 100 \mathrm{mg} / \mathrm{L}$ is shown in Appendix B. Samples containing iron compounds, sodium, calcium, sulphate, chloride, and carbonate have no interference to the arsenic speciation. Excessive hydrogen peroxide and nitrate can change the baseline and form overlapped peaks with arsenic peaks. Sodium sulfite can absorb wavelength of 
$193.7 \mathrm{~nm}$ but its peak is separated from arsenic species in the chromatogram.

\subsubsection{HPLC-HG-AAS System}

The HPLC-HG-AAS system is an extension of HPLC-UV/Vis system. The analyte eluent coming out of the end of the HPLC column is further processed by the HG-AAS as shown in Figure 4.6. The separated arsenic species from the analyte eluent react with reagents in hydride generator and form the gaseous arsine at different retention time. Arsine is heated up and atomized in the quartz tube by air-acetylene flame. The atomized arsine can absorb the light at wavelength of $193.7 \mathrm{~nm}$. The arsenic concentration is proportional to the absorbance of arsine, which is reflected by the intensity variation of the light source.

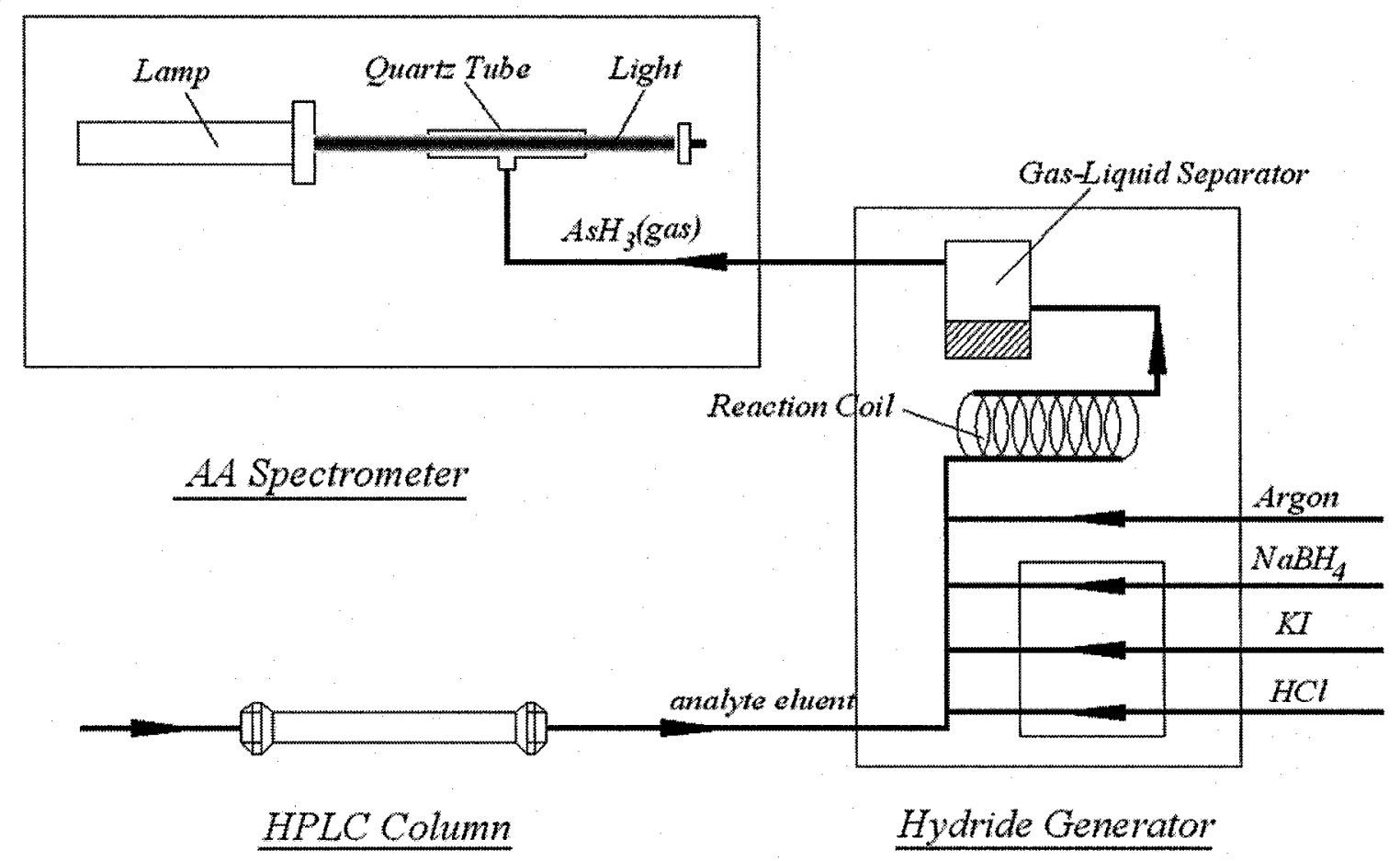

Figure 4.6 The schematic of HPLC-HG-AAS system 
This method was established based on the research work of Manning and Martens (1996). The HPLC-HG-AAS system was equipped with Dionex IonPac® AS11 column, Varian VGA-76 hydride generator and Varian AA-20 spectrophotometry. The Dionex IonPac® AS11 column was installed in the HPLC system above. The eluent condition of Dionex IonPac® AS11 column was adopted from Manning and Martens (1996): $30 \mathrm{mM}$ $\mathrm{NaOH} / 1 \%$ methanol with a flowrate of $1 \mathrm{~mL} / \mathrm{min}$. The sample injection volume of $100 \mu \mathrm{L}$ was chosen. The operating parameters of HG were modified and established: $0.16 \mathrm{M}$ NaBH4 with a flowrate of $1 \mathrm{~mL} / \mathrm{min}, 5 \mathrm{M} \mathrm{HCl}$ with a flowrate of $1 \mathrm{~mL} / \mathrm{min}$ and $1 \% \mathrm{KI}$ with a flowrate of $1 \mathrm{~mL} / \mathrm{min}$.

The detection limit of arsenic concentration by this method was established to be 5 $\mu \mathrm{g} / \mathrm{L}$, which is much lower than the HPLC-UV/Vis system. The calibration curve in the range of $5 \sim 40 \mu \mathrm{g} / \mathrm{L}$ is shown in Appendix C. The HG-AAS system can significantly improve the detection limit. It also has the advantage of eliminating the potential interference in the sample matrix, such as hydrogen peroxide and nitrate.

\subsubsection{CSE-HPLC-DAD System}

Prior to the establishment of HPLC-UV/Vis and HPLC-AAS systems, a preliminary method development of CSE-HPLC-DAD system was carried out at SAIC Canada's Environmental Analytical Laboratory. This technique has previously been developed and demonstrated to be useful for chromium and mercury (Cathum et al., 2002; Cathum et al., 2005). The major advantage of CSE-HPLC-DAD system is the chelation and solvent extraction process for the sample pre-treatment. Simultaneous analysis of multiple 
water-soluble and lipid-soluble arsenic species becomes possible following a chelation procedure. And the pre-concentration of samples by solvent extraction procedure can improve the detection limit without the requirement of any expensive analytical techniques, such as, ICP-MS. The operating procedure of this method is shown in Figure 4.7 and follows the steps below:

A) Take a certain volume (usually $4-5 \mathrm{~mL}$ ) of the original sample into the tube. (In our process, the $4 \sim 5 \mathrm{~mL}$ was used due to the limitation of tube volume. For large volume samples, separatory funnel can be used);

B) Add proper volume of chelant into the sample (the consumption of chelant must be in excess to guarantee that the arsenic in the sample can be fully chelated. $10 \sim 30 \mu \mathrm{L}$ in our case). To make sure the chelating reaction is completed, the sample with chelant can be mixed in a Votex Mixer for 30 seconds and then into an Ultrasonic Mixer for 30 minutes;

C) Add certain volume of solvent into the chelated sample (the volume is based on the pre-concentration ratio of sample to solvent).

D) Mix the sample from step C using Votex Mixer for 30 seconds and then place the samples into the Ultrasonic Mixer for 30 minutes. (This procedure is to make sure that the arsenic chelating complex in the sample can be maximally extracted into the solvent);

E) Cool down the mixed solvent and sample from step D;

F) Transfer the pre-treated sample into the GC vial and seal the GC vial with Teflon lined 
cap;

G) Place the sealed GC vial in the autosampler and analyze the sample by the HPLC system. The pre-treated sample is separated by the reversed-phase column using the water/methanol eluent.

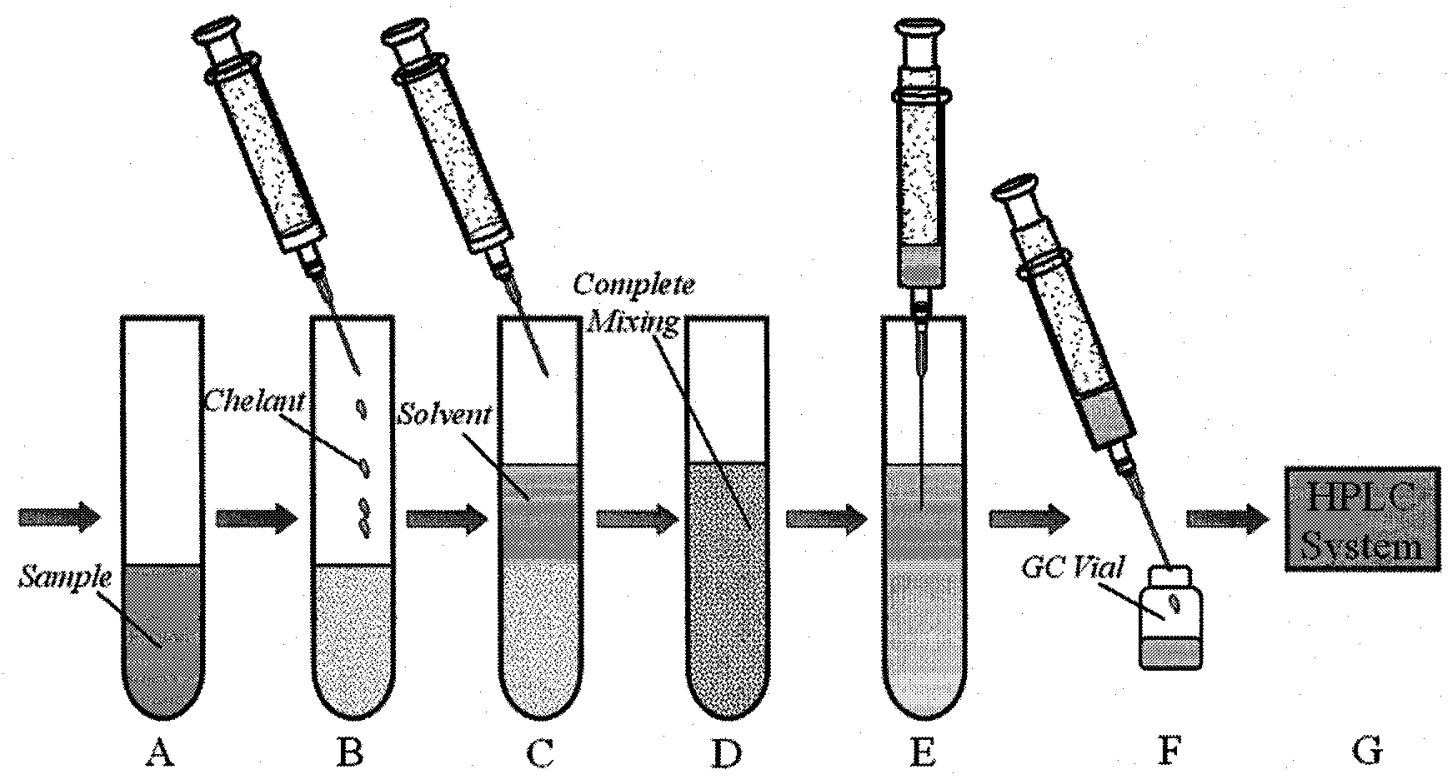

Figure 4.7 The procedure of chelation-solvent extraction

This method was confirmed to be applicable for arsenic speciation. Different arsenic species were separated in the samples and the peaks presented excellent signal-noise ratio as shown in Appendix D. Also the reproducibility of the method was verified. Due to the time constraint, this method was not fully established and evaluated before the start of this thesis research and was not applied to the As(III) oxidation research.

In this thesis research, most of the samples were analyzed using HPLC-UV/Vis system because the arsenic concentrations in the wastewater were in the analytical range of HPLC-UV/Vis system. HPLC-HG-AAS system was adapted in the course of this 
thesis research and was primarily used to analyze certain specific samples in which potential interference from excess hydrogen peroxide in HPLC-UV/Vis analysis was suspected. In these cases, the samples were diluted with DI water by nearly three orders of magnitude and subjected to HPLC-HG-AAS analysis. The HPLC-HG-AAS system was not employed for routine analysis.

The sample analysis followed the QA/QC procedures in NRCan to minimize the analytical error. For the daily sample analysis, a batch of arsenic standard solutions was run prior to the samples to validate the performance of the analytical procedure.

\subsubsection{Hydrogen Peroxide}

The existence of hydrogen peroxide residual can be identified by the HPLC-UV/Vis system. To quantify the hydrogen peroxide in the samples, the permanganate method was applied (Krishna et al., 2001). Hydrogen Peroxide can react with potassium permanganate with following reaction:

$$
2 \mathrm{MnO}_{4}^{-}+5 \mathrm{H}_{2} \mathrm{O}_{2}+6 \mathrm{H}^{+} \rightarrow 2 \mathrm{Mn}^{2+}+8 \mathrm{H}_{2} \mathrm{O}+5 \mathrm{O}_{2}
$$

In this study, first $3 \mathrm{~mL}$ of $6 \mathrm{M}$ sulphuric acid and two drops of $5 \%$ aqueous manganous sulphate solution were added into a $50 \mathrm{~mL}$ sample. Then this pre-treated sample was titrated with standardised $0.1 \mathrm{~N}$ potassium permanganate till the solution turned to pink colour.

\subsubsection{Sodium Sulfite}

The sodium sulfite was determined simultaneously with arsenic species by the 
Dionex ${ }^{\circledR}$ Ion Pac ICE-AS1 Ion-exclusion column since it can be identified and separated from arsenic species. The calibration curve was established using sodium sulfite standard solution in the range of $5 \sim 100 \mathrm{mg} / \mathrm{L}$ as shown in Appendix E.

\subsection{Sample Stability, Preservation and Pretreatment}

During the processes, the samples were collected in the intervals of 3 30 minutes. Each sample was divided into several portions. One portion was sent for the analyses of $\mathrm{As}(\mathrm{III})$ and $\mathrm{As}(\mathrm{V})$. The others were used for the measurements of DO concentration and Eh, $\mathrm{pH}$ values immediately after each sampling.

The samples collected in this study were analyzed within 48 hours. The samples stored overnight were kept in the refrigerator at the temperature $4^{\circ} \mathrm{C}$. An extensive study indicated that samples that contained $100 \mathrm{mg} / \mathrm{L}$ total arsenic and were stored at $4{ }^{\circ} \mathrm{C}$ were stable for 14 days. No loss of species was observed. In the presence of hydrogen peroxide or sodium sulfite, no transformation between $\mathrm{As}(\mathrm{III})$ and $\mathrm{As}(\mathrm{V})$ occurred.

No pretreatment was required to maintain the stability of the samples. But for the analytical purpose in HPLC-UV/Vis system, eliminating excessive hydrogen peroxide residual in the samples was preferred. The addition of hydrogen peroxide quencher should not change the composition of arsenic species in the original samples and have no interference to the chromatogram. Catalase, sodium thiosulfate $\left(\mathrm{Na}_{2} \mathrm{~S}_{2} \mathrm{O}_{3}\right)$, sodium sulfite $\left(\mathrm{Na}_{2} \mathrm{SO}_{3}\right)$ and potassium iodide $(\mathrm{KI})$ were evaluated in this study. The results indicated that only catalase does not affect the composition of $\mathrm{As}(\mathrm{III})$ and $\mathrm{As}(\mathrm{V})$ in the samples. 
However, catalase can only effectively quench hydrogen peroxide at alkaline conditions.

For the acidic samples, the analysis was carried out in HPLC-HG-AAS system.

\subsection{Experimental Procedure}

\subsubsection{Experimental Arrangement}

The oxidation of As(III) was preliminarily investigated in the dark conditions, in which no UV was applied. Then the UV-based oxidation processes were carried out in two systems: batch reactor and recirculation reactor. In both systems, the direct UV irradiation process was first investigated, and then the $\mathrm{UV} / \mathrm{H}_{2} \mathrm{O}_{2}$ process was further explored. Several parameters were taken into account: DO concentration, initial $\mathrm{pH}$, initial As(III) concentration, mixing efficiency, interfering compounds, temperature, and the $\mathrm{H}_{2} \mathrm{O}_{2} / \mathrm{As}(\mathrm{III})$ ratio in the $\mathrm{UV} / \mathrm{H}_{2} \mathrm{O}_{2}$ process. The details of the experimental arrangement in the thesis research are presented in Appendix F.

\subsubsection{Operating Procedure}

\subsubsection{Safe Handling and Waste Disposal}

In this study, we were dealing with very toxic arsenic compounds in aqueous solution at relatively high concentrations. Those arsenic compounds could potentially cause acute or chronic health effects to the human body via ingestion. Direct exposure to the UV light also could result in permanent damage to the eye. Therefore, extreme caution and proper procedures must be taken all through this study. Safety precautions as

per Material Safety Data Sheets (MSDS) and Workplace Hazardous Materials 
Information System (WHMIS) should be followed at all times. It is mandatory to wear laboratory coat, UV-protective glasses and safety gloves when doing an experiment.

The arsenic wastewater product from the reactors was collected in a $120 \mathrm{~L}$ waste disposal tank and treated by adding $\mathrm{FeSO}_{4} \cdot \mathrm{xH}_{2} \mathrm{O}$ with a As/Fe molar ratio of 1:4. This treated wastewater was routinely sent to the wastewater treatment plant at NRCan for further treatment and disposal.

\subsubsection{Batch Reactor}

In the batch reactor, the typical operating procedure is as follows:

1) Add 28L DI water into the UV reactor through the fill port;

2) Add the pre-dissolved $\mathrm{NaAsO}_{2}$ into the reactor through reagent addition port and adjust the $\mathrm{pH}$ in the solution by adding $\mathrm{H}_{2} \mathrm{SO}_{4}$ or $\mathrm{NaOH}$;

3) Make up the total reaction volume to $30 \mathrm{~L}$ and then adjust the dissolved oxygen in the solution by sparging with nitrogen or air;

4) Seal the tank with caps, and turn on the mixer at maximum speed for 5 minutes to completely mix the reagents;

5) Switch on the UV lamp with the lamp shutter in the closed position and turn on the faucet of the water cooling loop;

6) Stabilize the lamp for 15 minutes;

7) Open the caps and add the reagent through reagent port if it applies; submerge the compressed-air tube into the solution through fill port if the air sparging applies; sealed 
the tank with caps if it is necessary;

8) Turn on the mixer and open the lamp shutter immediately after adding the reagents in step 7. At the time that lamp shutter is opened, the reaction time is accounted as zero;

9) Collect samples from sampling port at various time intervals.

\subsubsection{Recirculation Reactor}

In the recirculation reactor, the operating procedure is similar to the batch reactor:

1) Add 58L DI water into the UV reactor through the fill port;

2) Add the pre-dissolved $\mathrm{NaAsO}_{2}$ into the reactor through reagent addition port and adjust the $\mathrm{pH}$ in the solution by adding $\mathrm{H}_{2} \mathrm{SO}_{4}$ or $\mathrm{NaOH}$;

3) Make up the total reaction volume to $60 \mathrm{~L}$, seal the tank with caps, and then turn on the pump and the mixer to completely mix the reagents (make sure all the valves are open);

4) Switch on the UV lamp with the lamp shutter in the closed position and turn on the faucet of the water cooling loop;

5) Stabilize the lamp for 15 minutes;

6) Open the caps and add the reagent through reagent port if it applies, and then sealed the tank with caps;

7) Turn on and open the lamp shutter immediately after adding the reagents in step 6. At the time that lamp shutter is opened, the reaction time is accounted as zero;

8) Collect samples from sampling port at various time intervals. 


\subsubsection{Parameter Control}

In this study, several operating parameters were controlled during the As(III) oxidation process. Those parameters includes: initial $\mathrm{As}(\mathrm{III})$ concentration, initial $\mathrm{H}_{2} \mathrm{O}_{2}$ concentration, initial $\mathrm{pH}, \mathrm{DO}$ concentration, mixing efficiency, temperature.

\subsubsection{Initial As(III) Concentration}

Certain amount of $\mathrm{NaAsO}_{2}$ was accurately weighed by the analytical balance and then directly dissolved into DI water to synthesize arsenic wastewater to reach the designated initial As(III) concentration. The DI water and not the tap water was used to preclude any possible interference from other contaminant ions in the tap water.

The initial As(III) concentration in the synthetic wastewater was selected in the range of $20 \mathrm{mg} / \mathrm{L}$ to $100 \mathrm{mg} / \mathrm{L}$. This range was chosen partly to conform to industrial situations.

\subsubsection{Initial $\mathrm{H}_{2} \mathrm{O}_{2}$ Concentration}

The initial $\mathrm{H}_{2} \mathrm{O}_{2}$ :As(III) ratio in the range from 1:4 to $2: 1$ was investigated. The required volume of $30 \% \mathrm{H}_{2} \mathrm{O}_{2}$ was calculated by the molar ratio of $\mathrm{H}_{2} \mathrm{O}_{2}$ /As(III) and directly added into the synthetic arsenic wastewater

\subsubsection{Initial $\mathrm{pH}$}

In the $\mathrm{As}(\mathrm{III})$ concentration range of this study, the basic $\mathrm{pH}$ of synthetic arsenic wastewater is about 10.0. The effect of $\mathrm{pH}$ was investigated in range of $2 \sim 12$. Sulphuric acid $\left(\mathrm{H}_{2} \mathrm{SO}_{4}\right)$ and Sodium hydroxide $(\mathrm{NaOH})$ were chosen to adjust the initial $\mathrm{pH}$ in the solution due to their stability under UV conditions. No $\mathrm{pH}$ buffer was added into the 
solution to avoid any unexpected interference to the As(III) oxidation.

\subsubsection{DO Concentration}

Preliminary experiments indicated that the DO concentration in the arsenic wastewater has significant effect on the photooxidation of As(III), thus different DO concentrations were compared and extensively investigated in this study. The original DO concentration in the DI water varied in the range of $3.0 \sim 6.0 \mathrm{mg} / \mathrm{L}$. Different initial DO concentrations were approached prior to the UV irradiation by sparging with nitrogen or air. To maintain higher DO concentration in the arsenic wastewater, air sparging was done in the course of As(III) oxidation process.

\subsubsection{Mixing Efficiency}

In the batch reactor, the high mixing efficiency was achieved by continuous stirring of the solution during the course of the oxidation process. In the recirculation reactor, the mixing efficiency was further enhanced by the high recycle rate. The cavitation process in the centrifugal pump would have also contributed to the complete mixing.

\subsubsection{Temperature}

In this study, the cooling system was applied to avoid the overheating of the lamp. However, the variation of temperature due to the seasonal change was considered since this study lasted almost a year. The effect of seasonal change could affect the cooling efficiency. The cooling system can be more efficient during the winter than summer due to the lower water temperature. During the winter, in the direct UV irradiation process, the temperature of the solution varied from $18{ }^{\circ} \mathrm{C}$ to $22^{\circ} \mathrm{C}$. While during the summer, the 
temperature varied from $21^{\circ} \mathrm{C}$ to $27^{\circ} \mathrm{C}$. No significant difference of $\mathrm{As}$ (III) oxidation was observed under different temperature ranges.

\subsubsection{Evaluation of the Experimental Reproducibility}

To confirm the reliability of the experimental results, besides the QA/QC procedure in the sample analysis, the evaluation of experimental reproducibility in this study was also applied.

The reproducibility of an experiment was evaluated by repeating each trial at least twice. Potential experimental errors, such as measurement, instrument limitation, variation of sampling time, weather changes etc., were taken into consideration. The evaluation showed that the experimental results were within $2 \sim 5 \%$ of each other and therefore acceptable as reproducible. The typical replicated experiments are presented in Appendix G. 


\section{CHAPTER 5. RESULTS AND DISCUSSION}

In this chapter, the results of the detailed investigation on the oxidation of As(III) by Direct Photolysis and the Advanced Oxidation Process using hydrogen peroxide are presented along with a discussion and interpretation of the results. The study was also extended to include a cursory evaluation of the potential for interference by selected ions that are likely to be present in some of the wastewaters containing arsenic.

A complete list of all the experiments along with the operating parameters is listed in the Appendix F.

\subsection{Absorption Spectra of As(III) and Hydrogen Peroxide}

The UV absorption spectra of As(III) (sodium arsenite) was determined using the Spectrophotometer (Perkin-Elmer Lambda 2) in the laboratories of SAIC Canada and is presented in Figure 5.1 below. As can be seen, As(III) has significant UV absorption below $220 \mathrm{~nm}$.

The UV absorption spectrum of $\mathrm{H}_{2} \mathrm{O}_{2}$ is presented in Figure 5.2 (US Peroxide Head Office, 2003). As can be seen in the figure, in the wavelength range of $200 \sim 300 \mathrm{~nm}$, the absorption of $\mathrm{H}_{2} \mathrm{O}_{2}$ increases exponentially as the wavelength decreases. The UV lamp used in the reactor has broad spectral energy peaks at $220 \mathrm{~nm}$ and $257 \mathrm{~nm}$. The molar extinction coefficients of $\mathrm{H}_{2} \mathrm{O}_{2}$ corresponding to these peaks are $\varepsilon_{220 \mathrm{~nm}}=76 \mathrm{M}^{-1} \cdot \mathrm{cm}^{-1}$ and $\varepsilon_{257 \mathrm{~nm}}=16.8 \mathrm{M}^{-1} \cdot \mathrm{cm}^{-1}$ respectively. 


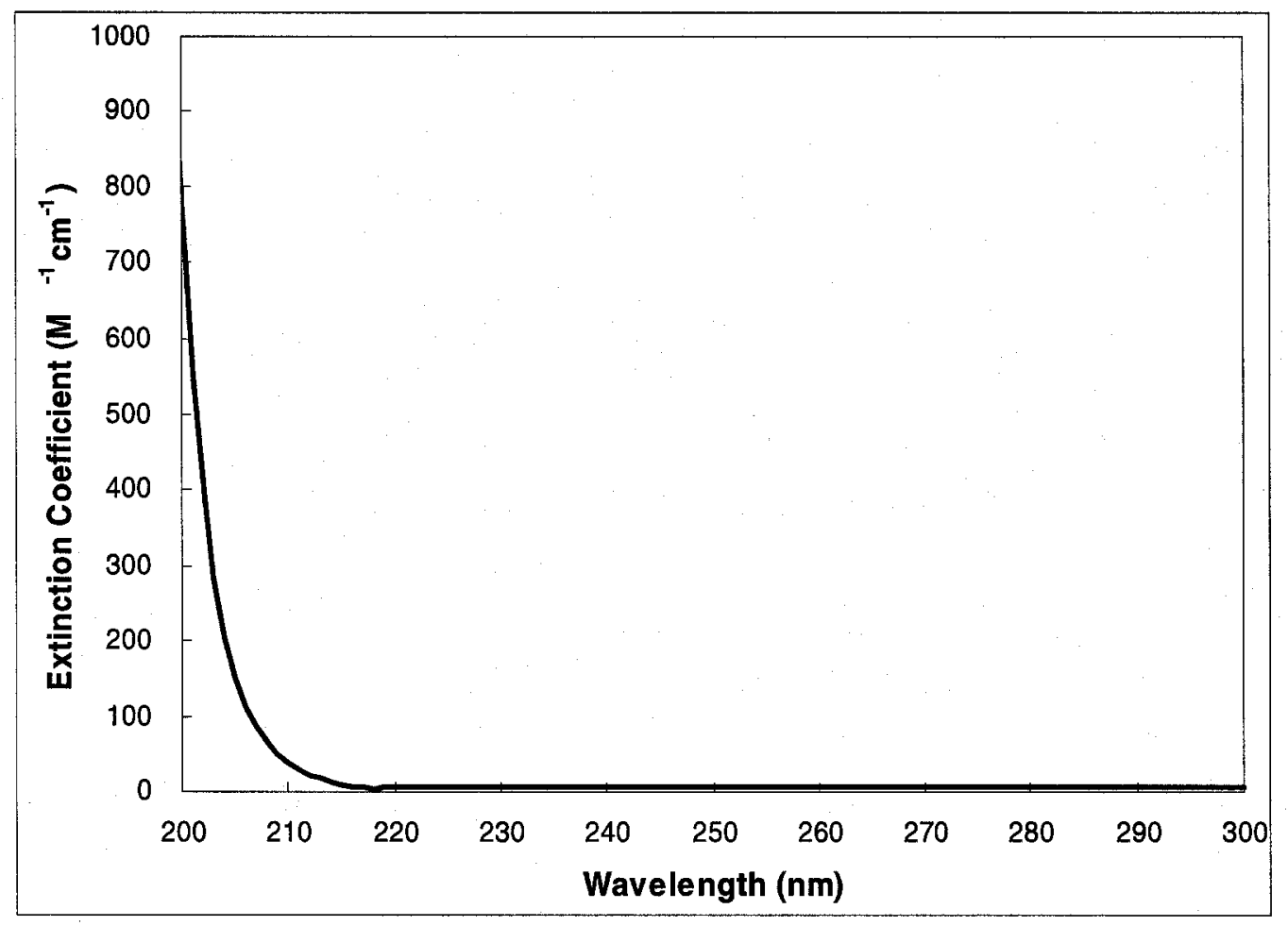

Figure 5.1 UV absorption spectra of sodium arsenite

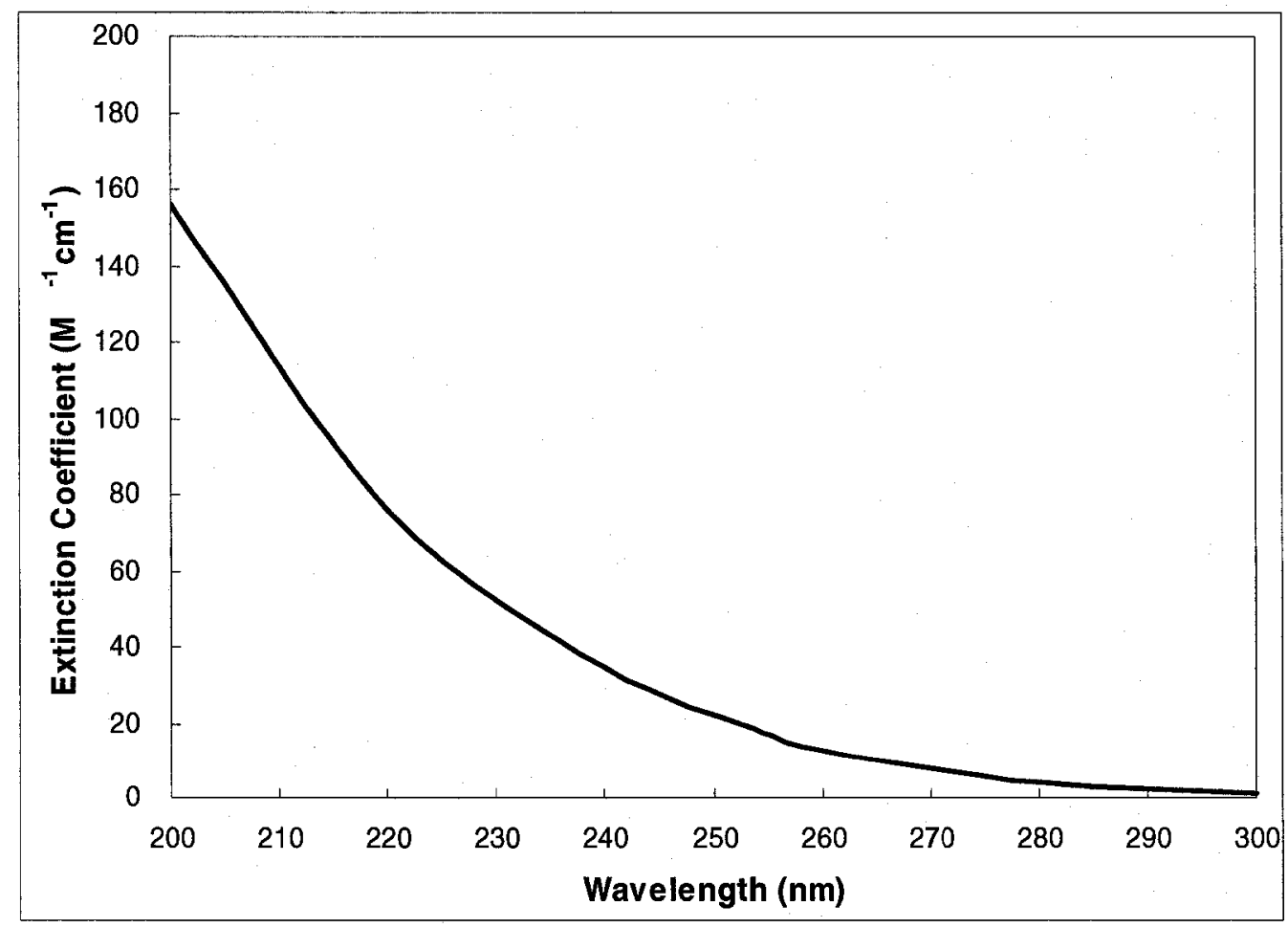

Figure 5.2 UV absorption spectra of hydrogen peroxide 


\subsection{Study of the Dark Reaction}

Prior to the launching of the main investigation, the potential oxidation of As(III) under dark condition (i.e., no UV) was evaluated to determine the baseline condition. No detectable conversion of $\mathrm{As}(\mathrm{III})$ to $\mathrm{As}(\mathrm{V})$ was observed over a period of six hours under both air-sparging (oxic) and no air-sparging (partially anoxic) conditions. The results indicated that there was no dark reaction under these operating conditions.

\subsection{Direct Photolysis}

The oxidation of As(III) by Direct Photolysis in the absence of any additive was investigated. Experiments were conducted to study the influence of the operating parameters such as UV dose, DO conditions, initial As(III) concentration, and initial pH on the progress and extent of the reaction in both batch reactor and recirculation tank.

\subsubsection{Direct Photolysis in the Batch Reactor}

\subsubsection{Influence of Dissolved Oxygen (DO)}

As stated earlier, very few investigations on the photolytic oxidation of As(III) had been reported in the literature and even in those studies the role of dissolved oxygen has not been clearly established. Hence one of the primary objectives of the present work was to study the influence of DO under different operating conditions. Field studies on arsenic in surface and groundwater systems indicate that arsenic species present and the oxidation state of arsenic are dependent on the oxic (high DO), suboxic (DO below 
saturation) or anoxic (without DO) conditions prevailing in the water system (Peyton et al., 2006). As explained in the methods section in the previous chapter, different levels of initial DO were achieved by sparging the reactor contents with either air or nitrogen. In addition to the sparging to control the DO concentration, the reactor itself can be operated as a "closed" system in which all the inlet and outlet ports are kept closed thus limiting the ingress of outside air. However, even in the "closed" system, DO equilibration with the plenum air above the liquid surface can occur.

The influence of DO was first investigated under oxic and near-anoxic conditions. In the oxic condition, the initial DO was at a saturated concentration of $8.0 \mathrm{mg} / \mathrm{L}$ and the solution was sparged with air all through the oxidation process. In the near-anoxic condition, the initial DO was controlled at or below of $1.0 \mathrm{mg} / \mathrm{L}$ and the tank was kept closed during the course of the reaction to limit the ingress of oxygen from outside of the tank. The parameters chosen were: $[\mathrm{As}(\mathrm{III})]_{0}=1.335 \mathrm{mM}(100 \mathrm{mg} / \mathrm{L})$; initial $\mathrm{pH}=10.0$. The experimental data of As(III), As(V), DO, pH and the measured Eh-pH diagram are shown from Figure 5.3 to Figure 5.7. 


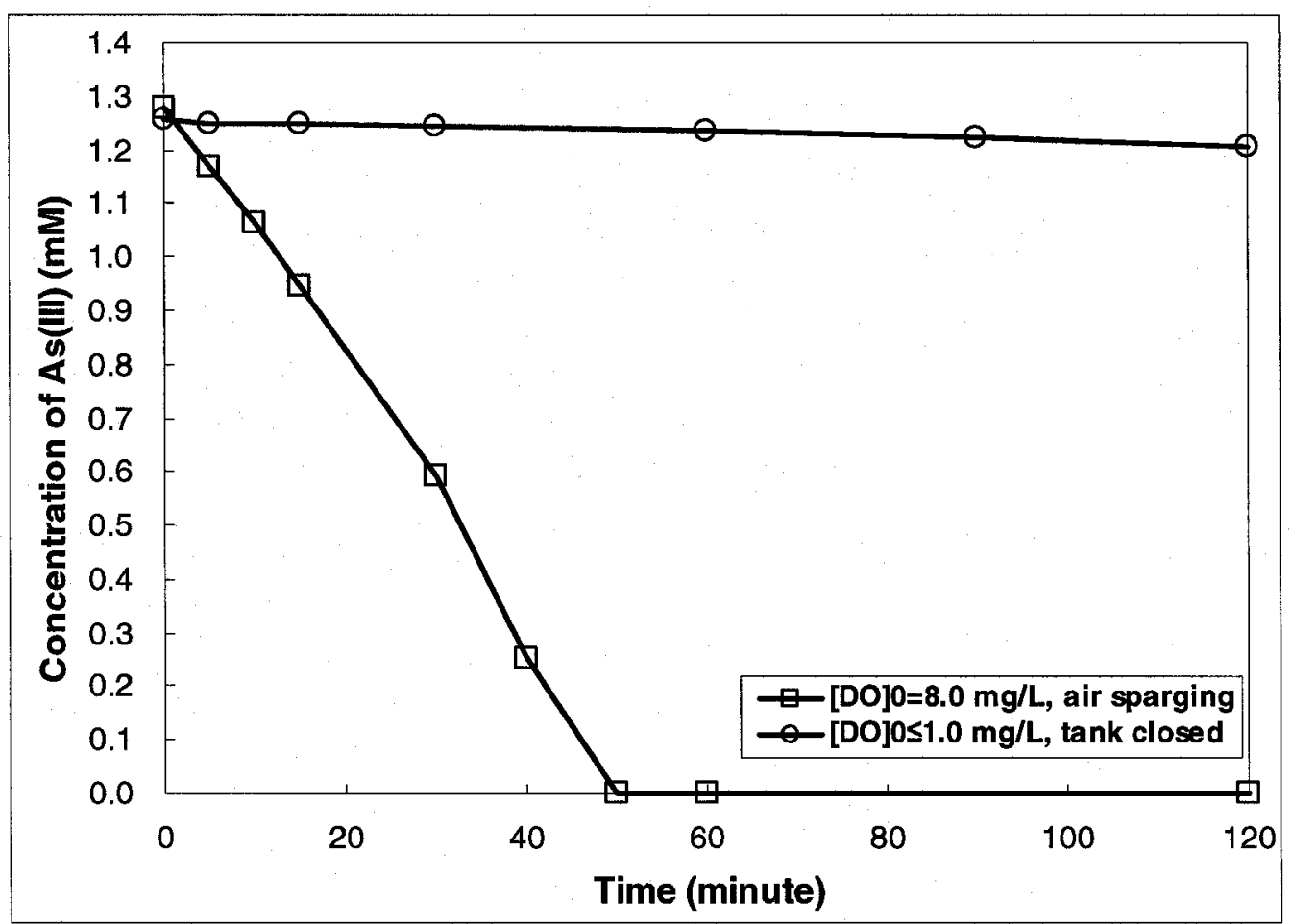

Figure 5.3 As (III) concentration as a function of irradiation time in Direct Photolysis under oxic and near-anoxic conditions (initial $\mathrm{pH}=10.0 ;[\mathrm{As}(\mathrm{III})]_{0}=1.335 \mathrm{mM}$ )

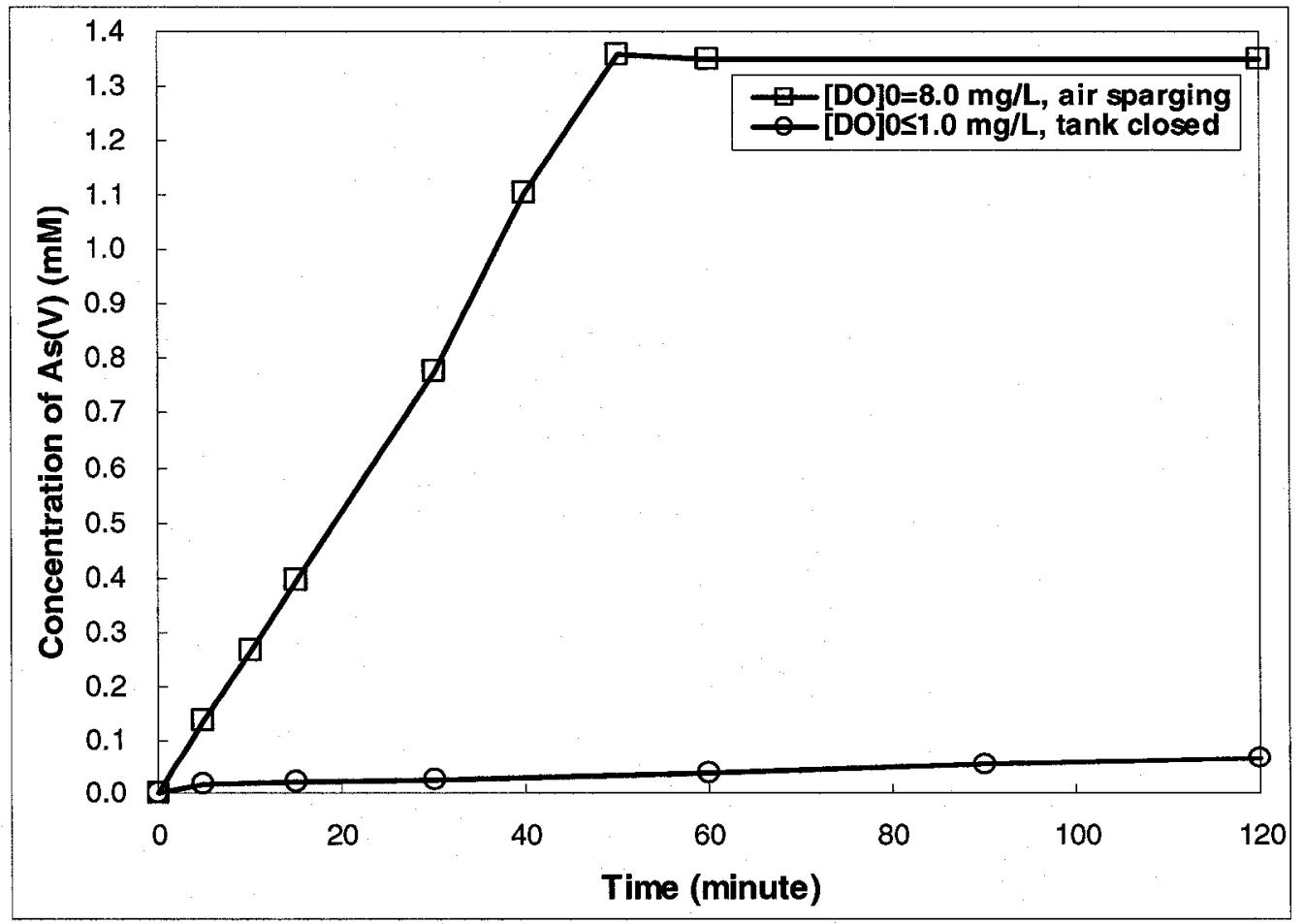

Figure 5.4 As (V) concentration as a function of irradiation time in Direct Photolysis under oxic and near-anoxic conditions (initial $\mathrm{pH}=10.0 ;[\text { As }(\mathrm{III})]_{0}=1.335 \mathrm{mM}$ ) 


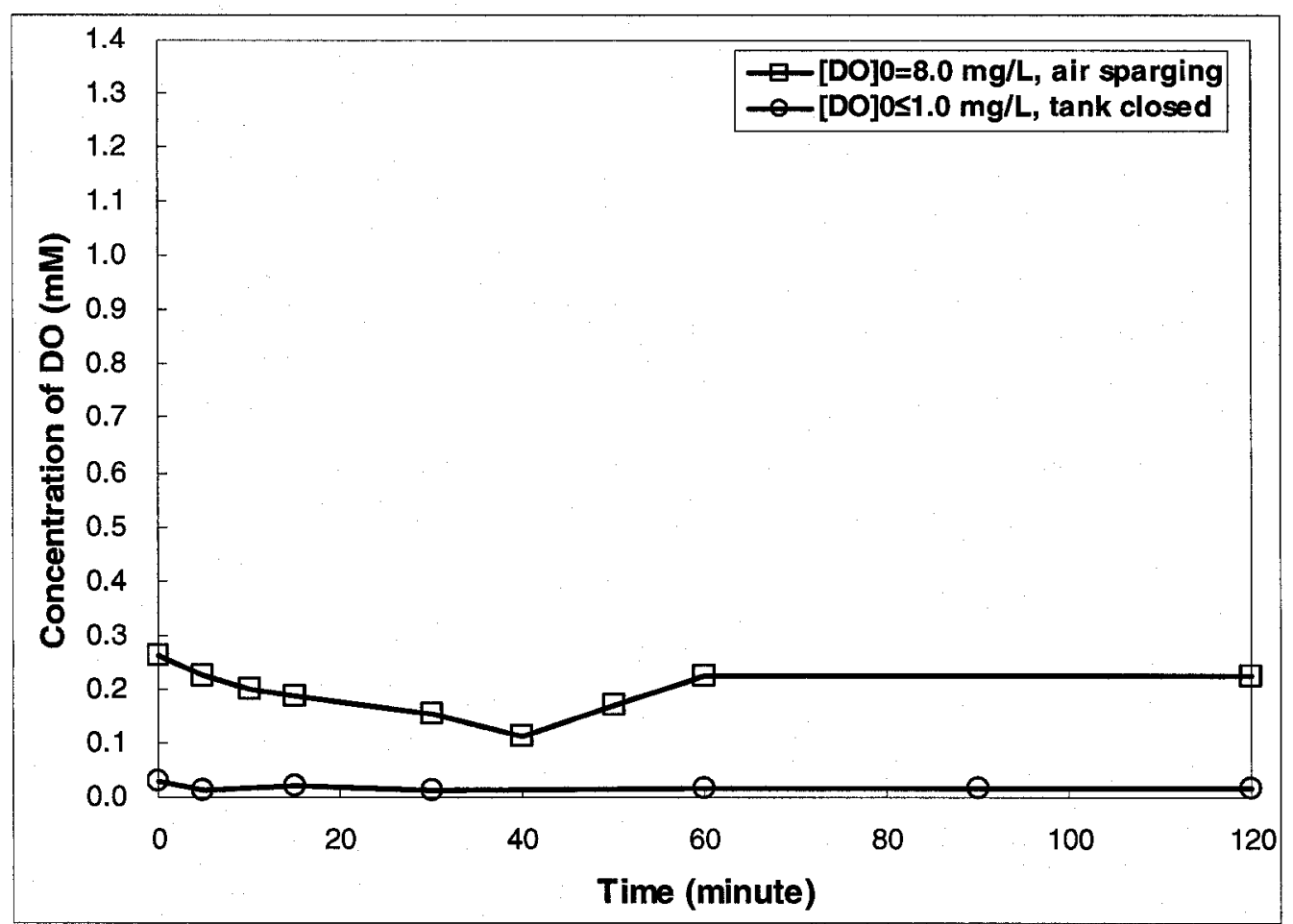

Figure 5.5 DO as a function of irradiation time in Direct Photolysis under oxic and near-anoxic conditions (initial $\mathrm{pH}=10.0 ;[\mathrm{As}(\mathrm{III})]_{0}=1.335 \mathrm{mM}$ )

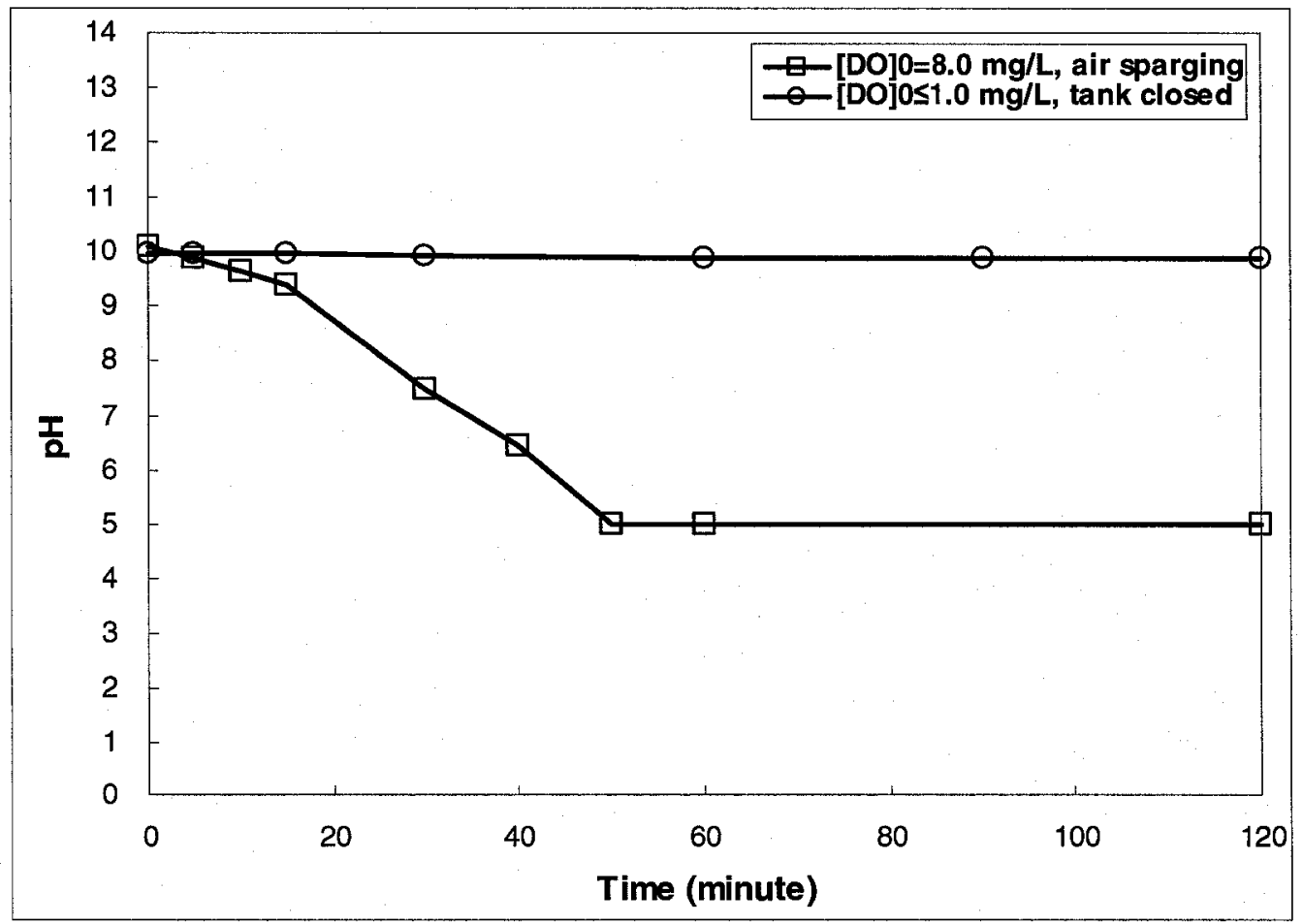

Figure $5.6 \mathrm{pH}$ as a function of irradiation time in Direct Photolysis under oxic and near-anoxic conditions (initial $\mathrm{pH}=10.0 ;[\mathrm{As} \text { (III) }]_{0}=1.335 \mathrm{mM}$ ) 


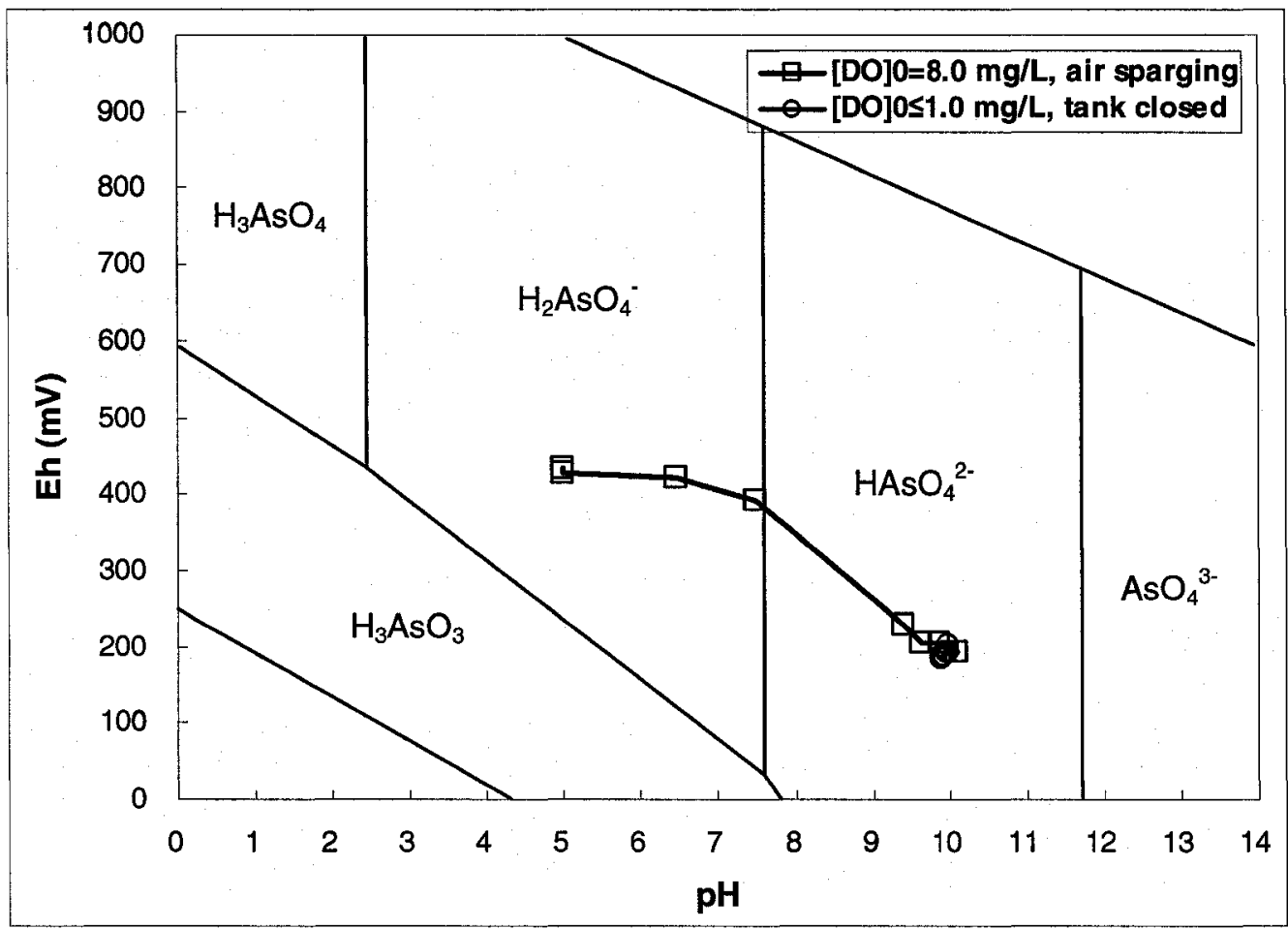

Figure 5.7 Measured Eh-pH diagram in Direct Photolysis under oxic and near-anoxic conditions (initial $\mathrm{pH}=10.0 ;[\text { As (III) }]_{0}=1.335 \mathrm{mM}$ )

Figure 5.3 indicates that in the oxic condition, As(III) can be completely oxidized within 1 hour. At the near-anoxic condition of less than $0.03 \mathrm{mM}(1 \mathrm{mg} / \mathrm{L})$ of DO concentration, the oxidation of As(III) was very limited and at a very low rate presumably due to the limitation of oxygen in the solution. These results indicate that oxidation of As(III) proceeds much faster under oxic condition than at near-anoxic condition.

It can be seen from Figure 5.4 that $\mathrm{As}(\mathrm{III})$ is oxidized to $\mathrm{As}(\mathrm{V})$. No other oxidation states of arsenic species, such as As(IV) were detected in the sample analysis. A material balance analysis also confirmed that the total arsenic in the final solution can be fully accounted for by the concentrations of As(III) and As(V) in the analyzed samples, within a $5 \%$ variation.

The monitoring of DO presented in Figure 5.5 indicates the decrease of DO in the 
oxic condition. However the DO concentration in the solution remained relatively at a high level because of the continuous air sparging all through the experiment, which helped replenish the depleting DO. In the near-anoxic condition, the DO dropped to a very low concentration of $0.007 \mathrm{mM}(0.22 \mathrm{mg} / \mathrm{L})$ and remained so during the oxidation process.

As shown in Figure 5.6, under oxic conditions, the $\mathrm{pH}$ of the solution decreased during the course of As(III) oxidation and dropped to a pH of 5.0 when complete oxidation of As(III) was achieved around the fifty minute mark and remained so. This drop in solution $\mathrm{pH}$ conforms to the release of $\mathrm{H}^{+}$in the set of proposed reactions in the oxidation process as explained in section 5.3.3.2.

By matching the Eh-pH conditions shown in Figure 5.7 with the standard Pourbaix diagram (Figure 2.3) it would be possible to determine the forms of the arsenic compounds in the aqueous system likely to exist at different reaction times. Initially arsenic is in the form of $\mathrm{H}_{2} \mathrm{AsO}_{3}{ }^{-}$while the final arsenic products could be $\mathrm{H}_{2} \mathrm{AsO}_{4}{ }^{-}$, $\mathrm{HAsO}_{4}{ }^{2-}$. There is also the indication that $\mathrm{As}(\mathrm{V})$ was the only final product of $\mathrm{As}(\mathrm{III})$ oxidation.

The investigation of Direct Photolysis of $\mathrm{As}(\mathrm{III})$ above indicates that DO concentration did have a significant effect on the extent and rate of oxidation of As(III). To determine the effect of the stoichiometric ratio of As(III) to DO, the effect of DO was further studied under the closed tank conditions by irradiating the feed solution maintained at different initial DO concentration, with all other conditions remaining the 
same as for the oxic and near-anoxic conditions above. Three initial DO conditions were compared: 1) $\left.\left.[\mathrm{DO}]_{0}=0.25 \mathrm{mM}(8.0 \mathrm{mg} / \mathrm{L}) ; 2\right)[\mathrm{DO}]_{0}=0.19 \mathrm{mM}(6.0 \mathrm{mg} / \mathrm{L}) ; 3\right)$ $[D O]_{0}=0.09 \mathrm{mM}(3.0 \mathrm{mg} / \mathrm{L})$.

The changes in the concentrations of As(III) and DO with time are shown in two separate plots in the same Figure 5.8 in such a way that one can follow the corresponding changes occurring in the concentrations as the reaction progressed. The points of inflexion on the curves are identified on the time scale as $\mathbf{A 1}, \mathbf{A 2}$ and $\mathbf{A 3}$ for the three curves, typically beyond which DO essentially falls to a very low level as discussed below. 


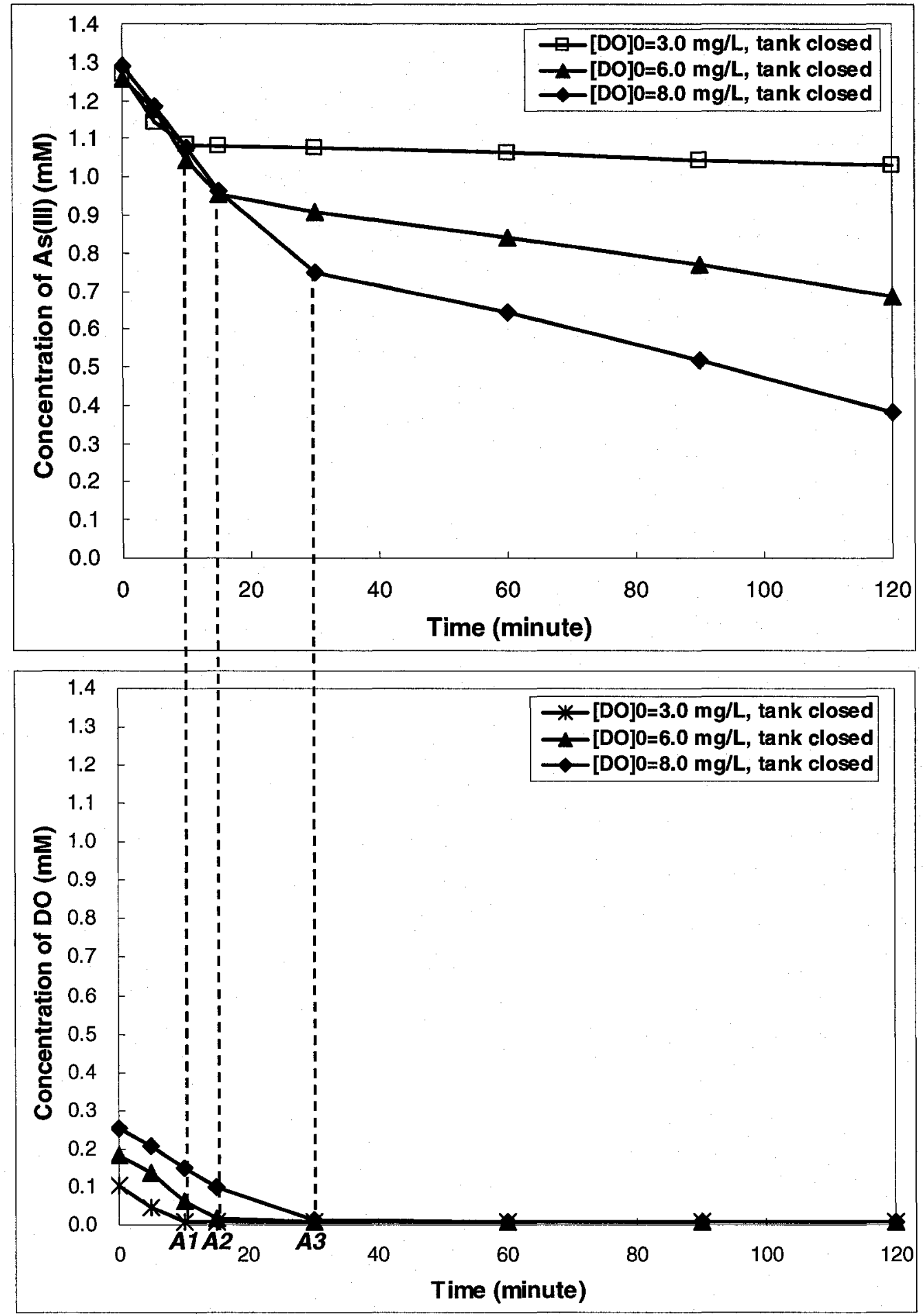

Figure 5.8 As (III) and DO concentrations as a function of irradiation time in Direct Photolysis under different $\mathrm{DO}$ concentrations (initial $\mathrm{pH}=10.0$; $[\mathrm{As}(\mathrm{III})]_{0}=1.335 \mathrm{mM}$ )

The plot clearly shows the influence of DO on the oxidation process. The DO conditions in the solution have a very significant effect on arsenic oxidation and it seems 
clear that higher initial DO concentrations resulted in higher final oxidation percentages.

During the oxidation process, the DO concentrations steadily decreased to 0.22 $\mathrm{mg} / \mathrm{L}$ after a period of irradiation time, and then remained at this measured level. After DO concentration reached $0.22 \mathrm{mg} / \mathrm{L}$, the oxidation process continued at relatively low reaction rates. In the range of conditions of $[\mathrm{DO}]_{0}=3.0 \sim 8.0 \mathrm{mg} / \mathrm{L}$, the change in rate of oxidation is observed to occur when DO levels reached around $0.22 \mathrm{mg} / \mathrm{L}$ as identified by the points A1, A2 and A3. The molar ratio of the As(III) to the oxygen consumed prior to points A1, A2 and A3 was about 2:1, which conforms to the stoichiometric value of $\mathrm{As}(\mathrm{III}): \mathrm{O}_{2}$ in the dark reaction equation (R2-1) in Table 2.3. Beyond these points, the As(III) concentration kept dropping, whereas the measured DO remained at the same level and the ratio did not conform to the stoichiometry.

The plot of DO concentration with time is juxtaposed directly below the As(III)-time plot to show that the consumption of DO during the oxidation process coincides with changes in the rates of oxidation of As(III). In all these experiments with DO below the saturation level, rapid oxidation occurs initially followed by a much lower rate of oxidation. This is in contrast to the results obtained under oxic (fully saturated DO) condition above, when the oxidation goes to completion with no change in the rate of oxidation.

Under different $\mathrm{DO}$ concentrations, the $\mathrm{pH}$ of the solution also decreased during the course of As(III) oxidation and the arsenic species indicated by the measured Eh and $\mathrm{pH}$ value are consistent with the air sparging condition above, as shown in Appendix $\mathrm{H}$. 


\subsubsection{Effect of Initial As(III) Concentration}

The effect of initial As(III) concentration was studied under the closed tank condition with the $[\mathrm{DO}]_{0}$ of $8.0 \mathrm{mg} / \mathrm{L}$. Other parameters remained the same as in the closed tank DO investigations reported above. Five initial As(III) concentrations were compared: 1) $\left.\left.[\mathrm{As}(\mathrm{III})]_{0}=0.267 \mathrm{mM}(20 \mathrm{mg} / \mathrm{L}) ; 2\right)[\mathrm{As}(\mathrm{III})]_{0}=0.534 \mathrm{mM}(40 \mathrm{mg} / \mathrm{L}) ; 3\right)$

$$
\begin{aligned}
& \left.\left.[\mathrm{As}(\mathrm{III})]_{0}=0.801 \mathrm{mM}(60 \mathrm{mg} / \mathrm{L}) ; 4\right)[\mathrm{As}(\mathrm{III})]_{0}=1.068 \mathrm{mM}(80 \mathrm{mg} / \mathrm{L}) ; 5\right)[\mathrm{As}(\mathrm{III})]_{0} \\
& =1.335 \mathrm{mM}(100 \mathrm{mg} / \mathrm{L}) .
\end{aligned}
$$

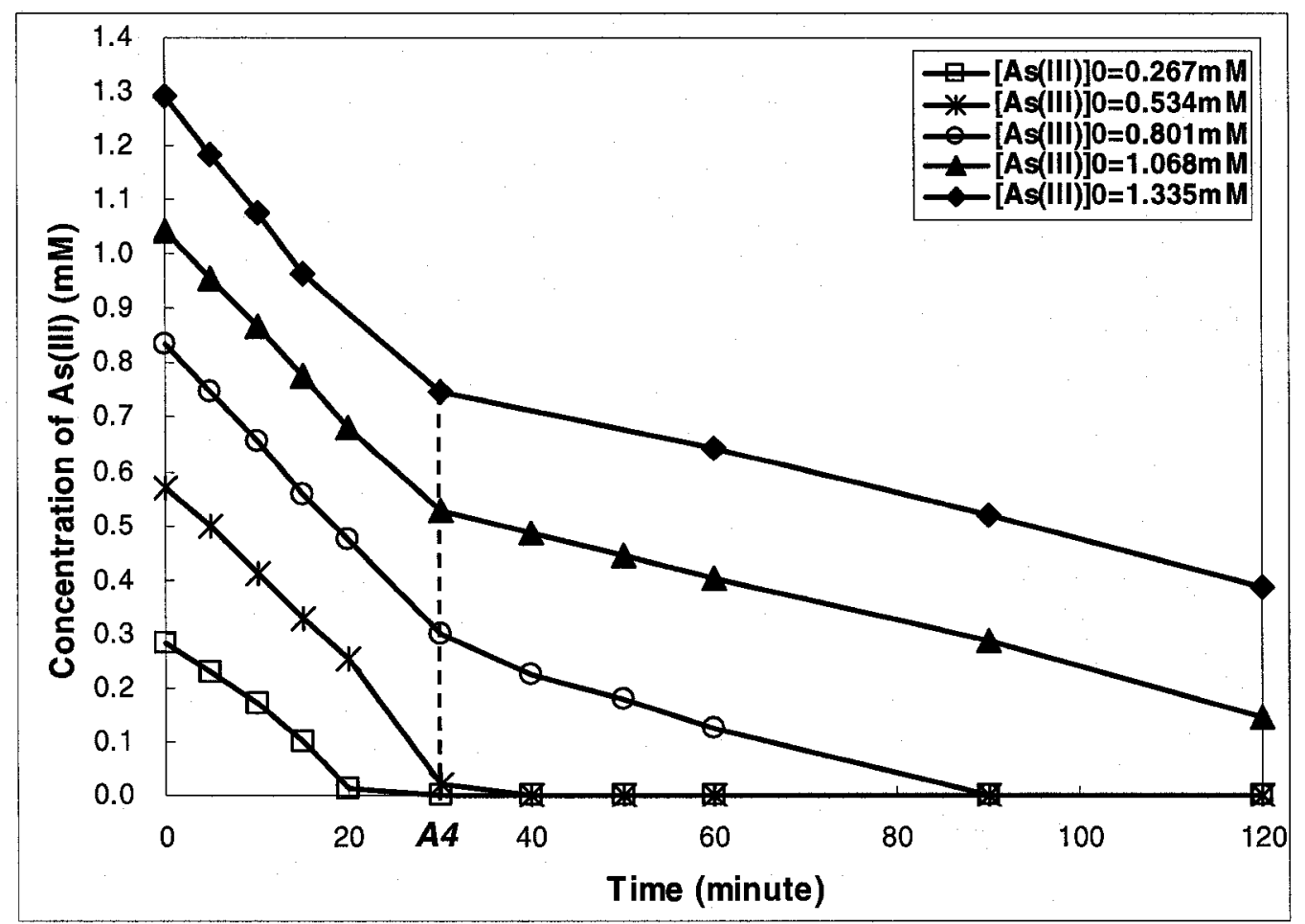

Figure 5.9 As(III) concentrations as a function of irradiation time in Direct Photolysis under different initial As(III) concentrations(initial pH $=10.0 ;[D O]_{0}=8.0 \mathrm{mg} / \mathrm{L}$ with the closed tank)

As can be seen in Figure 5.9, in the first 20 minutes of irradiation, the rate of change in As(III) concentration remains constant and almost identical for the different experiments starting with different initial arsenic concentrations. Beyond this time, at 
lower concentrations $[\mathrm{As}(\mathrm{III})]_{0} \leq 0.534 \mathrm{mM}, \mathrm{As}(\mathrm{III})$ can be completely oxidized within 40 minutes, whereas, at higher concentrations, a change in rate of oxidation is observed in the course of the experiment. The change in the oxidation rate seems to occur at a point denoted by $\mathrm{A} 4$ on the time axis, at which the DO levels reached around $0.22 \mathrm{mg} / \mathrm{L}$. It may further be noted that the rates of conversion of arsenite is comparable between all the experiments although the initial concentration of arsenic was different for each experiment. The point of inflexion could also very well signify a possible change in the mechanism or the pathway for the oxidation reaction.

\subsubsection{Effect of Initial $\mathrm{pH}$}

Under Direct Photolysis, feed solutions with three different initial $\mathrm{pH}$ conditions, from $\mathrm{pH} 3.0$ to 10.0 were studied. The parameters chosen were: $[\mathrm{As}(\mathrm{III})]_{0}=1.335 \mathrm{mM}$ $(100 \mathrm{mg} / \mathrm{L})$; medium stirring speed. As mentioned in the earlier section, DO condition is a significant factor in the oxidation of $\mathrm{As}(\mathrm{III})$. To examine the potential influence of $\mathrm{pH}$, the experiments were carried out under three different DO conditions: 1) [DO $]_{0} \leq 0.03$ $\mathrm{mM}(1.0 \mathrm{mg} / \mathrm{L})$ with the closed tank; 2$)[\mathrm{DO}]_{0}=0.25 \mathrm{mM}(8.0 \mathrm{mg} / \mathrm{L})$ with the closed tank; 3) $[\mathrm{DO}]_{0}=0.25 \mathrm{mM}(8.0 \mathrm{mg} / \mathrm{L})$ with air sparging.

As shown in Appendix $\mathrm{H}$, under the closed tank conditions at $[\mathrm{DO}]_{0} \leq 1.0 \mathrm{mg} / \mathrm{L}$ and $[\mathrm{DO}]_{0}=8.0 \mathrm{mg} / \mathrm{L}$, no significant effect of $\mathrm{pH}$ on the oxidation of $\mathrm{As}(\mathrm{III})$ was observed. At the lower DO condition, the As(III) oxidation process was very sluggish. At the higher DO condition, the variations of As(III) under two distinct slopes were also observed at all 
$\mathrm{pH}$ conditions. The experimental results with the condition of $[\mathrm{DO}]_{0}=8.0 \mathrm{mg} / \mathrm{L}$ with air sparging, are shown from Figure 5.10 to Figure 5.13.

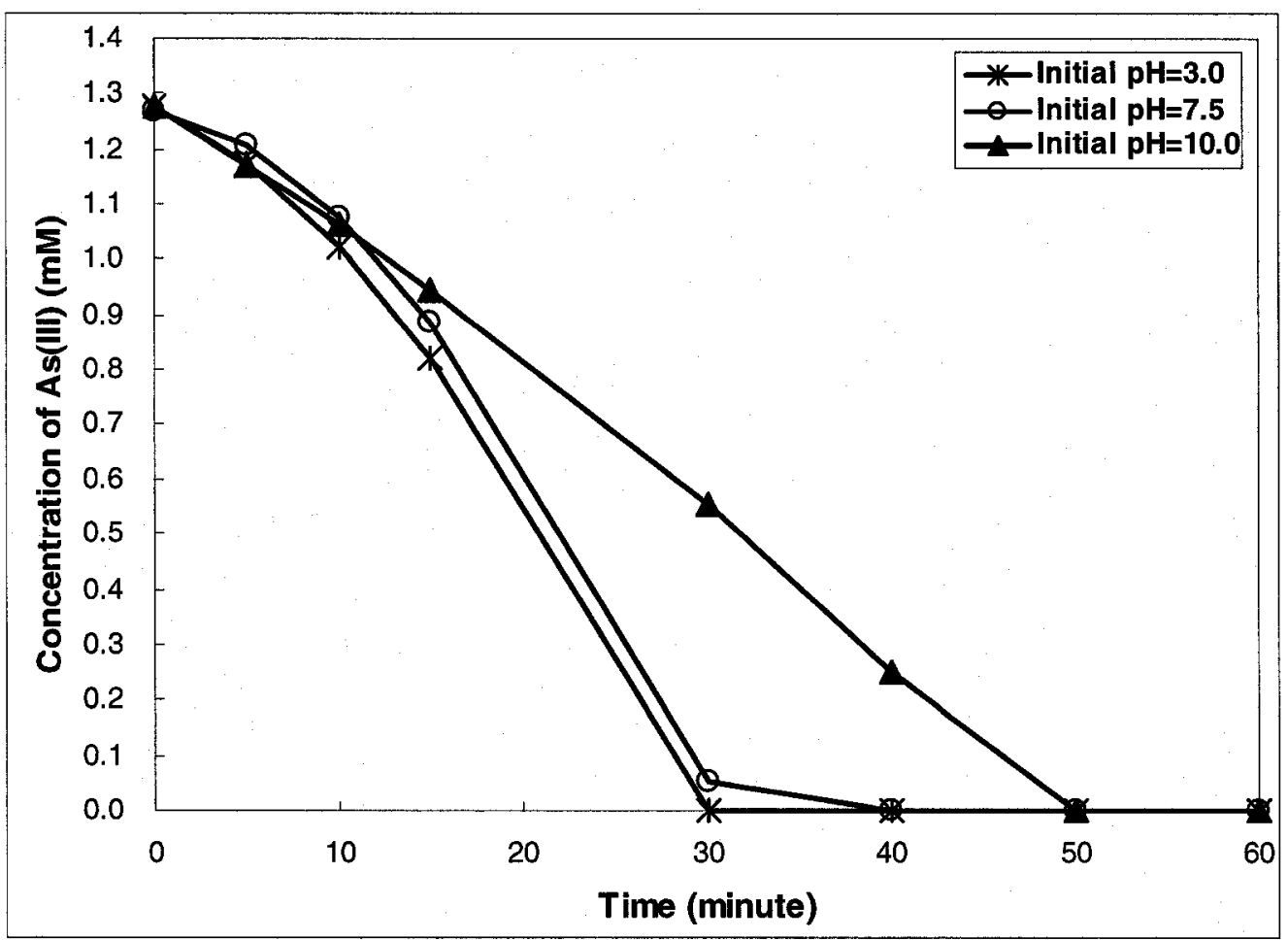

Figure 5.10 As (III) concentration as a function of irradiation time in Direct Photolysis under different initial $\mathrm{pH}\left([\mathrm{As}(\mathrm{III})]_{0}=1.335 \mathrm{mM} ;[\mathrm{DO}]_{0}=8.0 \mathrm{mg} / \mathrm{L}\right.$ with air sparging) 


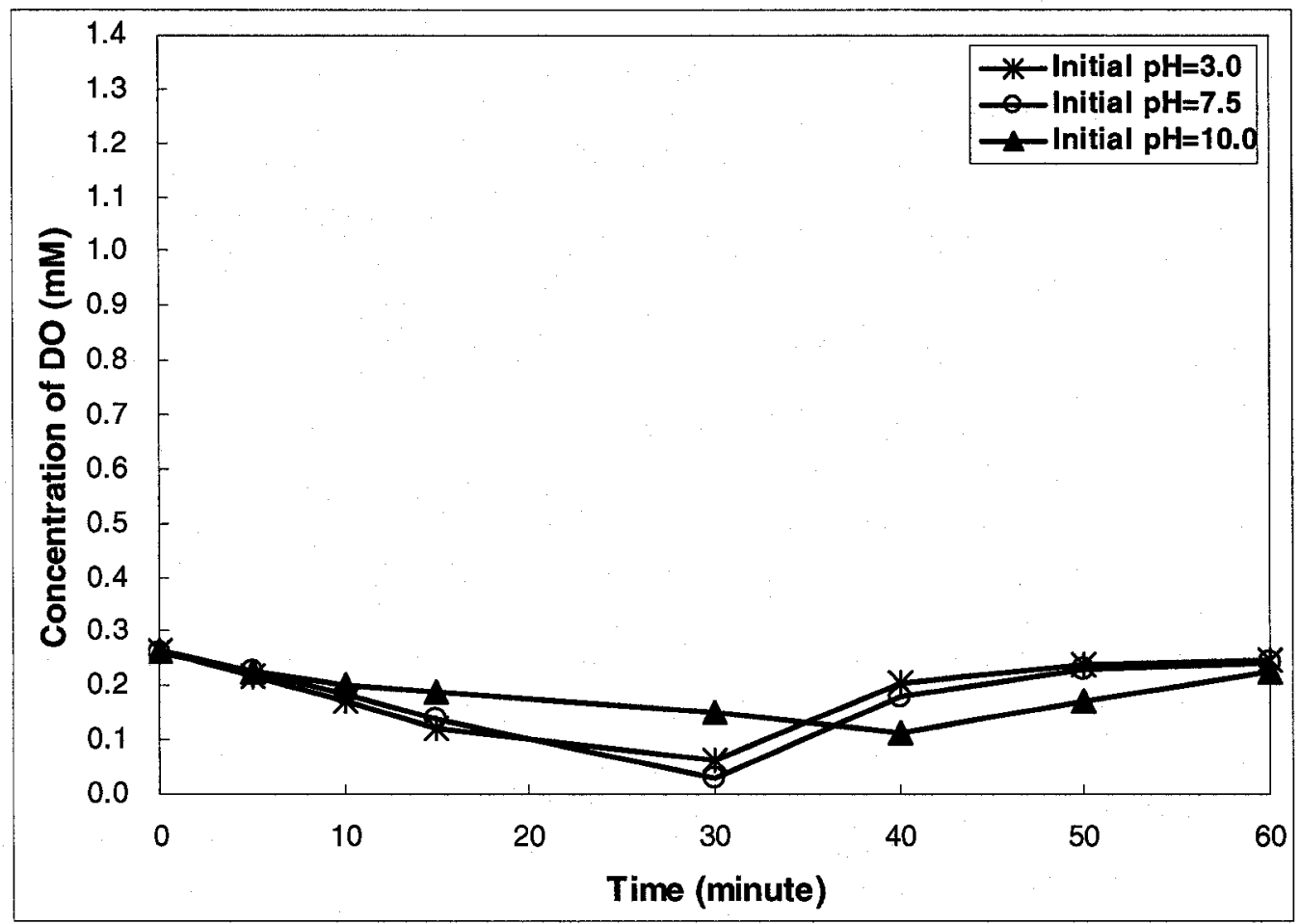

Figure 5.11 DO concentration as a function of irradiation time in Direct Photolysis under different initial $\mathrm{pH}\left([\mathrm{As}(\mathrm{III})]_{0}=1.335 \mathrm{mM},[\mathrm{DO}]_{0}=8.0 \mathrm{mg} / \mathrm{L}\right.$ with air sparging)

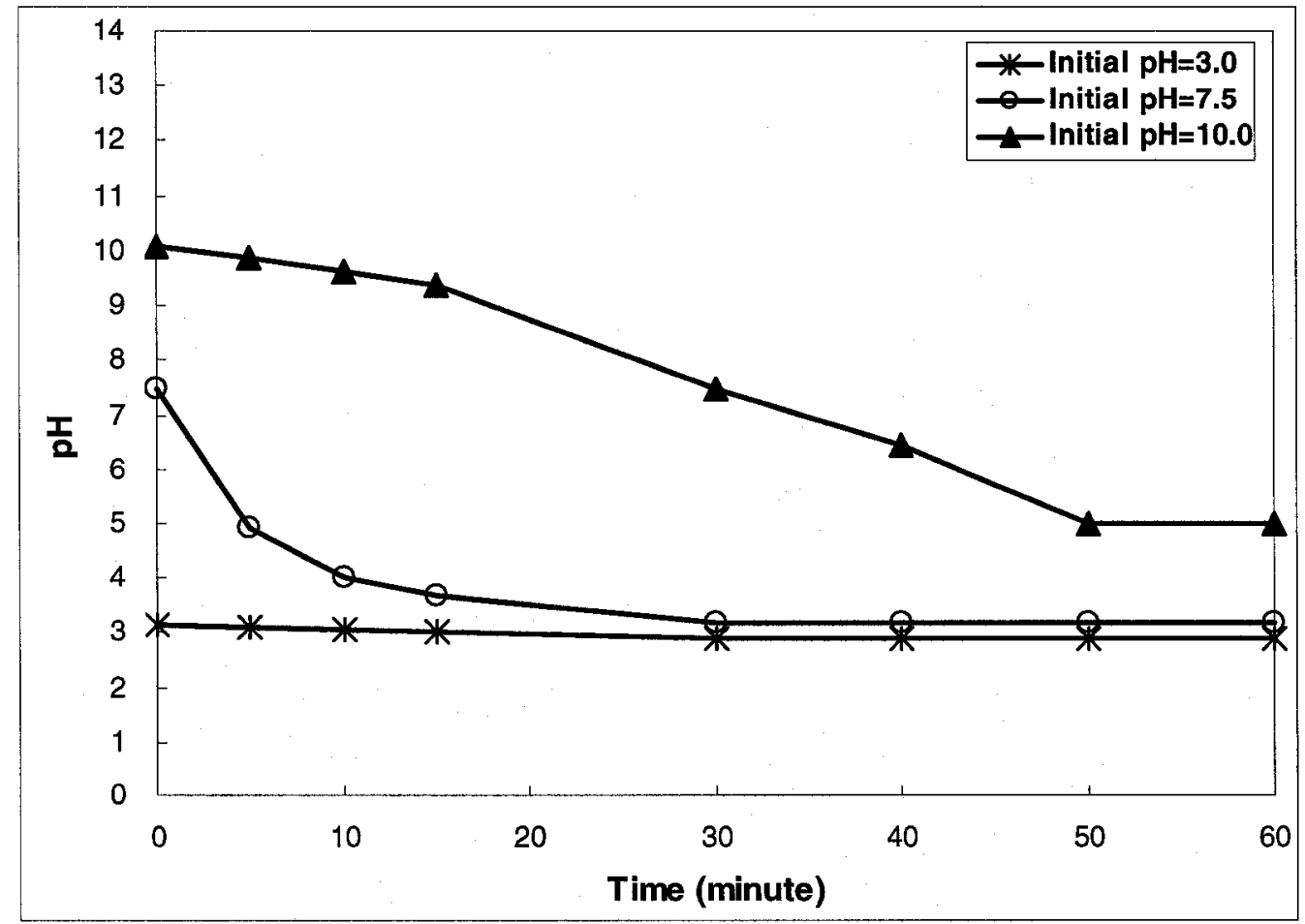

Figure $5.12 \mathrm{pH}$ as a function of irradiation time in Direct Photolysis under different initial $\mathrm{pH}\left([\mathrm{As}(\mathrm{III})]_{0}=1.335 \mathrm{mM} ;[\mathrm{DO}]_{0}=8.0 \mathrm{mg} / \mathrm{L}\right.$ with air sparging) 


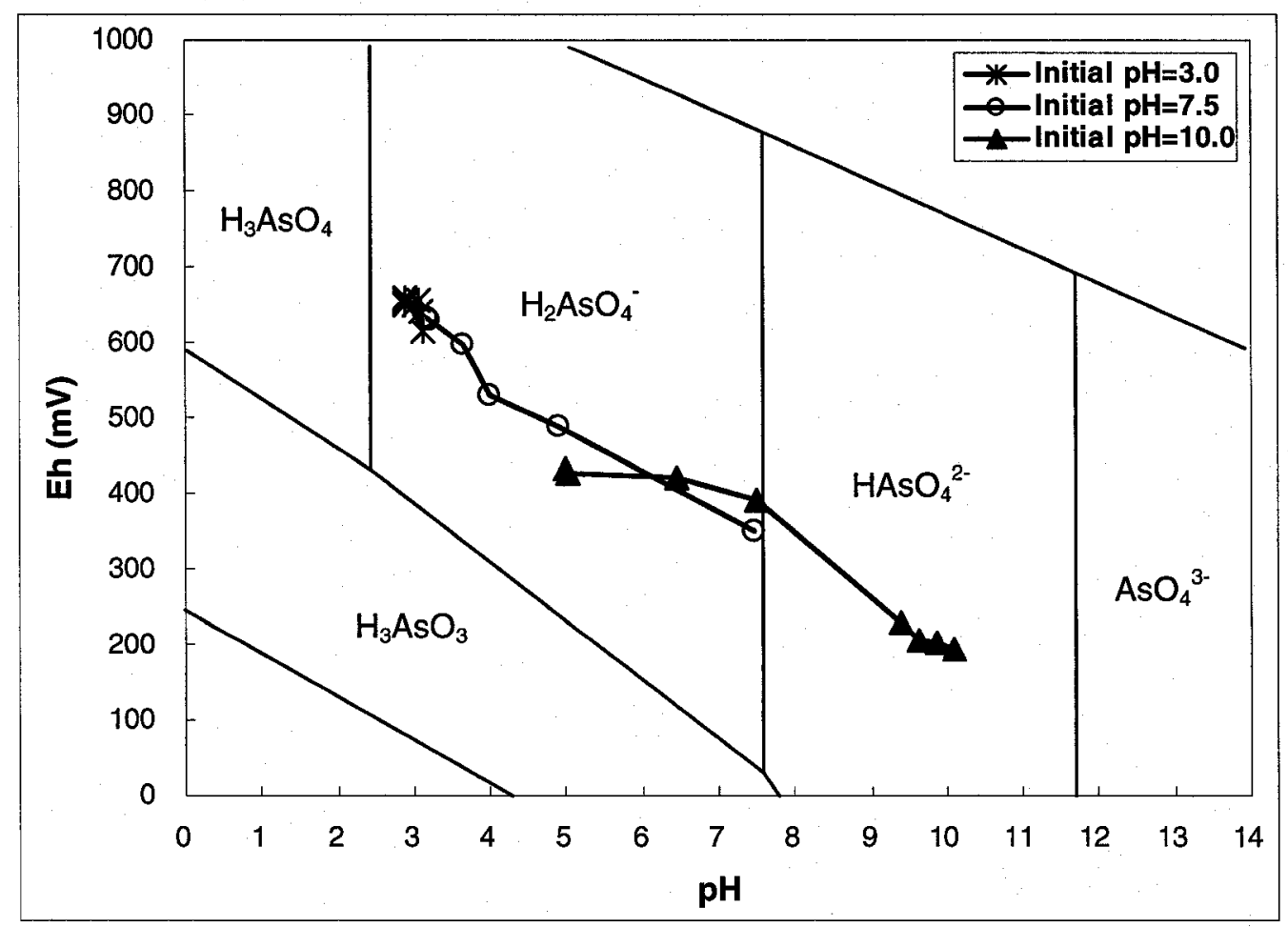

Figure 5.13 Measured Eh-pH diagram in Direct Photolysis under different initial pH ([As (III) $]_{0}=1.335 \mathrm{mM}$; [DO $]_{0}=8.0 \mathrm{mg} / \mathrm{L}$ with air sparging)

As can be seen in Figure 5.10, there is a faster conversion of As(III) to As(V) at lower $\mathrm{pH}$ conditions. At initial $\mathrm{pH}$ of 3.0, the oxidation of As(III) was completed within 30 minutes, whereas, at initial $\mathrm{pH}$ of 10.0 , the time for completion was almost doubled.

The consumption of DO was observed at all $\mathrm{pH}$ conditions, as shown in Figure 5.11. These results firmly establish the fact that dissolved oxygen is an essential component for the rapid oxidation of As(III) by Direct Photolysis.

Further in Figure 5.12, it was observed that in all experiments, as the reaction progressed, the $\mathrm{pH}$ continued to drop from the initial value, indicating the release of protons in the course of arsenite oxidation. The variation of $\mathrm{H}^{+}$released and As(V) produced in the course of Direct Photolysis is shown in Figure 5.14. The molar ratio of $\left[\mathrm{H}^{+}\right] /[\mathrm{As}(\mathrm{V})]$ in the final solution at different initial $\mathrm{pH}$ conditions is shown in Table 5.1. 
The results indicate the molar ratio of $\left[\mathrm{H}^{+}\right] /[\mathrm{As}(\mathrm{V})]$ is in the range of $0 \sim 1$. This ratio is further supported by the stoichiometric ratio as per reactions shown in Table 5.6.

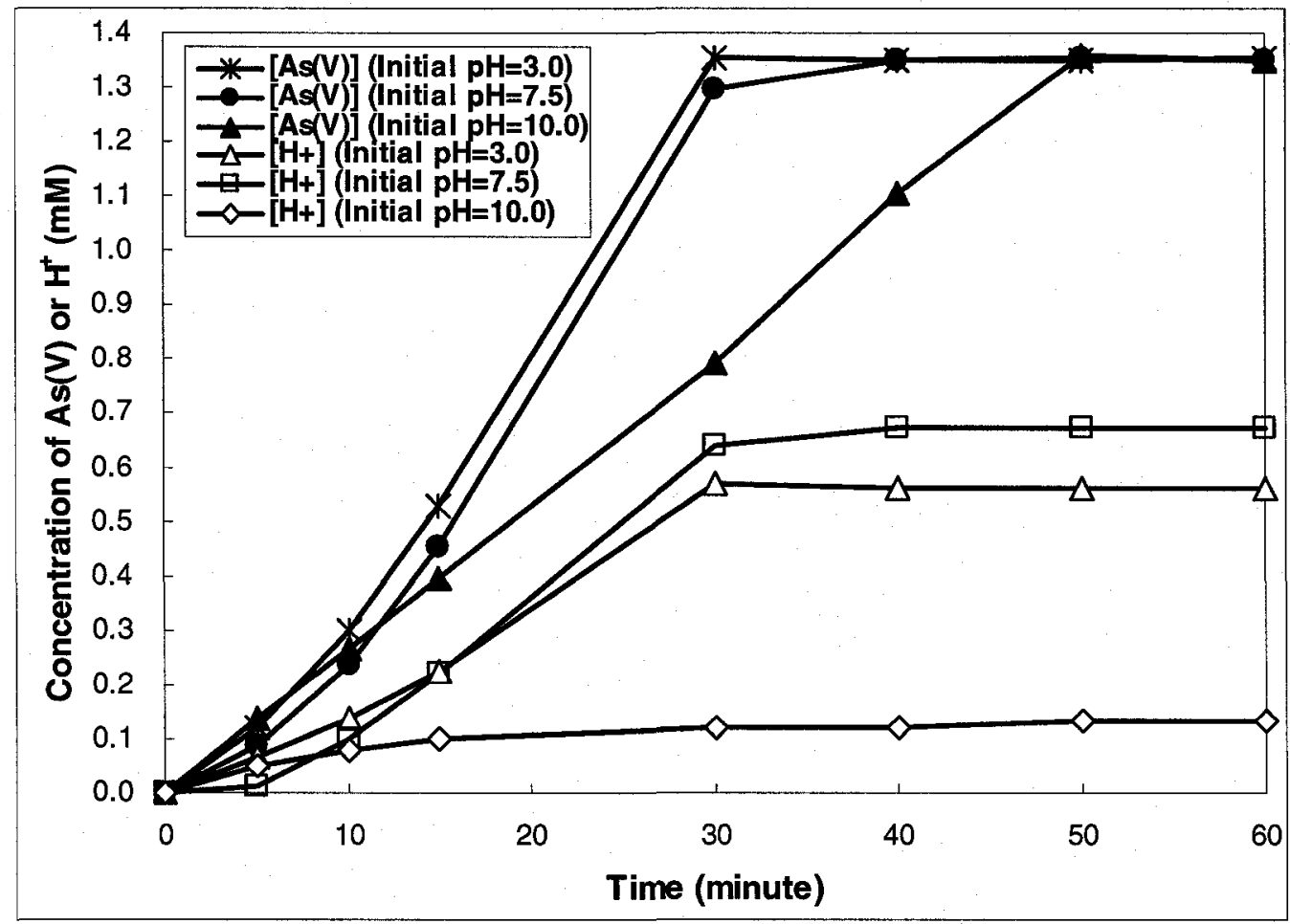

Figure 5.14 Production of $\mathrm{As}(\mathrm{V})$ and $\mathrm{H}^{+}$as a function of irradiation time in Direct Photolysis under different initial $\mathrm{pH}$ ( $[\text { As }(\mathrm{III})]_{0}=1.335 \mathrm{mM} ;[\mathrm{DO}]_{0}=8.0 \mathrm{mg} / \mathrm{L}$ with air sparging)

Table 5.1 Molar ratio of $\left[\mathrm{H}^{+}\right]$and $[\mathrm{As}(\mathrm{V})]$ in the final solution in Direct Photolysis process $\left([D O]_{0}=8.0 \mathrm{mg} / \mathrm{L}\right.$ with air sparging, $\left.[\mathrm{As}(\mathrm{III})]_{0}=1.335 \mathrm{mM}\right)$

\begin{tabular}{cccc}
\hline \hline Initial $\mathrm{pH}$ & {$\left[\mathrm{H}^{+}\right](\mathrm{mM})$} & Final $[\mathrm{As}(\mathrm{V})](\mathrm{mM})$ & Molar ratio of $\left[\mathrm{H}^{+}\right] /[\mathrm{As}(\mathrm{V})]$ \\
\hline $\mathrm{pH}=3.0$ & $0.619 \pm 0.082$ & $1.335 \pm 0.067$ & $0.450 \pm 0.091$ \\
$\mathrm{pH}=7.5$ & $0.671 \pm 0.047$ & $1.335 \pm 0.067$ & $0.503 \pm 0.098$ \\
$\mathrm{pH}=10.0$ & $0.132 \pm 0.091$ & $1.335 \pm 0.067$ & $0.101 \pm 0.074$ \\
\hline \hline
\end{tabular}

The Eh-pH diagram shown in Figure 5.13 indicates that in the initial $\mathrm{pH}$ conditions of 7.5 and 10.0, the shift of $\mathrm{pH}$ and $\mathrm{Eh}$ are significant, whereas, in the initial $\mathrm{pH}$ condition of 3.0, the shift is minimal. As indicated in the Eh-pH diagram in Figure 5.13, at the initial $\mathrm{pH}$ range of 3.0 7.5, arsenic is in form of $\mathrm{H}_{3} \mathrm{AsO}_{3}$ and after the complete 
conversion of $\mathrm{As}(\mathrm{III})$ to $\mathrm{As}(\mathrm{V}), \mathrm{H}_{3} \mathrm{AsO}_{4}$ and $\mathrm{H}_{2} \mathrm{AsO}_{4}{ }^{-}$are the final arsenic species in the solution; at initial $\mathrm{pH}$ of 10.0, arsenic is initially in form of $\mathrm{H}_{2} \mathrm{AsO}_{3}{ }^{-}$and finally exists as the As(V) species of $\mathrm{H}_{2} \mathrm{AsO}_{4}{ }^{-}, \mathrm{HAsO}_{4}{ }^{2-}$. The dominant arsenic species in the final solution can be further identified in the As(V)-pH plot shown in Figure 2.2, in which the fractional variation of the arsenic species with $\mathrm{pH}$ is given. In Figure 5.12, the final $\mathrm{pH}$ attained is shown for experiments with different initial $\mathrm{pH}$ conditions. According to the As(V)-pH plot, it can be found that $\mathrm{H}_{3} \mathrm{AsO}_{4}, \mathrm{H}_{2} \mathrm{AsO}_{4}^{-}$, and $\mathrm{HAsO}_{4}{ }^{2-}$ are the dominant species in the final solution of initial $\mathrm{pH} 3.0,7.5$ and 10.0 respectively. The arsenic species under different initial $\mathrm{pH}$ conditions before and after the complete oxidization of As(III) are summarized and shown in Table 5.2. The underlined are the dominant species.

Table 5.2 Arsenic species under different initial pH conditions

\begin{tabular}{ccc}
\hline \hline Initial pH & Initial arsenic species & Final arsenic species \\
\hline \hline 3.0 & $\mathrm{H}_{3} \mathrm{AsO}_{3}$ & $\underline{\mathrm{H}}_{3} \underline{A s O}_{4}, \mathrm{H}_{2} \mathrm{AsO}_{4}{ }^{-}$ \\
7.5 & $\mathrm{H}_{3} \mathrm{AsO}_{3}$ & $\mathrm{H}_{3} \mathrm{AsO}_{4}, \underline{\mathrm{H}}_{2} \mathrm{AsO}_{4}{ }^{-}$ \\
10.0 & $\mathrm{H}_{2} \mathrm{AsO}_{3}{ }^{-}$ & $\underline{\mathrm{H}}_{2} \mathrm{AsO}_{4}^{-}, \mathrm{HAsO}_{4}{ }^{2-}$ \\
\hline \hline
\end{tabular}

The investigation on the effect of $\mathrm{pH}$ was further carried out at different initial As(III) concentrations with the initial $\mathrm{pH}$ of 3.0 and 7.5. The results shown in Appendix $\mathrm{H}$ indicate similar variation of $\mathrm{As}(\mathrm{III}), \mathrm{As}(\mathrm{V}), \mathrm{DO}, \mathrm{pH}$ and $\mathrm{Eh}$.

\subsubsection{Direct Photolysis in the Recirculation Reactor}

The UV recirculation reactor consists of two tanks: the main reactor (batch reactor) and the recycle tank. The arsenic wastewater is irradiated in the main reactor at the same 
UV conditions as the batch reactor above. Wastewater circulates from the reactor to the recycle tank through a centrifugal pump in a closed loop. In the recirculation reactor, very high circulation rates can be achieved.

The recirculation reactor is schematically shown in Figure 5.15 and the material balance in the reactor system is expressed by equation (5-1).

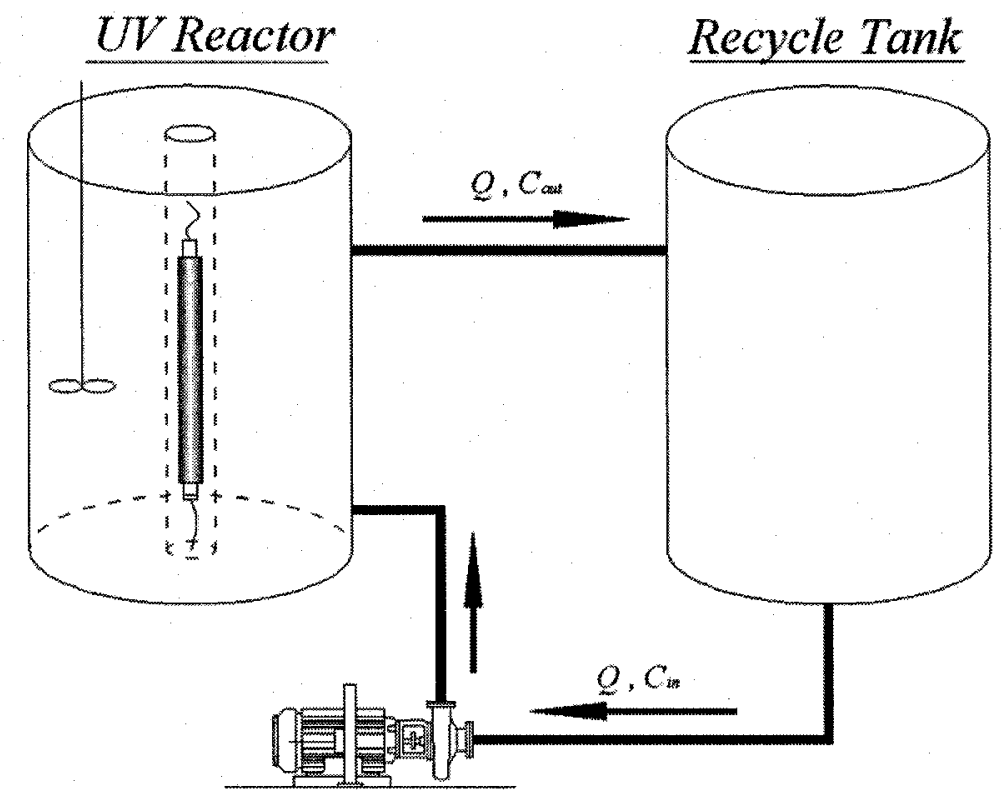

Figure 5.15 Schematic diagram of the recirculation reactor system

$$
\frac{d C_{i}}{d t} V=Q C_{i, i n}-Q C_{i, o u t}+r_{c i} V
$$

in which, $V$ is the volume of UV reactor; $Q$ is the recycle rate; $C_{i, \text { in }}$ and $C_{i, \text { out }}$ are the inlet and outlet concentrations of substance $i ; r_{c i}$ is the rate of generation or consumption of substance $i$.

As indicated by equation (5-1), besides the parameters of the batch reactor, the recycle rate also could influence the As(III) oxidation efficiency in the recirculation reactor. 


\subsubsection{Effect of Recycle Rate}

The effect of recycle rate was investigated by irradiating the feed solution at different recycle rates with other conditions remaining the same. The parameters chosen were: $[\mathrm{As}(\mathrm{III})]_{0}=1.335 \mathrm{mM}$ and initial $\mathrm{pH}=10.0$. Three recycle rates were compared: 1 ) $\left.\left.10 \mathrm{GPM}\left(0.63 \times 10^{-3} \mathrm{~m}^{3} / \mathrm{s}\right) ; 2\right) 17 \mathrm{GPM}\left(1.07 \times 10^{-3} \mathrm{~m}^{3} / \mathrm{s}\right) ; 3\right) 25 \mathrm{GPM}\left(1.58 \times 10^{-3} \mathrm{~m}^{3} / \mathrm{s}\right)$.

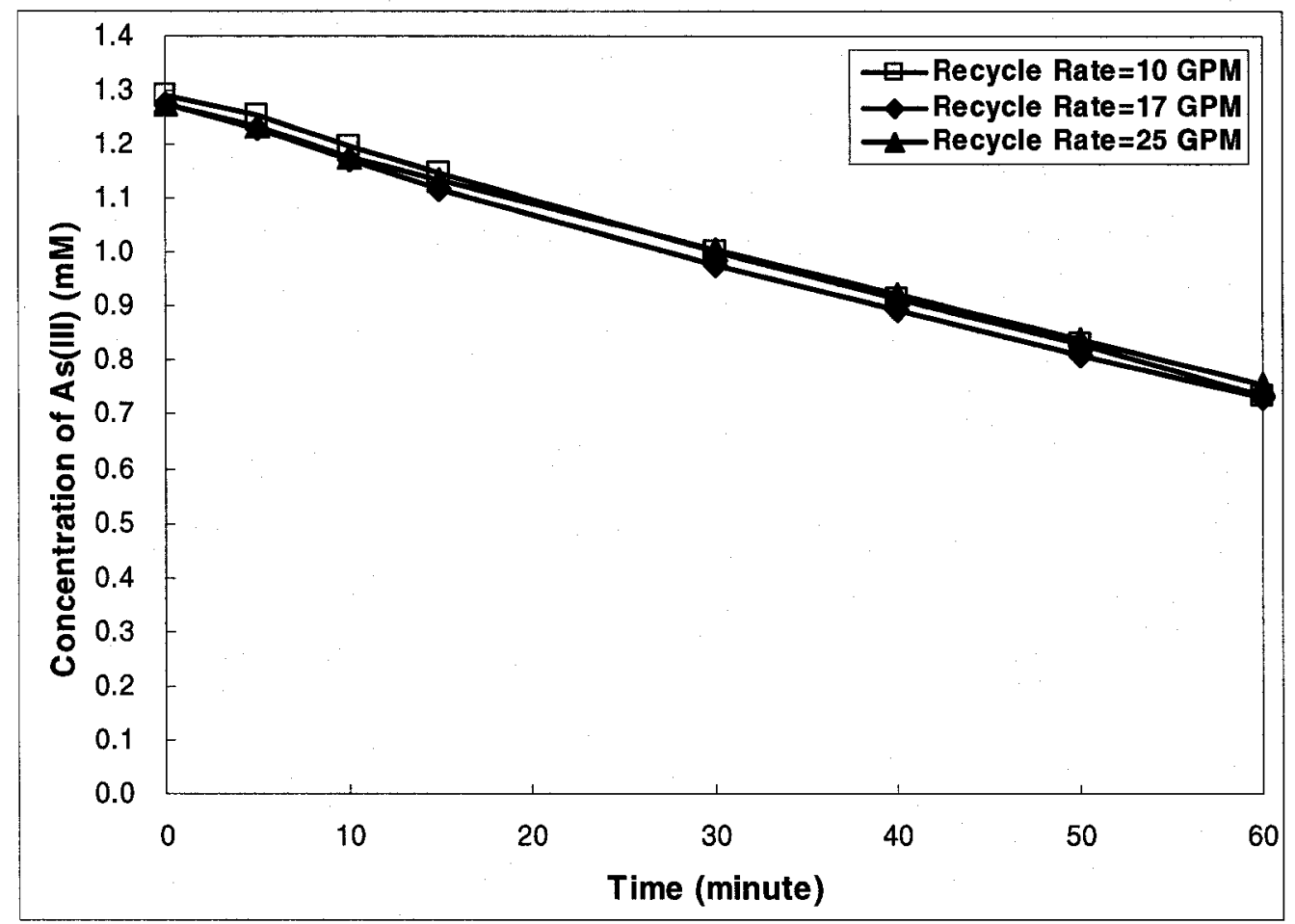

Figure 5.16 As(III) concentration as a function of irradiation time in the recirculation reactor in Direct Photolysis at different recycle rates $\left([\mathrm{As}(\mathrm{III})]_{0}=1.335 \mathrm{mM}\right.$; initial $\mathrm{pH}=10.0$; $[\mathrm{DO}]_{0}=8.0 \mathrm{mg} / \mathrm{L}$ with the closed tank)

As can been seen in Figure 5.16, the concentration-time curves for the three different recycle rates nearly overlap on each other indicating that the recycle rate does not seem to influence the conversion rates. It can be stated that mass transfer is not an inhibiting factor in the determination of the kinetics under these conditions.

As in the case of the batch reactor, the DO concentration and the $\mathrm{pH}$ dropped with 
irradiation time. However, the DO concentration did not go below $4.0 \mathrm{mg} / \mathrm{L}$. The maintenance of this DO level in the recirculation reactor could be due to the cavitation created by the high speed centrifugal pump in the system. The occurrence of cavitation could lead to the suction of air external to the system. This could have resulted in the high DO observed in the solution. Consequently, in the recirculation system, air sparging was found to be unnecessary.

\subsubsection{Effect of Initial $\mathrm{pH}$}

In the batch reactor, it appeared that the As(III) oxidation process is affected by the initial $\mathrm{pH}$. This aspect was investigated in the recirculation reactor. Three initial $\mathrm{pH}$ conditions from 3.0 to 10.0 were investigated. The parameters chosen were: $[\mathrm{As}(\mathrm{III})]_{0}$ $=1.335 \mathrm{mM}$ and a recycle rate of $25 \mathrm{GPM}$. As indicated in Figure 5.17, at lower initial pH, higher oxidation efficiency was obtained, which is consistent with the results obtained in the batch reactor. 


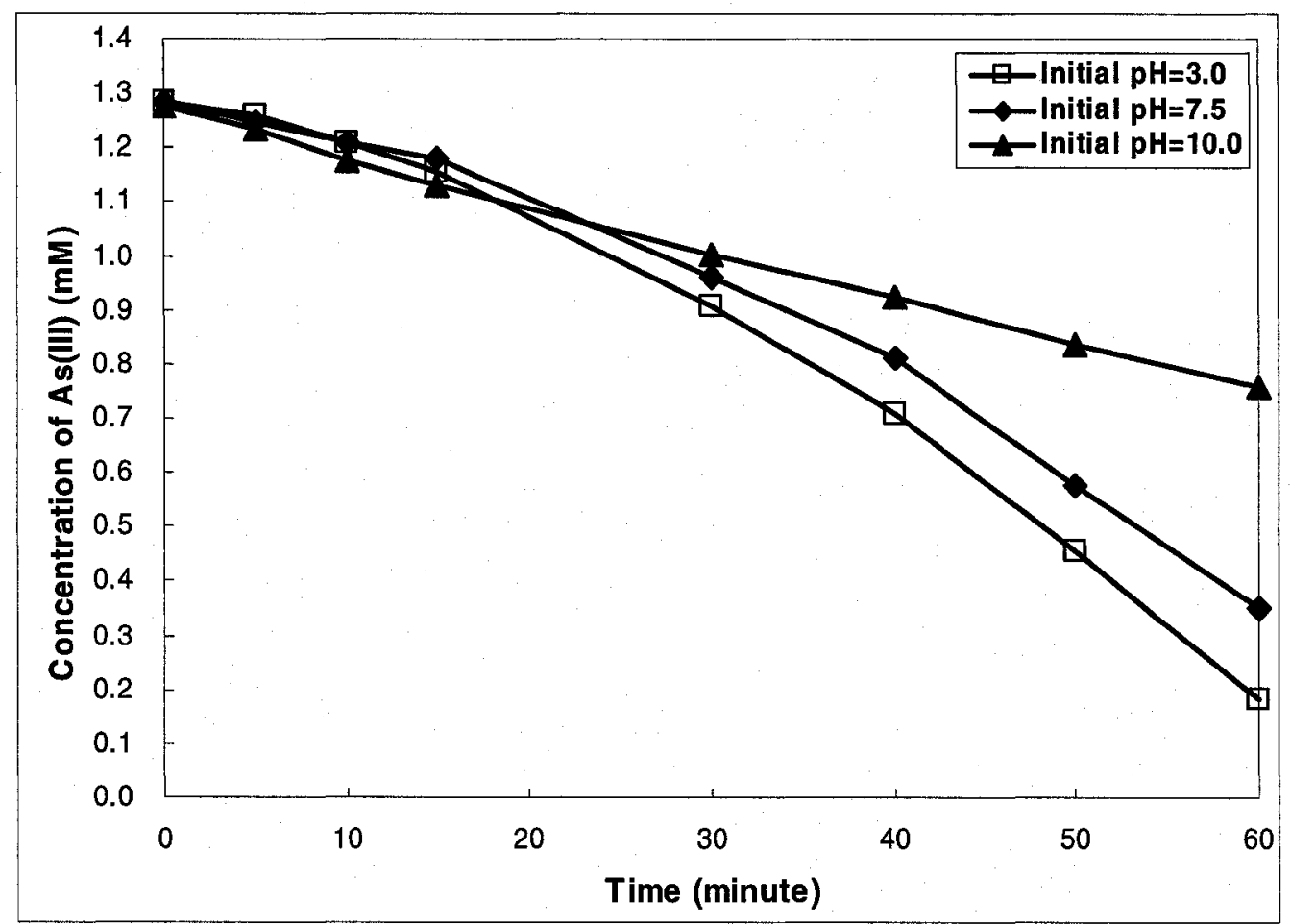

Figure $5.17 \mathrm{As}$ (III) concentration as a function of irradiation time in the recirculation reactor in Direct Photolysis under different initial $\mathrm{pH}\left([\mathrm{As}(\mathrm{III})]_{0}=1.335 \mathrm{mM}\right.$; recycle rate=25GPM; $[\mathrm{DO}]_{0}=8.0 \mathrm{mg} / \mathrm{L}$ with the closed tank)

\subsubsection{Effect of Initial As(III) Concentration}

The effect of initial As(III) concentration was investigated by irradiating the feed solution with different recycle rates with other conditions remaining the same. Two initial As(III) concentrations of $0.668 \mathrm{mM}$ and $1.335 \mathrm{mM}$ were investigated, corresponding to the As(III) concentration level in the batch reactor. The parameters chosen were: initial $\mathrm{pH}=10.0$ and recycle rate of $25 \mathrm{GPM}$.

As can be seen in Figure 5.18, the rates of conversion of As(III) are comparable between different initial concentrations, which is similar to the results in batch reactor. 


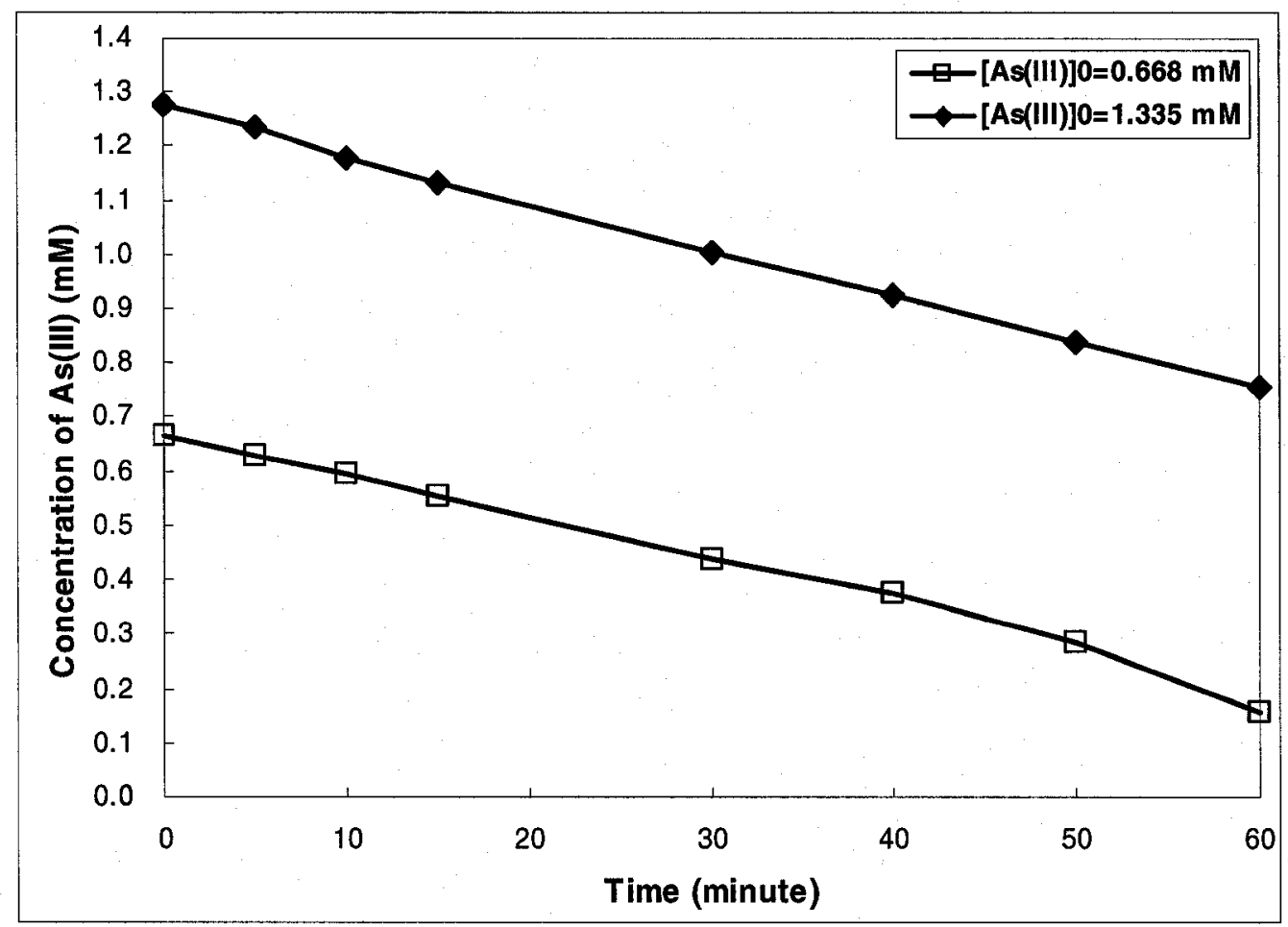

Figure 5.18 As(III) concentration as a function of irradiation time in the recirculation system in Direct Photolysis under different initial As(III) concentration (initial $\mathrm{pH}=10.0$; recycle rate=25GPM; $[D O]_{0}=8.0 \mathrm{mg} / \mathrm{L}$ with the closed tank)

\subsubsection{Kinetics of Direct Photolysis}

\subsubsection{Rate Equation and Reaction Order}

In this section, the rate equation and reaction order with respect to the arsenic concentration will be evaluated for both the batch reactor and the recirculation reactor.

\section{(1) Air sparging condition in batch reactor}

As stated earlier, at the air sparging condition, due to the continuous replenishment of oxygen to the solution, the DO concentration remained at a relatively high level. Therefore, it is reasonable to assume that there was excess DO at all times and its concentration did not directly influence the rate. Also differences in the progress of the 
reaction were observed with different initial $\mathrm{pH}$ conditions. Thus the kinetic calculation was carried out based on a set of typical experiments with the variation of initial $\mathrm{pH}$ from 3.0 to 10.0. No arsenic intermediates were observed in the analytical samples. As the arsenic exhibits UV absorption below $220 \mathrm{~nm}$, it is postulated that the primary reaction is the formation of an activated arsenic species as per the reaction (R5-1).

$$
A s(I I I) \stackrel{k}{\longrightarrow} A s(V)
$$

From the experimental data, the reaction order with respect to the arsenic concentration was determined using the standard methods of analysis (Levenspiel, 1999). Extensive statistical analysis and rate modelling was carried out examining in detail, rate models for reaction orders 0,1 , and 2 , as well as two 'shifting-order' models of the type $r_{A}=-\frac{d[A]}{d t}=\frac{k_{1}[A]}{1+k_{2}[A]}$.

As can be seen in Figure 5.19, the plots of linearized zero-order model gave a straight trendline for all the initial $\mathrm{pH}$ conditions. The zero order model gave the best fit compared to the first and second-order plots as well as the shifting-order models. From the analysis, one can conclude that in the air sparging condition, the Direct Photolysis of As(III) is a zero-order (or close to a zero-order) reaction with respect to the arsenic concentration. 


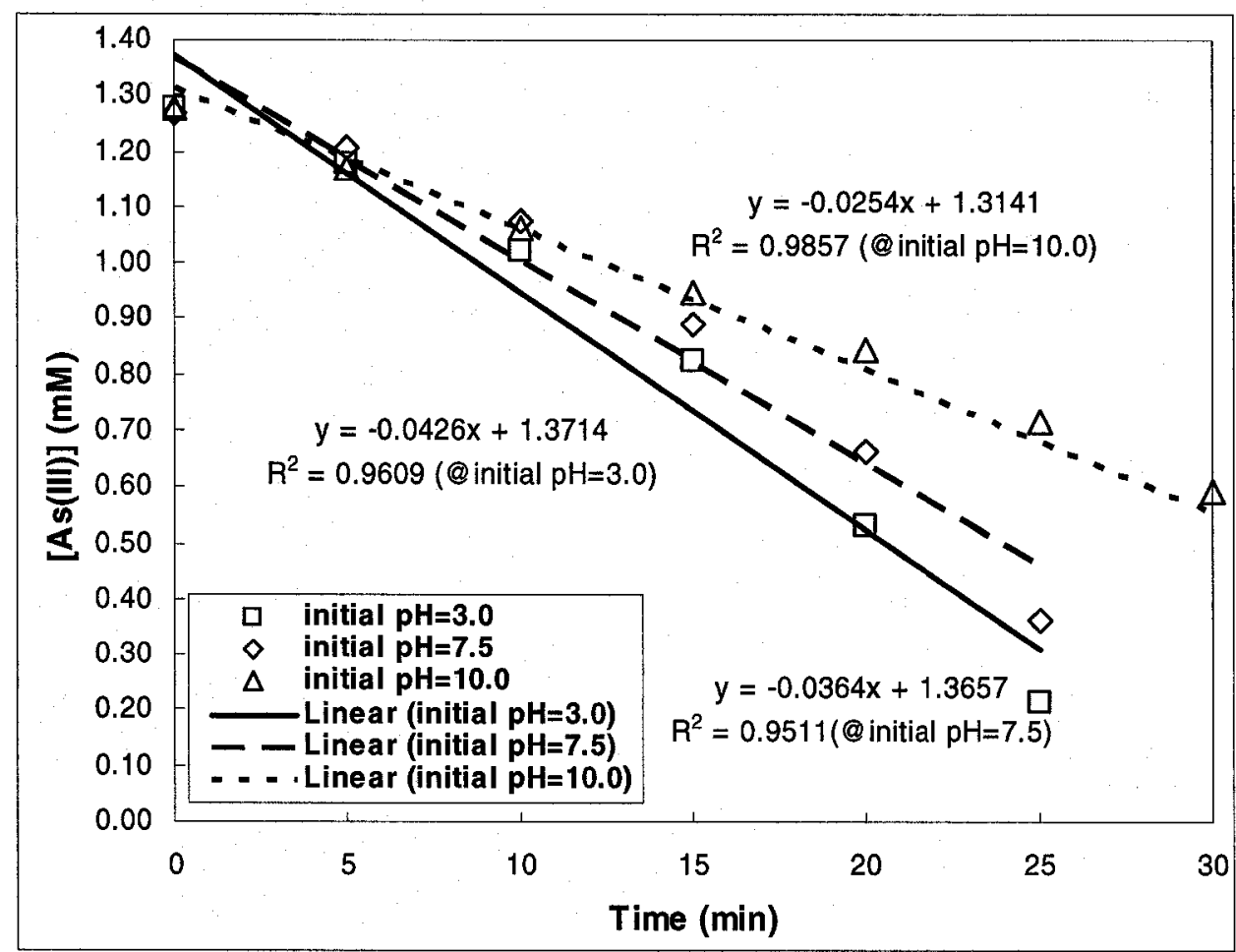

Figure 5.19 Evaluation of zero-order model with respect to the As(III) concentration ([DO $]_{0}=8.0 \mathrm{mg} / \mathrm{L}$ with air sparging)

From the fitted model equations shown in Figure 5.19, the zero-order rate constants are determined as $7.10 \times 10^{-7} \mathrm{M} \cdot \mathrm{s}^{-1}, 6.07 \times 10^{-7} \mathrm{M} \cdot \mathrm{s}^{-1}, 4.23 \times 10^{-7} \mathrm{M} \cdot \mathrm{s}^{-1}$ for the initial $\mathrm{pH}$ conditions of $3.0,7.5$ and 10.0 respectively.

\section{(2) Closed tank condition in batch reactor}

As stated in section 5.3.1.1, in the closed tank condition, there was no aeration of the solution during the course of the oxidation process and the DO is allowed to fall. Results in this case indicate that between the parameters $\mathrm{pH}$ initial and the $\mathrm{DO}$, the $\mathrm{pH}$ has a much less influence compared to the DO level, for the oxidation of As(III). Hence, the kinetic analyses were on the set of results obtained in the typical experiments with the initial $\mathrm{pH}$ of 10.0 and initial DO concentration range of $3.0 \sim 8.0 \mathrm{mg} / \mathrm{L}$. 
The reaction order with respect to the arsenic concentration was first evaluated by the standard methods of analysis. It was found that all the experimental data points in any particular experiment in this category could not satisfactorily be fitted by either zero-order or first-order model.

Further visual analysis of the results shown in Figure 5.8 indicates the possibility of a shift in the reaction mechanism itself beyond the point at which DO level reaches a very low concentration. In view of this possibility, the data was evaluated for the shifting order model. Based on the similarity of the experimental results with the aerated conditions and high As(III) concentrations, it was assumed that the reaction is zero-order initially and then shifts to the first-order for the latter part. However although the shifting order model gave a linear plot, the rate constant values backed out of the model were inconsistent. Hence, the shifting-order model was also rejected.

In view of the nature of the experimental data obtained, a further investigation was carried out by deliberately separating the original data into two stages at the points of A1, $\mathbf{A 2}$ and $\mathbf{A 3}$ on the time axis (i.e., at points of inflexion) in Figure 5.8. The two data sets were treated separately and evaluated following the standard methods. The results show that the data can be fitted to a zero-order in stage I and a first-order model in stage II. The rate constants determined by the linearized plots are shown in Table 5.3. 
Table 5.3 Rate constants from different rate models at different DO conditions (separation of oxidation process into two stages)

\begin{tabular}{|c|c|c|c|c|}
\hline \multirow{2}{*}{ Model } & \multirow{2}{*}{ Rate Equation } & \multicolumn{3}{|c|}{ Rate Constant } \\
\hline & & {$[D O]_{0}=8.0 \mathrm{mg} / \mathrm{L}$} & {$[D O]_{0}=6.0 \mathrm{mg} / \mathrm{L}$} & {$[D O]_{0}=3.0 \mathrm{mg} / \mathrm{L}$} \\
\hline \multicolumn{5}{|l|}{ Stage l: } \\
\hline Zero-order & $r=-k$ & $3.67 \times 10^{-7} \mathrm{M} \cdot \mathrm{s}^{-1}$ & $3.47 \times 10^{-7} \mathrm{M} \cdot \mathrm{s}^{-1}$ & $3.05 \times 10^{-7} \mathrm{M} \cdot \mathrm{s}^{-1}$ \\
\hline \multicolumn{5}{|l|}{ Stage II: } \\
\hline First-order & $r=-k[A s(I I I)]$ & $1.23 \times 10^{-4} \mathrm{~s}^{-1}$ & $5.17 \times 10^{-5} \mathrm{~s}^{-1}$ & $8.33 \times 10^{-6} \mathrm{~s}^{-1}$ \\
\hline
\end{tabular}

In stage I, both DO and As(III) were relatively high, which is similar to the air sparging (oxic) condition. The rate constants obtained from zero-order model at different DO conditions are comparable and consistent with the rate constant in the air sparging condition. Therefore, the experimental data can be best interpreted by zero-order.

The model of the first-stage was further investigated by the method of initial rates. As shown in Table 5.4, no significant variation of initial reaction rates was indicated with the change of initial As(III) concentration in the range of $0.267 \sim 1.335 \mathrm{mM}$. Hence the reaction order with respect to the arsenic concentration can be considered as zero-order, which is consistent with the conclusion above.

Table 5.4 Initial reaction rates at different initial As(III) concentration conditions ([DO $]_{0}=8.0 \mathrm{mg} / \mathrm{L}$ with tank closed, initial $\mathrm{pH}=10.0$ )

\begin{tabular}{cc}
\hline \hline Initial As(III) concentration & Initial Reaction rate (mM/min) \\
\hline \hline$[\mathrm{As}(\mathrm{III})]_{0}=0.267 \mathrm{mM}$ & $0.016 \pm 0.002$ \\
{$[\mathrm{As}(\mathrm{III})]_{0}=0.534 \mathrm{mM}$} & $0.019 \pm 0.002$ \\
{$[\mathrm{As}(\mathrm{III})]_{0}=0.801 \mathrm{mM}$} & $0.019 \pm 0.002$ \\
{$[\mathrm{As}(\mathrm{III})]_{0}=1.068 \mathrm{mM}$} & $0.021 \pm 0.001$ \\
{$[\mathrm{As}(\mathrm{III})]_{0}=1.335 \mathrm{mM}$} & $0.022 \pm 0.002$ \\
\hline
\end{tabular}


Summarizing the data analysis for the closed tank condition above, we suggest the interpretation of the experimental results after separating the data into two stages. In the higher DO condition in stage I, the reaction is zero-order; in the anoxic (or near-anoxic) condition in stage II, the reaction is first-order. From industrial application point of view, the results clearly indicate that for more effective conversion of $\mathrm{As}(\mathrm{III})$ to $\mathrm{As}(\mathrm{V})$, anoxic condition should be avoided, and aeration and maintenance of DO at a high level results in considerable increase in the rate of oxidation.. It is quite conceivable that in view of the multiple valencies and speciation of arsenic and its existence in various forms and their relative distribution in the $\mathrm{pH}$ range of the experiments, the actual reaction scheme could be far more complex.

\section{(3) Recirculation reactor}

The operating condition in the recirculation reactor was similar to that in the batch reactor with air sparging. The reaction order evaluated by standard methods indicated that the reaction is zero-order with respect to the arsenic concentration. The rate constants obtained at different initial $\mathrm{pH}$ in the recirculation reactor are listed in Table 5.5 and compared with the air-sparged batch reactor results. As can be seen, the rate constants in the recirculation reactor are somewhat lower than those in the batch reactor.

The arsenic oxidation efficiencies in both the air-sparged batch reactor and the recirculation reactor are compared based on the UV dose per unit of oxidized As(III). The UV doses in batch reactor and recirculation reactor are determined by the equation below: 


$$
U V \text { Dose }=\frac{E_{L}}{V} \times t
$$

in which, $E_{L}$ is the energy output of lamp $(1 \mathrm{~kW}) ; t$ is the irradiation time (hour); $V$ is the volume of the solution $\left(0.03 \mathrm{~m}^{3}\right.$ and $0.06 \mathrm{~m}^{3}$ in batch and recirculation reactors respectively). The UV doses for 1 hour of reaction time in the batch reactor and the recirculation reactor are $33.33 \mathrm{kWh} \cdot \mathrm{m}^{-3}$ and $16.67 \mathrm{kWh} \cdot \mathrm{m}^{-3}$ respectively. The arsenic oxidation efficiency is calculated based on the UV dose required for the oxidation of 1 $\mathrm{mM}$ As(III), as shown in equation (5-3):

$$
U V \text { dose per } 1 m M A s(I I) \text { oxidized }=\frac{\frac{E_{L}}{V} \times t}{[1 m M A s(I I) \text { oxidized }]}
$$

in which, $t$ is the time that the oxidation of $1 \mathrm{mM} \mathrm{As}(\mathrm{III})$ is achieved. The results are shown in Table 5.5 . 
Table 5.5 Summary of the performance comparison between the Batch Reactor and the Recirculation Reactor in Direct Photolysis process

\begin{tabular}{|c|c|c|c|c|}
\hline Reactor & $\begin{array}{l}\text { Type and Operating } \\
\text { Conditions }\end{array}$ & $\begin{array}{c}\text { Rate } \\
\text { Constant } \\
\left(\mathrm{M} \cdot \mathrm{s}^{-1}\right)\end{array}$ & $\begin{array}{c}\text { Reaction time } \\
\text { per } 1 \text { mM As(III) } \\
\text { Oxidized } \\
\text { (Hours/mM) }\end{array}$ & $\begin{array}{c}\text { UV Dose per } 1 \\
\text { mM As(III) } \\
\text { Oxidized } \\
\left(\mathrm{kWh} \cdot \mathrm{m}^{-3} / \mathrm{mM}\right)\end{array}$ \\
\hline \multirow{3}{*}{ Batch reactor } & $\begin{array}{c}\text { Initial pH=3.0; } \\
{[\mathrm{As}(\mathrm{III})]_{0}=1.335 \mathrm{mM}}\end{array}$ & $7.10 \times 10^{-7}$ & 0.42 & 14.00 \\
\hline & $\begin{array}{c}\text { Initial } \mathrm{pH}=7.5 ; \\
{[\mathrm{As}(\mathrm{III})]_{0}=1.335 \mathrm{mM}}\end{array}$ & $6.07 \times 10^{-7}$ & 0.44 & 14.67 \\
\hline & $\begin{array}{c}\text { Initial } \mathrm{pH}=10.0 \\
{[\mathrm{As}(\mathrm{III})]_{0}=1.335 \mathrm{mM}}\end{array}$ & $4.23 \times 10^{-7}$ & 0.65 & 21.66 \\
\hline \multirow{3}{*}{$\begin{array}{l}\text { Recirculation } \\
\text { reactor }\end{array}$} & $\begin{array}{c}\text { Initial } \mathrm{pH}=3.0 ; 25 \mathrm{GPM} \\
{[\mathrm{As}(\mathrm{III})]_{0}=1.335 \mathrm{mM}}\end{array}$ & $3.05 \times 10^{-7}$ & 0.94 & 15.67 \\
\hline & $\begin{array}{c}\text { Initial } \mathrm{pH}=7.5 ; 25 \mathrm{GPM} ; \\
{[\mathrm{As}(\mathrm{III})]_{0}=1.335 \mathrm{mM}}\end{array}$ & $2.55 \times 10^{-7}$ & 1.06 & 17.67 \\
\hline & $\begin{array}{c}\text { Initial } \mathrm{pH}=10.0 ; 25 \mathrm{GPM} ; \\
{[\mathrm{As}(\mathrm{III})]_{0}=1.335 \mathrm{mM}}\end{array}$ & $1.42 \times 10^{-7}$ & 1.96 & 32.67 \\
\hline
\end{tabular}

It can be seen in Table 5.5, the required UV dose in the batch reactor is lower than that of the recirculation reactor, which indicates the higher electrical efficiency in the batch reactor for identical conversion. This result, namely, the higher efficiency of the batch reactor as compared to the recirculation reactor is somewhat surprising but can be explained by the nature of the Direct Photolysis. It is conceivable that the retention of the activated species within the UV irradiation zone results in a higher conversion, whereas in the recirculation reactor this is not the case. The rapid flow rate could result in the active species being removed from the irradiation zone prematurely.

\subsubsection{Reaction Mechanism}

Direct photooxidation of As(III) by low-pressure UV lamp at $254 \mathrm{~nm}$ was indicated 
to be ineffective in the previous studies (Ganesh and Clifford, 2001; Lee and Choi, 2002). However, in this study, a medium-pressure UV lamp was used and the direct photooxidation of As(III) was achieved with considerable oxidation efficiency. This could be explained by the higher and broader spectral energy distribution of the medium-pressure lamp. As indicated in section 5.1, at a wavelength below $220 \mathrm{~nm}$, the UV absorption of As(III) is drastically increased. The As(III) molecules can be excited by absorbing UV light and these excited species could stimulate the conversion of As(III) to $\mathrm{As}(\mathrm{V})$. The decrease of DO concentration was observed in the course of oxidation process, which indicates that oxygen is a reactant in the process of photooxidation of As(III). This work is the first detailed study on the Direct Photolysis of As(III) and hence the results of this analysis could not be compared with any prior work.

As stated, the absorption of photons by the As(III) in the solution could result in the generation of an activated species denoted as As(III)* and the excited arsenic species could undergo oxidation in the presence of DO by the following steps:

$$
\mathrm{As}(\mathrm{III})^{*} \rightarrow \mathrm{As}(\mathrm{IV}) \rightarrow \mathrm{As}(\mathrm{V})
$$

$\mathrm{O}_{2}$ could react with $\mathrm{As}(\mathrm{IV})$ and produce $\mathrm{As}(\mathrm{V})$ and the intermediate $\mathrm{HO}_{2} \cdot$ (Kläning, 1989). The electron-transfer between two $\mathrm{HO}_{2} \cdot$ molecules can generate one hydrogen peroxide and release one $\mathrm{O}_{2}$ (Behar et al., 1970). The hydrogen peroxide can further form OH· under UV irradiation (Luñák and Sedlák, 1992). OH· is a very strong oxidant and can directly react with As(III) and generate As(IV) (Kläning, 1989). Based on such evidence, a reaction scheme can be postulated as shown below consisting of reactions 
(R5-2) to (R5-7):

$$
\begin{aligned}
& A s(I I I) \stackrel{h v\left(\Phi_{1}\right)}{\longrightarrow} A s(I I I) * \\
& A s(I I I)^{*}+A s(I I I) \stackrel{k_{1}}{\longrightarrow} A s(I V)+A s(V) \\
& A s(I V)+\mathrm{O}_{2} \stackrel{k_{2}}{\longrightarrow} A s(V)+\mathrm{HO}_{2} . \\
& 2 \mathrm{HO}_{2} \stackrel{k_{3}}{\longrightarrow} \mathrm{H}_{2} \mathrm{O}_{2}+\mathrm{O}_{2} \\
& \mathrm{H}_{2} \mathrm{O}_{2} \stackrel{h v\left(\Phi_{2}\right)}{\longrightarrow} 2 \mathrm{OH} \\
& A s(I I I)+O H \cdot \stackrel{k_{4}}{\longrightarrow} A s(I V)
\end{aligned}
$$

The rate equation of each component can be expressed by the following equations:

$$
\begin{aligned}
& -\frac{d\left[A s(I I I)^{*}\right]}{d t}=k_{1}\left[A s(I I I)^{*}\right][A s(I I I)]-\Phi_{1} \alpha_{1} I_{0, \leq 220 n m}[A s(I I I)] \\
& -\frac{d[A s(I I I)]}{d t}=\Phi_{1} \alpha_{1} I_{0, \leq 220 n m}[A s(I I I)]+k_{1}\left[A s(I I I)^{*}\right][A s(I I I)]+k_{4}[A s(I I I)][O H \cdot] \\
& -\frac{d[A s(I V)]}{d t}=k_{2}[A s(I V)]\left[O_{2}\right]-k_{1}\left[A s(I I I)^{*}\right][A s(I I I)]-k_{4}[A s(I I I)][O H \cdot] \\
& -\frac{d[A s(V)]}{d t}=-k_{1}\left[A s(I I I)^{*}\right][A s(I I I)]-k_{2}[A s(I V)]\left[O_{2}\right] \\
& -\frac{d\left[O_{2}\right]}{d t}=k_{2}[A s(I V)]\left[O_{2}\right]-\frac{k_{3}}{2}\left[H O_{2} \cdot\right]^{2} \\
& -\frac{d\left[H O_{2} \cdot\right]}{d t}=k_{3}\left[H O_{2} \cdot\right]^{2}-k_{2}[A s(I V)]\left[O_{2}\right] \\
& -\frac{d\left[H_{2} O_{2}\right]}{d t}=\Phi_{2} \alpha_{2} I_{0,200 \sim 300 n m}\left[H_{2} O_{2}\right]-\frac{k_{3}}{2}\left[H_{2} \cdot\right]^{2} \\
& -\frac{d[O H \cdot]}{d t}=k_{4}[A s(I I I)][O H \cdot]-2 \Phi_{2} \alpha_{2} I_{0,200 \sim 300 n m}\left[H_{2} O_{2}\right]
\end{aligned}
$$

in which, $\Phi_{1}\left(\mathrm{~mol} \cdot\right.$ Einstein $\left.^{-1}\right)$ and $\Phi_{2}\left(\mathrm{~mol} \cdot\right.$ Einstein $\left.^{-1}\right)$ are the quantum yields of absorbing reactants $\mathrm{As}(\mathrm{III})$ and $\mathrm{H}_{2} \mathrm{O}_{2}$ respectively. Both $\Phi_{1}$ and $\Phi_{2}$ are constant; $\alpha_{1}$ and $\alpha_{2}\left(\mathrm{~cm}^{2} \cdot \mathrm{mol}^{-1}\right)$ are the molar absorption coefficients of absorbing reactant As(III) 
and $\mathrm{H}_{2} \mathrm{O}_{2}$ respectively. Both $\alpha_{1}$ and $\alpha_{2}$ are constant; $I_{0, \leq 220 n m}$ and $I_{0,200 \sim 300 n m}$ are the incident light intensities. In this study, the light source from UV lamp remained the same for all the experiments. Therefore, $I_{0, \leq 220 \mathrm{~nm}}$ and $I_{0,200 \sim 300 \mathrm{~nm}}$ are constant.

The lifetimes of the intermediate species $\mathrm{As}(\mathrm{III})^{*}, \mathrm{As}(\mathrm{IV}), \mathrm{HO}_{2} \cdot$ and $\mathrm{OH} \cdot$ are very short. The observed hydrogen peroxide concentration was barely detectable. Based on the steady-state approximation hypothesis, we can assume that the concentrations of those reactants are low and constant. Therefore, we can write:

$$
\begin{aligned}
& -\frac{d\left[A s(I I I)^{*}\right]}{d t}=k_{1}\left[A s(I I I)^{*}\right][A s(I I I)]-\Phi_{1} \alpha_{1} I_{\leq 220 n m}[A s(I I I)]=0 \\
& -\frac{d[A s(I V)]}{d t}=k_{2}[A s(I V)]\left[O_{2}\right]-k_{1}\left[A s(I I I)^{*}\right][A s(I I I)]-k_{4}[A s(I I I)][O H \cdot]=0 \\
& -\frac{d\left[H O_{2} \cdot\right]}{d t}=k_{3}\left[H O_{2} \cdot\right]^{2}-k_{2}[A s(I V)]\left[O_{2}\right]=0 \\
& -\frac{d[O H \cdot]}{d t}=k_{4}[A s(I I I)][O H \cdot]-2 \Phi_{2} \alpha_{2} I_{200 \sim 300 n m}\left[H_{2} O_{2}\right]=0 \\
& -\frac{d\left[H_{2} O_{2}\right]}{d t}=\Phi_{2} \alpha_{2} I_{200 \sim 300 n m}\left[H_{2} O_{2}\right]-\frac{k_{3}}{2}\left[H O_{2} \cdot\right]^{2}=0
\end{aligned}
$$

By substituting the equations above into (5-5), (5-7), (5-8), we get:

$$
-\frac{d[A s(I I I)]}{d t}=-2 \frac{d\left[O_{2}\right]}{d t}=\frac{d[A s(V)]}{d t}=2 \Phi_{1} \alpha_{1} I_{<220 n m}[A s(I I I)]+2 \Phi_{2} \alpha_{2} I_{200 \sim 300 n m}\left[H_{2} O_{2}\right]
$$

The overall reaction can be obtained by combining reactions (R5-2) to (R5-7) based on the steady-state hypothesis:

$$
2 A s(I I I)+O_{2} \stackrel{h v}{\longrightarrow} 2 A s(V)
$$

Taking account of the arsenic forms in the solution at various $\mathrm{pH}$ conditions, the reactions of Direct Photolysis are shown in Table 5.6. The total quantity of As(V) species 
is divided into the fractions denoted as $a$ and $b$ for the two forms of $A s(V)$ in the solution as dictated by the Eh and $\mathrm{pH}$ conditions and consequently $a+b=1$. As can be seen from the overall reactions (R5-11) and (R5-14), the stoichiometric ratio of $\mathrm{As}(\mathrm{III})$ to $\mathrm{O}_{2}$ is $2: 1$, which is consistent with the experimental results discussed in section 5.3.1.1; the stoichiometric ratio of $\mathrm{H}^{+}$to $\mathrm{As}(\mathrm{V})$ can be obtained as $\left(\frac{b}{a+b}\right) \leq 1$, which is also consistent with the experimental results in section 5.3.1.3.

Table 5.6 Proposed reactions of As(III) oxidation in Direct Photolysis process

\begin{tabular}{cl}
\hline \hline No. & Reactions \\
\hline $\begin{array}{c}\text { R5-9 } \\
\text { R5-10 }\end{array}$ & $\frac{\text { Initial pH=3.0 7.5: }}{2 \mathrm{H}_{3} A s^{(I I)} \mathrm{O}_{3}+\mathrm{O}_{2} \stackrel{h v}{\longrightarrow} 2 \mathrm{H}_{3} A s^{(V)} \mathrm{O}_{4}}$ \\
$2 \mathrm{H}_{2} A s^{(I I I)} \mathrm{O}_{3}+\mathrm{O}_{2} \stackrel{h v}{\longrightarrow} 2 \mathrm{H}_{2} A s^{(V)} \mathrm{O}_{4}^{-}+2 H^{+}$ \\
\hline $\begin{array}{c}\text { Overall Reaction } \\
\text { (R5-11) }\end{array}$ & $\mathrm{H}_{2} A s^{(I I)} \mathrm{O}_{3}+\frac{1}{2} \mathrm{O}_{2} \stackrel{h v}{\longrightarrow} a \mathrm{H}_{3} A s^{(V)} \mathrm{O}_{4}+b \mathrm{H}_{2} A s^{(V)} \mathrm{O}_{4}^{-}+b H^{+}$ \\
\hline R5-12 & $\underline{\text { Initial pH=10.0: }}$ \\
R5-13 & $2 \mathrm{H}_{2} A s^{(I I I)} \mathrm{O}_{3}^{-}+\mathrm{O}_{2} \stackrel{h v}{\longrightarrow} 2 \mathrm{H}_{2} A s^{(V)} \mathrm{O}_{4}^{-}$ \\
\hline $\begin{array}{c}\text { Overall Reaction } \\
\text { (R5-14) }\end{array}$ & $2 \mathrm{H}_{2} A s^{(I I I)} \mathrm{O}_{3}^{-}+\mathrm{O}_{2} \stackrel{h v}{\longrightarrow} 2 \mathrm{HAs}^{(V)} \mathrm{O}_{4}^{2-}+H^{+}$ \\
\hline \hline
\end{tabular}

The effect of $\mathrm{pH}$ on the As(III) oxidation process probably can be explained by the reaction (R5-5) in which the self-decomposition of $\mathrm{HO}_{2} \cdot$ is $\mathrm{pH}$-dependent (Behar et al., 1970).

\subsection{Advanced Oxidation Process with $\mathrm{UV} / \mathrm{H}_{2} \mathrm{O}_{2}$}

Many of the operating parameters for the AOP, where possible, matched the 
parameters employed in Direct Photolysis. The experimental results obtained in the AOP study are discussed below. Where relevant, comparisons are made between the AOP results and Direct Photolysis results discussed earlier.

\subsubsection{Dark Reaction Experiment}

Pervious work on chemical oxidation process (i.e. dark reaction, no UV) reported in literature indicates that $\mathrm{As}(\mathrm{III})$ can be partially oxidized by $\mathrm{H}_{2} \mathrm{O}_{2}$ and this process is significantly affected by the $\mathrm{pH}$. With the increase of $\mathrm{pH}$, higher oxidation rate and percentage conversion can be obtained.

Prior to carrying out the main $\mathrm{UV} / \mathrm{H}_{2} \mathrm{O}_{2}$ study, a preliminary investigation of $\mathrm{As}$ (III) oxidation by $\mathrm{H}_{2} \mathrm{O}_{2}$ under dark condition was carried out. The percentage conversions after 30 minutes of complete mixing are shown in Table 5.7. The results indicate that the oxidation did proceed under dark conditions and the oxidation efficiency was much lower at low $\mathrm{pH}$ conditions than at high $\mathrm{pH}$ conditions. As can be seen in the table, at the conditions of initial $\mathrm{pH} 10.0$ and 7.5, reasonable conversion efficiencies were obtained but the level of oxidation efficiency did not significantly improve with the increase in the $\left[\mathrm{H}_{2} \mathrm{O}_{2}\right]_{0} /[\mathrm{As}(\mathrm{III})]_{0}$ ratio. At the initial $\mathrm{pH} 3.0$ condition, although the percentage conversion increased by four times with the increase of $\left[\mathrm{H}_{2} \mathrm{O}_{2}\right]_{0} /[\mathrm{As}(\mathrm{III})]_{0}$ ratio from 1 to 5 , the overall conversion remained below $13 \%$. At the initial $\mathrm{pH}$ condition of 10.0 and at the ratio of 5 , the percentage conversion could go up to $72 \%$. 
Table 5.7 Maximum percentage conversion of $\mathrm{As}(\mathrm{III})$ by $\mathrm{H}_{2} \mathrm{O}_{2}$ under dark reaction

\begin{tabular}{cccc}
\hline \hline $\left.\mathrm{H}_{2} \mathrm{O}_{2}\right]_{0}:[\mathrm{As}(\mathrm{III})]_{0}$ & \multicolumn{3}{c}{ Percentage Conversion (\%) } \\
\cline { 2 - 4 } Ratio & Initial $\mathbf{p H}=\mathbf{1 0 . 0}$ & Initial $\mathbf{~ p H = 7 . 5}$ & Initial $\mathbf{~ p H = 3 . 0}$ \\
\hline $1: 1$ & 63.56 & 23.68 & 2.84 \\
$2: 1$ & 70.89 & 29.38 & 5.84 \\
$4: 1$ & 71.64 & 32.35 & 10.76 \\
$5: 1$ & 71.69 & 33.70 & 12.76 \\
\hline \hline
\end{tabular}

Under the UV irradiation, $\mathrm{H}_{2} \mathrm{O}_{2}$ could rapidly decompose to hydroxyl radical $(\mathrm{OH} \cdot)$, which is a very strong oxidant. Previous research has indicated that high As(III) oxidation efficiency is obtained with $\mathrm{H}_{2} \mathrm{O}_{2}$ in the presence of UV (Yang et al., 1999). In this study, the performance of $\mathrm{UV} / \mathrm{H}_{2} \mathrm{O}_{2}$ process for the oxidation of $\mathrm{As}(\mathrm{III})$ was extensively studied and the effect of several parameters, such as $\left[\mathrm{H}_{2} \mathrm{O}_{2}\right]_{0}:[\mathrm{As}(\mathrm{III})]_{0}$ ratio, DO and $\mathrm{pH}$ were evaluated in detail.

\subsubsection{AOP in the Batch Reactor}

\subsubsection{Effect of $\left[\mathrm{H}_{2} \mathrm{O}_{2}\right]_{0}:[\mathrm{As}(\mathrm{III})]_{0}$ Ratio}

The effect of $\left[\mathrm{H}_{2} \mathrm{O}_{2}\right]_{0}:[\mathrm{As}(\mathrm{III})]_{0}$ ratio was studied with different initial $\mathrm{H}_{2} \mathrm{O}_{2}$ concentrations while other conditions remained the same. The parameters chosen were: $[\operatorname{As}(\mathrm{III})]_{0}=1.335 \mathrm{mM}(100 \mathrm{mg} / \mathrm{L}) ;[\mathrm{DO}]_{0}=0.25 \mathrm{mM}(8.0 \mathrm{mg} / \mathrm{L})$ with the closed tank; initial $\mathrm{pH}=3.0$.

Five $\left[\mathrm{H}_{2} \mathrm{O}_{2}\right]_{0}:[\mathrm{As}(\mathrm{III})]_{0}$ ratios were compared: 1) $1: 4$; 2) $1: 3$; 3) $1: 2$; 4) $1: 1$; 5) $2: 1$. The experimental data of $\mathrm{As}(\mathrm{III}), \mathrm{As}(\mathrm{V}), \mathrm{DO}, \mathrm{pH}$ and the measured Eh-pH diagram are shown from Figure 5.20 to Figure 5.24. 


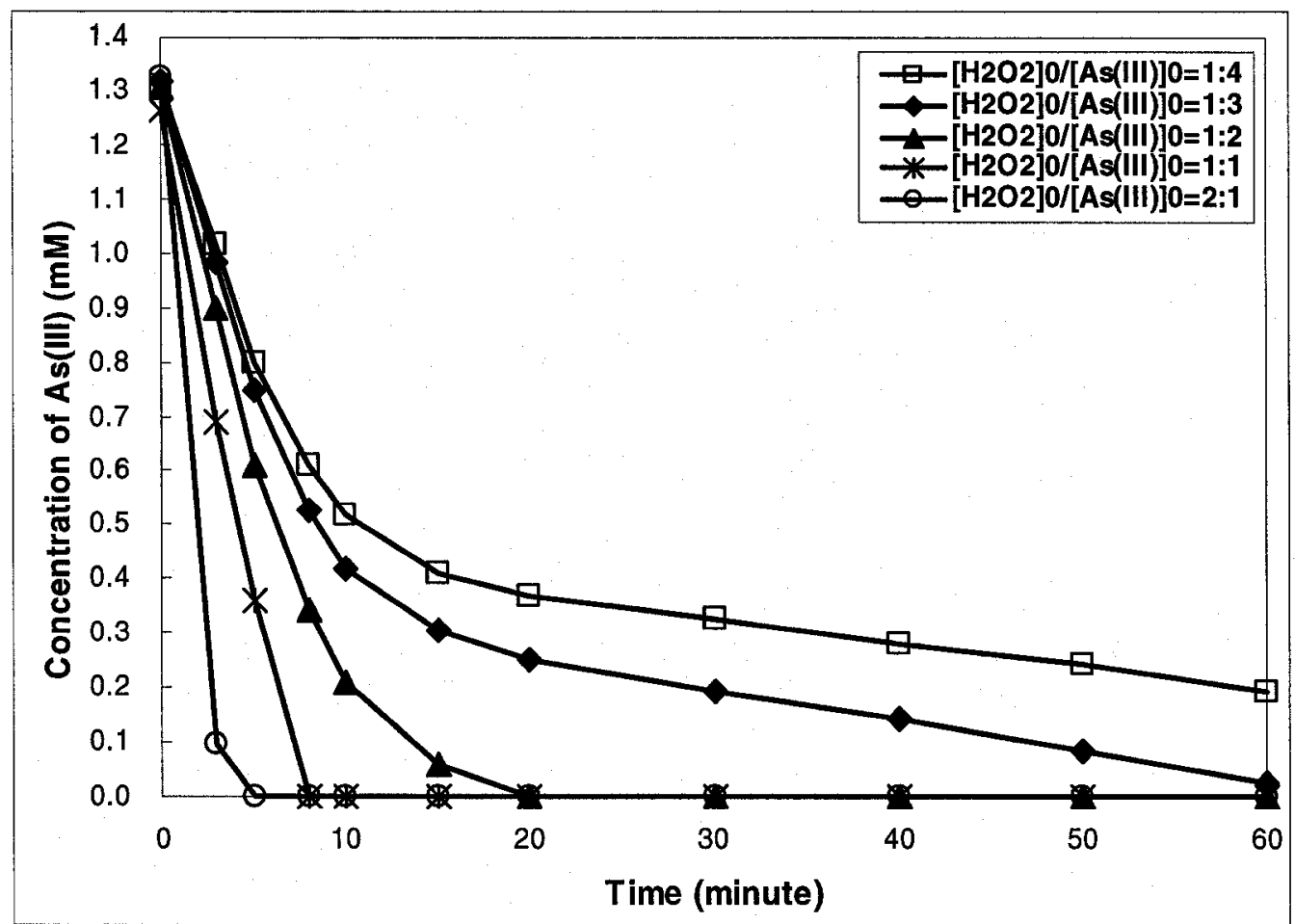

Figure 5.20 As(III) concentration as a function of irradiation time in AOP under different $\left[\mathrm{H}_{2} \mathrm{O}_{2}\right]_{0}:[\mathrm{As}(\mathrm{III})]_{0}$ ratios (initial $\mathrm{pH}=3.0 ;[\mathrm{As}(\mathrm{III})]_{0}=1.335 \mathrm{mM} ;[\mathrm{DO}]_{0}=8.0 \mathrm{mg} / \mathrm{L}$ with the closed tank)

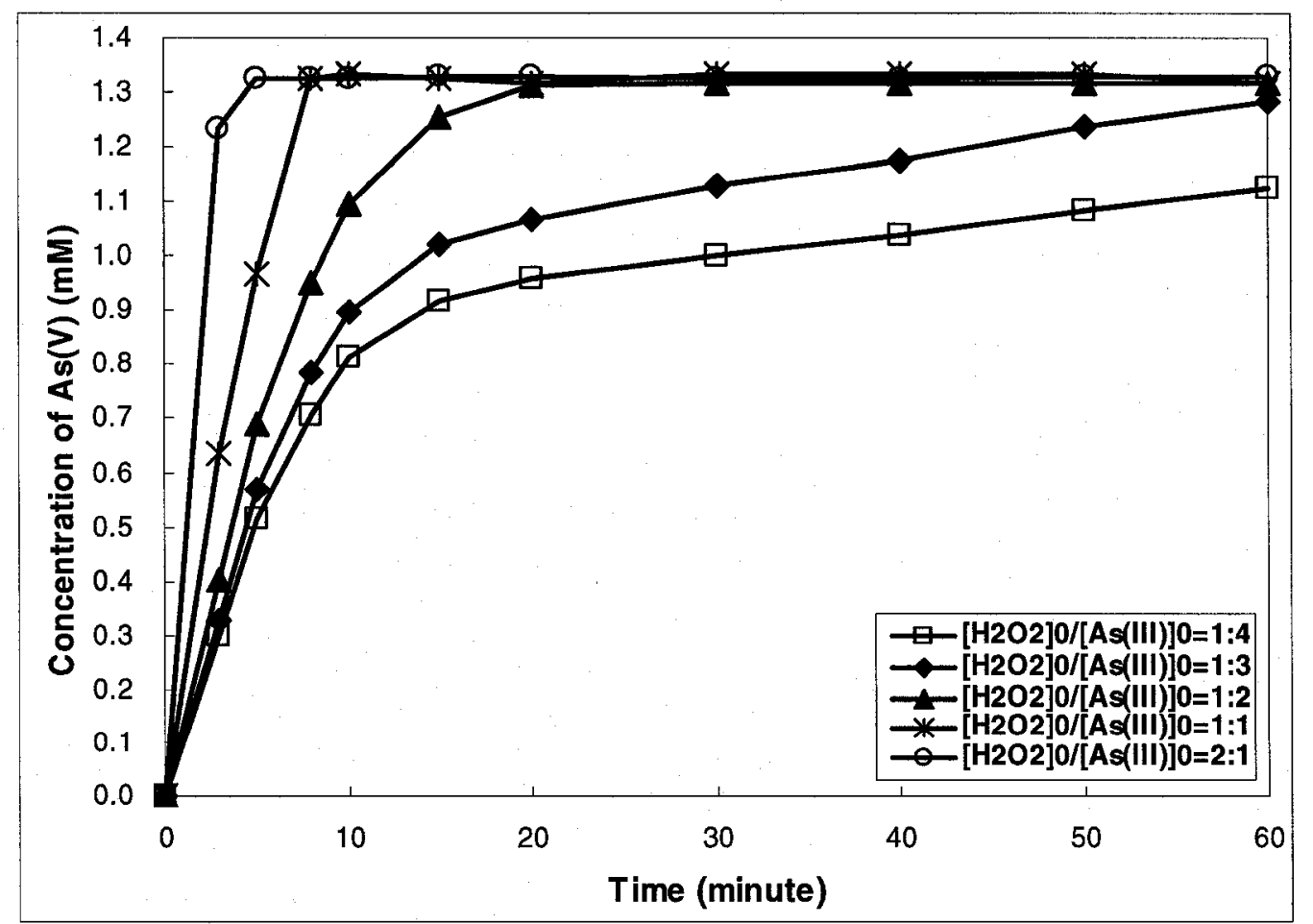

Figure 5.21 $\mathrm{As}(\mathrm{V})$ concentration as a function of irradiation time in AOP under different $\left[\mathrm{H}_{2} \mathrm{O}_{2}\right]_{0}:[\mathrm{As}(\mathrm{III})]_{0}$ ratios (initial $\mathrm{pH}=3.0 ;[\mathrm{As}(\mathrm{III})]_{0}=1.335 \mathrm{mM} ;[\mathrm{DO}]_{0}=8.0 \mathrm{mg} / \mathrm{L}$ with the closed tank) 


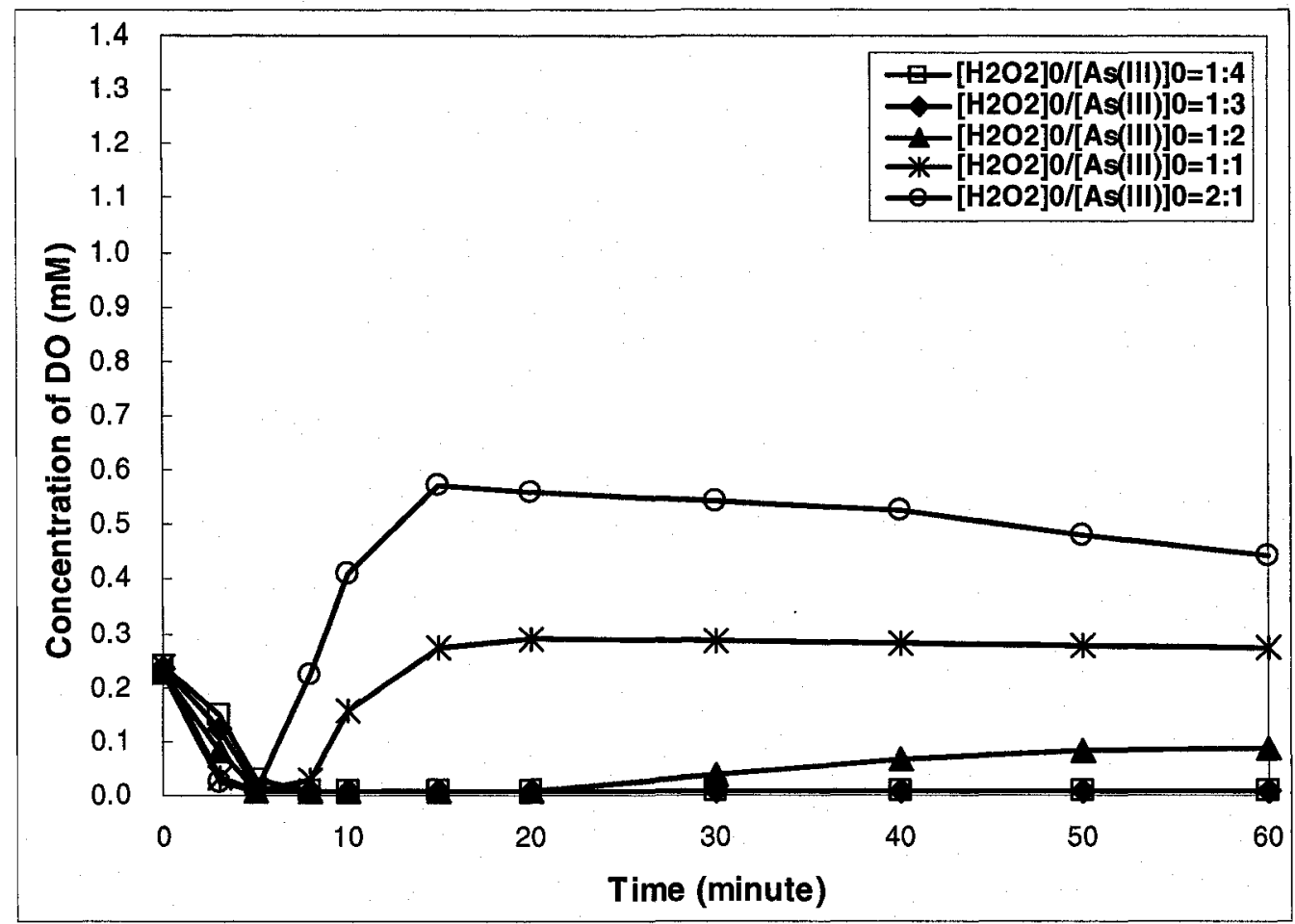

Figure 5.22 DO concentration as a function of irradiation time in AOP under different $\left[\mathrm{H}_{2} \mathrm{O}_{2}\right]_{0}:[\mathrm{As}(\mathrm{III})]_{0}$ ratios (initial $\mathrm{pH}=3.0 ;[\mathrm{As}(\mathrm{III})]_{0}=1.335 \mathrm{mM}$; $[\mathrm{DO}]_{0}=8.0 \mathrm{mg} / \mathrm{L}$ with the closed tank)

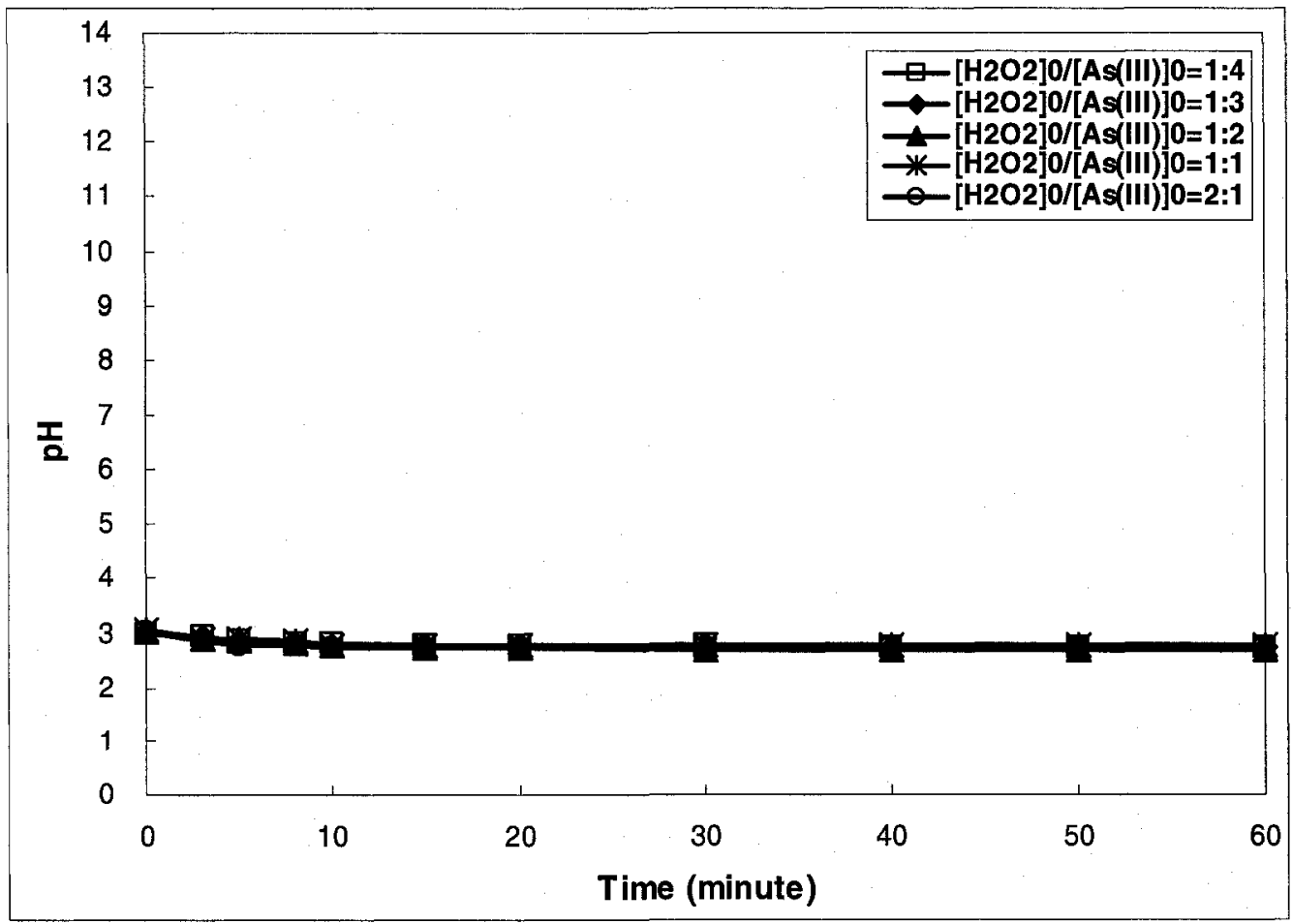

Figure $5.23 \mathrm{pH}$ as a function of irradiation time in AOP under different $\left[\mathrm{H}_{2} \mathrm{O}_{2}\right]_{0}:[\mathrm{As}(\mathrm{III})]_{0}$ ratios (initial $\mathrm{pH}=3.0 ;[\mathrm{As}(\mathrm{III})]_{0}=1.335 \mathrm{mM} ;[\mathrm{DO}]_{0}=8.0 \mathrm{mg} / \mathrm{L}$ with the closed tank) 


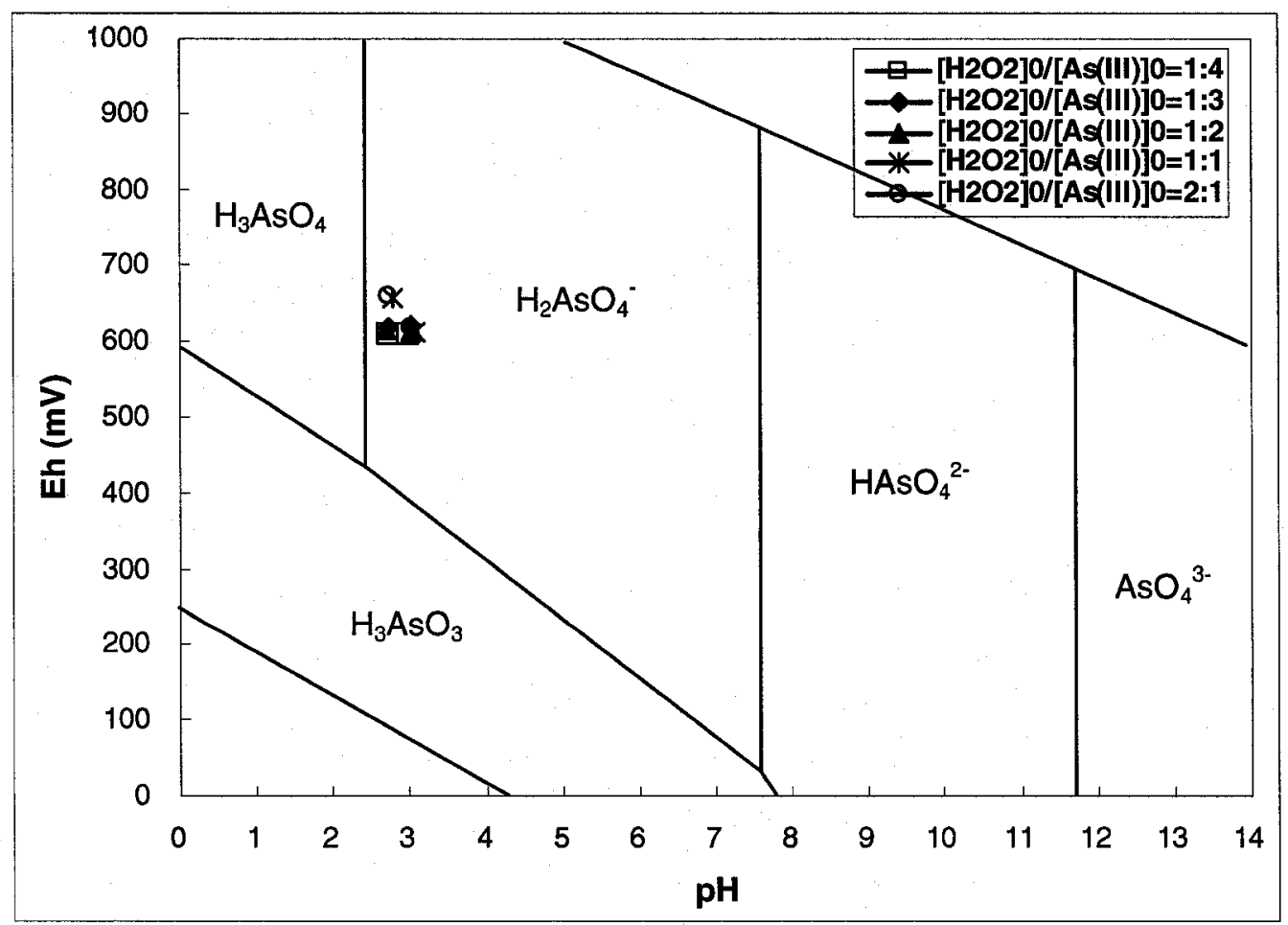

Figure 5.24 Measured Eh-pH diagram in AOP under different $\left[\mathrm{H}_{2} \mathrm{O}_{2}\right]_{0}:[\mathrm{As}(\mathrm{III})]_{0}$ ratios (initial pH=3.0; $[\mathrm{As}(\mathrm{III})]_{0}=1.335 \mathrm{mM} ;[\mathrm{DO}]_{0}=8.0 \mathrm{mg} / \mathrm{L}$ with the closed tank)

The results indicated that there is a very significant improvement of As(III) oxidation efficiency in the $\mathrm{UV} / \mathrm{H}_{2} \mathrm{O}_{2}$ process compared to the dark condition. Figure 5.20 shows the significant effect of $\left[\mathrm{H}_{2} \mathrm{O}_{2}\right]_{0}:[\mathrm{As}(\mathrm{III})]_{0}$ ratio on the $\mathrm{As}(\mathrm{III})$ oxidation efficiency. With the increase of $\left[\mathrm{H}_{2} \mathrm{O}_{2}\right]_{0}:[\mathrm{As}(\mathrm{III})]_{0}$ ratio, the oxidation of As(III) is significantly improved. For example, for a ratio of $\left[\mathrm{H}_{2} \mathrm{O}_{2}\right]_{0} /[\mathrm{As}(\mathrm{III})]_{0} \geq 0.5$ the oxidation process can be completed within 20 minutes. At the $\left[\mathrm{H}_{2} \mathrm{O}_{2}\right]_{0} /[\mathrm{As}(\mathrm{III})]_{0}$ ratio of 0.25 , As(III) can only be partially oxidized. The results obtained in this study on the influence of the ratio of peroxide to arsenic are generally similar to those obtained in the study by Yang et al. (1999). However in the latter study, for identical ratios, the oxidation efficiency was even higher, possibly due to the differences in the experimental conditions such as the initial As(III) concentration, the $\mathrm{pH}$ and more importantly the UV dose. 
As in the case of Direct Photolysis, As(V) was found to be the only final product in the $\mathrm{As}$ (III) oxidation process. The decrease in DO concentration and $\mathrm{pH}$ were also similar to those in the Direct Photolysis process. After As(III) has been completely oxidized, as can be seen in Figure 5.22, DO recovery takes place. The increased DO concentration can be attributed to the decomposition of the excess $\mathrm{H}_{2} \mathrm{O}_{2}$. The maximum recovered $\mathrm{DO}$ concentration was also influenced by the $\left[\mathrm{H}_{2} \mathrm{O}_{2}\right]_{0} / \mathrm{As}[(\mathrm{III})]_{0}$ ratio.

\subsubsection{Influence of Dissolved Oxygen}

The effect of DO was studied by irradiating the feed solution with different DO levels while other conditions remained the same. The parameters chosen were: $[\mathrm{As}(\mathrm{III})]_{0}$ $=1.335 \mathrm{mM}(100 \mathrm{mg} / \mathrm{L})$; initial $\mathrm{pH}=3.0$. The $\left[\mathrm{H}_{2} \mathrm{O}_{2}\right]_{0}:[\mathrm{As}(\mathrm{III})]_{0}$ ratios at three levels were chosen:1) 1:1, 2) 1:2; 3) 1:4. Three DO conditions were compared: 1) [DO $]_{0} \leq 1.0 \mathrm{mg} / \mathrm{L}$ with the closed tank; 2) $[\mathrm{DO}]_{0}=8.0 \mathrm{mg} / \mathrm{L}$ with the closed tank; 2) $[\mathrm{DO}]_{0}=8.0 \mathrm{mg} / \mathrm{L}$ with air sparging. The experimental data of $\mathrm{As}(\mathrm{III})$ and DO under different DO conditions at different $\left[\mathrm{H}_{2} \mathrm{O}_{2}\right]_{0}:[\mathrm{As}(\mathrm{III})]_{0}$ ratios are shown in Figure 5.25 to Figure 5.27. 

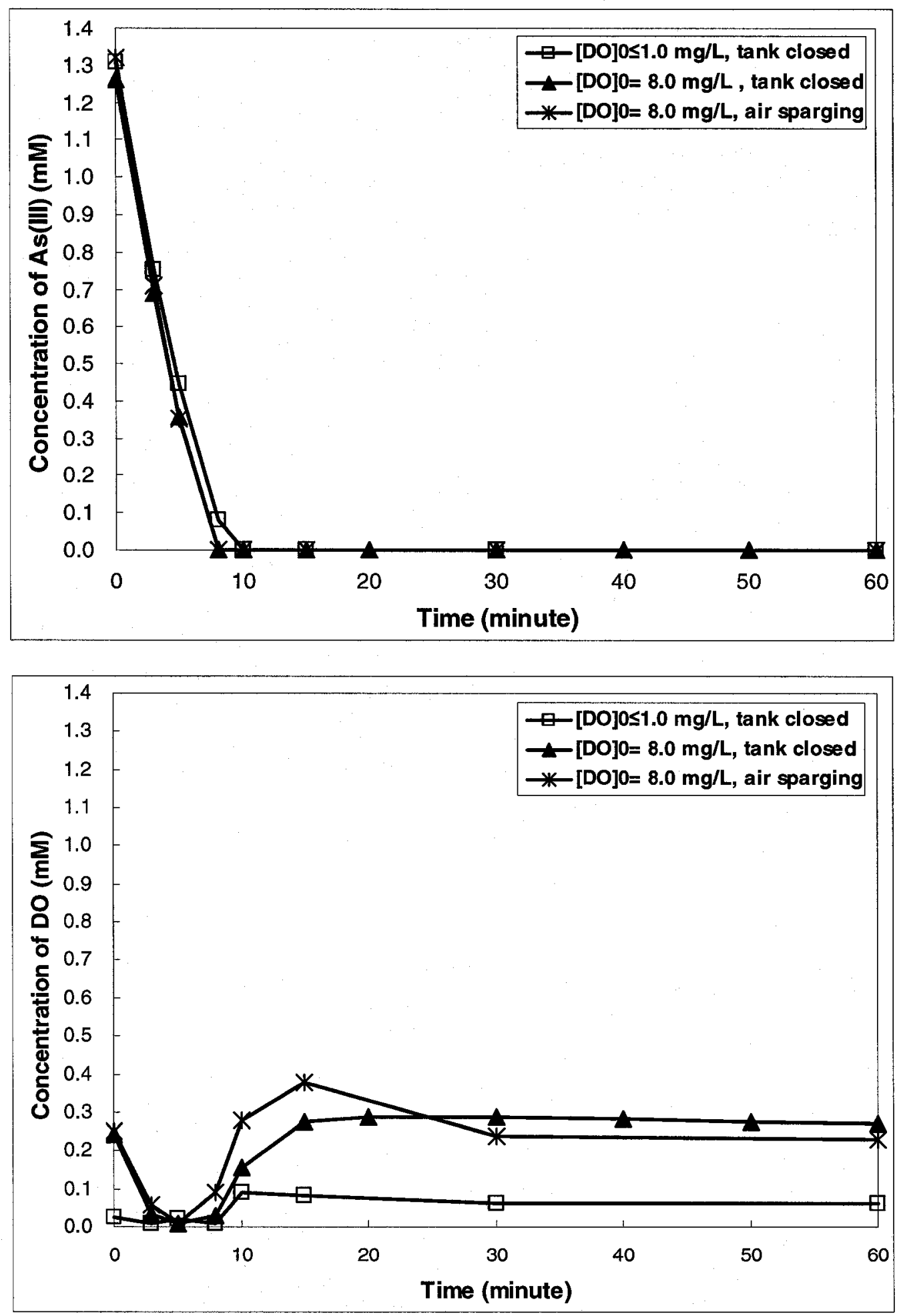

Figure 5.25 As(III) and DO concentrations as a function of irradiation time in AOP under different DO conditions with $\left[\mathrm{H}_{2} \mathrm{O}_{2}\right]_{0}:[\mathrm{As}(\mathrm{III})]_{0}=1: 1$ (initial $\mathrm{pH}=3.0 ;[\mathrm{As}(\mathrm{III})]_{0}=1.335 \mathrm{mM}$ ) 


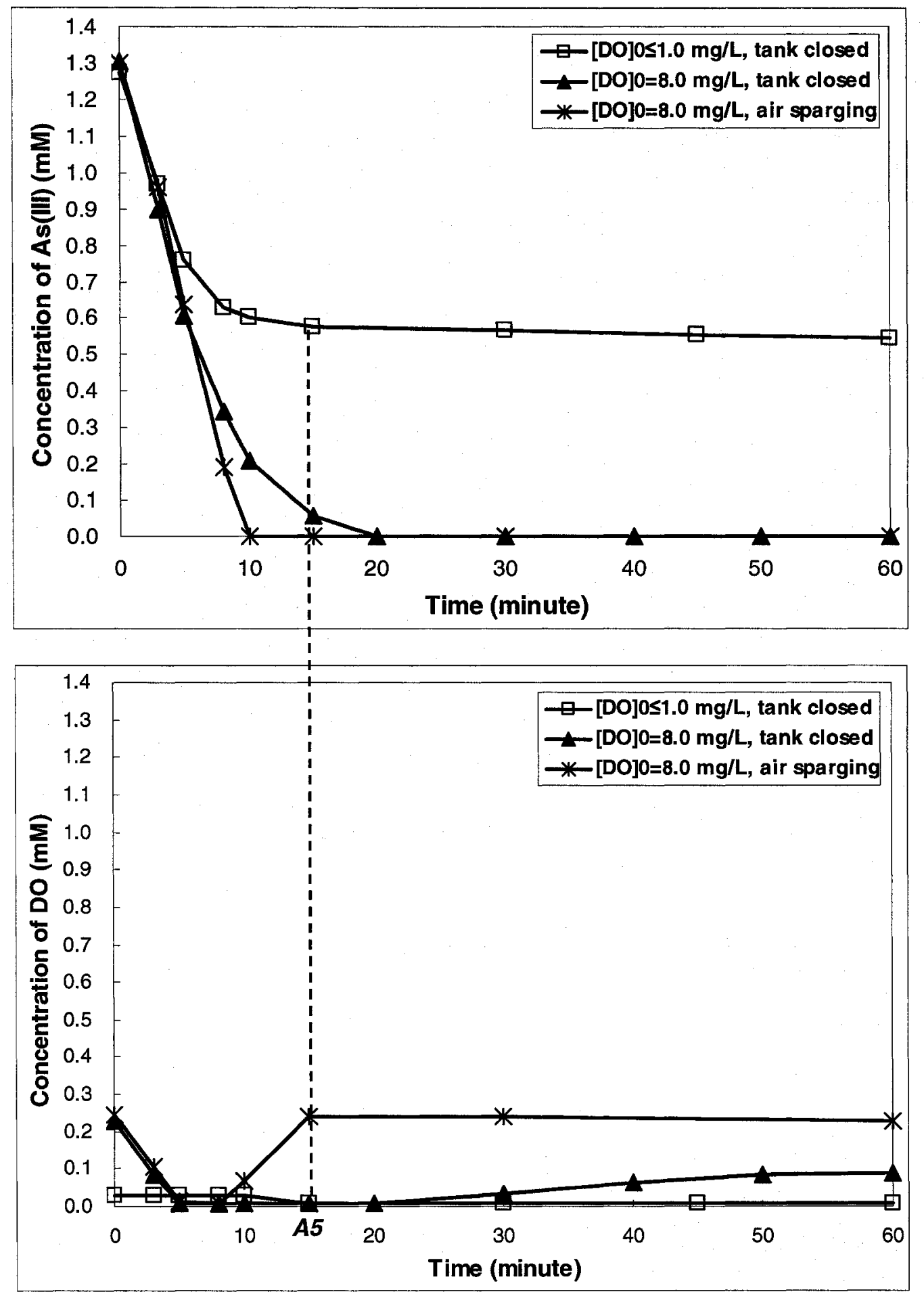

Figure 5.26 $\mathrm{As}$ (III) and $\mathrm{DO}$ concentrations as a function of irradiation time in AOP under different DO conditions with $\left[\mathrm{H}_{2} \mathrm{O}_{2}\right]_{0}:[\mathrm{As}(\mathrm{III})]_{0}=1: 2$ (initial $\mathrm{pH}=3.0 ;[\mathrm{As}(\mathrm{III})]_{0}=1.335 \mathrm{mM}$ ) 


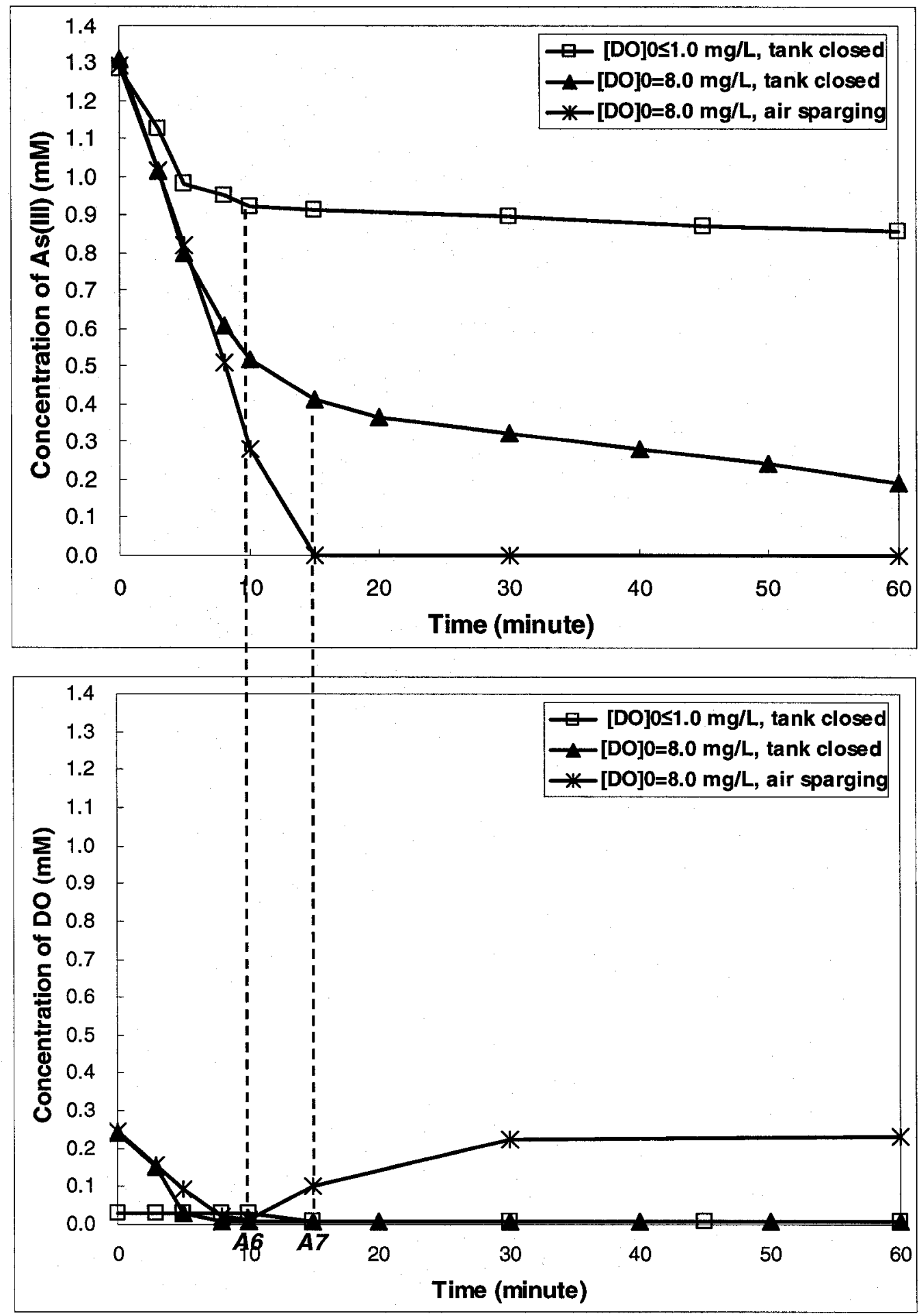

Figure 5.27 As(III) and DO concentrations as a function of irradiation time in AOP under different DO conditions with $\left[\mathrm{H}_{2} \mathrm{O}_{2}\right]_{0}:[\mathrm{As}(\mathrm{III})]_{0}=1: 4$ (initial $\mathrm{pH}=3.0 ;[\mathrm{As}(\mathrm{III})]_{0}=1.335 \mathrm{mM}$ )

The results shown in Figure 5.25 indicate that at $\left[\mathrm{H}_{2} \mathrm{O}_{2}\right]_{0}:[\mathrm{As}(\mathrm{III})]_{0}=1: 1$, no obvious difference in the variation of As(III) concentration with time was observed at different 
DO levels. At all DO conditions As(III) can be completely and rapidly oxidized within 10 minutes.

As shown in Figure 5.26 and Figure 5.27, when the $\left[\mathrm{H}_{2} \mathrm{O}_{2}\right]_{0} /[\mathrm{As}(\mathrm{III})]_{0}$ ratios are less than 1, DO level had significant effect on As(III) oxidation. In these cases, in the presence of $\mathrm{H}_{2} \mathrm{O}_{2}$, As(III) concentrations rapidly decreased. After $\mathrm{H}_{2} \mathrm{O}_{2}$ was completely consumed as represented at points $\mathbf{A 5}, \mathbf{A 6}$ and $\mathbf{A 7}$ shown on the time axis, at the condition of [DO $]_{0}$ $=8.0 \mathrm{mg} / \mathrm{L}$ with the closed tank, the As(III) oxidation continued at a relatively low rate; at the condition of $[\mathrm{DO}]_{0} \leq 1.0 \mathrm{mg} / \mathrm{L}$ with the closed tank, the oxidation process was very sluggish. The conversion percentages at 1 hour were $33.0 \pm 3.2 \%$ and $57 \pm 4.7 \%$ for the $\left[\mathrm{H}_{2} \mathrm{O}_{2}\right]_{0}:[\mathrm{As}(\mathrm{III})]_{0}$ ratios of $1: 4$ and $1: 2$ respectively. Summarizing, these results indicate that for the oxidation to proceed at a reasonable rate, the $\left[\mathrm{H}_{2} \mathrm{O}_{2}\right]_{0}:[\mathrm{As}(\mathrm{III})]_{0}$ ratio should be at least 1:1. So for the study on other parameters reported below, this ratio was maintained. Unlike Direct Photolysis, for the AOP system, air sparging was found to be unnecessary.

\subsubsection{Effect of $\mathrm{pH}$}

The effect of $\mathrm{pH}$ was studied by irradiating the feed solution at different initial $\mathrm{pH}$ while other conditions remained the same. The parameters chosen were: $[\mathrm{As}(\mathrm{III})]_{0}=1.335$ $\mathrm{mM}(100 \mathrm{mg} / \mathrm{L}) ;\left[\mathrm{H}_{2} \mathrm{O}_{2}\right]_{0}:[\mathrm{As}(\mathrm{III})]_{0}=1: 1 ;[\mathrm{DO}]_{0}=8.0 \mathrm{mg} / \mathrm{L}$ with the closed tank. Three initial $\mathrm{pH}$ conditions, from 3.0 to 10.0 , were investigated and the data obtained on As(III), $\mathrm{DO}, \mathrm{pH}$, and the measured Eh-pH diagram at different initial $\mathrm{pH}$ are shown in Figure 5.28 
to Figure 5.31.

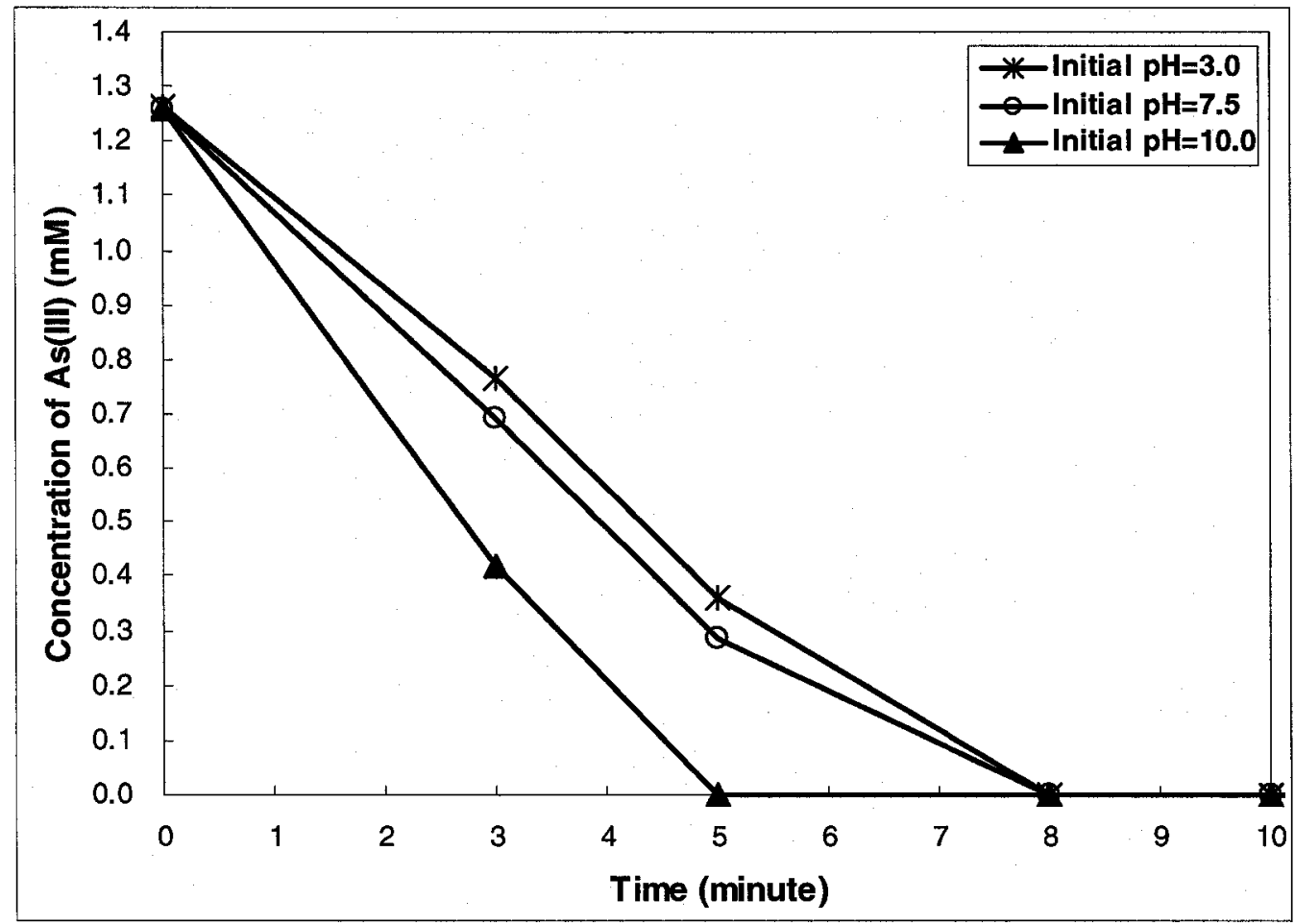

Figure 5.28 As (III) concentration as a function of irradiation time in AOP under different initial pH $\left([\mathrm{As}(\mathrm{III})]_{0}=1.335 \mathrm{mM} ;\left[\mathrm{H}_{2} \mathrm{O}_{2}\right]_{0}:[\mathrm{As}(\mathrm{III})]_{0}=1: 1 ;[\mathrm{DO}]_{0}=8.0 \mathrm{mg} / \mathrm{L}\right.$ with the closed tank)

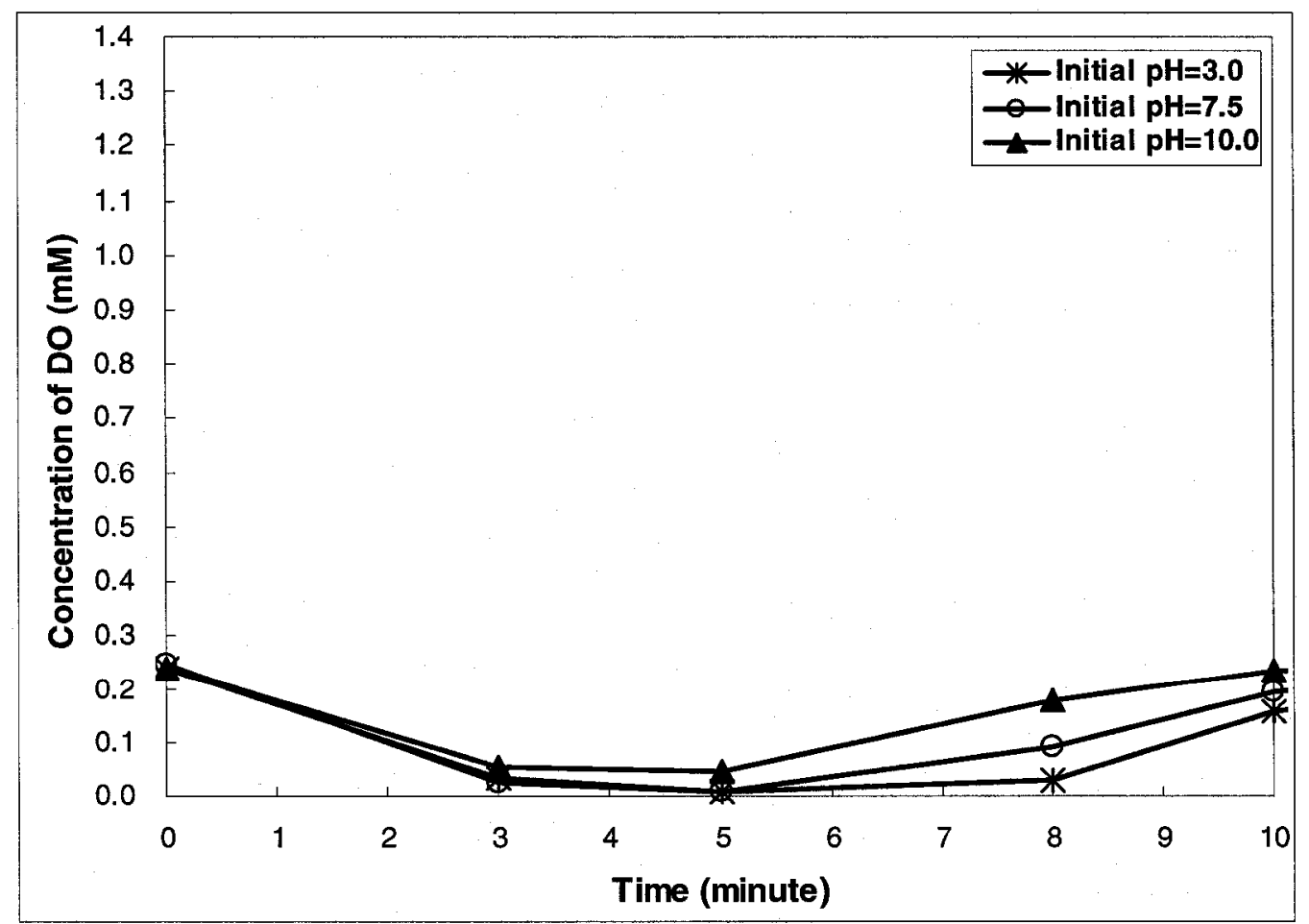

Figure 5.29 DO concentration as a function of irradiation time in AOP under different initial $\mathrm{pH}\left([\mathrm{As}(\mathrm{III})]_{0}=1.335 \mathrm{mM} ;\left[\mathrm{H}_{2} \mathrm{O}_{2}\right]_{0}:[\mathrm{As}(\mathrm{III})]_{0}=1: 1 ;[D O]_{0}=8.0 \mathrm{mg} / \mathrm{L}\right.$ with the closed tank) 


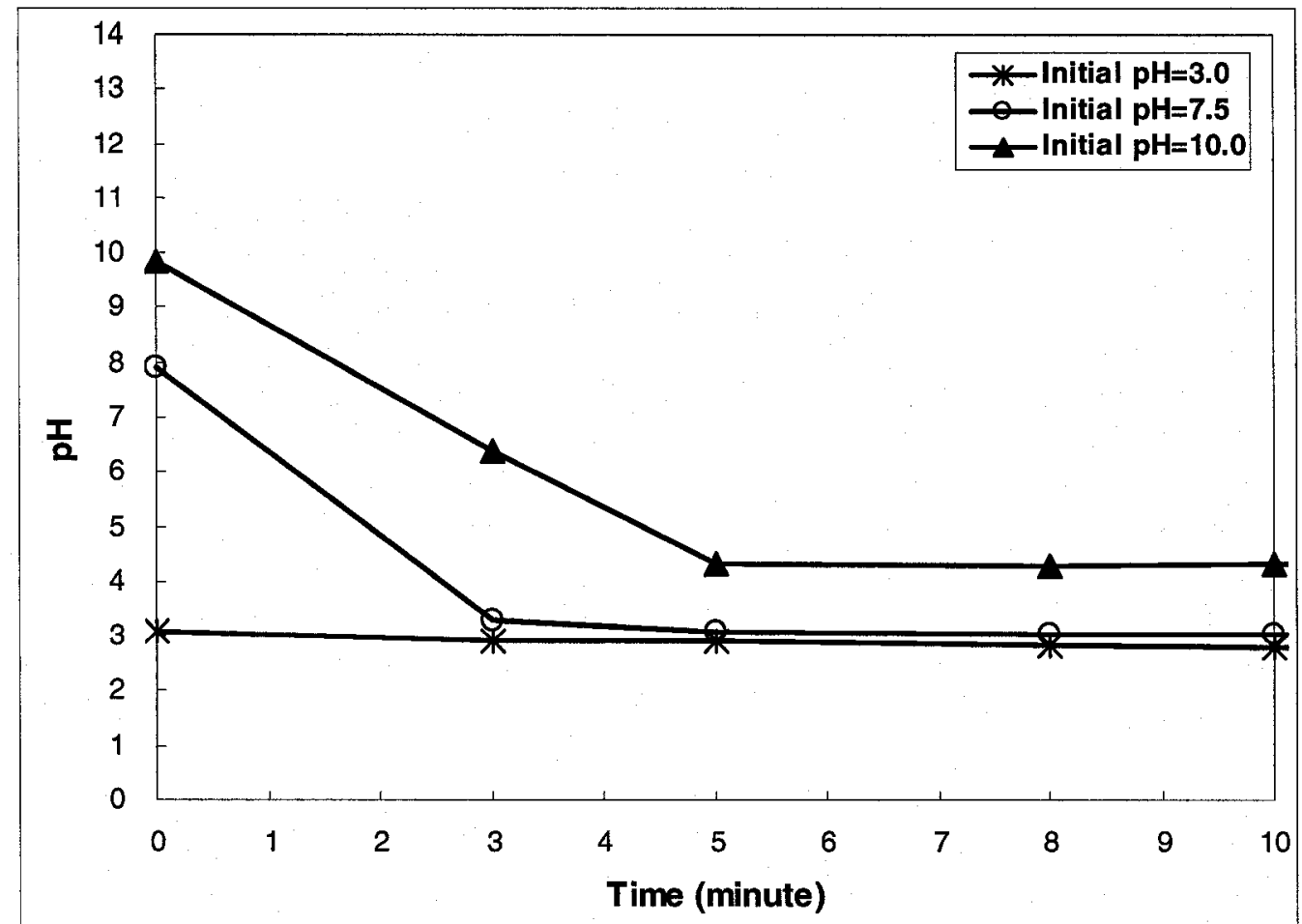

Figure $5.30 \mathrm{pH}$ as a function of irradiation time in AOP under different initial $\mathrm{pH}$ $\left([\mathrm{As}(\mathrm{III})]_{0}=1.335 \mathrm{mM} ;\left[\mathrm{H}_{2} \mathrm{O}_{2}\right]_{0}:[\mathrm{As}(\mathrm{III})]_{0}=1: 1 ;[\mathrm{DO}]_{0}=8.0 \mathrm{mg} / \mathrm{L}\right.$ with the closed tank)

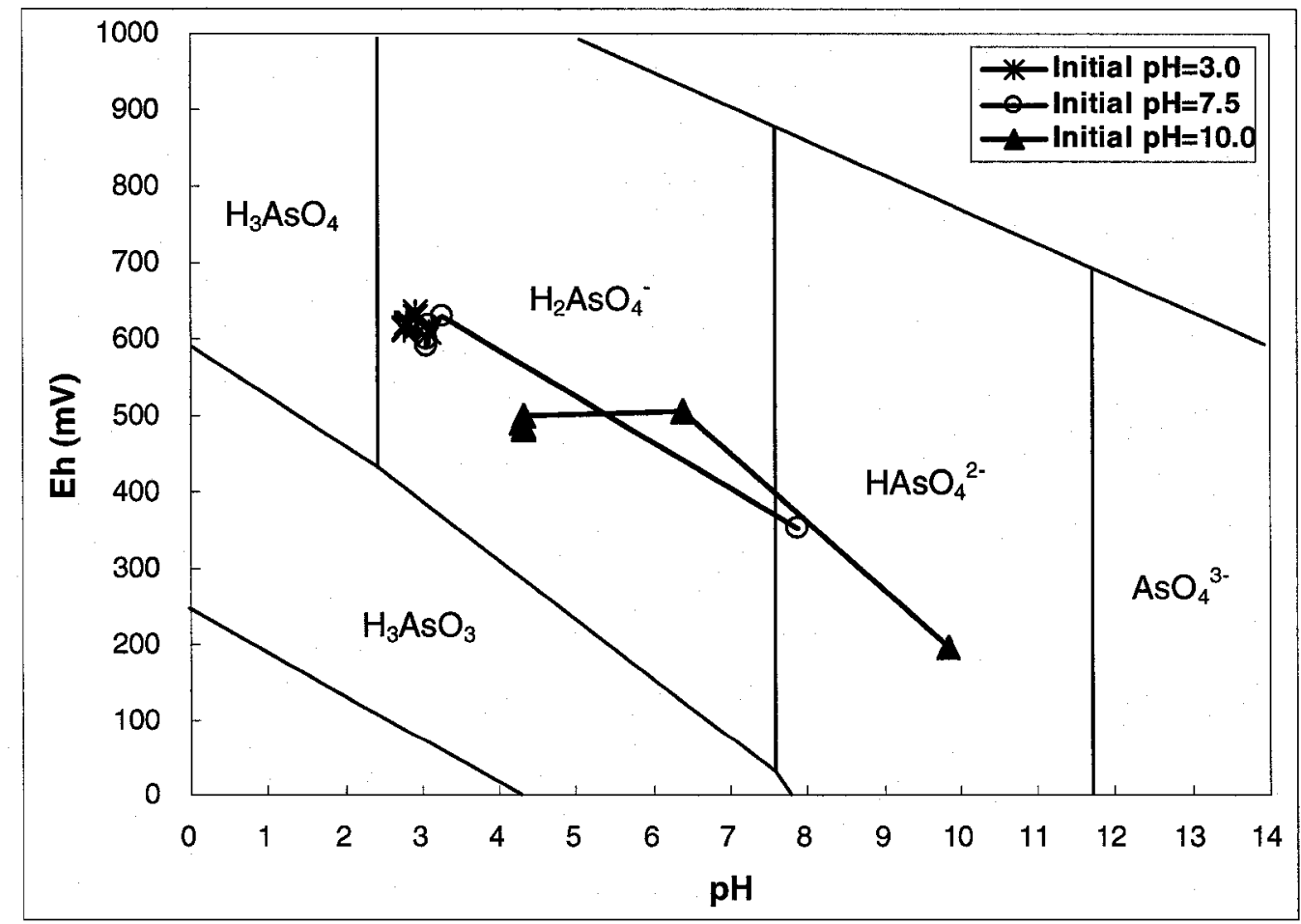

Figure 5.31 Measured Eh-pH diagram in AOP under different initial pH $\left([\mathrm{As}(\mathrm{III})]_{0}=1.335 \mathrm{mM} ;\left[\mathrm{H}_{2} \mathrm{O}_{2}\right]_{0}:[\mathrm{As}(\mathrm{III})]_{0}=1: 1 ;[\mathrm{DO}]_{0}=8.0 \mathrm{mg} / \mathrm{L}\right.$ with the closed tank) 
The results in Figure 5.28 indicate that initial $\mathrm{pH}$ impacted the oxidation process. At higher $\mathrm{pH}$, the oxidation process can be completed faster than at lower $\mathrm{pH}$ condition. The oxidation of $\operatorname{As}(\mathrm{III})$ was completed within 8 and 5 minutes at the initial $\mathrm{pH}$ of 3.0 and 10.0 respectively. The reason could be that the molar absorption coefficient of peroxide anion at alkaline condition is higher, which results in a higher quantum yield (Legrini et al., 1993).

The decrease and the recovery of DO concentration were observed at all initial $\mathrm{pH}$, as shown in Figure 5.29. The $\mathrm{pH}$ change during the course of the reaction was similar to that in the Direct Photolysis process. At initial $\mathrm{pH}$ of $3.0 \sim 10.0$, a decrease in $\mathrm{pH}$ was observed. The molar ratios of $\left[\mathrm{H}^{+}\right]$to $[\mathrm{As}(\mathrm{V})]$ in the final solution were also in the range of $0 \sim 1$, as shown in Table 5.8 .

Table 5.8 Molar ratio of $\left[\mathrm{H}^{+}\right]$and $[\mathrm{As}(\mathrm{V})]$ in the final solution in AOP $\left(\left[\mathrm{H}_{2} \mathrm{O}_{2}\right]_{0}:[\mathrm{As}(\mathrm{III})]_{0}=1: 1 ;[\mathrm{DO}]_{0}=8.0 \mathrm{mg} / \mathrm{L}\right.$ with the closed tank; $\left.[\mathrm{As}(\mathrm{III})]_{0}=1.335 \mathrm{mM}\right)$

\begin{tabular}{cccc}
\hline \hline Initial pH & {$\left[\mathrm{H}^{+}\right](\mathbf{m M})$} & Final $[\mathrm{As}(\mathrm{V})](\mathbf{m M})$ & Molar Ratio of $\left[\mathrm{H}^{+}\right] / \mathbf{A}[\mathbf{s}(\mathrm{V})]$ \\
\hline $\mathrm{pH}=3.0$ & $0.753 \pm 0.015$ & $1.335 \pm 0.067$ & $0.566 \pm 0.055$ \\
$\mathrm{pH}=7.5$ & $0.782 \pm 0.046$ & $1.335 \pm 0.067$ & $0.587 \pm 0.068$ \\
$\mathrm{pH}=10.0$ & $0.102 \pm 0.018$ & $1.335 \pm 0.067$ & $0.077 \pm 0.013$ \\
\hline \hline
\end{tabular}

The measured Eh-pH changes were also similar to that in Direct Photolysis. The decrease in $\mathrm{pH}$ observed could be due to various arsenic species formed as shown in Table 5.2.

The effect of $\mathrm{pH}$ was further investigated at $\mathrm{DO}$ conditions of $[\mathrm{DO}]_{0} \leq 1.0 \mathrm{mg} / \mathrm{L}$ with the closed tank and $[\mathrm{DO}]_{0}=8.0 \mathrm{mg} / \mathrm{L}$ with air sparging, shown in Appendix $\mathrm{H}$. The 
results were similar to the $[\mathrm{DO}]_{0}=8.0 \mathrm{mg} / \mathrm{L}$ with the closed tank condition. No significant effect of DO on oxidation process was observed.

\subsubsection{Effect of Initial As(III) Concentration}

To confirm the effect of the ratio $\left[\mathrm{H}_{2} \mathrm{O}_{2}\right]_{0} /[\mathrm{As}(\mathrm{III})]_{0}=1$ at various initial $\mathrm{As}(\mathrm{III})$ concentration conditions, experiments were carried out at different initial As(III) concentrations. The parameters chosen were: $[D O]_{0}=8.0 \mathrm{mg} / \mathrm{L}$ with the closed tank; initial $\mathrm{pH}=3.0$. Five initial As(III) concentrations were compared: 1 ) $[\mathrm{As}(\mathrm{III})]_{0}=0.267 \mathrm{mM} ; 2$ ) $\left.[\mathrm{As}(\mathrm{III})]_{0}=0.534 \mathrm{mM} ; 3\right)[\mathrm{As}(\mathrm{III})]_{0}=0.801 \mathrm{mM}$; 4) $\left.[\mathrm{As}(\mathrm{III})]_{0}=1.068 \mathrm{mM} ; 5\right)[\mathrm{As}(\mathrm{III})]_{0}$ $=1.335 \mathrm{mM}$.

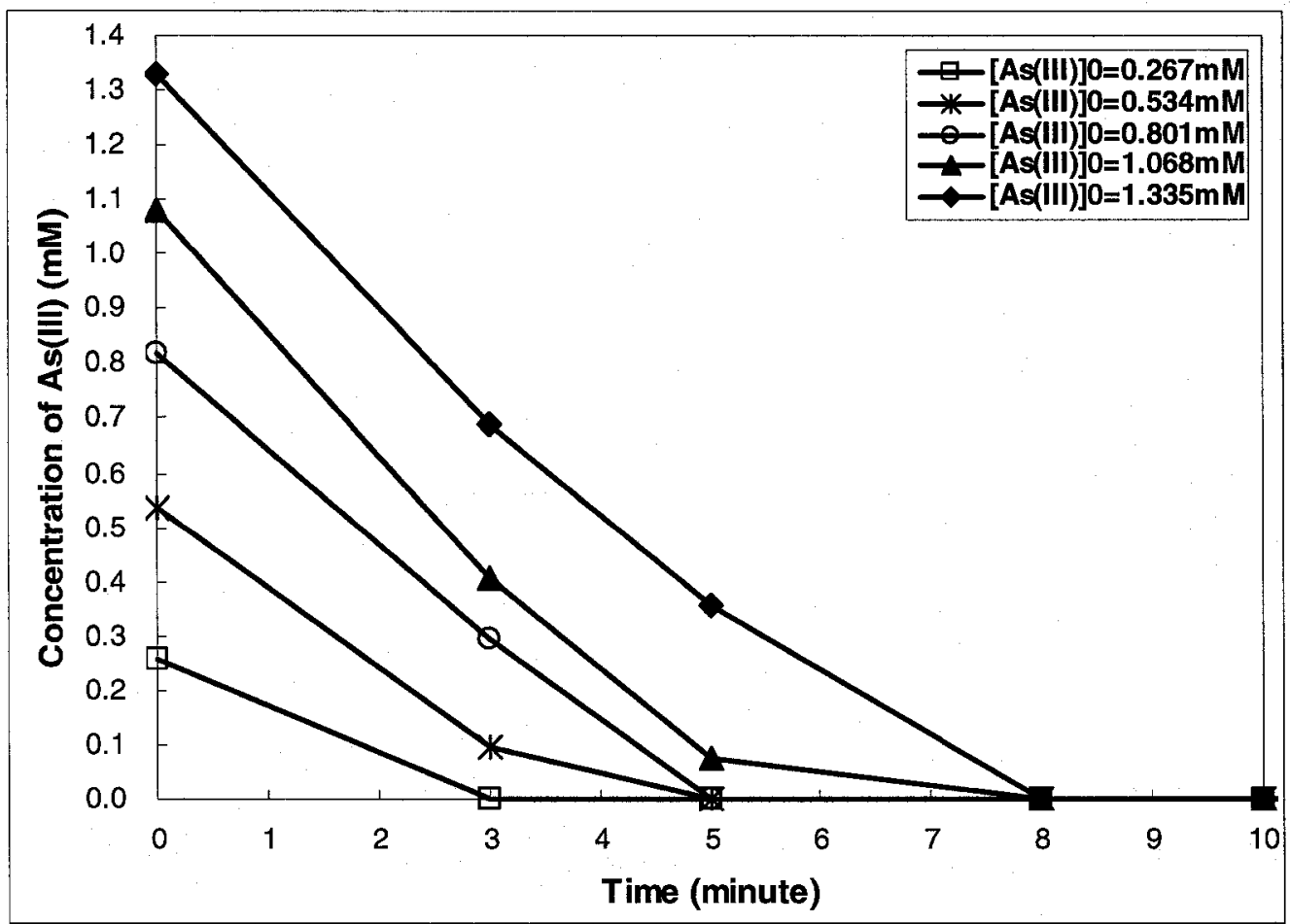

Figure $5.32 \mathrm{As}$ (III) concentration as a function of irradiation time in AOP under different initial As(III) concentration (initial $\mathrm{pH}=3.0 ;\left[\mathrm{H}_{2} \mathrm{O}_{2}\right]_{0}:[\mathrm{As}(\mathrm{III})]_{0}=1: 1 ;[\mathrm{DO}]_{0}=8.0 \mathrm{mg} / \mathrm{L}$ with the closed tank)

As can be seen in Figure 5.32, at $\left[\mathrm{H}_{2} \mathrm{O}_{2}\right]_{0}:[\mathrm{As}(\mathrm{III})]_{0}=1: 1$, As(III) was completely 
oxidized within 10 minutes at initial As(III) concentration range of $0.267 \sim 1.335 \mathrm{mM}$. High oxidation efficiency can be attained at $\left[\mathrm{H}_{2} \mathrm{O}_{2}\right]_{0}:[\mathrm{As}(\mathrm{III})]_{0}$ ratio=1:1 irrespective of the initial As(III) concentration in the range studied..

\subsubsection{AOP in the Recirculation Reactor}

\subsubsection{Effect of $\left[\mathrm{H}_{2} \mathrm{O}_{2}\right]_{0}:[\mathrm{As}(\mathrm{III})]_{0}$ Ratio}

In the batch reactor, the ratio of $\left[\mathrm{H}_{2} \mathrm{O}_{2}\right]_{0}:[\mathrm{As}(\mathrm{III})]_{0}$ was observed to be a significant factor in determining the oxidation efficiency of $\mathrm{As}(\mathrm{III})$. In the recirculation reactor, two $\left[\mathrm{H}_{2} \mathrm{O}_{2}\right]_{0}:[\mathrm{As}(\mathrm{III})]_{0}$ ratios of $1: 4$ and $1: 1$ were compared. As can be seen in Figure 5.33, As(III) was completely oxidized within 15 and 30 minutes at $\left[\mathrm{H}_{2} \mathrm{O}_{2}\right]_{0}:[\mathrm{As}(\mathrm{III})]_{0}$ ratio of 1:1 and 1:4 respectively. At higher $\left[\mathrm{H}_{2} \mathrm{O}_{2}\right]_{0}:[\mathrm{As}(\mathrm{III})]_{0}$ ratio, the oxidation process was even more effective. These results in the recirculation reactor are similar to those obtained in the batch reactor. 


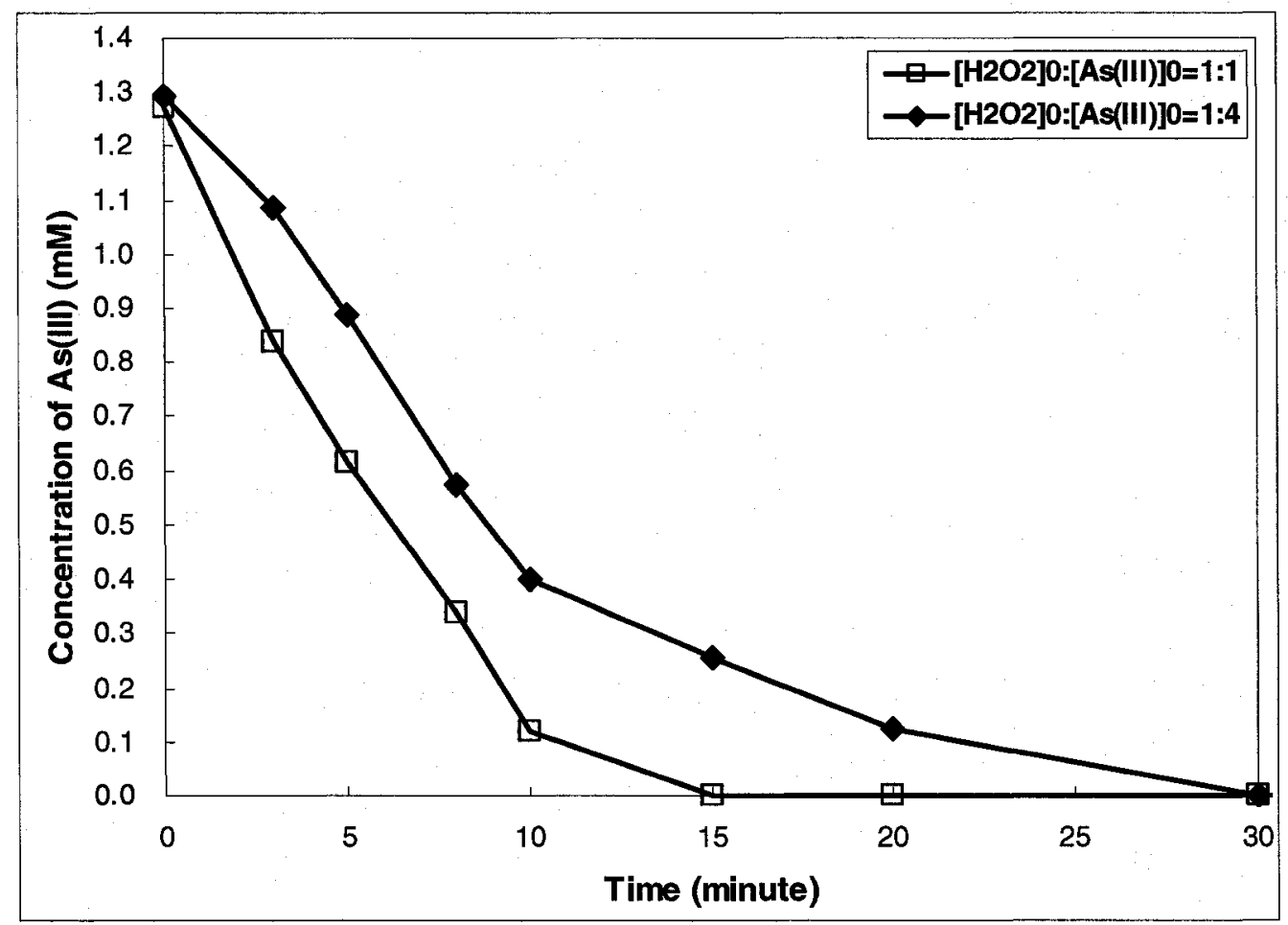

Figure 5.33 As(III) concentration as a function of irradiation time in the recirculation reactor in AOP under different $\left[\mathrm{H}_{2} \mathrm{O}_{2}\right]_{0}:[\mathrm{As}(\mathrm{III})]_{0}$ ratios $\left([\mathrm{As}(\mathrm{III})]_{0}=1.335 \mathrm{mM}\right.$; recycle rate=25GPM; initial $\mathrm{pH}=3.0$; $[\mathrm{DO}]_{0}=8.0 \mathrm{mg} / \mathrm{L}$ with the closed tank)

\subsubsection{Effect of Recycle Rate}

The effect of recycle rate was also investigated in the AOP. The parameters chosen were: $[\mathrm{As}(\mathrm{III})]_{0}=1.335 \mathrm{mM},\left[\mathrm{H}_{2} \mathrm{O}_{2}\right]_{0}:[\mathrm{As}(\mathrm{III})]_{0}=1: 1$ and initial $\mathrm{pH}=3.0$. Three recycle rates were compared: 10 GPM, 17 GPM and 25 GPM. As can be seen in Figure 5.34, the variation of recycle rate had no significant effect on the oxidation efficiency. This is consistent with the results obtained earlier in the Direct Photolysis process. 


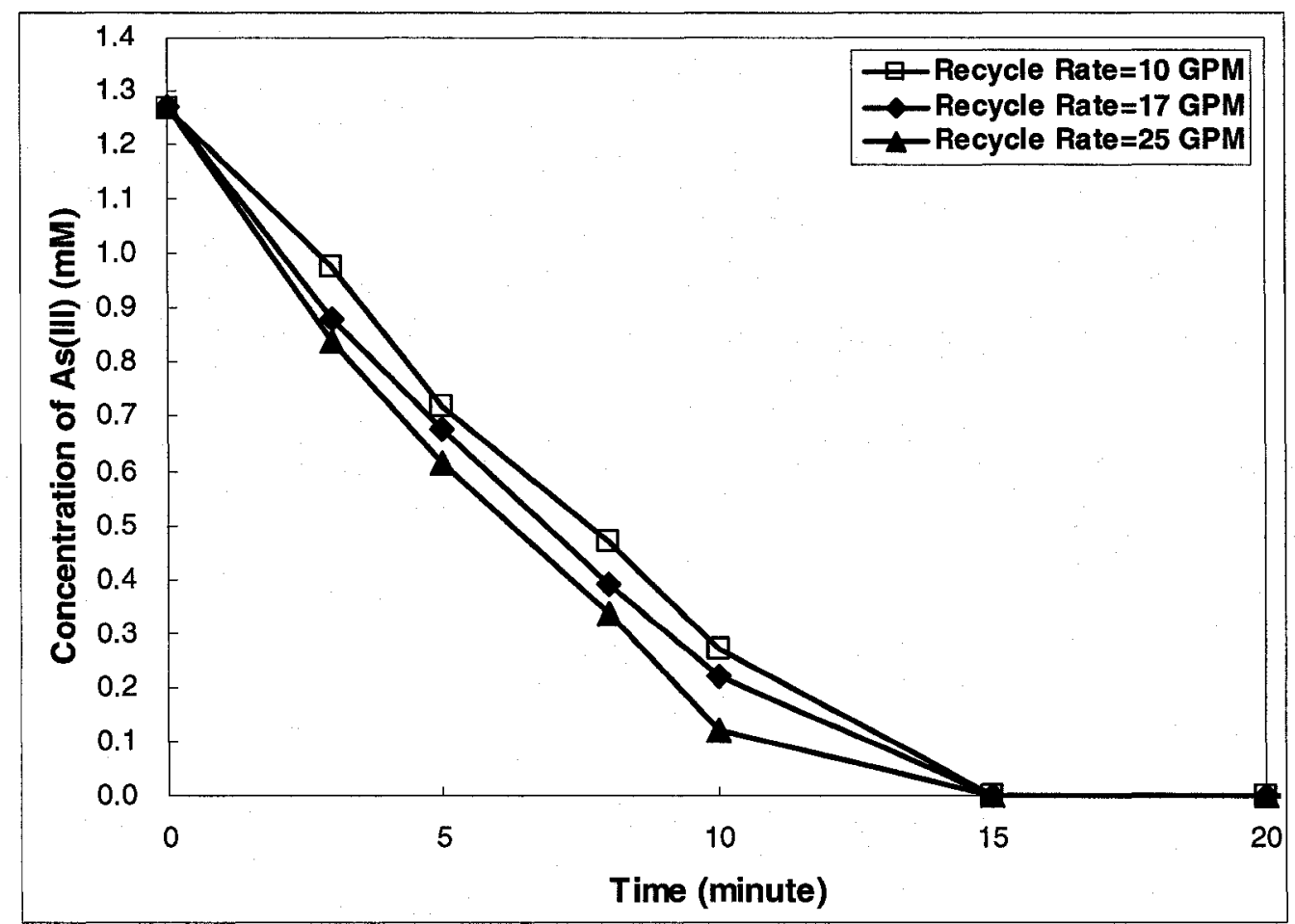

Figure 5.34 As(III) concentration as a function of irradiation time in the recirculation reactor in AOP under different recycle rates $\left([\mathrm{As}(\mathrm{III})]_{0}=1.335 \mathrm{mM} ;\left[\mathrm{H}_{2} \mathrm{O}_{2}\right]_{0}:[\mathrm{As}(\mathrm{III})]_{0}=1: 1\right.$; initial $\mathrm{pH}=3.0 ;[\mathrm{DO}]_{0}=8.0 \mathrm{mg} / \mathrm{L}$ with the closed tank)

\subsubsection{Effect of Initial $\mathrm{pH}$}

The investigation of the effect of initial $\mathrm{pH}$ is shown in Figure 5.35. As can been seen, the higher oxidation efficiency was obtained at the alkaline condition of initial $\mathrm{pH}$ 10.0. No significant difference was observed between initial $\mathrm{pH}$ of 3.0 and 7.5. This is also consistent with the results in the batch reactor and can be explained by the effect of $\mathrm{pH}$ on the quantum yield of $\mathrm{H}_{2} \mathrm{O}_{2}$. 


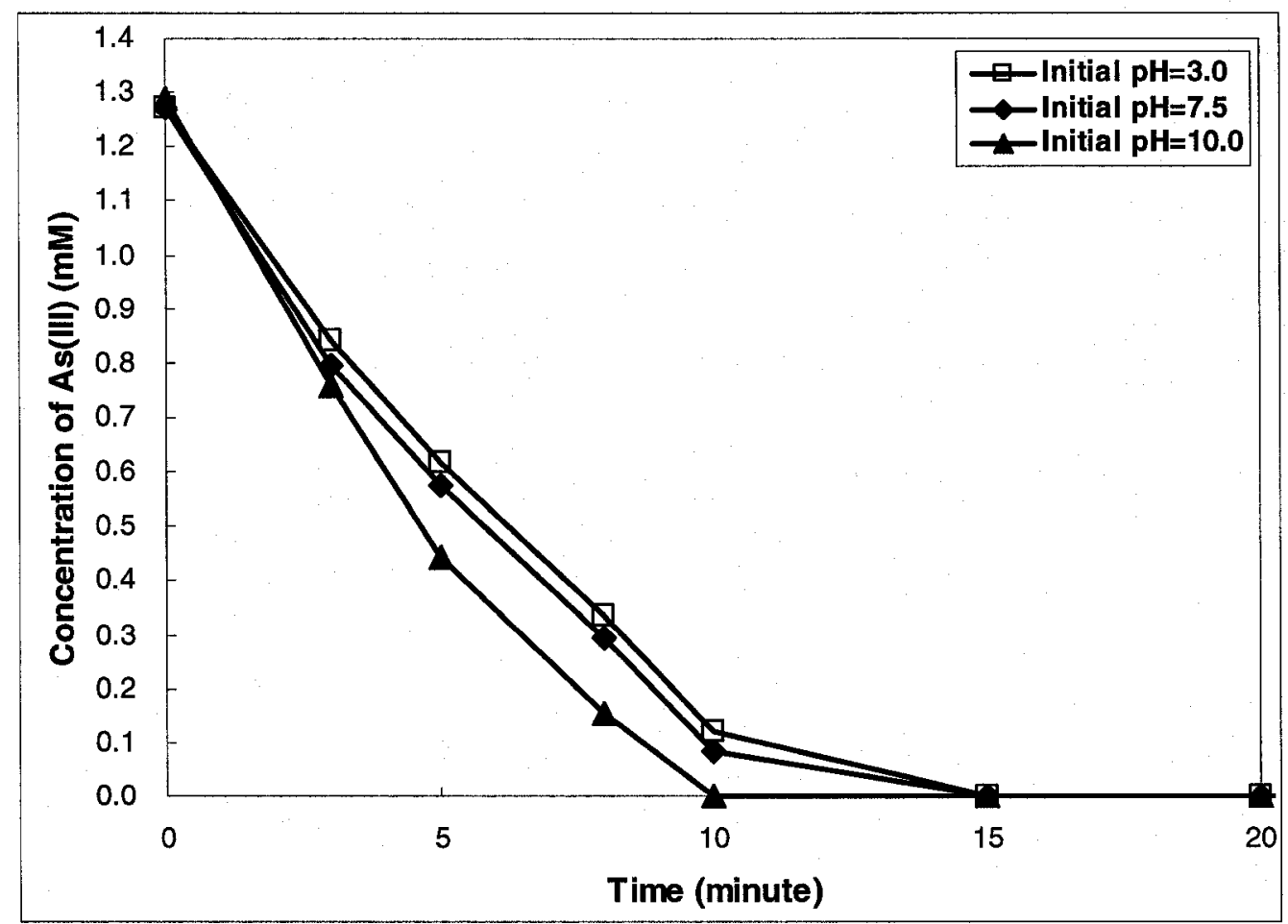

Figure 5.35 As(III) concentration as a function of irradiation time in the recirculation reactor in AOP under different initial $\mathrm{pH}\left([\mathrm{As}(\mathrm{III})]_{0}=1.335 \mathrm{mM}\right.$; $\left[\mathrm{H}_{2} \mathrm{O}_{2}\right]_{0}:[\text { As (III) }]_{0}=1: 1$; recycle rate=25GPM; $[D O]_{0}=8.0 \mathrm{mg} / \mathrm{L}$ with the closed tank)

\subsubsection{Effect of Initial As(III) Concentration}

Two initial As(III) concentrations of $0.668 \mathrm{mM}$ and $1.335 \mathrm{mM}$ were investigated in the AOP. As can be seen in Figure 5.36, the variation of initial As(III) concentrations had minor effect on the oxidation efficiency at the $\left[\mathrm{H}_{2} \mathrm{O}_{2}\right]_{0}:[\mathrm{As}(\mathrm{III})]_{0}$ ratio of $1: 1$, which is comparable to the results in the batch reactor. 


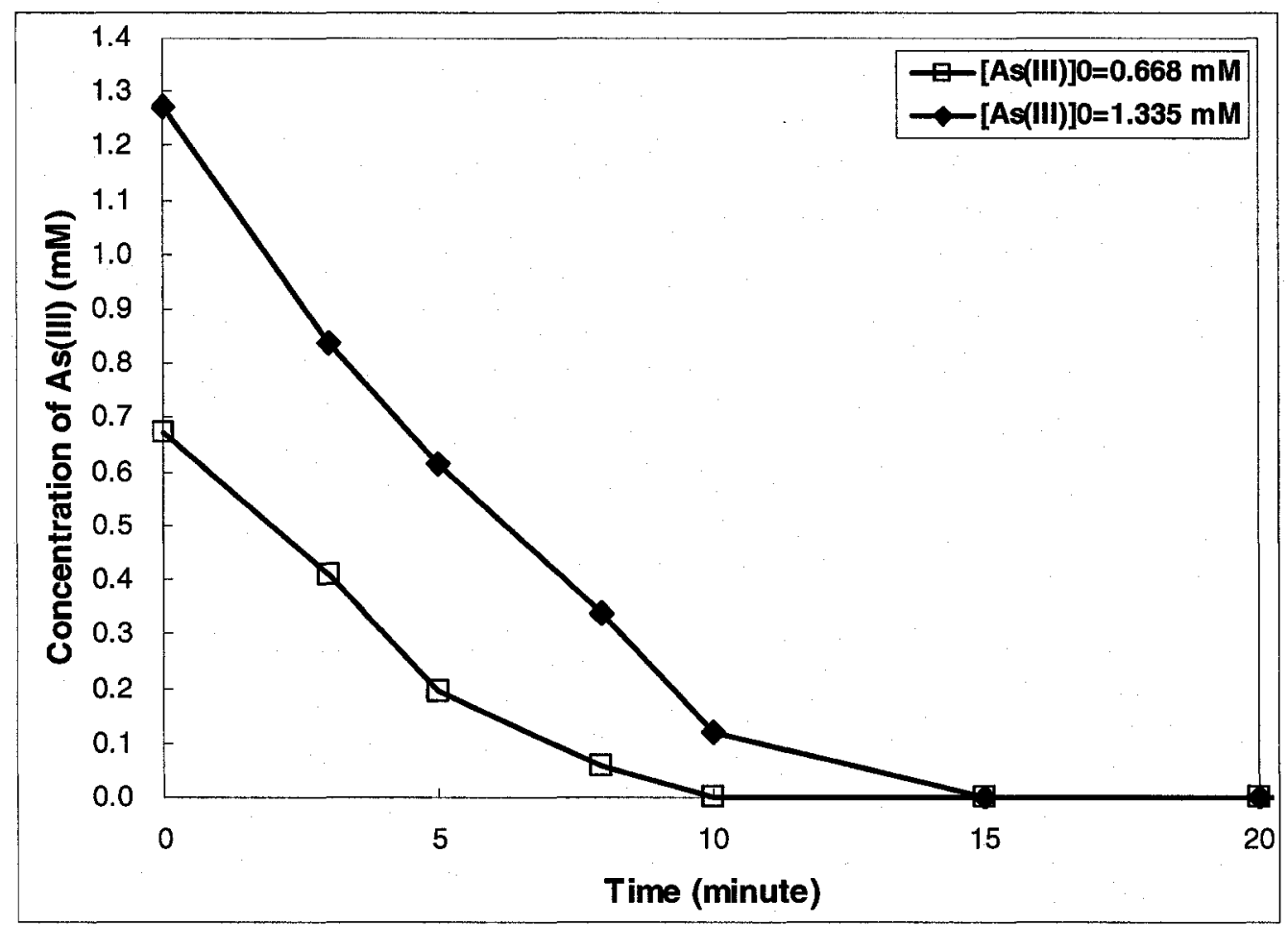

Figure 5.36 As(III) concentration as a function of irradiation time in the recirculation reactor in AOP under different initial As(III) concentrations $\left(\left[\mathrm{H}_{2} \mathrm{O}_{2}\right]_{0}:[\mathrm{As}(\mathrm{III})]_{0}=1: 1\right.$; initial $\mathrm{pH}=3.0$; Recycle rate $=25 \mathrm{GPM} ;[\mathrm{DO}]_{0}=8.0 \mathrm{mg} / \mathrm{L}$ with the closed tank)

\subsubsection{Kinetics of the $\mathrm{H}_{2} \mathrm{O}_{2} / \mathrm{UV}$ Process}

\subsubsection{Rate Equation and Reaction Order}

(1) Near-anoxic condition with closed tank in batch reactor

The kinetic calculation was first carried out for the near-anoxic condition in batch reactor, in which the potential DO effect is found to be negligible. Therefore, the As(III) oxidation process is only affected by the parameter $\mathrm{H}_{2} \mathrm{O}_{2}$. A set of typical experiments at initial pH 3.0 with the variation of $\left[\mathrm{H}_{2} \mathrm{O}_{2}\right]_{0}:[\mathrm{As}(\mathrm{III})]_{0}$ ratio from 1:1 to $1: 4$ was evaluated. The reaction order with respect to the arsenic concentration was also determined following the standard methods of analysis.

At $\left[\mathrm{H}_{2} \mathrm{O}_{2}\right]_{0}:[\mathrm{As}(\mathrm{III})]_{0}$ ratio of $1: 1$, the experimental data were fitted by the first-order 
model. At $\left[\mathrm{H}_{2} \mathrm{O}_{2}\right]_{0}:[\mathrm{As}(\mathrm{III})]_{0}$ ratio of $1: 2$ and $1: 4$, the experimental data could not satisfactorily be fitted by either zero-order or first-order model. Clipping the tail of the curves after the time points A5 and A6 shown in Figure 5.26 and Figure 5.27, in which $\mathrm{H}_{2} \mathrm{O}_{2}$ has been completely consumed, the experimental data could be fitted with the first-order model. The first-order rate constants derived are $3.53 \times 10^{-3} \mathrm{~s}^{-1}, 1.29 \times 10^{-3} \mathrm{~s}^{-1}$, $8.82 \times 10^{-4} \mathrm{~s}^{-1}$ at the $\left[\mathrm{H}_{2} \mathrm{O}_{2}\right]_{0}:[\mathrm{As}(\mathrm{III})]_{0}$ ratios of $1: 1,1: 2$ and $1: 4$ respectively. The different rate constants are in proportion to the $\left[\mathrm{H}_{2} \mathrm{O}_{2}\right]_{0}:[\mathrm{As}(\mathrm{III})]_{0}$ ratios.

\section{(2) Impact of other parameters on batch reactor performance}

The data obtained under saturated oxygen in the solution was analyzed for the impact of $\left[\mathrm{H}_{2} \mathrm{O}_{2}\right]_{0}:[\mathrm{As}(\mathrm{III})]_{0}$ ratio. In the closed tank condition at initial $\mathrm{pH} 3.0$, the experimental data were fitted by the first-order model at $\left[\mathrm{H}_{2} \mathrm{O}_{2}\right]_{0}:[\mathrm{As}(\mathrm{III})]_{0}$ ratios of $1: 1$ and $1: 2$. At $\left[\mathrm{H}_{2} \mathrm{O}_{2}\right]_{0}:[\mathrm{As}(\mathrm{III})]_{0}$ ratio of $1: 4$, the experimental data can be fitted by the first-order model only after clipping the tail of the curves after the time point $\mathbf{A 7}$ shown in Figure 5.27. The first-order rate constants are determined to be $4.13 \times 10^{-3} \mathrm{~s}^{-1}, 3.06 \times 10^{-3}$ $\mathrm{s}^{-1}, 1.58 \times 10^{-3} \mathrm{~s}^{-1}$ at the $\left[\mathrm{H}_{2} \mathrm{O}_{2}\right]_{0}:[\mathrm{As}(\mathrm{III})]_{0}$ ratios of $1: 1,1: 2$ and $1: 4$ respectively.

In the air sparging condition at initial $\mathrm{pH} 3.0$, the analysis of reaction order and rate equation with respect to the arsenic concentration also indicated that the experimental data were fitted by first-order model. The rate constants are determined to be $4.33 \times 10^{-3} \mathrm{~s}^{-1}$, $3.95 \times 10^{-3} \mathrm{~s}^{-1}, 2.47 \times 10^{-3} \mathrm{~s}^{-1}$ at the $\left[\mathrm{H}_{2} \mathrm{O}_{2}\right]_{0}:[\mathrm{As}(\mathrm{III})]_{0}$ ratios of $1: 1,1: 2$ and $1: 4$ respectively.

From the rate constants obtained at different DO conditions, it can be stated that the 
rate constant increased with the increase of DO concentration in the solution. This increase is more significant at low $\left[\mathrm{H}_{2} \mathrm{O}_{2}\right]_{0}:[\mathrm{As}(\mathrm{III})]_{0}$ ratio conditions.

The rate constants are further investigated at different initial $\mathrm{pH}$ with $\left[\mathrm{H}_{2} \mathrm{O}_{2}\right]_{0}:[\mathrm{As}(\mathrm{III})]_{0}$ ratios of $1: 1$ in the air sparging condition. The first-order rate constants are determined to be $4.74 \times 10^{-3} \mathrm{~s}^{-1}$ and $6.05 \times 10^{-3} \mathrm{~s}^{-1}$ at initial $\mathrm{pH} 7.5$ and 10.0 respectively. The results indicate that higher initial $\mathrm{pH}$ conditions yield higher rate constants.

\section{(3) Recirculation reactor}

The evaluation of reaction order in the recirculation reactor also indicated that the reaction is first-order. The rate constants obtained at different initial $\mathrm{pH}$ in the recirculation reactor at $\left[\mathrm{H}_{2} \mathrm{O}_{2}\right]_{0}:[\mathrm{As}(\mathrm{III})]_{0}$ ratio of $1: 1$ are shown and compared with batch reactor results, shown in Table 5.9. As can be seen, the rate constants in the recirculation reactor are relatively lower than those in the batch reactor.

The comparison of arsenic oxidation efficiencies based on the UV dose in both the batch reactor and the recirculation reactor are also shown in Table 5.9. It can be seen, the required UV dose per unit As(III) in the recirculation reactor is lower than that of the batch reactor, which indicates the higher electrical efficiency in the recirculation reactor. The probable explanation could be that the recirculation improves the mixing of the reacting fluid, which results in a much improved performance. 
Table 5.9 Summary of the performance comparison between the Batch Reactor and the Recirculation Reactor in AOP

\begin{tabular}{|c|c|c|c|c|}
\hline Reactor & $\begin{array}{l}\text { Type and Operating } \\
\text { Conditions }\end{array}$ & $\begin{array}{l}\text { Rate Constant } \\
\qquad\left(\mathrm{M} \cdot \mathrm{s}^{-1}\right)\end{array}$ & $\begin{array}{c}\text { Reaction time } \\
\text { per } 1 \text { mM As(III) } \\
\text { Oxidized } \\
\text { (Hours/mM) }\end{array}$ & $\begin{array}{c}\text { UV Dose per } 1 \\
\text { mM As(III) } \\
\text { Oxidized } \\
\left.\text { (kWh } \mathrm{m}^{-3} / \mathrm{mM}\right)\end{array}$ \\
\hline \multirow{3}{*}{ Batch reactor } & $\begin{array}{c}\text { Initial } \mathrm{pH}=3.0 ; \\
{[\mathrm{As}(\mathrm{III})]_{0}=1.335 \mathrm{mM}}\end{array}$ & $4.33 \times 10^{-3}$ & 0.09 & 3.00 \\
\hline & $\begin{array}{c}\text { Initial } \mathrm{pH}=7.5 ; \\
{[\mathrm{As}(\mathrm{III})]_{0}=1.335 \mathrm{mM}}\end{array}$ & $4.74 \times 10^{-3}$ & 0.09 & 3.00 \\
\hline & $\begin{array}{c}\text { Initial pH=10.0; } \\
{[\mathrm{As}(\mathrm{III})]_{0}=1.335 \mathrm{mM}}\end{array}$ & $6.05 \times 10^{-3}$ & 0.06 & 2.00 \\
\hline \multirow{3}{*}{$\begin{array}{l}\text { Recirculation } \\
\text { reactor }\end{array}$} & $\begin{array}{c}\text { Initial } \mathrm{pH}=3.0 ; 25 \mathrm{GPM} ; \\
{[\mathrm{As}(\mathrm{III})]_{0}=1.335 \mathrm{mM}}\end{array}$ & $3.70 \times 10^{-3}$ & 0.14 & 2.33 \\
\hline & $\begin{array}{c}\text { Initial pH=7.5; } 25 \mathrm{GPM} ; \\
{[\mathrm{As}(\mathrm{III})]_{0}=1.335 \mathrm{mM}}\end{array}$ & $4.20 \times 10^{-3}$ & 0.14 & 2.33 \\
\hline & $\begin{array}{c}\text { Initial } \mathrm{pH}=10.0 ; 25 \mathrm{GPM} \\
{[\mathrm{As}(\mathrm{III})]_{0}=1.335 \mathrm{mM}}\end{array}$ & $4.40 \times 10^{-3}$ & 0.11 & 1.83 \\
\hline
\end{tabular}

\subsubsection{Reaction Mechanism}

AOP with $\mathrm{UV} / \mathrm{H}_{2} \mathrm{O}_{2}$ presented remarkable improvement on the As(III) oxidation in comparison to both dark condition and Direct Photolysis. The increase of oxidation efficiency in the AOP relative to the dark condition could be explained by the photolysis of $\mathrm{H}_{2} \mathrm{O}_{2}$. As stated earlier, the medium-pressure UV lamp applied in this study can emit the UV light in the wavelength range of $200 \sim 300 \mathrm{~nm}$, in which $\mathrm{H}_{2} \mathrm{O}_{2}$ can be effectively decomposed to $\mathrm{OH}$. by the UV irradiation. $\mathrm{OH}$. being a more powerful oxidant than $\mathrm{H}_{2} \mathrm{O}_{2}$, the oxidation process can proceed rapidly. The increased reaction rate compared to Direct Photolysis is due to the addition of $\mathrm{H}_{2} \mathrm{O}_{2}$, in which both $\mathrm{H}_{2} \mathrm{O}_{2}$ and its hydroxyl derivate 
$\mathrm{OH} \cdot$ can replace oxygen as the electron acceptor and more rapidly react with $\mathrm{As}(\mathrm{III})$.

Daniels (1962) had investigated the AOP of As(III) oxidation and had discussed the potential pathway of the photooxidation process in the absence and in the presence of oxygen as further discussed below.

\section{(1) Oxygen-free condition}

In the oxygen-free condition, Daniels (1962) suggested the reaction scheme as shown in reactions (R5-6), (R5-7) and (R5-15):

$$
\begin{gathered}
\mathrm{H}_{2} \mathrm{O}_{2} \stackrel{h v\left(\Phi_{2}\right)}{\longrightarrow} 2 \mathrm{OH} \\
A s(I I I)+O H \cdot \stackrel{k_{4}}{\longrightarrow} A s(I V) \\
2 A s(I V) \stackrel{k_{5}}{\longrightarrow} A s(I I I)+A s(V)
\end{gathered}
$$

In these reactions, the intermediate oxidation state $\mathrm{As}(\mathrm{IV})$ is presumed to be generated due to the effect of oxygen. But the existence of As(IV) had not been directly proved by Daniels (1962)'s experiment. According to the proposed reactions, the reaction rates of each component can be expressed by the following equations:

$$
\left\{\begin{array}{l}
-\frac{d\left[\mathrm{H}_{2} \mathrm{O}_{2}\right]}{d t}=\Phi_{2} \alpha_{2} I_{0,200 \sim 300 \mathrm{~nm}}\left[\mathrm{H}_{2} \mathrm{O}_{2}\right] \\
-\frac{d[\mathrm{OH} \cdot]}{d t}=k_{4}[\mathrm{OH} \cdot][A s(I I I)]-2 \Phi_{2} \alpha_{2} I_{0,200 \sim 300 \mathrm{~mm}}\left[\mathrm{H}_{2} \mathrm{O}_{2}\right] \\
-\frac{d[A s(I I I)]}{d t}=k_{4}[O H \cdot][A s(I I I)]-\frac{1}{2} k_{5}[A s(I V)]^{2} \\
-\frac{d[A s(I V)]}{d t}=k_{5}[A s(I V)]^{2}-k_{4}[O H \cdot][A s(I I I)] \\
-\frac{d[A s(V)]}{d t}=-\frac{1}{2} k_{5}[A s(I V)]^{2}
\end{array}\right.
$$

Based on the steady-state hypothesis, we can get the rate equation (5-19): 


$$
-\frac{d[A s(I I I)]}{d t}=-\frac{d\left[\mathrm{H}_{2} \mathrm{O}_{2}\right]}{d t}=\frac{d[A s(V)]}{d t}=\Phi_{2} \alpha_{2} I_{0,200 \sim 300 \mathrm{~nm}}\left[\mathrm{H}_{2} \mathrm{O}_{2}\right]
$$

As stated earlier, $\Phi_{2}, \alpha_{2}$ and $I_{0,200 \sim 300 m m}$ are constant. Therefore the equation (5-19) can be written as:

$$
-\frac{d[A s(I I I)]}{d t}=-\frac{d\left[H_{2} O_{2}\right]}{d t}=\frac{d[A s(V)]}{d t}=k_{6}\left[H_{2} O_{2}\right]
$$

The rate equation indicates that the oxidation efficiency is unrelated to the variation of As(III), which is consistent with the observation in this study. It also further confirms the first-order model indicated in section 5.3.5.1. According to the equation, the higher rate constant in the alkaline conditions can be explained by the higher quantum yield for peroxide at high $\mathrm{pH}$ as indicated earlier (Legrini et al., 1993).

The overall reaction of AOP with $\mathrm{UV} / \mathrm{H}_{2} \mathrm{O}_{2}$ in the oxygen-free condition can be expressed as:

$$
\mathrm{H}_{2} \mathrm{O}_{2}+\mathrm{As}(\mathrm{III}) \rightarrow \mathrm{H}_{2} \mathrm{O}+\mathrm{As}(\mathrm{V})
$$

Taking account of the arsenic forms in the solution at various $\mathrm{pH}$ conditions, the reactions of AOP are shown in Table 5.10. As can be seen from the overall reactions (R5-19) and (R5-20), the stoichiometric ratio of As(III) to $\mathrm{H}_{2} \mathrm{O}_{2}$ is 1:1, which is consistent with the experimental results in the near-anoxic condition in section 5.4.2.2; the stoichiometric ratio of $\mathrm{H}^{+}$to $\operatorname{As}(\mathrm{V})$ can be obtained as $\left(\frac{b}{a+b}\right) \leq 1$, which is also consistent with the experimental results in section 5.4.2.3. 
Table 5.10 Proposed reactions of As(III) oxidation in AOP

\begin{tabular}{|c|c|}
\hline No. & Reactions \\
\hline & Initial pH=3.0 7.5: \\
\hline R5-17 & $\overline{\mathrm{H}_{3} \mathrm{As}^{(I I I)} \mathrm{O}_{3}+\mathrm{H}_{2}} \mathrm{O}_{2} \stackrel{h v}{\longrightarrow} \mathrm{H}_{3} A s^{(V)} \mathrm{O}_{4}+\mathrm{H}_{2} \mathrm{O}$ \\
\hline R5-18 & $\mathrm{H}_{2} \mathrm{As}^{(I I I)} \mathrm{O}_{3}+\mathrm{H}_{2} \mathrm{O}_{2} \stackrel{h v}{\longrightarrow} \mathrm{H}_{2} A s^{(V)} \mathrm{O}_{4}^{-}+\mathrm{H}_{2} \mathrm{O}+\mathrm{H}^{+}$ \\
\hline \multirow[t]{2}{*}{$\begin{array}{c}\text { Overall Reaction } \\
\text { (R5-19) } \\
\end{array}$} & $\mathrm{H}_{2} A s^{(I I)} \mathrm{O}_{3}+\mathrm{H}_{2} \mathrm{O}_{2} \stackrel{h v}{\longrightarrow} a H_{3} A s^{(V)} \mathrm{O}_{4}+b H_{2} A s^{(V)} \mathrm{O}_{4}^{-}+\mathrm{H}_{2} \mathrm{O}+b \mathrm{H}^{+}$ \\
\hline & Initial $\mathrm{pH}=10.0$ : \\
\hline R5-20 & $\mathrm{H}_{2} \mathrm{As}^{(I I I)} \mathrm{O}_{3}^{-}+\mathrm{H}_{2} \mathrm{O}_{2} \stackrel{h v}{\longrightarrow} \mathrm{H}_{2} \mathrm{As}^{(\mathrm{V})} \mathrm{O}_{4}^{-}+\mathrm{H}_{2} \mathrm{O}$ \\
\hline R5-21 & $\mathrm{H}_{2} \mathrm{As}^{(I I I)} \mathrm{O}_{3}^{-}+\mathrm{H}_{2} \mathrm{O}_{2} \stackrel{h v}{\longrightarrow} H A s^{(V)} \mathrm{O}_{4}^{2-}+\mathrm{H}_{2} \mathrm{O}+\mathrm{H}^{+}$ \\
\hline $\begin{array}{l}\text { Overall Reaction } \\
\text { (R5-22) }\end{array}$ & $\mathrm{H}_{2} A s^{(I I I)} \mathrm{O}_{3}^{-}+\mathrm{H}_{2} \mathrm{O}_{2} \stackrel{h v}{\longrightarrow} a \mathrm{H}_{2} A s^{(V)} \mathrm{O}_{4}^{-}+b H A s^{(V)} \mathrm{O}_{4}^{2-}+\mathrm{H}_{2} \mathrm{O}+b \mathrm{H}^{+}$ \\
\hline
\end{tabular}

(2) In the presence of oxygen

In the presence of oxygen in the solution, the reaction scheme is more complicated. According to Daniels (1962), oxygen could affect the oxidation process by reacting with As(IV). Therefore the reactions (R5-4) and (R5-5) might be involved in the AOP with $\mathrm{UV} / \mathrm{H}_{2} \mathrm{O}_{2}$

Based on the steady-state hypothesis, we can get the rate equation as:

$$
\left\{\begin{array}{l}
-\frac{d[A s(I I I)]}{d t}=\frac{d[A s(V)]}{d t}=k_{6}\left[H_{2} O_{2}\right]+k_{2}[A s(I V)]\left[O_{2}\right] \\
-\frac{d\left[H_{2} O_{2}\right]}{d t}=k_{6}\left[H_{2} O_{2}\right]-k_{2}[A s(I V)]\left[O_{2}\right]
\end{array}\right.
$$

The rate equation indicates that increase in DO concentration will increase the oxidation rate of As(III). At the same time, increase in DO would result in a decrease in the $\mathrm{H}_{2} \mathrm{O}_{2}$ decomposition rate. This conclusion seems to be supported by the experimental results obtained in this study. 


\subsection{Cost Evaluation}

The parametric investigation of photooxidation of $\mathrm{As}(\mathrm{III})$ has been conducted in the batch and recirculation reactors and the results were presented and discussed in the previous section. The optimal operating conditions are determined as: initial $\mathrm{pH}$ of 3.0 with air sparging in the Direct Photolysis process; initial $\mathrm{pH}$ of 10.0 with the $\left[\mathrm{H}_{2} \mathrm{O}_{2}\right]_{0}:[\mathrm{As}(\mathrm{III})]_{0}$ ratio of 1:1.

In this part, for a set of optimal operating conditions, a preliminary cost evaluation for the oxidation of $\mathrm{As}(\mathrm{III})$ is carried out, taking into account the electrical costs and the chemical (hydrogen peroxide) costs.

Electrical power of $\$ 0.06 / \mathrm{kWh}$ and the hydrogen peroxide price of $\$ 0.002 / \mathrm{ppm} / \mathrm{m}^{3}$ are used in the calculations. In this study, the UV doses for 1 hour of reaction time are $33.33 \mathrm{kWh} / \mathrm{m}^{3}$ and $16.67 \mathrm{kWh} / \mathrm{m}^{3}$ in the batch reactor and the recirculation reactor respectively. The electrical cost for air sparging in batch reactor is equal to the cost for flow recycle in recirculation system with the power of $0.5 \mathrm{kWh} / \mathrm{m}^{3}$ per hour.

The total power cost can be determined by the equation (5-22) and (5-23):

Electrical Cost $=(U V$ Dose per hour + other power per hour $) \times t \times$ Power Cost

$$
\mathrm{H}_{2} \mathrm{O}_{2} \mathrm{Cost}=\left(\mathrm{H}_{2} \mathrm{O}_{2} \text { Concentration }\right) \times \mathrm{H}_{2} \mathrm{O}_{2} \text { price }
$$

in which, $t$ is the time that the reduction of As(III) from 100ppm and 1ppm is achieved. The total operating cost is based on the equation (5-24):

Total Operating Cost $=1.45 \times($ Electrical Cost $)+\mathrm{H}_{2} \mathrm{O}_{2}$ Cost

in which the coefficient 1.45 is the factor for the replacement of lamp and other 
equipment. The total operating costs are calculated and listed in Table 5.11.

Table 5.11 Cost evaluation in different photooxidation processes and reactor modes

\begin{tabular}{|c|c|c|c|c|}
\hline $\begin{array}{c}\text { Reactor } \\
\text { Type }\end{array}$ & $\begin{array}{l}\text { Oxidation } \\
\text { Process }\end{array}$ & $\begin{array}{c}\text { Operating } \\
\text { Time } \\
\text { (hours) } \\
\end{array}$ & $\begin{array}{c}\text { Consumption } \\
\text { of } \mathrm{H}_{2} \mathrm{O}_{2} \\
\left(\mathrm{~g} / \mathrm{m}^{3}\right) \\
\end{array}$ & $\begin{array}{c}\text { Total Operating } \\
\text { Cost } \\
\left(\$ / \mathrm{m}^{3}\right)\end{array}$ \\
\hline Batch & Direct Photolysis & 0.5 & - & 1.47 \\
\hline reactor & AOP & 0.08 & 100 & 0.44 \\
\hline Recirculation & Direct Photolysis & 1.33 & - & 1.99 \\
\hline reactor & AOP & 0.17 & 100 & 0.45 \\
\hline
\end{tabular}

As can be seen, the AOP is more economical than the Direct Photolysis process. No significant difference on the cost was observed between the batch mode and the recirculation mode in AOP.

\subsection{Interferencing Ion Effect}

The interference effect of certain ions was investigated in both Direct Photolysis and $\mathrm{H}_{2} \mathrm{O}_{2} / \mathrm{UV}$ process. Carbonate $\left(\mathrm{CO}_{3}{ }^{2-}\right)$, chloride $\left(\mathrm{Cl}^{-}\right)$and calcium $\left(\mathrm{Ca}^{2+}\right)$ are the ions that may be commonly present in the groundwater and could likely cause some interference as photon scavengers which could affect the oxidation process. In an earlier work reported in the literature (Khoe et al., 1998), it has been claimed that sulfite $\left(\mathrm{SO}_{3}{ }^{2-}\right)$ behaved as a photocatalyst enhancing the oxidation rate and efficiency. So sulfite was also included in the ions tested.

In order to evaluate the above, experiments were carried out in which $1.335 \mathrm{mM}$ of 
$\mathrm{Na}_{2} \mathrm{CO}_{3}, \mathrm{NaCl}, \mathrm{CaCl}_{2}$ and $\mathrm{Na}_{2} \mathrm{SO}_{3}$ were added to the synthetic arsenic solution respectively and investigated under the following conditions: $[\mathrm{As}(\mathrm{III})]_{0}=1.335 \mathrm{mM}(100$ $\mathrm{mg} / \mathrm{L}) ;[\mathrm{DO}]_{0}=0.25 \mathrm{mM}(8.0 \mathrm{mg} / \mathrm{L})$ with air sparging. To cover the typical groundwater $\mathrm{pH}$ regimes, the ion interference was investigated at the initial $\mathrm{pH}$ of 7.5 (the $\mathrm{pH}$ was adjusted prior to the addition of interfering ions); for the $\mathrm{H}_{2} \mathrm{O}_{2} / \mathrm{UV}$ process, the $\left[\mathrm{H}_{2} \mathrm{O}_{2}\right]_{0}:[\mathrm{As}(\mathrm{III})]_{0}=1: 1$ was applied.

\subsubsection{Batch Reactor}

The variations of As(III) concentration in the presence of different interfering ions in the Direct Photolysis process and $\mathrm{H}_{2} \mathrm{O}_{2} / \mathrm{UV}$ processes are shown in Figure 5.37 and Figure 5.38 respectively.

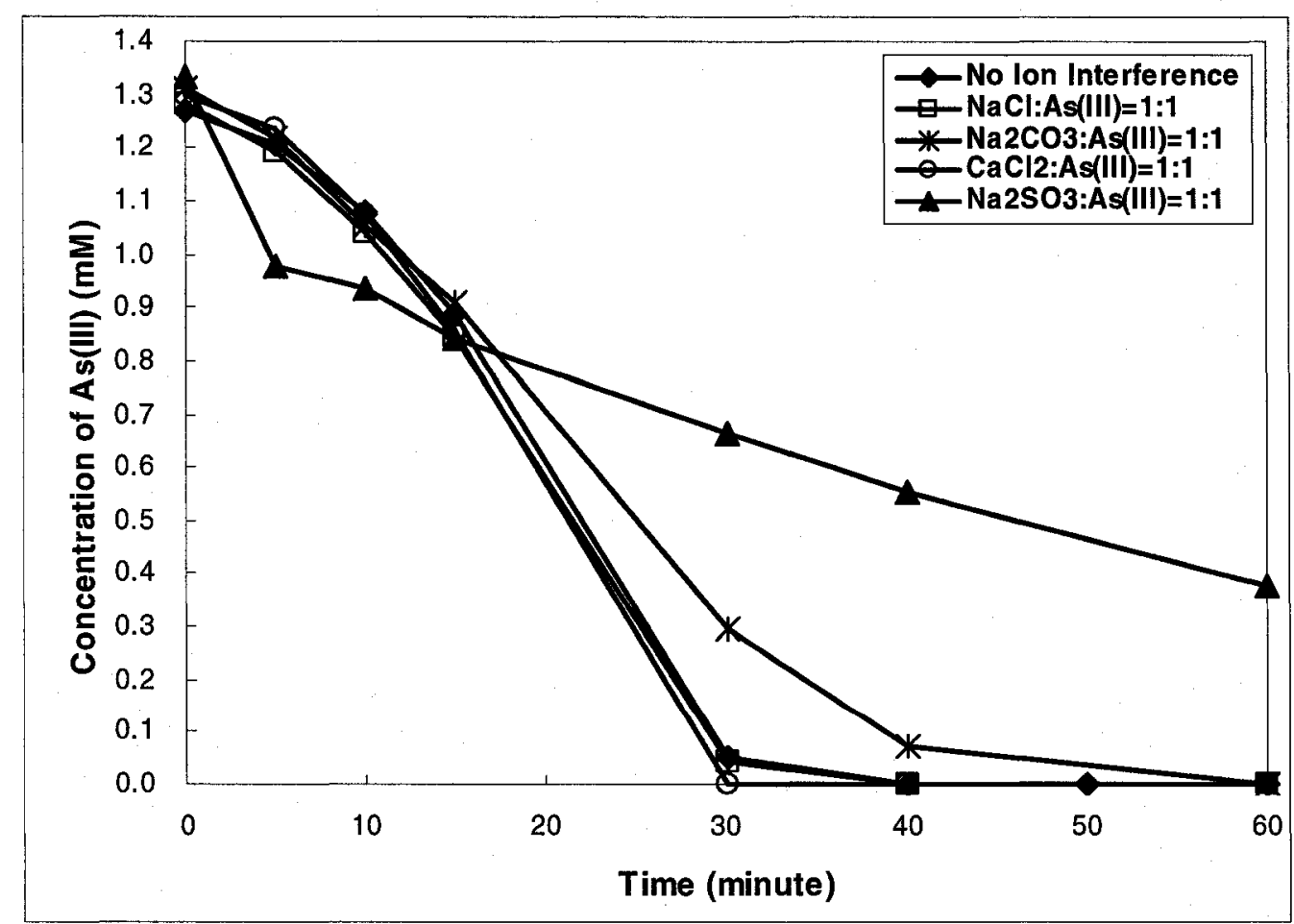

Figure 5.37 As(III) concentration as a function of irradiation time in the batch reactor in direct photolysis in the presence of different interfering ions 


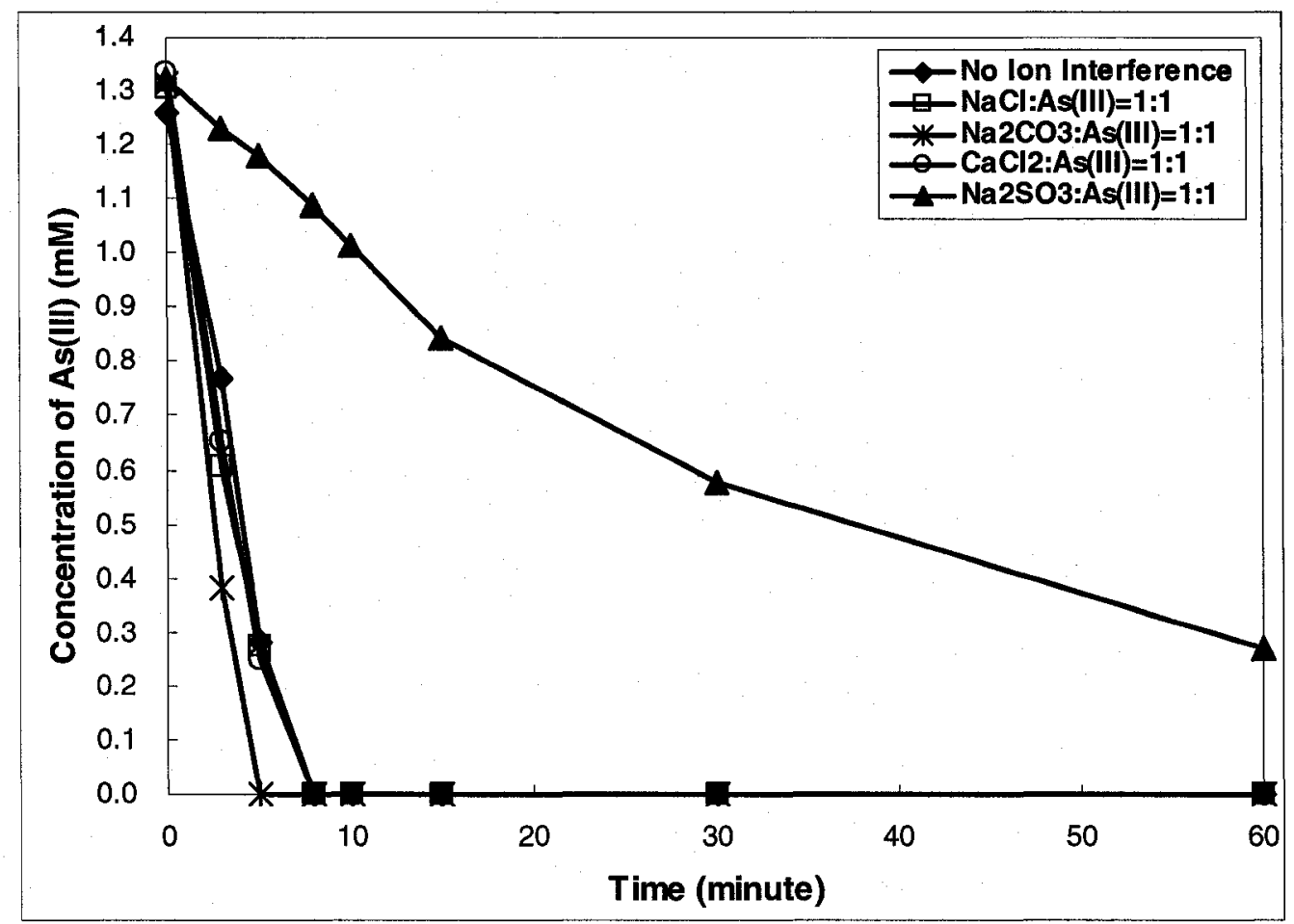

Figure $5.38 \mathrm{As}(\mathrm{III})$ concentration as a function of irradiation time in the batch reactor in AOP in the presence of different interfering ions

The results indicated that $\mathrm{Cl}^{-}$and $\mathrm{Ca}^{2+}$ had no significant interference to the As(III) oxidation in both the Direct Photolysis and the $\mathrm{H}_{2} \mathrm{O}_{2} / \mathrm{UV}$ process.

The presence of $\mathrm{CO}_{3}{ }^{2-}$ in the Direct Photolysis process resulted in the slight decrease of the oxidation efficiency; whereas, in the $\mathrm{H}_{2} \mathrm{O}_{2} / \mathrm{UV}$ process, an increase in the reaction rate by $\mathrm{CO}_{3}{ }^{2-}$ was observed. The effect of $\mathrm{CO}_{3}{ }^{2-}$ on the $\mathrm{As}$ (III) oxidation efficiency in both UV processes could be the reason for buffering effect of $\mathrm{CO}_{3}{ }^{2-}$ indicated in the experimental results.

In the Direct Photolysis process, the enhancement of $\mathrm{As}(\mathrm{III})$ oxidation by $\mathrm{SO}_{3}{ }^{2-}$ was observed in the first 5 minutes of irradiation time, which is consistent with the results indicated the literature (Khoe et al., 1998; Ganesh and Clifford, 2001; Khoe et al., 2005). However, after that initial time, As(III) oxidation rate fell drastically due to the rapid 
consumption of oxygen which remained low in the solution. Air was sparged into the solution during the process but it didn't bring up the DO concentration until the complete decomposition of $\mathrm{SO}_{3}{ }^{2-}$ in the solution. The replenishment of oxygen by air sparging might not be effective to recover the oxygen consumed by the $\mathrm{SO}_{3}{ }^{2-}$. Thus the As(III) oxidation process was inhibited by the lack of oxygen, and it finally resulted in the reduction of overall oxidation efficiency at this condition.

In the $\mathrm{H}_{2} \mathrm{O}_{2} / \mathrm{UV}$ process, the oxidation of $\mathrm{As}(\mathrm{III})$ was significantly interfered by the $\mathrm{SO}_{3}{ }^{2-}$. The drastic decrease of $\mathrm{H}_{2} \mathrm{O}_{2}$ and $\mathrm{SO}_{3}{ }^{2-}$ concentrations was observed in the first 5 minutes of irradiation time. It indicates the reaction of $\mathrm{SO}_{3}{ }^{2-}$ with $\mathrm{H}_{2} \mathrm{O}_{2}$ shown below:

$$
\mathrm{H}_{2} \mathrm{O}_{2}+\mathrm{SO}_{3}^{2-} \rightarrow \mathrm{H}_{2} \mathrm{O}+\mathrm{SO}_{4}^{2-}
$$

$\mathrm{H}_{2} \mathrm{O}_{2}$ was consumed by the reaction (R5-23) prior to its reaction with $\mathrm{As}(\mathrm{III})$, which causes the inhibition of $\mathrm{As}(\mathrm{III})$ oxidation in $\mathrm{H}_{2} \mathrm{O}_{2} / \mathrm{UV}$ process.

\subsubsection{Recirculation Reactor}

The variations of As(III) concentration in the presence of different interfering ions in the Direct Photolysis process and $\mathrm{H}_{2} \mathrm{O}_{2} / \mathrm{UV}$ process are shown in Figure 5.39 and Figure 5.40 respectively. 


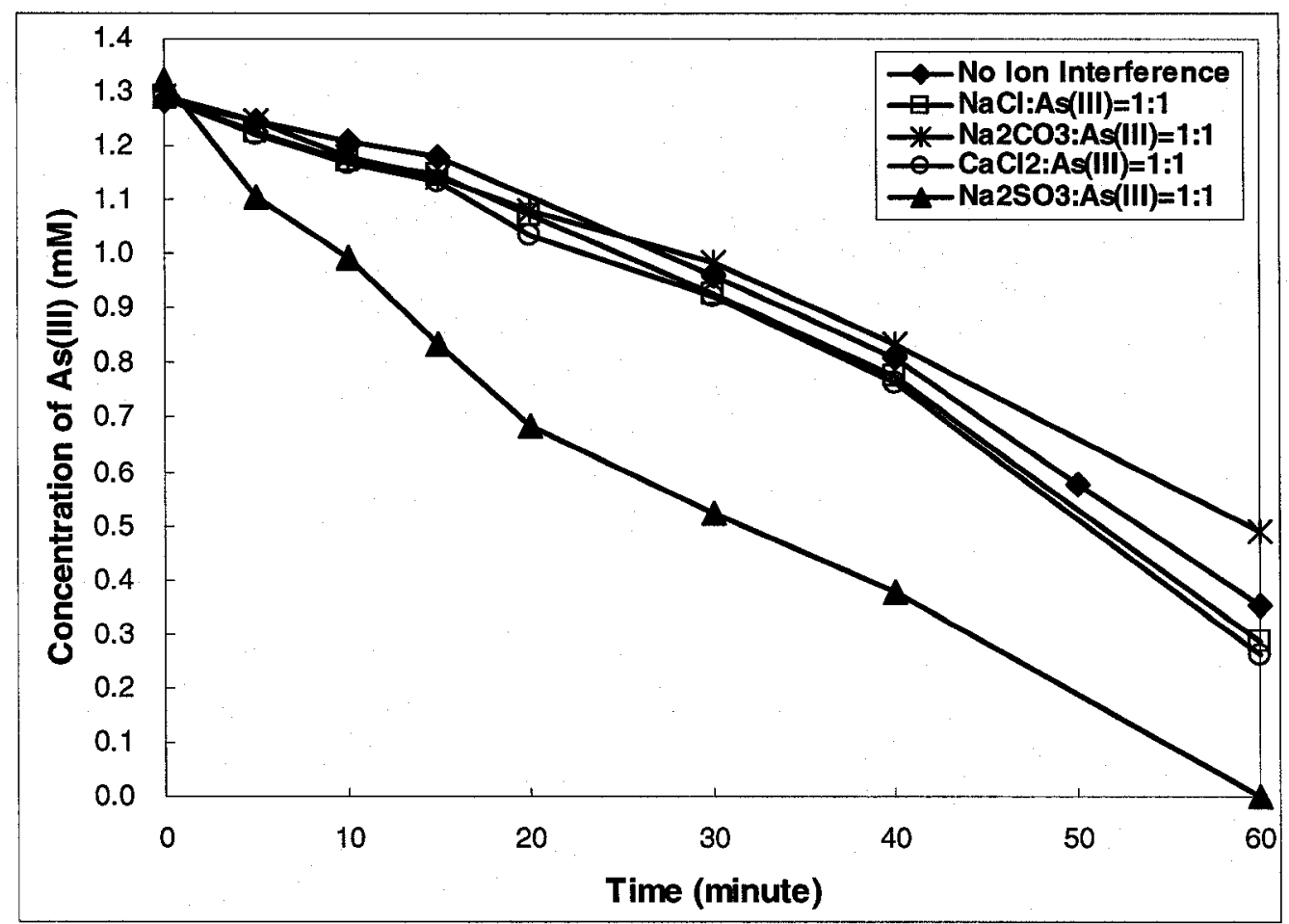

Figure $5.39 \mathrm{As}$ (III) concentration as a function of irradiation time in the recirculation reactor in direct photolysis in the presence of different interfering ions

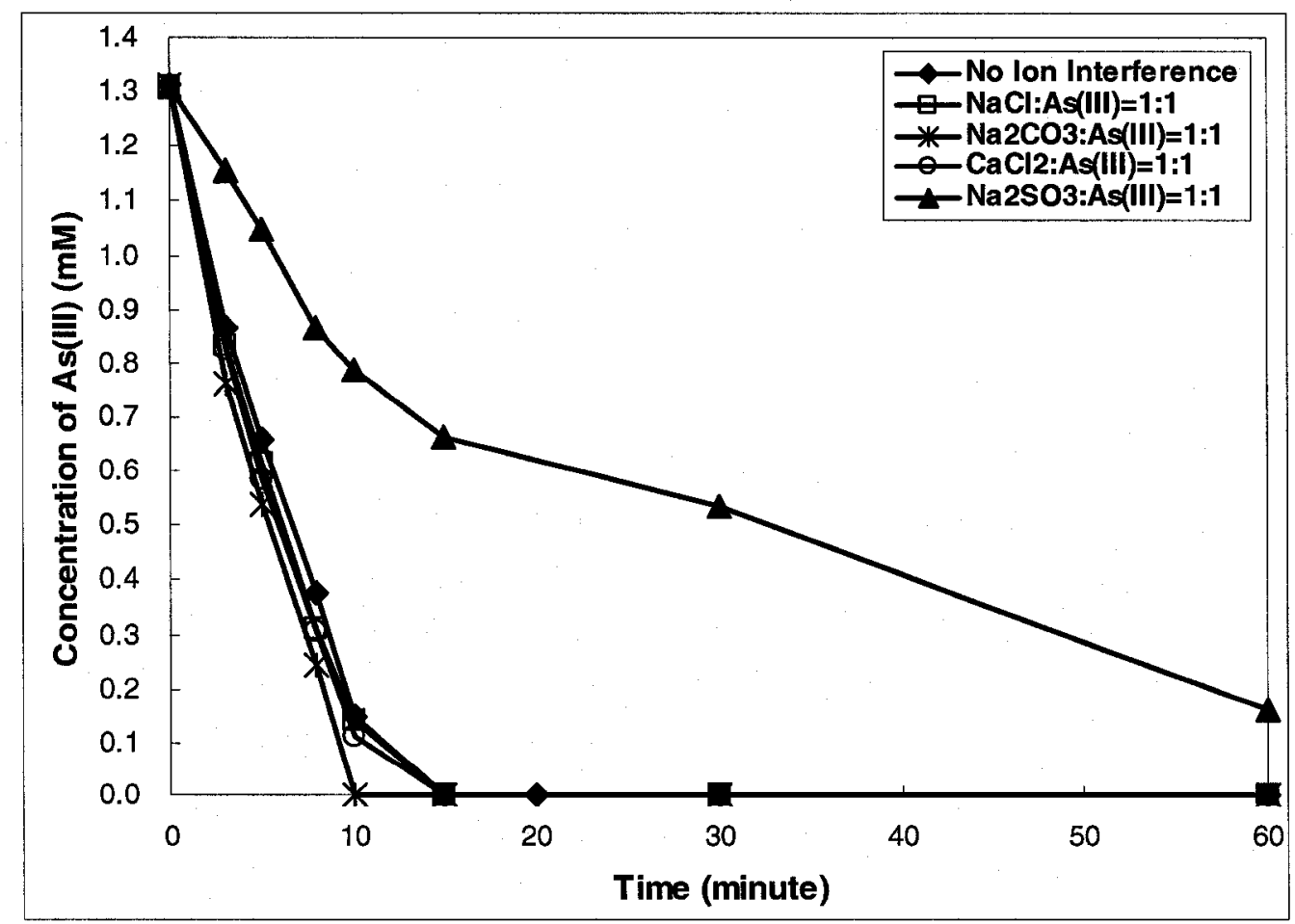

Figure $5.40 \mathrm{As}$ (III) concentration as a function of irradiation time in recirculation reactor in $A O P$ in the presence of different interfering ions

As can be seen, the influences of $\mathrm{Cl}^{-}, \mathrm{Ca}^{2+}$ and $\mathrm{CO}_{3}{ }^{2-}$ on the $\mathrm{As}(\mathrm{III})$ oxidation in both 
Direct Photolysis and AOP are consistent with the results in the batch reactor. Significant interference by $\mathrm{SO}_{3}{ }^{2-}$ to the oxidation efficiency was observed in the $\mathrm{H}_{2} \mathrm{O}_{2} / \mathrm{UV}$ process and it also can be explained by the reaction (R5-23).

In the recirculation reactor, the promotion of As(III) oxidation efficiency by adding sulfite in the Direct Photolysis process was more significant than that in the batch reactor. This is probably due to more efficient replenishment of DO in the recirculation reactor. 


\section{CHAPTER 6. CONCLUSIONS AND RECOMMENDATIONS}

\subsection{Conclusions}

Arsenic found in the natural water systems and in the effluents of industrial operations poses a significant health risk to humans and is currently regarded as a global problem that needs to be dealt with some urgency. Regulatory guidelines have been drastically revised downwards in many jurisdictions around the world and there is a need to develop efficient arsenic removal technologies that are also economic.

The effectiveness of many available arsenic removal technologies can be considerably improved with a pre-oxidation step in which $\mathrm{As}(\mathrm{III})$ is converted to $\mathrm{As}(\mathrm{V})$ prior to its removal and is the basis for the photo-oxidation process evaluated in this study. Both Direct Photolysis and the Advanced Oxidation Process using $\mathrm{H}_{2} \mathrm{O}_{2}$ were investigated in considerable detail in two types of reactor systems, viz., the Batch Reactor and the Recirculation Reactor. The synthetic arsenic wastewater with the initial As(III) concentration range of $20 \sim 100 \mathrm{ppm}$ was investigated at various operating conditions, such as dissolved oxygen, initial $\mathrm{pH}$, initial concentrations of $\mathrm{As}(\mathrm{III})$ and $\mathrm{H}_{2} \mathrm{O}_{2}$. The feasibility of the process has been established in the laboratory batch reactor and then extended on to a custom-modified recirculation reactor.

As(III) could be oxidized to As(V) in both Direct Photolysis and the $\mathrm{UV} / \mathrm{H}_{2} \mathrm{O}_{2}$ process, and $\mathrm{As}(\mathrm{V})$ is found to be the only final arsenic product. In Direct Photolysis, the reaction rate was considerably higher under acidic conditions, around $\mathrm{pH} 3.0$, whereas, in 
contrast, in the $\mathrm{UV} / \mathrm{H}_{2} \mathrm{O}_{2}$ process, higher reaction rates were observed at higher $\mathrm{pH}$ conditions. This difference is partially attributed to the higher rate of formation of the powerful $\mathrm{OH} \cdot$ radicals from the $\mathrm{H}_{2} \mathrm{O}_{2}$ at higher $\mathrm{pH}$ conditions. In all experiments, the changes in Eh and $\mathrm{pH}$ were monitored throughout an experiment and based on the Pourbaix diagram for the Arsenic-Water system, elucidation of the possible arsenic species that are formed at different operating conditions has been made. This information is also utilized in the postulation of the reaction scheme. Kinetic models were derived from the experimental data and the respective rate constants have been evaluated for the different operating conditions.

In Direct Photolysis, the dissolved oxygen concentration is the most important process parameter for the effective oxidation of arsenite. In the anoxic conditions, the oxidation process is very sluggish. In the oxic and suboxic conditions, significant oxidation of As(III) was observed. Further investigation indicates that the oxidation reaction rate is not affected by the oxygen level when the dissolved oxygen concentration is above $1.0 \mathrm{mg} / \mathrm{L}$.

In the $\mathrm{UV} / \mathrm{H}_{2} \mathrm{O}_{2}$ process, $\left[\mathrm{H}_{2} \mathrm{O}_{2}\right]_{0}:[\mathrm{As}(\mathrm{III})]_{0}$ ratio is found to be the key process parameter. An optimal $\left[\mathrm{H}_{2} \mathrm{O}_{2}\right]_{0}:[\mathrm{As}(\mathrm{III})]_{0}$ ratio of 1:1 was established. It is indicated that when $\left[\mathrm{H}_{2} \mathrm{O}_{2}\right]_{0}:[\mathrm{As}(\mathrm{III})]_{0}$ ratio is below the optimal value, the oxidation efficiency is also affected by the dissolved oxygen level.

The kinetic study and analysis of the rate data indicate that in Direct Photolysis, in the air sparging condition, the As(III) oxidation process is zero-order in arsenic. In the 
closed tank condition, the process appears to proceed in two stages. At the higher DO condition in the first stage, the reaction is zero-order; at the near-anoxic condition in second stage, the reaction is first-order. In the $\mathrm{UV} / \mathrm{H}_{2} \mathrm{O}_{2}$ process, all the experimental data fit the first-order model very well.

The preliminary study on ion interference indicates that both Direct Photolysis and Advanced Oxidation Process are not significantly affected by some of the common ions such as carbonate, chloride and calcium in the natural and industrial water systems. In Direct Photolysis, the addition of sulfite could enhance the oxidation rate and efficiency, but its performance is very much dependent on the dissolved oxygen concentration in the solution. In the $\mathrm{H}_{2} \mathrm{O}_{2} / \mathrm{UV}$ process, sulfite significantly inhibits the As(III) oxidation process as it rapidly reacts and consumes the $\mathrm{H}_{2} \mathrm{O}_{2}$.

For the oxidation of $\mathrm{As}(\mathrm{III})$ to $\mathrm{As}(\mathrm{V})$, for the range of parameter conditions investigated in this study, the Advanced Oxidation Process is the preferred process due to its higher efficiency and overall economics.

The extensive kinetic results and rate data collected in this study for the different operating conditions can be used in the design of photochemical reactors to treat arsenic contaminated wastewater. Approximate plant costs can also be arrived at from the basic power consumption data collected in this study.

Some of the generalized conclusions from this study are listed in Table 6.1. 
Table 6.1 Summary of the general conclusions

\begin{tabular}{|c|c|c|}
\hline Process & Reactor Type & Conclusions \\
\hline \multirow[t]{2}{*}{$\begin{array}{c}\text { Direct } \\
\text { Photolysis }\end{array}$} & Batch reactor & $\begin{array}{l}\text { 1) For a set of operating conditions, the rate of oxidation of } \\
\text { As(III) remains unchanged until the dissolved oxygen } \\
\text { falls to a very low level. Beyond this point, the rate of } \\
\text { oxidation of As(III) is significantly reduced. } \\
\text { 2) The initial As(III) concentration did not affect the } \\
\text { oxidation rate. } \\
\text { 3) Initial pH of the solution influenced the arsenic oxidation } \\
\text { rate. In the acidic range, higher oxidation rates were } \\
\text { obtained. } \\
\text { 4) At dissolved oxygen levels above approximately } 1 \mathrm{mg} / \mathrm{L} \text {, } \\
\text { As(III) oxidation process is zero-order in arsenic. }\end{array}$ \\
\hline & Recirculation reactor & $\begin{array}{l}\text { 5) The results in 2) to 4) above were also observed in the } \\
\text { recirculation reactor. } \\
\text { 6) Per } \mathrm{mM} \text { of } \mathrm{As} \text { (III) oxidized, power consumption of the } \\
\text { batch reactor is lower than that of the recirculation } \\
\text { reactor. }\end{array}$ \\
\hline \multirow[t]{2}{*}{$\begin{array}{l}\text { AOP with } \\
\mathrm{UV} / \mathrm{H}_{2} \mathrm{O}_{2}\end{array}$} & Batch reactor & $\begin{array}{l}\text { 7) }\left[\mathrm{H}_{2} \mathrm{O}_{2}\right]_{0} /[\mathrm{As}(\mathrm{III})]_{0} \text { ratio had a significant effect on the } \\
\text { oxidation efficiency. } \\
\text { 8) Dissolved oxygen decreases in the course of As(III) } \\
\text { oxidation process in Advanced Oxidation Process. } \\
\text { 9) When the }\left[\mathrm{H}_{2} \mathrm{O}_{2}\right]_{0} /[\mathrm{As}(\mathrm{III})]_{0} \text { ratio was below } 1 \text {, the } \\
\text { dissolved oxygen level has a positive effect on the } \\
\text { percentage conversion of As(III). Above } 1 \text {, dissolved } \\
\text { oxygen does not have a significant impact. } \\
\text { 10) Under alkaline conditions the rate of oxidation is high. } \\
\text { 11) Initial As(III) concentration in the range of } 0.267 \sim 1.335 \\
\text { mM did not significantly impact the oxidation rate. } \\
\text { 12) All the experimental data fit the first-order model. }\end{array}$ \\
\hline & Recirculation reactor & $\begin{array}{l}\text { 13) The results in 7) to 12) above were also observed in the } \\
\text { recirculation reactor. } \\
\text { 14) Per } \mathrm{mM} \text { of } \mathrm{As}(\mathrm{III}) \text { oxidized, power consumption of the } \\
\text { recirculation reactor is lower than that of the batch } \\
\text { reactor. }\end{array}$ \\
\hline
\end{tabular}




\subsection{Recommendations}

The feasibility of the photooxidation for As(III) by both Direct Photolysis and Advanced Oxidation Process has been confirmed in the present study. The proposed kinetics models provide good explanation of the effect of several parameters on the performance of oxidation process in different reactor modes. Based on the results obtained in the present study, the possible directions for future work and recommendations for future research in this area are as follows:

1) The reaction mechanism of photooxidation process is fairly complex, which involves a series of reactions between molecules, atoms and radicals including the photo-initiating step, propagation steps and termination steps. The proposed reaction schemes in this study need to be explored in detail to verify the existence of possible intermediates, such as $\mathrm{HO}_{2} \cdot$ and $\mathrm{H}_{2} \mathrm{O}_{2}$ (in Direct Photolysis) and further to determine the distribution of those products in the As(III) oxidation process under the different operating conditions.

2) The overall kinetics model needs to be developed further to incorporate the effect of the spectral distribution of light source and the light intensity profile in the reactor.

3) Theoretical analysis of fluid flow patterns in the reactor would be useful to get a better handle on the mixing patterns that can help in the prediction of the efficiency of the reactor for the oxidation process.

4) Further kinetics studies in a film-type Rotospray Photolytic Reactor (RPR) are recommended. In this type of reactor, the reaction pathway can be simplified and 
controlled by elimination of reactions that occur due to the continued irradiation of the primary reaction products. Also, the flow pattern in the RPR is more easily analyzed and the kinetic rate data obtained in such a reactor would be easier to interpret and perhaps more reliable.

5) The understanding of the mechanism of photooxidation of arsenic could be enhanced with further advances in arsenic speciation methods that can separate the different forms of arsenic quantitatively.

6) Only a preliminarily investigation of ion interference was carried out in this study. The further exploration of the application of Advanced Oxidation Process with $\mathrm{UV} / \mathrm{H}_{2} \mathrm{O}_{2}$ on the arsenic-contaminated field wastewater representative of actual contaminated site is recommended in which potential interfering ions can be properly evaluated.

7) It is also worthwhile to combine the investigation of preoxidation of arsenite with the incorporation of the follow-up arsenic removal processes, such as ion-exchange process and membrane filtration process to determine the feasibility of the integrated process technology. 


\section{REFERENCES}

Behar, D., Czapski, G., Rabani, J., Dorfman, L. M., Schwarz, H. A.(1970). Acid

Dissociation Constant and Decay Kinetics of the Perhydroxyl Radical. The Journal of Physical Chemistry, 74(17): 3209 - 3213.

Bisceglia, K. J., Rader, K. J., Carbonaro, R. F., Mahony, J. D., Toro, D. M. (2005). Iron(II)-Catalyzed Oxidation of Arsenic(III) in a Sediment Column. Environmental Science \& Technology, 39(23): 9217-9222.

Bissen, M., Frimmel, F. H. (2003). Arsenic - A Review. Part I: Occurrence, Toxicity, Speciation, Mobility. Acta Hydrochimica et Hydrobiologica, 31(1): 9-18.

Bissen, M., Frimmel, F. H. (2003). Arsenic - A Review. Part II: Oxidation of Arsenic and Its Removal in Water Treatment. Acta Hydrochimica et Hydrobiologica, 31(2): 97-107.

Bissen, M., Veiillard-Baron, M. M., Schindelin, A. J., Frimmel, F. H. (2001). $\mathrm{TiO}_{2}$-catalyzed Photooxidation of Arsenite to Arsenate in Aqueous Samples. Chemosphere, 44(4): 751-757.

Boucher, P., Accominotte, M., Vallon, J. J. (1996). Arsenic Speciation by Ion Pair Reversed-phase Liquid Chromatography with Coupled Amperometric and Ultraviolet Detection. Journal of Chromatographic Science, 34(5): 226-229.

Brookins, D.G. (1988). Eh-pH Diagrams for Geochemistry. Springer-Verlag, New York, USA. 
Brooks, W.E. (2007). Arsenic Statistics and Information.

http://minerals.usgs.gov/minerals/pubs/commodity/arsenic/, U.S. Geological Survey.

Buldini, P. L., Ferri, D., Zini, Q. (1980). Differential Pulse Polarographic Determination of Inorganic and Organic Arsenic in Natural Waters. Microchimica Acta, 73(1-2): $71-78$.

Burguera, M., Burguera, J. L. (1997). Analytical Methodology for Speciation of Arsenic in Environmental and Biological Samples. Talanta, 44(9): 1581-1604.

Buschmann, J., Canonica, S., Lindauer, U., Hug, S. J., Sigg, L. (2005). Photoirradiation of Dissolved Humic Acid Induces Arsenic (III) Oxidation. Environmental Science \& Technology, 39(24): 9541-9546.

Calvert, J.G., Pitts, J.N. (1966) Photochemistry, Wiley, New York.

Canadian Council of Ministers of the Environment (2006). Canadian Water Quality Guidelines for the Protection of Aquatic Life.

http://www.ccme.ca/publications/ceqg_rcqe.html, Canada.

Canadian Council of Ministers of the Environment (2006). Canadian Water Quality Guidelines for the Protection of Agricultural Water Uses.

http://www.ccme.ca/publications/ceqg_rcqe.html, Canada.

Cathum, S.J., Brown, C.E, Wong, E. (2002). Determination of $\mathrm{Cr}^{3+}, \mathrm{CrO}_{4}{ }^{2-}$, and $\mathrm{Cr}_{2} \mathrm{O}_{7}{ }^{2-}$ in Environmental Matrixes by High-performance Liquid Chromatography with Diode-array Detection (HPLC-DAD). Analytical and Bioanalytical Chemistry, 373(1): 103-110. 
Cathum, S.J., Velicogna, D., Obenauf, A., Dumouchel, A., Punt, M., Brown, C.E., Ridal, J. (2005). Detoxification of Mercury in the Environment. Analytical and Bioanalytical Chemistry, 381(8): 1491-1498.

Council of the European Union (1998). Council Directive 98/83/EC of 3 November 1998 on the quality of water intended for human consumption. http://eur-lex.europa.eu/LexUriServ/site/en/oj/1998/1_330/1_33019981205en003200 54.pdf, Official Journal of the European Communities.

Cox, P.A. (2004). Inorganic Chemistry. Bios Scientific Publishers, New York.

Daniels, M. (1962). Photochemically-induced Oxidation of Arsenite: Evidence for the Existence of Arsenic(IV). The Journal of Physical Chemistry, 66(3): 1473-1475.

Department of Justice Canada (2007). Metal Mining Effluent Regulations (SOR/2002-222).http://laws.justice.gc.ca/en/F-14/SOR-2002-222/index.html, Canada.

Diffey, B. L. (2002). Sources and Measurement of Ultraviolet Radiation. Methods, 28(1): $4-13$

Do, B., Robinet, S., Pradeau, D., Guyon, F. (2001). Speciation of Arsenic and Selenium Compounds by Ion-pair Reversed-phase Chromatography with Electrothermic Atomic Absorption Spectrometry: Application of Experimental Design for Chromatographic Optimization. Journal of Chromatography. A, 918(1): 87-98.

Dodd, M. C., Vu, N. D., Ammann, A., Le, V. C., Kissner, R., Pham, H. V., Cao, T. H., Berg., M., Gunten, U. V. (2006). Kinetics and Mechanistic Aspects of As (III) 
Oxidation by Aqueous Chlorine, Chloramines, and Ozone. Environmental Science \& Technology, 40(10): 3285-3292.

Driehaus, W., Jekel, M. (1993). Oxidationsverfahren für dreiwertiges Arsen. In: Jekel, M. (Ed.): Arsen in der Trinkwasserversorgung. Wasser, 82: 55-70.

Dutta, P. K., Pehkonen, S. O., Sharma, V. K., Ray, A. K. (2005). Photocatalytic Oxidation of Arsenic(III): Evidence of Hydroxyl Radicals. Environmental Science \& Technology, 39(6): 1827-1834.

Eisler, R. (1988). Arsenic Hazards to Fish, Wildlife, and Invertebrates: A Synoptic Review. U.S. Fish and Wildlife Service, Biological Report 85 (1.12).

Emett M. T., Khoe G. H. (2001). Photochemical Oxidation of Arsenic by Oxygen and Iron in Acidic Solutions. Water Research, 35(3): 649-656.

Ferguson, M. A., Hoffmann, M. R., Hering, J.G. (2005). TiO ${ }_{2}$-Photocatalyzed As (III) Oxidation in Aqueous Suspensions: Reaction Kinetics and Effects of Adsorption. Environmental Science \& Technology, 39(6): 1880-1886.

Frank, P., Clifford, D. (1986). Arsenic (III) Oxidation and Removal from Drinking Water. EPA-600-S2-86-021, USA.

Ganesh, G., Clifford, D. (2001). Laboratory Study on the Oxidation of As(III) to As(V). EPA-600-R-01-021, USA.

Glaze, W. H., Kang, J. W., Chapin, D. H.(1987). The Chemistry of Water Treatment Processes Involving Ozone, Hydrogen Peroxide and UV-radiation Ozone. Science and Engineering, 9(4): 335-352. 
Gottschalk, C., Schmitz, S., Driehaus, W., Jekel, M. (1992). Methods for Oxidation of Arsenic(III) in Drinking Water Treatment. Vom Wasser, 79: 225-235.

Greenwood, N. N., Earnshaw, A. 1984. Chemistry of the Elements. Pergamon Press, London.

Guerin, T., Astruc. A., Astruc. M.(1999). Speciation of Arsenic and Selenium Compounds by HPLC Hyphenated to Specific Detectors: A Review of the Main Separation Techniques. Talanta, 50(1): 1-24.

Health Canada (1999). Summary of Guidelines for Canadian Drinking Water Quality. http://dsp-psd.communication.gc.ca/Collection/H48-10-2000E.pdf, Canada.

Health Canada (2006). Guidelines for Canadian Drinking Water Quality - Arsenic. http://www.hc-sc.gc.ca/ewh-semt/pubs/water-eau/doc_sup-appui/arsenic/index_e.ht ml, Canada.

Hug, S. J., Canonica, L., Wegelin, M., Gechter, D., Gunten, U. V. (2001). Solar Oxidation and Removal of Arsenic at Circumneutral pH in Iron Containing Waters. Environmental Science \& Technology, 35(10): 2114-2121.

Hug, S. J., Leupin, O. (2003). Iron-catalyzed Oxidation of Arsenic (III) by Oxygen and by Hydrogen Peroxide: pH-dependent Formation of Oxidants in the Fenton Reaction. Environmental Science \& Technology, 37 (12): 2734-2742.

Hughes, M. F. (2002). Arsenic Toxicity and Potential Mechanisms of Action. Toxicology Letters, 133 (1): 1-16.

Jayaweera, P. M., Godakumbura, P. I., Pathiratne, K. A. S. (2003). Photocatalytic 
Oxidation of As(III) to As(V) in Aqueous Solutions: A Low Cost Pre-oxidative Treatment for Total Removal of Arsenic from Water. Current Science, 84(4): 541-543.

Kanel, S. R., Manning, B., Charlet, L., Choi, H. (2005). Removal of Arsenic (III) from Groundwater by Nanoscale Zero-Valent Iron. Environmental Science \& Technology, 39(5): 1291-1298.

Kartinen E.O., Martin C.J. (1995). An Overview of Arsenic Removal Processes. Desalination, 103(1-2): 79-88.

Khoe, G. H., Emett, M. T., Robins, R. G. (1997). Photoassisted Oxidation of Species in Solution. Patent: US 5,688,378, USA.

Khoe, G.H., Zaw, M., Prasad, P.S., Emett, M.T. (1998). Photo-assisted Oxidation of Inorganic Species in Aqueous Solutions. Patent: PCT/AU1998/000576.

Khoe, G.H., Zaw, M., Prasad, P.S., Emett, M.T. (2005). Photo-assisted Oxidation of Inorganic Species in Aqueous Solution. Patent: US 84,391 B1, USA.

Kim, M. J., Nriagu, J. (2000). Oxidation of Arsenite in Groundwater Using Ozone and Oxygen. Science of the Total Environment, 247: 71-79.

Kläning, U. K., Bielski, V. B. H. J., Sehesteds, K. (1989). Arsenic(IV). A Pulse-radiolysis Study. Inorganic Chemistry, 28(14): 2717-2724.

Knör, G., Vogler, A. (1994). Photochemistry and Photophysics of Antimony(II1) Hyper Porphyrins: Activation of Dioxygen Induced by a Reactive sp Excited State. Inorganic Chemistry, 33(2): 314-318. 
Kocar, B. D., Inskeep, W. P. (2003). Photochemical Oxidation of As (III) in Ferrioxalate Solutions. Environmental Science \& Technology, 37(8): 1581-1588.

Krishna, M.V., Chandrasekaran, K., Karunasagar, D., Arunachalam, J. (2001). A Combined Treatment Approach Using Fenton's Reagent and Zero Valent Iron for the Removal of Arsenic from Drinking Water. Journal of Hazardous Materials, 84(2-3): 229-240.

Lawer, J. E. (2004). Resonance broadening of $\mathrm{Hg}$ lines as a density diagnostic in high intensity discharge lamps. Plasma Sources Science and Technology, 13(2): 321-328.

Laintz, K. E., Shieh, G. M., Wai, C. M. (1992). Simultaneous Determination of Arsenic and Antimony Species in Environmental Samples Using Bis(trifluoroethyl) dithiocarbamate Chelation and Supercritical Fluid Chromatography. Journal of Chromatographic Science, 30(4): 120-123.

Le, X. C., Cullen, W. R., Reimer, K. J. (1994). Speciation of Arsenic Compounds by HPLC with Hydride Generation Atomic Absorption Spectrometry and Inductively Coupled Plasma Mass Spectrometry Detection. Talanta, 41(4): 495.

Lee, H., Choi, W. (2002). Photocatalytic Oxidation of Arsenite in $\mathrm{TiO}_{2}$ Suspension: Kinetics and Mechanisms. Environmental Science \& Technology, 36(17): 3872-3878.

Lee, Y., Um, I. H., Yoon, J. (2003). Arsenic(III) Oxidation by Iron (VI) (Ferrate) and Subsequent Removal of Arsenic(V) by Iron(III) Coagulation. Environmental Science \& Technology, 37(24): 5750-5756. 
Legrini, O., Oliveros, E., and Braun, A. M. (1993). Photochemical Processes for Water Treatment. Chemical Reviews, 93(2): 671-698.

Letterman, A. [Ed.] (1999). Water Quality and Treatment: A Handbook of Community Water Supplies. American Water Works Association, McGraw-Hill, New York.

Levenspiel, O (1999). Chemical Reaction Engineering (Third Edition). John Wiley \& Sons, Inc., New York, USA.

Liu, L. (1999). Ammonia Removal from Industrial Wastewater-Analysis of Photochemical Reaction Performance (Master Thesis), Carleton University, Canada. Luñák, S, Sedlák, P. (1992). Photoinitiated Reactions of Hydrogen Peroxide in the Liquid Phase. Journal of Photochemistry and Photobiology A: Chemistry, 68 (1): 1-33.

McNaught, A.D., Wilkinson, A. (1997). Compendium of Chemical Terminology: IUPAC recommendations (2nd edition). Blackwell Science.

Mandal, B. K., Suzuki, K. T.(2002). Arsenic Round the World-A Review. Talanta, 58(1): 201-235.

Manning, B. A., Martens, D. A. (1997). Speciation of Arsenic(III) and Arsenic (V) in Sediment Extracts by High-Performance Liquid Chromatography-Hydride Generation Atomic Absorption Spectrophotometry. Environmental Science \& Technology. 31(7): 171-177.

Meharg, A. A. (2005). Venomous Earth - How Arsenic Caused the World's Worst Mass Poisoning. Macmillan Science, New York, USA.

Morin, P., Amran, M. B., Favier, S., Heimburger, R., Leroy, M.(1991). Speciation of 
Arsenical Species by Anion-exchange and Ion-pair Reversed-phase Liquid Chromatography. Fresenius' Journal of Analytical Chemistry, 339(7): 504-509.

Munoz, E., Palmero, S. (2005). Analysis and Speciation of aArsenic by Stripping Potentiometry: A Review. Talanta, 65(3): 613-620.

Munter, R. (2001). Advanced Oxidation Processes - Current Status and Prospects. Proceedings of the Estonian Academy of Sciences: Chemistry, 50(2): 59-80.

National Academy of Sciences (2001), Drinking Water Needs and Infrastructure Hearing before the Subcommittee on Environment and Hazardous Materials of the Committee on Energy and Commerce House of Representatives (Serial No. 107-59). http://republicans.energycommerce.house.gov/107/action/107-59.pdf, Government of USA.

National Research Council of Canada (1978). Effects of Arsenic in the Canadian Environment. Associate Committee on Scientific Criteria for Environmental Quality, Canada.

Ng, K. S., Ujang, Z., Le-Clech, P. (2004). Arsenic Removal Technologies for Drinking Water Treatment. Reviews in Environmental Science and Bio/Technology, 3(1): 43-53.

Ochsenkiihn-Petropulu, M., Schramel, P. (1995). On-line Ion Exchange System Coupled to Inductively Coupled Plasma Atomic Emission Spectrometer with Ultrasonic Nebulization for the Separation, Preconcentration and Determination of Arsenic(V) and Monomethylarsonate. Analytica Chimica Acta, 313(3): 243-252. 
Office of Research and Development (2000). Regulations on the Disposal of Arsenic Residuals from Drinking Water Treatment Plants. EPA-600-R-00-025, USA.

Office of Solid waste and Emergency Response (2002). Arsenic Treatment Technologies for Soil, Waste, and Water. EPA-542-R-02-004, USA.

Office of Water (2000). Technologies and Costs for Removal of Arsenic from Drinking Water. EPA-815-R-00-028, USA.

Office of Water (2003). Arsenic Treatment Technology Evaluation Handbook for Small Systems. EPA-816-R-03-014, USA.

Pena, M. E., Korfiatis, G. P., Patel, M., Lippincott, L., Meng, X. G. (2005). Adsorption of As(V) and As(III) by Nanocrystalline Titanium Dioxide. Water Research, 39(11): 2327-2337.

Pettine, M., Campanella, L., Millero, F. J. (1999). Arsenite Oxidation by $\mathrm{H}_{2} \mathrm{O}_{2}$ in Aqueous Solutions. Geochimica et Cosmochimica Acta, 63(18): 2727-2735.

Peyton, G. R., Holm, T. R., Shim, J. (2006). Development of Low Cost Treatment Options for Arsenic Removal in Water Treatment Facilities. ISWS Contract Report 2006-09, USA.

Philips R. (1983). Sources and Applications of Ultraviolet Radiation, Academic Press Inc. Ltd, London, England.

Pourbaix, M. (1974). Atlas of Electrochemical Equilibria in Aqueous Solutions (2nd edition). National Association of Corrosion Engineers, Houston, USA.

Pozdnyakov, I. P., Glebov, E. M., Plyusnin, V. F., Grivin, V. P., Ivanov, Y. V., Vorobyev, 
D. Y., Bazhin, N. M. (2000). Mechanism of $\mathrm{Fe}(\mathrm{OH})^{2+}($ aq) Photolysis in Aqueous

Solution. Pure and Applied Chemistry, 72(11): 2187-2197.

Riveros, P.A., Dutrizac, J.E., Spencer, P. (1999). Arsenic Disposal Practices in the Metallurgical Industry. Canadian Metallurgical Quarterly, 40(4): 395-420.

Roy, P., Saha, A. (2002). Metabolism and Toxicity of Arsenic: A Human Carcinogen. Current Science, 82(1): 38-45.

Ryu, J., Choi, W. (2004). Effects of $\mathrm{TiO}_{2}$ Surface Modifications on Photocatalytic Oxidation of Arsenite: The Role of Superoxides. Environmental Science \& Technology, 38(10): 2928-2933.

Schlegel, D., Mattusch, J., Wennrich. R. (1996). Speciation analysis of arsenic and selenium compounds by capillary electrophoresis. Fresenius' Journal of Analytical Chemistry, 354(5-6): 535-539.

Schoen, A., Beck, B., Sharma, R., Dubé, E. (2004). Arsenic toxicity at low doses: epidemiological and mode of action considerations. Toxicology and Applied Pharmacology, 198 (3): 253-267.

Simon, S., Tran, H., Pannier, F., Potin-Gautier, M. (2004). Simultaneous Determination of Twelve Inorganic and Organic Arsenic Compounds by Liquid Chromatography-ultraviolet Irradiation-hydride Generation Atomic Fluorescence Spectrometry. Journal of Chromatography. A, 1024(1-2): 105-113.

Slaveykova, V., Rastegar, F., Leroy, M. J. F. (1996). Behaviour of Various Arsenic Species in Electrothermal Atomic Absorption Spectrometry. Journal of Analytical Atomic 
Spectrometry, 11(10): 997-1002.

Šlejkovec, Z., Byrne, A. R., Dermelj, M. (1993). Neutron Activation Analysis of Arsenic Species. Journal of Radioanalytical and Nuclear Chemistry, 173(2): 357-364.

Smedley, P.L., Kinniburgh, D.G. (2002). A Review of the Source, Behaviour and Distribution of Arsenic in Natural Waters. Applied Geochemistry, 17(5): 517-568.

Smith, A. H., Hopenhayn-Rich, C., Bates, M. N., Goeden, H. M., Hertz-Picciotto, I., Duggan, H. M., Wood, R., Kosnett, M. J., Smith, M. T. (1992). Cancer Risk from Arsenic in Drinking Water. Environmental Health Perspectives, 97: 259-267.

Smith, A. H., Lopipero, P. A., Bates, M. N., Steinmaus, C. M. (2002). Arsenic Epidemiology and Drinking Water Standards. Science, 296: 2145-2146.

Smith, E., Smith, J., Smith, L., Biswas, T., Correll, R., Naidu, R. (2003). Arsenic in Australian Environment - An Overview. Journal of Environmental Science And Health, Part A- Toxic/Hazardous Substances \& Environmental Engineering, A38(1): $223-239$.

Sridhar, S., Liu, L., Yang, X., Gould, D. (2000). Ammonia Removal from Industrial Wastewater- Analysis of Performance of Photochemical Reactors. Sustainable Energy and Environmental Technologies (3rd Asia-Pacific Conference): 582-589.

Stummeyer, J., Harazim, B., Wippermann, T. (1996). Speciation of Arsenic in Water Samples by High-performance Liquid Chromatography-hydride Generation-atomic Absorption Spectrometry at Trace Levels Using a Post-column Reaction System. Fresenius' Journal of Analytical Chemistry, 354(3): 344-351. 
Tapio, S., Grosche, B. (2006). Arsenic in the Aetiology of Cancer. Mutation Research, 612(3): 215-246.

Tchounwou, P. B., Patlolla, A. K., Centeno, J. A. (2003). Carcinogenic and Systemic Health Effects Associated with Arsenic Exposure- A Critical Review. Toxicologic Pathology, 31(6): 575-588.

Terlecka, E. (2005). Arsenic Speciation Analysis in Water Samples: A Review of the Hyphenated Techniques. Environmental Monitoring and Assessment, 107(1-3): 259-284.

Tomeik, P., Jursa, S., Mesaros, S., Bustin, D. (1997). Titration of As(III) with Electrogenerated Iodine in the Diffusion Layer of an Interdigitated Microelectrode Array. Journal of Electroanalytical Chemistry, 423(1-2): 115-118.

US Peroxide Head Office (2003). Introduction to Hydrogen Peroxide -Physical and Chemical Properties of Hydrogen Peroxide.

http://www.h2o2.com/intro/properties.html

Vega, L., Styblo, M., Patterson, R., Cullen, W., Wang, C., Germolec, D. (2001). Differential Effects of Trivalent and Pentavalent Arsenicals on Cell Proliferation and Cytokine Secretion in Normal Human Epidermal Keratinocytes. Toxicology and Applied Pharmacology, 172(3): 225-232.

Vink, B. W. (1996). Stability Relations of Antimony and Arsenic Compounds in the Light of Revised and Extended Eh-pH Diagrams. Chemical Geology, 130(1-2): 21-30.

Woller, A., Mester, Z., Fodor, P. (1995). Determination of Arsenic Species by 
High-performance Liquid Chromatography-ultrasonic Nebulization-atomic Fluorescence Spectrometry. Journal of Analytical Atomic Spectrometry, 10(9): 609-613.

Xu, T., Kamat, P. V., O'Shea, K. E. (2005). Mechanistic Evaluation of Arsenite Oxidation in $\mathrm{TiO}_{2}$ - assisted Photocatalysis. The Journal of Physical Chemistry A, 109(40): 9070-9075.

Yang, H., Lin, W. Y., Rajeshwar, K. (1999). Homogeneous and Heterogeneous Photocatalytic Reactions Involving As(III) and As(V) Species in Aqueous Media. Journal of Photochemistry and Photobiology A: Chemistry, 123(1-3): 137-143.

Yang, X. (1998). Advanced Photo-oxidation Process for Ammonia Removal from Industrial Wastewater (Master Thesis), Carleton University, Canada.

Yoon, S. H., Lee, J. H. (2005). Oxidation Mechanism of As(III) in the UV/TiO 2 System: Evidence for a Direct Hole Oxidation Mechanism. Environmental Science \& Technology, 39(24): 9695-9701.

Zaw, M., Emett, M. T. (2002). Arsenic Removal from Water Using Advanced Oxidation Processes. Toxicology Letters, 133(1): 113-118. 


\section{Appendix A. List of Chemicals}

\begin{tabular}{|c|c|c|}
\hline Chemicals & Supplier & Purpose \\
\hline \multicolumn{3}{|l|}{ All Purpose: } \\
\hline Concentrated sulphuric acid $\left(\mathrm{H}_{2} \mathrm{SO}_{4}\right)$ & Fisher Scientific & Adjustment of $\mathrm{pH}$ \\
\hline Sodium hydroxide $(\mathrm{NaOH})$ & Fisher Scientific & Adjustment of $\mathrm{pH}$ \\
\hline \multicolumn{3}{|l|}{ As(III) Oxidation Process: } \\
\hline Sodium arsenite $\left(\mathrm{NaAsO}_{2}\right)$ & Sigma & Synthetic arsenic wastewater \\
\hline $30 \%(w / w)$ Hydrogen peroxide $\left(\mathrm{H}_{2} \mathrm{O}_{2}\right)$ & Fisher Scientific & Potential oxidant for As (III) oxidation \\
\hline Compressed Nitrogen & - & Adjustment of dissolved oxygen \\
\hline Sodium sulphite $\left(\mathrm{Na}_{2} \mathrm{SO}_{3}\right)$ & Fisher Scientific & Potential interfering chemical \\
\hline Sodium carbonate $\left(\mathrm{Na}_{2} \mathrm{CO}_{3}\right)$ & Fisher Scientific & Potential interfering chemical \\
\hline Calcium chloride $\left(\mathrm{CaCl}_{2} \cdot 2 \mathrm{H}_{2} \mathrm{O}\right)$ & Fisher Scientific & Potential interfering chemical \\
\hline Sodium chloride $(\mathrm{NaCl})$ & Fisher Scientific & Potential interfering chemical \\
\hline Ferric Sulfate $\left(\mathrm{Fe}_{2}\left(\mathrm{SO}_{4}\right)_{3} \cdot \mathrm{xH}_{2} \mathrm{O}\right)$ & Fisher Scientific & Pre-treatment of wastes \\
\hline \multicolumn{3}{|l|}{ Sample Analysis and Pretreatment: } \\
\hline Sodium arsenite $\left(\mathrm{NaAsO}_{2}\right)$ & Fisher Scientific & Preparation of standard solution \\
\hline Sodium arsenate $\left(\mathrm{NaAsO}_{2}\right)$ & Fisher Scientific & Preparation of standard solution \\
\hline Orthophosphoric acid $\left(\mathrm{H}_{3} \mathrm{PO}_{4}\right)$ & Fisher Scientific & Eluent of AS1 HPLC column \\
\hline Catalase from bovine liver & Sigma & $\mathrm{H}_{2} \mathrm{O}_{2}$ residual scavenger \\
\hline EDTA & Fisher Scientific & Preparation of standard solution \\
\hline Methanol & Fisher Scientific & Eluent of AS11 HPLC column \\
\hline Hydrochloric acid $(\mathrm{HCl})$ & Fisher Scientific & Reagent for hydride generation \\
\hline Sodium tetrahydridoborate $(\mathrm{NaBH} 4)$ & Fisher Scientific & Reagent for hydride generation \\
\hline Potassium iodide(KI) & Fisher Scientific & Reagent for hydride generation \\
\hline Potassium permanganate $\left(\mathrm{KMnO}_{4}\right)$ & Fisher Scientific & Titration of $\mathrm{H}_{2} \mathrm{O}_{2}$ \\
\hline Manganous sulphate $\left(\mathrm{MnSO}_{4}\right)$ & Fisher Scientific & Titration of $\mathrm{H}_{2} \mathrm{O}_{2}$ \\
\hline \multicolumn{3}{|l|}{ Chemical Actinometry: } \\
\hline Oxalic acid $\left(\mathrm{H}_{2} \mathrm{C}_{2} \mathrm{O}_{4}\right)$ & Fisher Scientific & Reagent of chemical actinometry \\
\hline Uranyl trioxide $\left(\mathrm{UO}_{3}\right)$ & - & Catalyst of chemical actinometry \\
\hline Potassium permanganate $\left(\mathrm{KMnO}_{4}\right)$ & Fisher Scientific & Titration of oxalic acid \\
\hline \multicolumn{3}{|l|}{ Other Chemicals: } \\
\hline $\mathrm{pH}$ buffers (at $\mathrm{pH}=4,7,10$ ) & Fisher Scientific & Calibration of $\mathrm{pH}$ meter \\
\hline YSI 3682 Zobel Solution & Fisher Scientific & Calibration of Eh meter \\
\hline
\end{tabular}


Appendix B. Calibration Curve of Arsenic Speciation by HPLC-UV/Vis
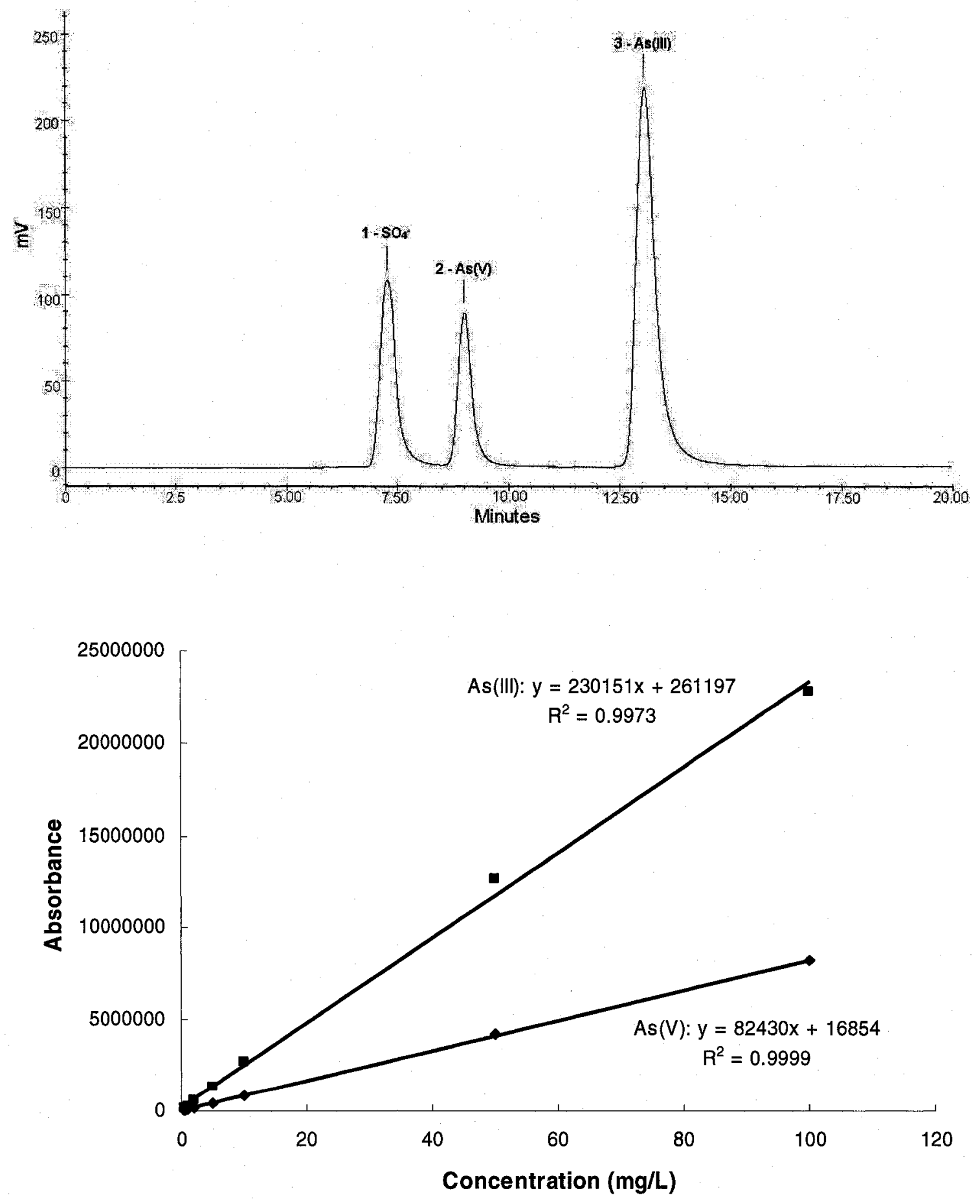
Appendix C. Calibration Curve of Arsenic Speciation by HPLC-HG-AAS
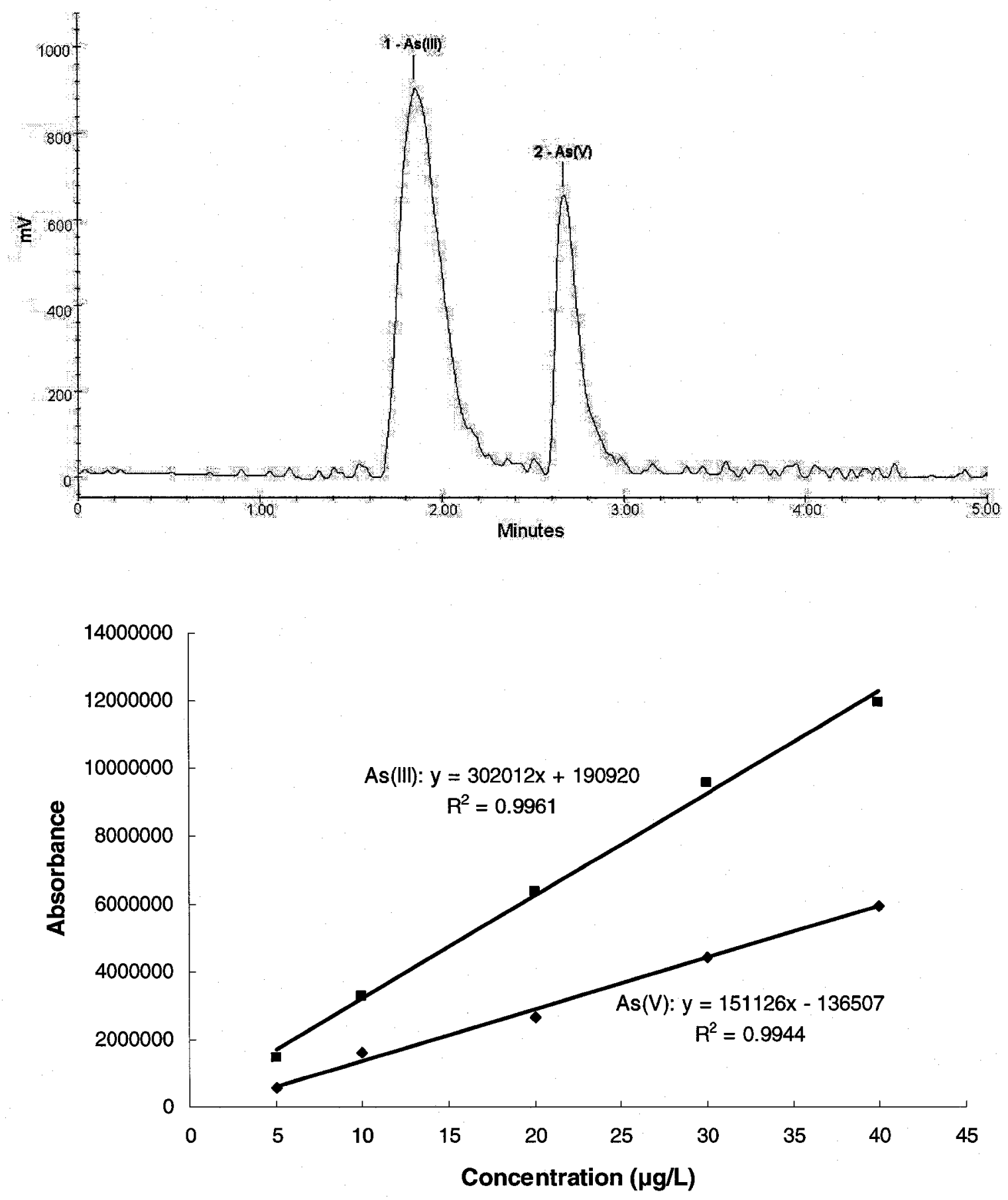
Appendix D. Arsenic Speciation by CES-HPLC-DAD

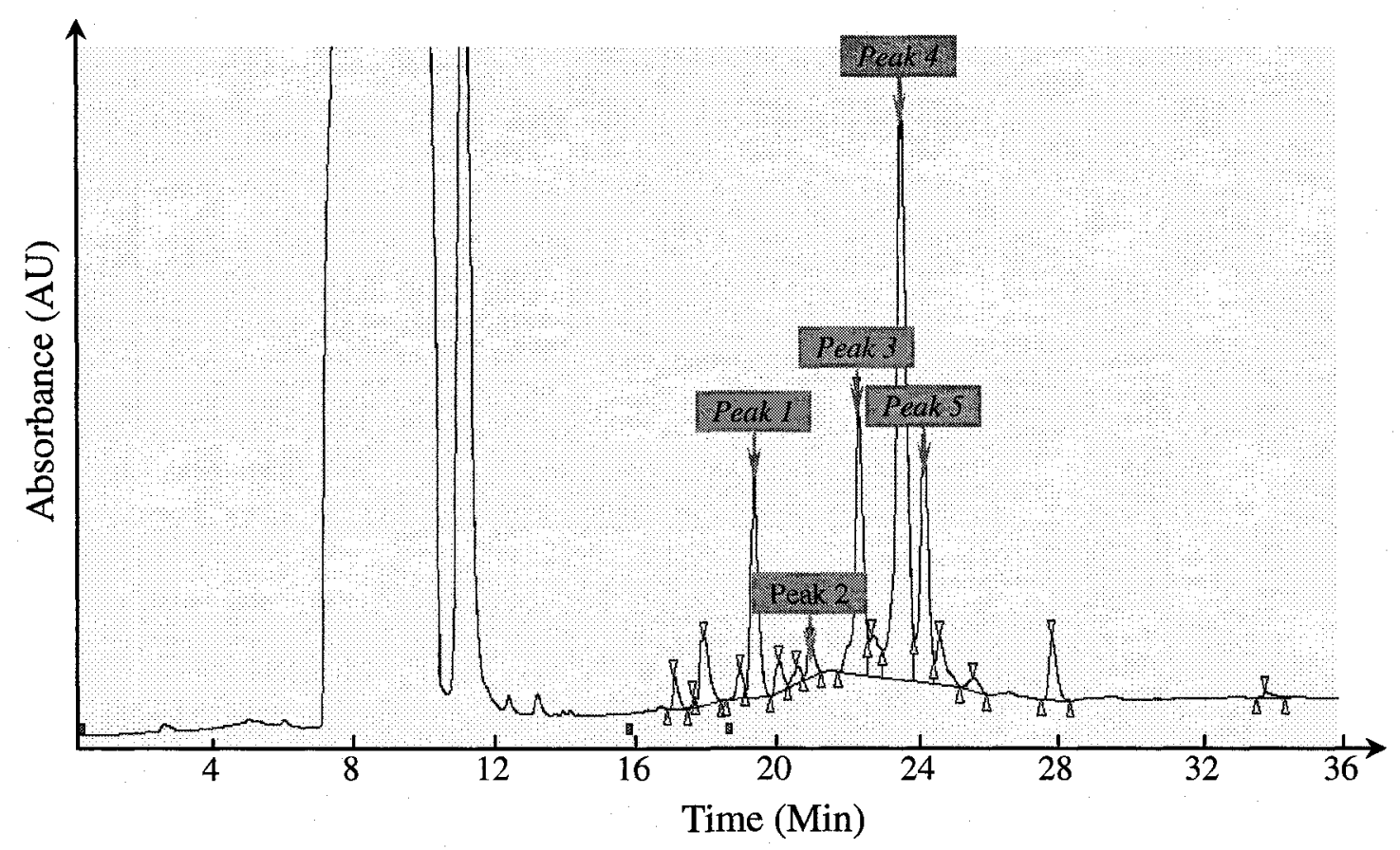

\begin{tabular}{ccc}
\hline Peak No. & $\begin{array}{c}\text { Retention Time } \\
\text { (minute) }\end{array}$ & Potential Arsenic Species \\
\hline Peak 1 & 18.4 & Uncertain \\
Peak 2 & 20.6 & $\mathrm{As}(\mathrm{III}): \mathrm{Na}_{2} \mathrm{AsO}_{2}, \mathrm{As}_{2} \mathrm{O}_{3}$ \\
Peak 3 & 21.3 & $\mathrm{As}(\mathrm{III}): \mathrm{Na}_{2} \mathrm{AsO}_{2}, \mathrm{As}_{2} \mathrm{O}_{3}$ \\
Peak 4 & 22.5 & $\mathrm{As}(\mathrm{V}): \mathrm{Na}_{2} \mathrm{HAsO}_{4} \cdot 7 \mathrm{H}_{2} \mathrm{O}, \mathrm{KH}_{2} \mathrm{AsO}_{4}$ \\
Peak 5 & 23.0 & $\mathrm{As}(\mathrm{V}): \mathrm{Na}_{2} \mathrm{HAsO}_{4} \cdot 7 \mathrm{H}_{2} \mathrm{O}, \mathrm{KH}_{2} \mathrm{AsO}_{4}$ \\
\hline \hline
\end{tabular}


Appendix E. Determination of S(IV) by HPLC-UV/Vis
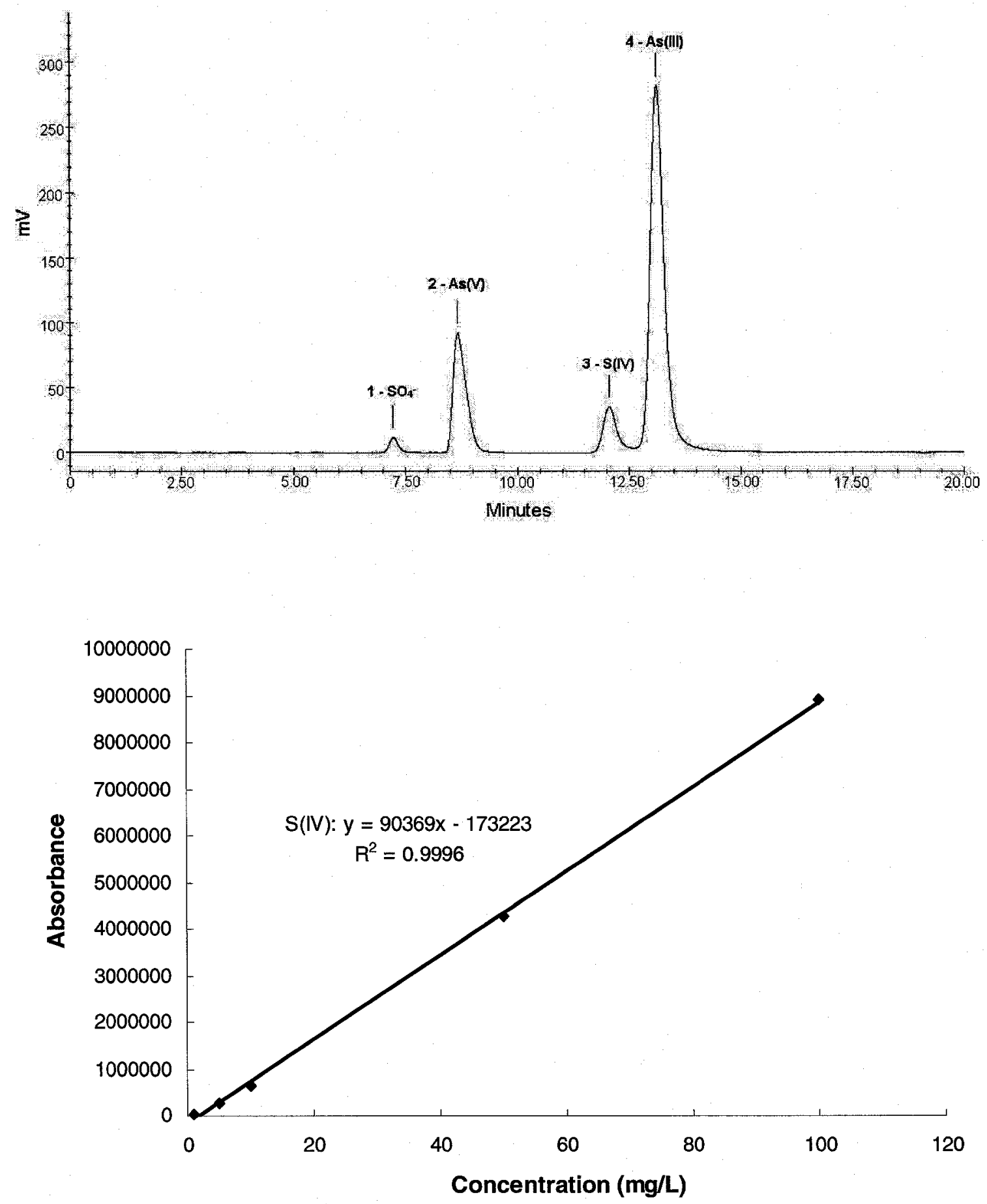


\section{Appendix F. Category of Experiments}

Part A: Batch Reactor

A.1: Dark Reaction

\begin{tabular}{|c|c|c|c|c|}
\hline \hline No. & Initial $\boldsymbol{p H}$ & Initlal As(III) & DO Condition & UV Source \\
\hline DR01 & 10.0 & $1.335 \mathrm{mM}$ & {$[\mathrm{DO}]_{0}=8.0 \mathrm{mg} / \mathrm{L}$, with air sparging } & No UV \\
DR02 & 10.0 & $1.335 \mathrm{mM}$ & {$[\mathrm{DO}]_{0}=8.0 \mathrm{mg} / \mathrm{L}$, with tank sealed } & No UV \\
\hline \hline
\end{tabular}

A.2: Direct Photolysis

\begin{tabular}{|c|c|c|c|}
\hline No. & Initial pH & Initial As(III) & DO Condition, etc. \\
\hline \multicolumn{4}{|c|}{ 1) Effect of DO } \\
\hline DP01 & 10.0 & $1.335 \mathrm{mM}$ & {$[\mathrm{DO}]_{0}=8.0 \mathrm{mg} / \mathrm{L}$, with air sparging } \\
\hline DP02 & 10.0 & $1.335 \mathrm{mM}$ & {$[\mathrm{DO}]_{0} \leq 1.0 \mathrm{mg} / \mathrm{L}$, with the tank closed } \\
\hline DP03 & 10.0 & $1.335 \mathrm{mM}$ & {$[\mathrm{DO}]_{0}=8.0 \mathrm{mg} / \mathrm{L}$, with the tank closed } \\
\hline DP04 & 10.0 & $1.335 \mathrm{mM}$ & {$[D O]_{0}=6.0 \mathrm{mg} / \mathrm{L}$, with the tank closed } \\
\hline DP05 & 10.0 & $1.335 \mathrm{mM}$ & {$[D O]_{0}=3.0 \mathrm{mg} / \mathrm{L}$, with the tank closed } \\
\hline \multicolumn{4}{|c|}{ 2) Effect of $\mathrm{pH}$} \\
\hline DP06 & 3.0 & $1.335 \mathrm{mM}$ & {$[\mathrm{DO}]_{0} \leq 1.0 \mathrm{mg} / \mathrm{L}$, with the tank closed } \\
\hline DP07 & 7.5 & $1.335 \mathrm{mM}$ & {$[D O]_{0} \leq 1.0 \mathrm{mg} / \mathrm{L}$, with the tank closed } \\
\hline DPO2 & 10.0 & $1.385 \mathrm{mM}$ & DOJ. $\leq 1.0 \mathrm{mg} \mathrm{L}$, with the tank closed \\
\hline DP08 & 3.0 & $1.335 \mathrm{mM}$ & {$[D O]_{0}=8.0 \mathrm{mg} / \mathrm{L}$, with the tank closed } \\
\hline DP09 & 7.5 & $1.335 \mathrm{mM}$ & {$[D O]_{0}=8.0 \mathrm{mg} / \mathrm{L}$, with the tank closed } \\
\hline DPos & 10.0 & $1.385 \mathrm{mM}$ & {$[D O J=8.0 m g / L$, with the tank closed } \\
\hline DP10 & 3.0 & $1.335 \mathrm{mM}$ & {$[D O]_{0}=8.0 \mathrm{mg} / \mathrm{L}$, with air sparging } \\
\hline DP11 & 7.5 & $1.335 \mathrm{mM}$ & {$[D O]_{0}=8.0 \mathrm{mg} / \mathrm{L}$, with air sparging } \\
\hline DP01 & 10.0 & $1.385 \mathrm{mM}$ & {$[D O]_{0}=8.0 \mathrm{mg} / \mathrm{L}$, with air sparging } \\
\hline \multicolumn{4}{|c|}{ 3) Effect of Initial As(III) Concentration } \\
\hline DP12 & 10.0 & $0.267 \mathrm{mM}$ & {$[\mathrm{DO}]_{0}=8.0 \mathrm{mg} / \mathrm{L}$, with the tank closed } \\
\hline DP13 & 10.0 & $0.534 \mathrm{mM}$ & {$[\mathrm{DO}]_{0}=8.0 \mathrm{mg} / \mathrm{L}$, with the tank closed } \\
\hline DP14 & 10.0 & $0.801 \mathrm{mM}$ & {$[D O]_{0}=8.0 \mathrm{mg} / \mathrm{L}$, with the tank closed } \\
\hline DP15 & 10.0 & $1.068 \mathrm{mM}$ & {$[\mathrm{DO}]_{0}=8.0 \mathrm{mg} / \mathrm{L}$, with the tank closed } \\
\hline DPOS & 10.0 & $1.385 \mathrm{cmM}$ & [DOJ $=8.0 \mathrm{mg}$, with the tank closed \\
\hline
\end{tabular}


Continued:

\begin{tabular}{|c|c|c|c|}
\hline No. & Initial pH & Initial As(III) & DO Condition, etc. \\
\hline \multicolumn{4}{|c|}{ 3) Effect of Initial As(III) Concentration } \\
\hline DP16 & 7.5 & $0.267 \mathrm{mM}$ & {$[\mathrm{DO}]_{0}=8.0 \mathrm{mg} / \mathrm{L}$, with air sparging } \\
\hline DP17 & 7.5 & $0.534 \mathrm{mM}$ & {$[D O]_{0}=8.0 \mathrm{mg} / \mathrm{L}$, with air sparging } \\
\hline DP18 & 7.5 & $0.801 \mathrm{mM}$ & {$[D O]_{0}=8.0 \mathrm{mg} / \mathrm{L}$, with air sparging } \\
\hline DP19 & 7.5 & $1.068 \mathrm{mM}$ & {$[\mathrm{DO}]_{0}=8.0 \mathrm{mg} / \mathrm{L}$, with air sparging } \\
\hline DP11 & 75 & $1.385 \mathrm{mM}$ & 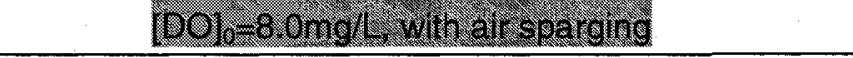 \\
\hline DP20 & 3.0 & $0.267 \mathrm{mM}$ & {$[D O]_{0}=8.0 \mathrm{mg} / \mathrm{L}$, with air sparging } \\
\hline DP21 & 3.0 & $0.534 \mathrm{mM}$ & {$[D O]_{0}=8.0 \mathrm{mg} / \mathrm{L}$, with air sparging } \\
\hline DP22 & 3.0 & $0.801 \mathrm{mM}$ & {$[\mathrm{DO}]_{0}=8.0 \mathrm{mg} / \mathrm{L}$, with air sparging } \\
\hline DP23 & 3.0 & $1.068 \mathrm{mM}$ & {$[D O]_{0}=8.0 \mathrm{mg} / \mathrm{L}$, with air sparging } \\
\hline DP10 & 3.0 & $1.335 \mathrm{mM}$ & [DO] $=8.0 \mathrm{mg} / \mathrm{L}$, with alr sparging \\
\hline \multicolumn{4}{|c|}{ 4) Ion Effect } \\
\hline DP24 & 7.5 & $1.335 \mathrm{mM}$ & {$[\mathrm{DO}]_{0}=8.0 \mathrm{mg} / \mathrm{L}$, with air sparging, $\mathrm{Na}_{2} \mathrm{CO}_{3}: \mathrm{As}(\mathrm{III})=1: 1$} \\
\hline DP25 & 7.5 & $1.335 \mathrm{mM}$ & {$[\mathrm{DO}]_{0}=8.0 \mathrm{mg} / \mathrm{L}$, with air sparging, $\mathrm{Na}_{2} \mathrm{SO}_{3}: \mathrm{As}(\mathrm{III})=1: 1$} \\
\hline DP26 & 7.5 & $1.335 \mathrm{mM}$ & {$[D O]_{0}=8.0 \mathrm{mg} / \mathrm{L}$, with air sparging, $\mathrm{NaCl}: \mathrm{As}(\mathrm{III})=1: 1$} \\
\hline DP27 & 7.5 & $1.335 \mathrm{mM}$ & {$[D O]_{0}=8.0 \mathrm{mg} / \mathrm{L}$, with air sparging, $\mathrm{CaCl}_{2}: \mathbf{A s}(\mathrm{III})=1: 1$} \\
\hline
\end{tabular}

\section{A.3: AOP with UV/ $\mathrm{H}_{2} \mathrm{O}_{2}$}

\begin{tabular}{|c|c|c|c|c|}
\hline No. & $\begin{array}{c}\text { Initial } \\
\text { pH }\end{array}$ & Initial As(III) & $\begin{array}{c}\text { Initial } \mathrm{H}_{2} \mathrm{O}_{2} \\
\left(\mathrm{H}_{2} \mathrm{O}_{2}: A s(I I I)\right)\end{array}$ & DO Condition, etc. \\
\hline \multicolumn{5}{|c|}{ 1) Effect of Initial $\mathrm{H}_{2} \mathrm{O}_{2}$} \\
\hline AP01 & 3.0 & $1.335 \mathrm{mM}$ & $0.334 \mathrm{mM}(1: 4)$ & {$[\mathrm{DO}]_{0}=8.0 \mathrm{mg} / \mathrm{L}$, with the tank closed } \\
\hline AP02 & 3.0 & $1.335 \mathrm{mM}$ & $0.445 \mathrm{mM}(1: 3)$ & {$[\mathrm{DO}]_{0}=8.0 \mathrm{mg} / \mathrm{L}$, with the tank closed } \\
\hline AP03 & 3.0 & $1.335 \mathrm{mM}$ & $0.668 \mathrm{mM}(1: 2)$ & {$[\mathrm{DO}]_{0}=8.0 \mathrm{mg} / \mathrm{L}$, with the tank closed } \\
\hline AP04 & 3.0 & $1.335 \mathrm{mM}$ & $1.335 \mathrm{mM}(1: 1)$ & {$[\mathrm{DO}]_{0}=8.0 \mathrm{mg} / \mathrm{L}$, with the tank closed } \\
\hline AP05 & 3.0 & $1.335 \mathrm{mM}$ & $2.670 \mathrm{mM}(2: 1)$ & {$[\mathrm{DO}]_{0}=8.0 \mathrm{mg} / \mathrm{L}$, with the tank closed } \\
\hline \multicolumn{5}{|c|}{ 2) Effect of DO } \\
\hline AP06 & 3.0 & $1.335 \mathrm{mM}$ & $1.335 \mathrm{mM}(1: 1)$ & {$[\mathrm{DO}]_{0} \leq 1.0 \mathrm{mg} / \mathrm{L}$, with the tank closed } \\
\hline AP04 & 3.0 & $1.305 \mathrm{mM}$ & $1.335 \mathrm{mM}(1.1)$ & {$\left[\mathrm{BO}_{a}=8.0 \mathrm{mg} \mathrm{L}\right.$, with the tank closed } \\
\hline AP07 & 3.0 & $1.335 \mathrm{mM}$ & $1.335 \mathrm{mM}(1: 1)$ & {$[\mathrm{DO}]_{0}=8.0 \mathrm{mg} / \mathrm{L}$, with air sparging } \\
\hline AP08 & 3.0 & $1.335 \mathrm{mM}$ & $0.668 \mathrm{mM}(1: 2)$ & {$[D O]_{0} \leq 1.0 \mathrm{mg} / \mathrm{L}$, with the tank closed } \\
\hline AP03 & 3.0 & $1.335 \mathrm{mM}$ & $0.668 \mathrm{mu}(1: 2)$ & {$[D O]_{0}=8.0 m g /$, with the tank closed } \\
\hline AP09 & 3.0 & $1.335 \mathrm{mM}$ & $0.668 \mathrm{mM}(1: 2)$ & {$[D O]_{0}=8.0 \mathrm{mg} / \mathrm{L}$, with air sparging } \\
\hline
\end{tabular}


Continued:

\begin{tabular}{|c|c|c|c|c|}
\hline No. & $\begin{array}{c}\text { Initial } \\
\mathrm{pH}\end{array}$ & Initial As(III) & $\begin{array}{c}\text { Initial } \mathrm{H}_{2} \mathrm{O}_{2} \\
\left(\mathrm{H}_{2} \mathrm{O}_{2}: \mathrm{As}(I I I)\right)\end{array}$ & DO Condition, etc. \\
\hline \multicolumn{5}{|c|}{ 2) Effect of DO } \\
\hline AP10 & 3.0 & $1.335 \mathrm{mM}$ & $0.334 \mathrm{mM}(1: 4)$ & {$[\mathrm{DO}]_{0} \leq 1.0 \mathrm{mg} / \mathrm{L}$, with the tank closed } \\
\hline APo1 & 3.0 & $1.335 \mathrm{mM}$ & $0.334 \mathrm{~mm}(124)$ & DOla=8.0mold, with the tank olosed \\
\hline AP11 & 3.0 & $1.335 \mathrm{mM}$ & $0.334 \mathrm{mM}(1: 4)$ & {$[D O]_{0}=8.0 \mathrm{mg} / \mathrm{L}$, with air sparging } \\
\hline \multicolumn{5}{|c|}{ 3) Effect of pH } \\
\hline AP06 & 30 & $1.335 \mathrm{mM}$ & 1385 mM (11) & bol. $\leq 1.0 \mathrm{mg}$, with the tank closed \\
\hline AP12 & 7.5 & $1.335 \mathrm{mM}$ & $1.335 \mathrm{mM}(1: 1)$ & {$[\mathrm{DO}]_{0} \leq 1.0 \mathrm{mg} / \mathrm{L}$, with the tank closed } \\
\hline AP13 & 10.0 & $1.335 \mathrm{mM}$ & $1.335 \mathrm{mM}(1: 1)$ & {$[\mathrm{DO}]_{0} \leq 1.0 \mathrm{mg} / \mathrm{L}$, with the tank closed } \\
\hline AP04 & 30 & $1.335 \mathrm{~mm}$ & 1.335 mM (1.1) & {$[\mathrm{DO}]_{0}=8,0 \mathrm{mg} \mathrm{L}$, with the tank closed } \\
\hline AP14 & 7.5 & $1.335 \mathrm{mM}$ & $1.335 \mathrm{mM}(1: 1)$ & {$[\mathrm{DO}]_{0}=8.0 \mathrm{mg} / \mathrm{L}$, with the tank closed } \\
\hline AP15 & 10.0 & $1.335 \mathrm{mM}$ & $1.335 \mathrm{mM}(1: 1)$ & {$[\mathrm{DO}]_{0}=8.0 \mathrm{mg} / \mathrm{L}$, with the tank closed } \\
\hline APO27 & 80 & $1335 \mathrm{mM}$ & $1.335 \mathrm{mM}(121)$ & {$[10010=8.0 \mathrm{mg} / \mathrm{l}$, with air sparging } \\
\hline AP16 & 7.5 & $1.335 \mathrm{mM}$ & $1.335 \mathrm{mM}(1: 1)$ & {$[\mathrm{DO}]_{0}=8.0 \mathrm{mg} / \mathrm{L}$, with air sparging } \\
\hline AP17 & 10.0 & $1.335 \mathrm{mM}$ & $1.335 \mathrm{mM}(1: 1)$ & {$[\mathrm{DO}]_{0}=8.0 \mathrm{mg} / \mathrm{L}$, with air sparging } \\
\hline \multicolumn{5}{|c|}{ 4) Effect of Initial As(III) Concentration } \\
\hline AP18 & 3.0 & $0.267 \mathrm{mM}$ & $0.267 \mathrm{mM}(1: 1)$ & {$[\mathrm{DO}]_{0}=8.0 \mathrm{mg} / \mathrm{L}$, with the tank closed } \\
\hline AP19 & 3.0 & $0.534 \mathrm{mM}$ & $0.534 \mathrm{mM}(1: 1)$ & {$[\mathrm{DO}]_{0}=8.0 \mathrm{mg} / \mathrm{L}$, with the tank closed } \\
\hline AP20 & 3.0 & $0.801 \mathrm{mM}$ & $0.801 \mathrm{mM}(1: 1)$ & {$[\mathrm{DO}]_{0}=8.0 \mathrm{mg} / \mathrm{L}$, with the tank closed } \\
\hline AP21 & 3.0 & $1.068 \mathrm{mM}$ & $1.068 \mathrm{mM}(1: 1)$ & {$[\mathrm{DO}]_{0}=8.0 \mathrm{mg} / \mathrm{L}$, with the tank closed } \\
\hline APO4 & 6.0 & $1395 \mathrm{mM}$ & $1.335 \mathrm{mM}(1: 1)$ & {$[\mathrm{DO}]_{0}=8$. Ong L, with the tank closed } \\
\hline \multicolumn{5}{|c|}{ 5) Ion Effect } \\
\hline AP22 & 7.5 & $1.335 \mathrm{mM}$ & $1.335 \mathrm{mM}(1: 1)$ & 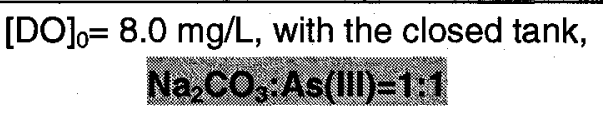 \\
\hline AP23 & 7.5 & $1.335 \mathrm{mM}$ & $1.335 \mathrm{mM}(1: 1)$ & $\begin{array}{c}{[D O]_{0}=8.0 \mathrm{mg} / \mathrm{L}, \text { with the closed tank, }} \\
\qquad \mathrm{Na}_{2} \mathrm{SO}_{3}: \mathrm{As}(1 \mathrm{II})=1 \mathrm{I} 1\end{array}$ \\
\hline AP24 & 7.5 & $1.335 \mathrm{mM}$ & $1.335 \mathrm{mM}(1: 1)$ & $\begin{array}{l}{[\mathrm{DO}]_{0}=8.0 \mathrm{mg} / \mathrm{L}, \text { with the closed tank, }} \\
\qquad \mathrm{NaCl} \text { (IS }(111)=1: 1\end{array}$ \\
\hline AP25 & 7.5 & $1.335 \mathrm{mM}$ & $1.335 \mathrm{mM}(1: 1)$ & $\begin{array}{c}{[\mathrm{DO}]_{0}=8.0 \mathrm{mg} / \mathrm{L}, \text { with the closed tank, }} \\
\qquad \mathrm{CaCl}_{2}: \mathrm{As}(\mathrm{III})=1: 1\end{array}$ \\
\hline
\end{tabular}


Part B: Recirculation Reactor

B.1: Direct Photolysis

\begin{tabular}{|c|c|c|c|}
\hline No. & Initial pH & Initial As(III) & Recycle Rate \& DO Condition, etc. \\
\hline \multicolumn{4}{|c|}{ 1) Effect of Recycle Rate } \\
\hline RD01 & 10.0 & $1.335 \mathrm{mM}$ & $10 \mathrm{GPM},[\mathrm{DO}]_{0}=8.0 \mathrm{mg} / \mathrm{L}$, with the closed tank \\
\hline RD02 & 10.0 & $1.335 \mathrm{mM}$ & $17 \mathrm{GPM},[\mathrm{DO}]_{0}=8.0 \mathrm{mg} / \mathrm{L}$, with the closed tank \\
\hline $\mathrm{RD} 03$ & 10.0 & $1.335 \mathrm{mM}$ & $25 \mathrm{GPM},[\mathrm{DO}]_{0}=8.0 \mathrm{mg} / \mathrm{L}$, with the closed tank \\
\hline \multicolumn{4}{|c|}{ 2) Effect of pH } \\
\hline RD04 & 3.0 & $1.335 \mathrm{mM}$ & $25 \mathrm{GPM},[\mathrm{DO}]_{0}=8.0 \mathrm{mg} / \mathrm{L}$, with the closed tank \\
\hline RD05 & 7.5 & $1.335 \mathrm{mM}$ & $25 \mathrm{GPM},[\mathrm{DO}]_{0}=8.0 \mathrm{mg} / \mathrm{L}$, with the closed tank \\
\hline RDO3 & 10.0 & $1.385 \mathrm{mM}$ & 25 GPM: [DOJo=8.0mgL, will the closedtank \\
\hline \multicolumn{4}{|c|}{ 3) Effect of Initial As(III) Concentration } \\
\hline RD06 & 10.0 & $0.668 \mathrm{mM}$ & $25 \mathrm{GPM},[\mathrm{DO}]_{0}=8.0 \mathrm{mg} / \mathrm{L}$, with the closed tank \\
\hline ADos & 100 & $1.335 \mathrm{mM}$ & $25 \mathrm{GPM},[\mathrm{DO}]_{0}=8.0 \mathrm{mg} \mathrm{L}$, with the closed tank \\
\hline \multicolumn{4}{|c|}{ 4) Ion Effect } \\
\hline RD07 & 7.5 & $1.335 \mathrm{mM}$ & 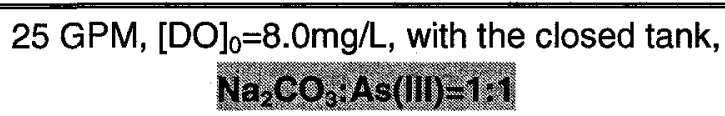 \\
\hline RD08 & 7.5 & $1.335 \mathrm{mM}$ & $\begin{array}{c}25 \mathrm{GPM},[\mathrm{DO}]_{0}=8.0 \mathrm{mg} / \mathrm{L} \text {, with the closed tank, } \\
\qquad \mathrm{Na}_{2} \mathrm{SO}_{3} \mathrm{AAs}(\mathrm{II})=1: 1\end{array}$ \\
\hline RD09 & 7.5 & $1.335 \mathrm{mM}$ & $\begin{array}{l}25 \mathrm{GPM},[\mathrm{DO}]_{0}=8.0 \mathrm{mg} / \mathrm{L}, \text { with the closed tank, } \\
\text { Naclass }(111)=1.1\end{array}$ \\
\hline $\mathrm{RD} 10$ & 7.5 & $1.335 \mathrm{mM}$ & $\begin{aligned} 25 \mathrm{GPM},[\mathrm{DO}]_{0} & =8.0 \mathrm{mg} / \mathrm{L}, \text { with the closed tank, } \\
& \mathrm{CaCl}_{2}: \mathrm{As}(\mathrm{III})=1: 1\end{aligned}$ \\
\hline
\end{tabular}


B.2: AOP with $\mathrm{UV} / \mathrm{H}_{2} \mathrm{O}_{2}$

\begin{tabular}{|c|c|c|c|c|}
\hline No. & $\begin{array}{c}\text { Initial } \\
\mathrm{pH}\end{array}$ & $\begin{array}{l}\text { Initial } \\
\text { As }(I I I)\end{array}$ & $\begin{array}{c}\text { Initial } \mathrm{H}_{2} \mathrm{O}_{2} \\
\left(\mathrm{H}_{2} \mathrm{O}_{2}: A s(I I I)\right)\end{array}$ & Recycle Rate \& DO Condition, etc. \\
\hline \multicolumn{5}{|c|}{ 1) Effect of Initial $\mathrm{H}_{2} \mathrm{O}_{2}$} \\
\hline RA01 & 3.0 & $1.335 \mathrm{mM}$ & $0.334 \mathrm{mM}(1: 4)$ & $25 \mathrm{GPM},[\mathrm{DO}]_{0}=8.0 \mathrm{mg} / \mathrm{L}$, with tank sealed \\
\hline RA02 & 3.0 & $1.335 \mathrm{mM}$ & $1.335 \mathrm{mM}(1: 1)$ & $25 \mathrm{GPM},[\mathrm{DO}]_{0}=8.0 \mathrm{mg} / \mathrm{L}$, with tank sealed \\
\hline \multicolumn{5}{|c|}{ 2) Effect of Recycle Rate } \\
\hline RA03 & 3.0 & $1.335 \mathrm{mM}$ & $1.335 \mathrm{mM}(1: 1)$ & $10 \mathrm{GPM},[\mathrm{DO}]_{0}=8.0 \mathrm{mg} / \mathrm{L}$, with tank sealed \\
\hline RA04 & 3.0 & $1.335 \mathrm{mM}$ & $1.335 \mathrm{mM}(1: 1)$ & $17 \mathrm{GPM},[\mathrm{DO}]_{0}=8.0 \mathrm{mg} / \mathrm{L}$, with tank sealed \\
\hline RAO2 & 3.0 & $1.335 \mathrm{mM}$ & $1.335 \mathrm{~mm}(1: 1)$ & 25 GPM. IDOJ=8.0nig/L, with tank sealed \\
\hline \multicolumn{5}{|c|}{ 3) Effect of pH } \\
\hline RAO2 & 3.0 & $1.335 \mathrm{mM}$ & $1.335 \mathrm{mM}(1.11)$ & 25.GPM, $[D O]_{0}=8.0 \mathrm{mg} \Lambda$, wih tank sealed \\
\hline RA05 & 7.5 & $1.335 \mathrm{mM}$ & $1.335 \mathrm{mM}(1: 1)$ & $25 \mathrm{GPM},[\mathrm{DO}]_{0}=8.0 \mathrm{mg} / \mathrm{L}$, with tank sealed \\
\hline RA06 & 10.0 & $1.335 \mathrm{mM}$ & $1.335 \mathrm{mM}(1: 1)$ & $25 \mathrm{GPM},[\mathrm{DO}]_{0}=8.0 \mathrm{mg} / \mathrm{L}$, with tank sealed \\
\hline \multicolumn{5}{|c|}{ 4) Effect of Initial As(III) Concentration } \\
\hline RA07 & 3.0 & $0.668 \mathrm{mM}$ & $1.335 \mathrm{mM}(1: 1)$ & $25 \mathrm{GPM},[\mathrm{DO}]_{0}=8.0 \mathrm{mg} / \mathrm{L}$, with tank sealed \\
\hline RAO2 & 3.0 & $1.385 \mathrm{mM}$ & $1.335 \mathrm{mM}(1 \times 1)$ & $25 \mathrm{GPV},[D O]_{0}=8.0 \mathrm{mg} L$, with tank sealed \\
\hline \multicolumn{5}{|c|}{ 7) Ion Effect } \\
\hline RA08 & 7.5 & $1.335 \mathrm{mM}$ & $1.335 \mathrm{mM}(1: 1)$ & $\begin{array}{c}25 \mathrm{GPM},[\mathrm{DO}]_{0}=8.0 \mathrm{mg} / \mathrm{L}, \text { with tank sealed } \\
\qquad \mathrm{Na}_{2} \mathrm{CO} \cdot \mathrm{As}(1 \mathrm{U})=1 \mathrm{1}\end{array}$ \\
\hline RA09 & 7.5 & $1.335 \mathrm{mM}$ & $1.335 \mathrm{mM}(1: 1)$ & $\begin{array}{c}25 \text { GPM, }[D O]_{0}=8.0 \mathrm{mg} / \mathrm{L}, \text { with tank sealed } \\
\mathrm{Na}_{2} \mathrm{SO}_{3} \mathrm{As}(\mathrm{MI})=1: 1\end{array}$ \\
\hline RA10 & 7.5 & $1.335 \mathrm{mM}$ & $1.335 \mathrm{mM}(1: 1)$ & $\begin{array}{c}25 \text { GPM, }[\mathrm{DO}]_{0}=8.0 \mathrm{mg} / \mathrm{L}, \text { with tank sealed } \\
\text { NaC:As }(11)=11\end{array}$ \\
\hline RA11 & 7.5 & $1.335 \mathrm{mM}$ & $1.335 \mathrm{mM}(1: 1)$ & $\begin{array}{c}25 \mathrm{GPM},[\mathrm{DO}]_{0}=8.0 \mathrm{mg} / \mathrm{L}, \text { with tank sealed } \\
\qquad \mathrm{CaCl}_{2}: \mathrm{As}(\mathrm{III})=1 \mathrm{a}\end{array}$ \\
\hline
\end{tabular}




\section{Appendix G: Verification of Reproducibility of Results}

A. Direct Photolysis (Experimental No.DP08: initial pH $=3.0 ;[\mathrm{As}(\mathrm{III})]_{0}=1.335 \mathrm{mM} ;[\mathrm{DO}]_{0}=8.0 \mathrm{mg} / \mathrm{L}$ with tank closed)

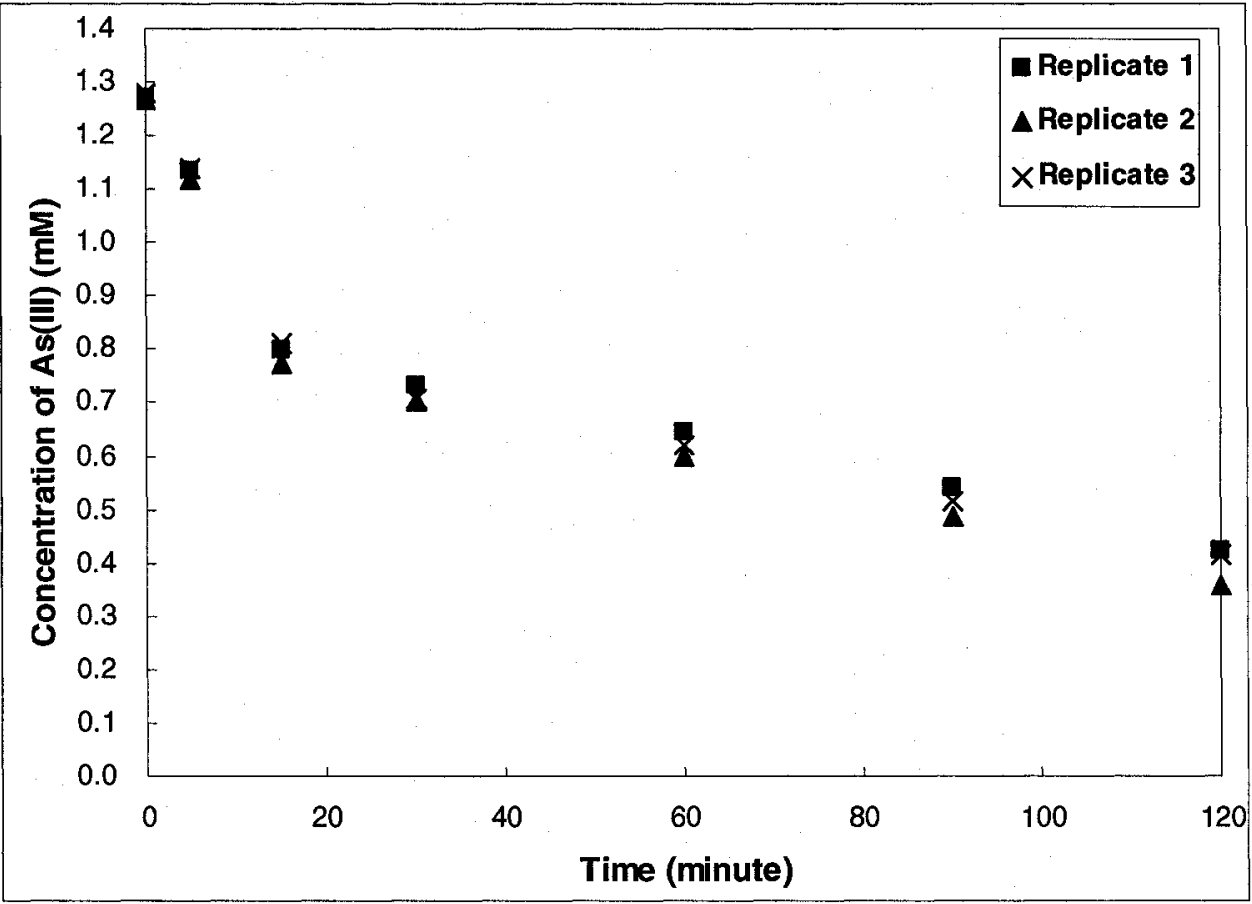

B.AOP with UV/ $\mathrm{H}_{2} \mathrm{O}_{2}$ (Experimental No.RA02: initial pH =3.0; $\left[\mathrm{H}_{2} \mathrm{O}_{2}\right]_{0}:[\mathrm{As}(\mathrm{III})]_{0}=1: 1 ;[\mathrm{As}(\mathrm{III})]_{0}=$ $1.335 \mathrm{mM} ;[\mathrm{DO}]_{0}=8.0 \mathrm{mg} / \mathrm{L}$ with tank closed, $25 \mathrm{GPM}$ )

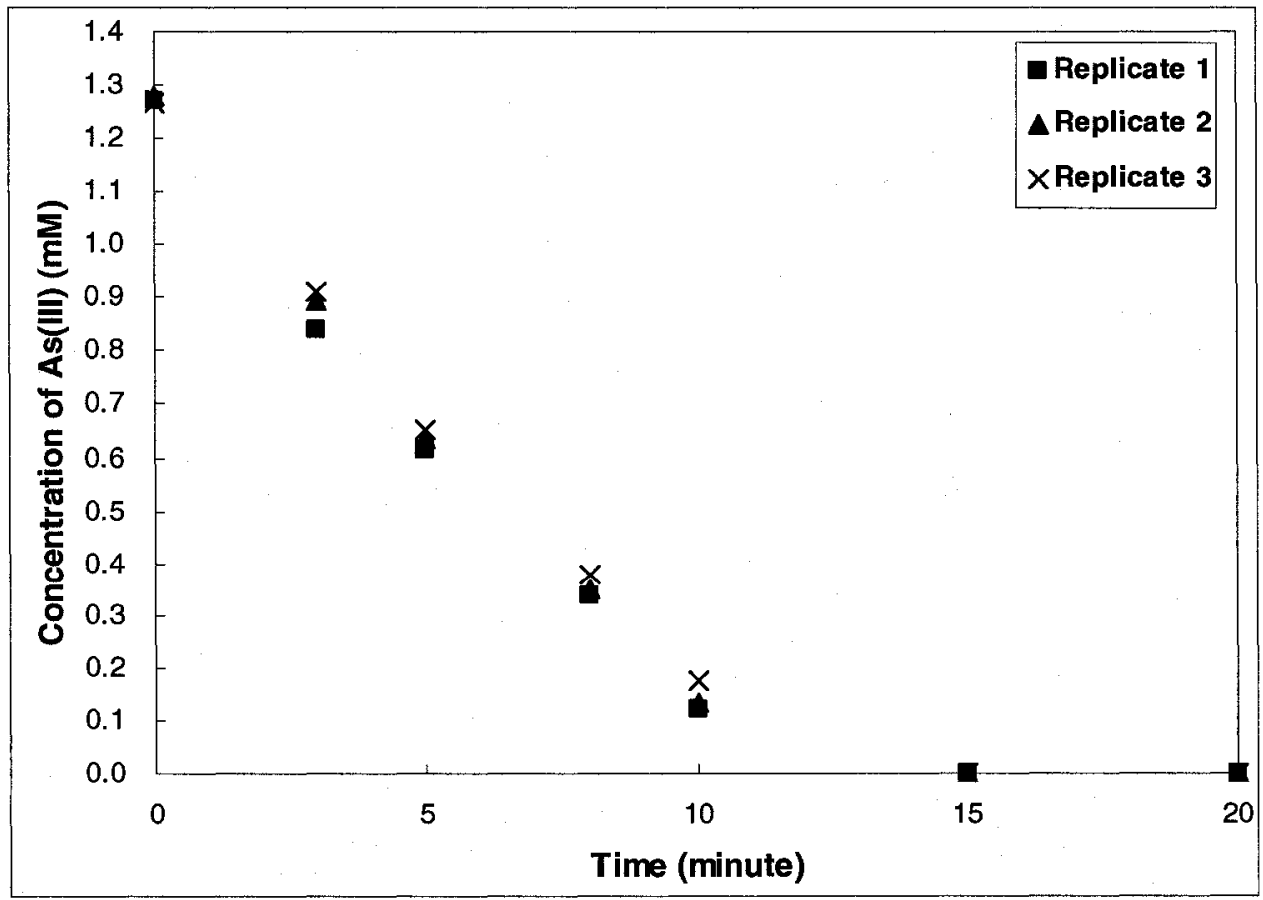




\section{Appendix H: Detailed Experimental Data}

\section{A.1: Dark Reaction in Batch Reactor}

\begin{tabular}{|c|c|c|c|c|c|c|c|c|c|c|c|}
\hline \multicolumn{6}{|c|}{ Experimental No.: DR01 ${ }^{1,2}$} & \multicolumn{6}{|c|}{ Experimental No.: DR01 } \\
\hline $\begin{array}{l}\text { Time } \\
\text { (min) }\end{array}$ & pH & $\begin{array}{l}\mathrm{As}(\mathrm{V}) \\
(\mathrm{mg} / \mathrm{L})\end{array}$ & $\begin{array}{l}\text { As(III) } \\
\text { (mg/L) }\end{array}$ & $\begin{array}{c}\mathrm{DO} \\
(\mathrm{mg} / \mathrm{L})\end{array}$ & $\begin{array}{c}\text { Eh } \\
(\mathrm{mV})\end{array}$ & $\begin{array}{l}\text { Time } \\
\text { (min) }\end{array}$ & pH & $\begin{array}{l}\text { As }(\mathbf{V}) \\
(\mathrm{mg} / \mathrm{L})\end{array}$ & $\begin{array}{l}\text { As(III) } \\
(\mathrm{mg} / \mathrm{L})\end{array}$ & $\begin{array}{c}\text { DO } \\
(\mathrm{mg} / \mathrm{L})\end{array}$ & $\begin{array}{c}\text { Eh } \\
(\mathrm{mV})\end{array}$ \\
\hline 0 & 10.09 & ND & 95.69 & - & - & 0 & 10.12 & ND & 96.83 & - & - \\
\hline 30 & 10.09 & ND & 95.69 & - & - & 30 & 10.12 & ND & 96.85 & - & - \\
\hline 60 & 10.09 & ND & 95.68 & - & - & 60 & 10.12 & ND & 96.85 & - & - \\
\hline 90 & 10.09 & ND & 95.70 & - & - & 90 & 10.12 & ND & 96.85 & - & - \\
\hline 120 & 10.09 & ND & 95.68 & - & - & 120 & 10.12 & ND & 96.84 & - & - \\
\hline 180 & 10.09 & ND & 95.69 & . & - & 180 & 10.12 & ND & 96.84 & - & - \\
\hline 240 & 10.09 & ND & 95.69 & - & - & 240 & 10.12 & ND & 96.82 & - & - \\
\hline 300 & 10.09 & ND & 95.68 & - & - & 300 & 10.12 & ND & 96.82 & - & - \\
\hline
\end{tabular}

1: All the samples were analyzed by HPLC-UV/Vis system except those specifically indicated; 2: ND - not detectable.

\section{A.2: Direct Photolysis in Batch Reactor}

\begin{tabular}{|c|c|c|c|c|c|c|c|c|c|c|c|}
\hline \multicolumn{6}{|c|}{ Experimental No.: DP01 } & \multicolumn{6}{|c|}{ Experimental No.: DP02 } \\
\hline $\begin{array}{l}\text { Time } \\
\text { (min) }\end{array}$ & pH & $\begin{array}{l}\mathrm{As}(\mathrm{V}) \\
(\mathrm{mg} / \mathrm{L})\end{array}$ & $\begin{array}{l}\text { As(III) } \\
(\mathrm{mg} / \mathrm{L})\end{array}$ & $\begin{array}{c}\text { DO } \\
(\mathrm{mg} / \mathrm{L})\end{array}$ & $\begin{array}{c}\text { Eh } \\
(\mathrm{mV})\end{array}$ & $\begin{array}{l}\text { Time } \\
\text { (min) }\end{array}$ & $\mathrm{pH}$ & $\begin{array}{l}\mathbf{A s}(\mathbf{V}) \\
(\mathrm{mg} / \mathrm{L})\end{array}$ & $\begin{array}{l}\text { As(III) } \\
(\mathrm{mg} / \mathrm{L})\end{array}$ & $\begin{array}{c}\text { DO } \\
(\mathrm{mg} / \mathrm{L})\end{array}$ & $\begin{array}{c}\text { Eh } \\
(\mathrm{mV})\end{array}$ \\
\hline 0 & 10.09 & ND & 95.69 & 8.43 & 194 & 0 & 9.98 & ND & 94.29 & 0.89 & 203 \\
\hline 5 & 9.87 & 10.29 & 87.62 & 7.24 & 204 & 5 & 9.96 & 1.17 & 93.54 & 0.45 & 193 \\
\hline 10 & 9.64 & 19.93 & 79.69 & 6.43 & 206 & 15 & 9.98 & 1.43 & 93.43 & 0.70 & 193 \\
\hline 15 & 9.38 & 29.46 & 70.88 & 6.01 & 229 & 30 & 9.93 & 1.76 & 93.21 & 0.40 & 188 \\
\hline 30 & 7.49 & 58.33 & 44.42 & 4.88 & 391 & 60 & 9.89 & 2.70 & 92.49 & 0.52 & 187 \\
\hline 40 & 6.45 & 82.94 & 18.82 & 3.62 & 420 & 90 & 9.88 & 4.13 & 91.60 & 0.54 & 184 \\
\hline 50 & 5.00 & 101.83 & ND & 5.47 & 426 & 120 & 9.88 & 4.89 & 90.27 & 0.53 & 183 \\
\hline 60 & 4.99 & 101.19 & ND & 7.24 & 432 & & & & & & \\
\hline 120 & 4.99 & 101.19 & ND & 7.24 & 432 & & & & & & \\
\hline \multicolumn{6}{|c|}{ Experimental No.: DP03 } & \multicolumn{6}{|c|}{ Experimental No.: DP04 } \\
\hline $\begin{array}{l}\text { Time } \\
\text { (min) }\end{array}$ & $\mathrm{pH}$ & $\begin{array}{l}\mathrm{As}(\mathrm{V}) \\
(\mathrm{mg} / \mathrm{L})\end{array}$ & $\begin{array}{l}\text { As(III) } \\
\text { (mg/L) }\end{array}$ & $\begin{array}{c}\text { DO } \\
\text { (mg/L) }\end{array}$ & $\begin{array}{c}\text { Eh } \\
(\mathrm{mV})\end{array}$ & $\begin{array}{l}\text { Time } \\
(\min )\end{array}$ & $\mathrm{pH}$ & $\begin{array}{l}\text { As(V) } \\
(\mathrm{mg} / \mathrm{L})\end{array}$ & $\begin{array}{l}\text { As(III) } \\
\text { (mg/L) }\end{array}$ & $\begin{array}{c}\text { DO } \\
(\mathrm{mg} / \mathrm{L})\end{array}$ & $\begin{array}{c}\text { Eh } \\
(\mathrm{mV})\end{array}$ \\
\hline 0 & 10.12 & ND & 96.83 & 8.13 & 222 & 10.20 & ND & 94.29 & 5.84 & 194 & 10.20 \\
\hline 5 & 9.95 & 9.65 & 88.73 & 6.63 & 207 & 10.04 & 7.19 & 88.24 & 4.33 & 203 & 10.04 \\
\hline 10 & 9.75 & 19.38 & 80.53 & 4.83 & 224 & 9.75 & 19.03 & 78.06 & 2.01 & 218 & 9.75 \\
\hline 15 & 9.51 & 28.66 & 72.13 & 3.20 & 232 & 9.51 & 26.42 & 71.65 & 0.58 & 226 & 9.51 \\
\hline 30 & 8.83 & 46.72 & 55.96 & 0.44 & 323 & 9.38 & 30.23 & 68.18 & 0.21 & 313 & 9.38 \\
\hline 60 & 7.96 & 56.40 & 48.16 & 0.25 & 379 & 9.18 & 35.07 & 63.02 & 0.22 & 354 & 9.18 \\
\hline 90 & 7.31 & 64.36 & 38.85 & 0.22 & 429 & 8.88 & 41.24 & 57.53 & 0.23 & 389 & 8.88 \\
\hline 120 & 6.94 & 74.55 & 28.82 & 0.21 & 426 & 8.36 & 46.91 & 51.34 & 0.22 & 410 & 8.36 \\
\hline
\end{tabular}




\begin{tabular}{|c|c|c|c|c|c|c|c|c|c|c|c|}
\hline \multicolumn{6}{|c|}{ Experimental No.: DP05 } & \multicolumn{6}{|c|}{ Experimental No.: DP06 } \\
\hline $\begin{array}{l}\text { Time } \\
\text { (min) }\end{array}$ & $\mathrm{pH}$ & $\begin{array}{l}\mathrm{As}(\mathrm{V}) \\
(\mathrm{mg} / \mathrm{L})\end{array}$ & $\begin{array}{l}\mathrm{As}(I I I) \\
(\mathrm{mg} / \mathrm{L})\end{array}$ & $\begin{array}{c}\text { DO } \\
\text { (mg/L) }\end{array}$ & $\begin{array}{c}\text { Eh } \\
(\mathrm{mV})\end{array}$ & $\begin{array}{l}\text { Time } \\
(\min )\end{array}$ & pH & $\begin{array}{l}\mathrm{As}(\mathrm{V}) \\
(\mathrm{mg} / \mathrm{L})\end{array}$ & $\begin{array}{l}\text { As(III) } \\
(\mathrm{mg} / \mathrm{L})\end{array}$ & $\begin{array}{c}\mathrm{DO} \\
\text { (mg/L) }\end{array}$ & $\begin{array}{c}\text { Eh } \\
(\mathrm{mV})\end{array}$ \\
\hline 0 & 10.16 & ND & 95.02 & 3.36 & 205 & 0 & 3.18 & ND & 95.64 & 0.75 & 0.02 \\
\hline 5 & 9.94 & 10.53 & 85.69 & 1.45 & 211 & 5 & 3.18 & 0.30 & 93.97 & 0.73 & 0.02 \\
\hline 10 & 9.83 & 15.58 & 81.28 & 0.27 & 214 & 15 & 3.17 & 0.63 & 93.65 & 0.54 & 0.02 \\
\hline 15 & 9.80 & 15.51 & 80.95 & 0.22 & 222 & 30 & 3.16 & 1.03 & 93.26 & 0.51 & 0.02 \\
\hline 30 & 9.78 & 16.1 & 80.63 & 0.23 & 269 & 60 & 3.14 & 2.00 & 92.19 & 0.58 & 0.02 \\
\hline 60 & 9.72 & 17.24 & 79.84 & 0.22 & 283 & 90 & 3.14 & 3.27 & 91.15 & 0.53 & 0.02 \\
\hline 90 & 9.70 & 19.26 & 78.1 & 0.22 & 288 & 120 & 3.14 & 5.21 & 89.20 & 0.53 & 0.02 \\
\hline 120 & 9.67 & 20.27 & 77.03 & 0.22 & 292 & & & & & & \\
\hline \multicolumn{6}{|c|}{ Experimental No.: DP07 } & \multicolumn{6}{|c|}{ Experimental No.: DP08 } \\
\hline $\begin{array}{l}\text { Time } \\
(\min )\end{array}$ & $\mathrm{pH}$ & $\begin{array}{l}\mathrm{As}(\mathrm{V}) \\
(\mathrm{mg} / \mathrm{L})\end{array}$ & $\begin{array}{l}\text { As(III) } \\
\text { (mg/L) }\end{array}$ & $\begin{array}{c}\text { DO } \\
(\mathrm{mg} / \mathrm{L})\end{array}$ & $\begin{array}{c}\text { Eh } \\
(\mathrm{mV})\end{array}$ & $\begin{array}{l}\text { Time } \\
\text { (min) }\end{array}$ & pH & $\begin{array}{l}\mathrm{As}(\mathrm{V}) \\
(\mathrm{mg} / \mathrm{L})\end{array}$ & $\begin{array}{l}\text { As(III) } \\
\text { (mg/L) }\end{array}$ & $\begin{array}{c}\mathrm{DO} \\
(\mathrm{mg} / \mathrm{L})\end{array}$ & $\begin{array}{c}\text { Eh } \\
(\mathrm{mV})\end{array}$ \\
\hline 0 & 7.93 & ND & 95.22 & 0.91 & 0.03 & 0 & 3.13 & ND & 94.19 & 8.24 & 644 \\
\hline 5 & 7.28 & 2.01 & 93.16 & 0.52 & 0.02 & 5 & 3.09 & 4.31 & 90.00 & 7.12 & 648 \\
\hline 15 & 7.17 & 2.15 & 92.88 & 0.49 & 0.02 & 10 & 3.05 & 14.26 & 81.60 & 5.03 & 652 \\
\hline 30 & 7.00 & 2.55 & 92.67 & 0.50 & 0.02 & 15 & 2.99 & 27.77 & 69.94 & 2.32 & 654 \\
\hline 60 & 6.75 & 3.76 & 91.60 & 0.50 & 0.02 & 30 & 2.93 & 46.28 & 53.69 & 0.31 & 654 \\
\hline 90 & 6.39 & 5.04 & 90.12 & 0.77 & 0.02 & 60 & 2.91 & 54.30 & 45.32 & 0.21 & 651 \\
\hline \multirow[t]{2}{*}{120} & 5.87 & 6.63 & 88.75 & 0.54 & 0.02 & 90 & 2.88 & 63.73 & 36.35 & 0.24 & 652 \\
\hline & & & & & & 120 & 2.85 & 74.82 & 24.98 & 0.23 & 650 \\
\hline \multicolumn{6}{|c|}{ Experimental No.: DP09 } & \multicolumn{6}{|c|}{ Experimental No.: DP10 } \\
\hline $\begin{array}{l}\text { Time } \\
\text { (min) }\end{array}$ & pH & $\begin{array}{l}\mathrm{As}(\mathrm{V}) \\
(\mathrm{mg} / \mathrm{L})\end{array}$ & $\begin{array}{l}\text { As(III) } \\
(\mathrm{mg} / \mathrm{L})\end{array}$ & $\begin{array}{c}\mathrm{DO} \\
(\mathrm{mg} / \mathrm{L})\end{array}$ & $\begin{array}{c}\text { Eh } \\
(\mathrm{mV})\end{array}$ & $\begin{array}{l}\text { Time } \\
\text { (min) }\end{array}$ & pH & $\begin{array}{l}\mathrm{As}(\mathrm{V}) \\
(\mathrm{mg} / \mathrm{L})\end{array}$ & $\begin{array}{l}\mathrm{As}(\mathrm{III}) \\
(\mathrm{mg} / \mathrm{L})\end{array}$ & $\begin{array}{c}\text { DO } \\
(\mathrm{mg} / \mathrm{L})\end{array}$ & $\begin{array}{c}\text { Eh } \\
(\mathrm{mV})\end{array}$ \\
\hline 0 & 7.91 & ND & 95.01 & 8.56 & 222 & 0 & 3.13 & ND & 95.53 & 8.39 & 614 \\
\hline 5 & 6.11 & 6.09 & 89.81 & 7.26 & 207 & 5 & 3.09 & 8.93 & 88.10 & 6.96 & 640 \\
\hline 10 & 4.10 & 17.96 & 79.47 & 4.88 & 224 & 10 & 3.05 & 22.56 & 76.49 & 5.47 & 655 \\
\hline 15 & 3.70 & 37.64 & 65.15 & 1.54 & 232 & 15 & 3.01 & 39.59 & 61.55 & 3.87 & 650 \\
\hline 30 & 3.50 & 48.80 & 51.83 & 0.31 & 323 & 30 & 2.88 & 101.47 & ND & 2.03 & 650 \\
\hline 60 & 3.40 & 58.93 & 41.67 & 0.29 & 379 & 40 & 2.88 & 101.15 & ND & 6.54 & 657 \\
\hline 90 & 3.33 & 70.13 & 30.53 & 0.26 & 429 & 50 & 2.88 & 101.17 & ND & 7.64 & 659 \\
\hline 120 & 3.26 & 82.36 & 17.26 & 0.26 & 426 & 60 & 2.88 & 101.38 & ND & 7.90 & 653 \\
\hline
\end{tabular}




\begin{tabular}{|c|c|c|c|c|c|c|c|c|c|c|c|}
\hline \multicolumn{6}{|c|}{ Experimental No.: DP11 } & \multicolumn{6}{|c|}{ Experimental No.: DP12 } \\
\hline $\begin{array}{l}\text { Time } \\
(\min )\end{array}$ & pH & $\begin{array}{l}\mathbf{A s}(\mathbf{V}) \\
(\mathrm{mg} / \mathrm{L})\end{array}$ & $\begin{array}{l}\text { As(III) } \\
(\mathrm{mg} / \mathrm{L})\end{array}$ & $\begin{array}{c}\text { DO } \\
(\mathrm{mg} / \mathrm{L})\end{array}$ & $\begin{array}{c}\text { Eh } \\
(\mathrm{mV})\end{array}$ & $\begin{array}{l}\text { Time } \\
(\mathrm{min})\end{array}$ & pH & $\begin{array}{l}\text { As(V) } \\
\text { (mg/L) }\end{array}$ & $\begin{array}{l}\text { As(III) } \\
\text { (mg/L) }\end{array}$ & $\begin{array}{c}\text { DO } \\
\text { (mg/L) }\end{array}$ & $\begin{array}{l}\text { Eh } \\
\text { (mV) }\end{array}$ \\
\hline 0 & 7.46 & ND & 95.15 & 8.26 & 350 & 0 & 9.84 & ND & 21.04 & 7.15 & - \\
\hline 5 & 4.90 & 6.67 & 90.43 & 7.25 & 489 & 5 & 9.57 & 3.33 & 16.99 & 6.73 & - \\
\hline 10 & 4.01 & 17.83 & 80.65 & 5.90 & 528 & 10 & 8.93 & 7.50 & 12.66 & 6.06 & - \\
\hline 15 & 3.66 & 33.87 & 66.56 & 4.42 & 597 & 15 & 7.18 & 13.23 & 7.60 & 5.26 & - \\
\hline 30 & 3.19 & 97.01 & 3.96 & 0.94 & 628 & 20 & 6.07 & 19.30 & 0.78 & 4.15 & - \\
\hline 40 & 3.17 & 101.29 & ND & 5.83 & 631 & 30 & 5.43 & 20.37 & ND & 4.30 & - \\
\hline 50 & 3.17 & 101.38 & ND & 7.40 & 632 & 40 & 5.43 & 20.37 & ND & 4.93 & - \\
\hline \multirow[t]{2}{*}{60} & 3.17 & 101.16 & ND & 7.84 & 632 & 50 & 5.43 & 20.37 & ND & 4.64 & - \\
\hline & & & & & & 60 & 5.43 & 20.37 & ND & 4.53 & - \\
\hline \multicolumn{6}{|c|}{ Experimental No.: DP13 } & \multicolumn{6}{|c|}{ Experimental No.: DP14 } \\
\hline $\begin{array}{l}\text { Time } \\
(\min )\end{array}$ & pH & $\begin{array}{l}\text { As(V) } \\
(m g / L)\end{array}$ & $\begin{array}{l}\text { As(III) } \\
\text { (mg/L) }\end{array}$ & $\begin{array}{c}\text { DO } \\
(\mathrm{mg} / \mathrm{L})\end{array}$ & $\begin{array}{c}\text { Eh } \\
(m V)\end{array}$ & $\begin{array}{l}\text { Time } \\
\text { (min) }\end{array}$ & pH & $\begin{array}{c}\mathbf{A s}(\mathbf{V}) \\
(\mathrm{mg} / \mathrm{L})\end{array}$ & $\begin{array}{l}\mathrm{As}(\mathrm{III}) \\
(\mathrm{mg} / \mathrm{L})\end{array}$ & $\begin{array}{c}\text { DO } \\
\text { (mg/L) }\end{array}$ & $\begin{array}{c}\text { Eh } \\
\text { (mV) }\end{array}$ \\
\hline 0 & 10.03 & ND & 42.61 & 7.40 & - & 0 & 10.14 & ND & 62.53 & 7.50 & - \\
\hline 5 & 9.82 & 4.93 & 37.28 & 6.71 & - & 5 & 9.94 & 6.25 & 55.98 & 6.56 & - \\
\hline 10 & 9.50 & 11.43 & 30.93 & 5.80 & - & 10 & 9.68 & 13.62 & 49.10 & 5.57 & - \\
\hline 15 & 8.98 & 17.92 & 24.59 & 4.79 & - & 15 & 9.34 & 21.00 & 41.84 & 4.36 & - \\
\hline 20 & 7.60 & 23.80 & 19.06 & 3.60 & - & 20 & 8.85 & 27.62 & 35.44 & 3.09 & $\cdot$ \\
\hline 30 & 5.96 & 41.15 & 1.50 & 0.69 & - & 30 & 7.10 & 41.66 & 22.36 & 0.24 & - \\
\hline 40 & 5.35 & 42.23 & ND & 1.26 & - & 40 & 6.85 & 46.7 & 16.71 & 0.24 & - \\
\hline 50 & 5.34 & 42.35 & ND & 1.85 & - & 50 & 6.67 & 50.68 & 13.29 & 0.31 & - \\
\hline \multirow[t]{2}{*}{60} & 5.34 & 42.33 & ND & 2.34 & - & 60 & 6.44 & 54.87 & 9.23 & 0.29 & - \\
\hline & & & & & & 90 & 5.27 & 63.79 & ND & 0.70 & - \\
\hline \multicolumn{6}{|c|}{ Experimental No.: DP15 } & \multicolumn{6}{|c|}{ Experimental No.: DP16 } \\
\hline $\begin{array}{l}\text { Time } \\
(\min )\end{array}$ & pH & $\begin{array}{l}\mathbf{A s}(\mathbf{V}) \\
(\mathrm{mg} / \mathrm{L})\end{array}$ & $\begin{array}{l}\text { As(III) } \\
\text { (mg/L) }\end{array}$ & $\begin{array}{c}\text { DO } \\
(\mathrm{mg} / \mathrm{L})\end{array}$ & $\begin{array}{c}\text { Eh } \\
(\mathrm{mV})\end{array}$ & $\begin{array}{l}\text { Time } \\
\text { (min) }\end{array}$ & pH & $\begin{array}{l}\mathrm{As}(\mathrm{V}) \\
(\mathrm{mg} / \mathrm{L})\end{array}$ & $\begin{array}{l}\text { As(III) } \\
(\mathrm{mg} / \mathrm{L})\end{array}$ & $\begin{array}{c}\text { DO } \\
\text { (mg/L) }\end{array}$ & $\begin{array}{c}\text { Eh } \\
(\mathrm{mV})\end{array}$ \\
\hline 0 & 10.17 & ND & 78.01 & 7.85 & - & 0 & 6.64 & ND & 21.42 & 7.60 & - \\
\hline 5 & 9.96 & 7.68 & 71.69 & 6.60 & - & 5 & 5.31 & 1.44 & 19.30 & 7.25 & - \\
\hline 10 & 9.75 & 15.83 & 65.00 & 5.27 & - & 10 & 4.48 & 5.09 & 15.52 & 6.87 & - \\
\hline 15 & 9.48 & 23.72 & 58.27 & 3.93 & - & 15 & 4.10 & 10.68 & 9.37 & 6.45 & - \\
\hline 20 & 9.16 & 31.17 & 50.89 & 2.60 & - & 20 & 3.89 & 16.94 & 2.96 & 6.09 & - \\
\hline 30 & 7.88 & 42.18 & 39.40 & 0.39 & - & 30 & 3.80 & 20.32 & ND & 6.78 & - \\
\hline 40 & 7.56 & 45.68 & 36.43 & 0.30 & - & 40 & 3.80 & 20.32 & ND & 6.96 & - \\
\hline 50 & 7.38 & 48.63 & 33.41 & 0.30 & - & 50 & 3.80 & 20.32 & ND & 7.21 & - \\
\hline 60 & 7.17 & 51.68 & 30.33 & 0.32 & - & 60 & 3.80 & 20.32 & ND & 7.34 & - \\
\hline 90 & 6.78 & 58.79 & 21.54 & 0.27 & - & & & & & & \\
\hline 120 & 6.38 & 69.94 & 11.03 & 0.30 & - & & & & & & \\
\hline
\end{tabular}




\begin{tabular}{|c|c|c|c|c|c|c|c|c|c|c|c|}
\hline \multicolumn{6}{|c|}{ Experimental No.: DP17 } & \multicolumn{6}{|c|}{ Experimental No.: DP18 } \\
\hline $\begin{array}{l}\text { Time } \\
(\min )\end{array}$ & $\mathbf{p H}$ & $\begin{array}{l}\mathbf{A s}(\mathbf{V}) \\
(\mathrm{mg} / \mathrm{L})\end{array}$ & $\begin{array}{l}\text { As(III) } \\
(\mathrm{mg} / \mathrm{L})\end{array}$ & $\begin{array}{c}\text { DO } \\
(\mathrm{mg} / \mathrm{L})\end{array}$ & $\begin{array}{c}\text { Eh } \\
(\mathrm{mV})\end{array}$ & $\begin{array}{l}\text { Time } \\
\text { (min) }\end{array}$ & pH & $\begin{array}{l}\text { As(V) } \\
(\mathrm{mg} / \mathrm{L})\end{array}$ & $\begin{array}{l}\text { As(III) } \\
\text { (mg/L) }\end{array}$ & $\begin{array}{c}\mathrm{DO} \\
(\mathrm{mg} / \mathrm{L})\end{array}$ & $\begin{array}{c}\text { Eh } \\
(\mathrm{mV})\end{array}$ \\
\hline 0 & 7.96 & ND & 42.74 & 7.72 & - & 0 & 8.16 & ND & 63.80 & 7.74 & - \\
\hline 5 & 6.45 & 2.80 & 39.33 & 7.23 & - & 5 & 6.67 & 3.80 & 60.08 & 7.16 & - \\
\hline 10 & 4.48 & 8.58 & 33.63 & 6.67 & - & 10 & 4.42 & 11.60 & 52.65 & 6.43 & - \\
\hline 15 & 4.02 & 17.71 & 25.58 & 6.08 & - & 15 & 3.92 & 23.39 & 41.97 & 5.57 & - \\
\hline 20 & 3.76 & 28.51 & 15.27 & 5.50 & - & 20 & 3.66 & 37.77 & 29.22 & 4.86 & - \\
\hline 30 & 3.54 & 42.58 & ND & 6.36 & - & 30 & 3.38 & 66.03 & ND & 3.99 & - \\
\hline 40 & 3.54 & 42.58 & ND & 6.89 & - & 40 & 3.38 & 66.03 & ND & 6.52 & - \\
\hline 50 & 3.54 & 42.58 & ND & 7.11 & - & 50 & 3.38 & 66.03 & ND & 6.85 & - \\
\hline 60 & 3.54 & 42.58 & ND & 7.24 & - & 60 & 3.38 & 66.03 & ND & 7.14 & - \\
\hline \multicolumn{6}{|c|}{ Experimental No.: DP19 } & \multicolumn{6}{|c|}{ Experimental No.: DP20 } \\
\hline $\begin{array}{l}\text { Time } \\
(\min )\end{array}$ & $\mathrm{pH}$ & $\begin{array}{l}\text { As }(\mathrm{V}) \\
(\mathrm{mg} / \mathrm{L})\end{array}$ & $\begin{array}{l}\text { As(III) } \\
(\mathrm{mg} / \mathrm{L})\end{array}$ & $\begin{array}{c}\text { DO } \\
(\mathrm{mg} / \mathrm{L})\end{array}$ & $\begin{array}{c}\text { Eh } \\
(\mathrm{mV})\end{array}$ & $\begin{array}{l}\text { Time } \\
(\min )\end{array}$ & pH & $\begin{array}{l}\mathrm{As}(\mathrm{V}) \\
(\mathrm{mg} / \mathrm{L})\end{array}$ & $\begin{array}{l}\text { As(III) } \\
\text { (mg/L) }\end{array}$ & $\begin{array}{c}\text { DO } \\
(\mathrm{mg} / \mathrm{L})\end{array}$ & $\begin{array}{c}\text { Eh } \\
(\mathrm{mV})\end{array}$ \\
\hline 0 & 7.99 & ND & 80.79 & 7.86 & - & 0 & 2.98 & ND & 21.60 & 7.46 & - \\
\hline 5 & 6.27 & 4.24 & 77.11 & 6.99 & - & 5 & 2.96 & 1.98 & 18.86 & 7.11 & - \\
\hline 10 & 4.26 & 14.50 & 68.95 & 6.07 & - & 10 & 2.95 & 7.27 & 13.91 & 6.73 & - \\
\hline 15 & 3.83 & 28.62 & 57.71 & 5.14 & - & 15 & 2.94 & 14.75 & 6.84 & 6.28 & - \\
\hline 20 & 3.60 & 44.97 & 42.89 & 4.29 & - & 20 & 2.92 & 21.56 & ND & 5.90 & - \\
\hline 30 & 3.29 & 80.67 & 2.48 & 3.01 & - & 30 & 2.92 & 21.56 & ND & 6.88 & - \\
\hline 40 & 3.28 & 83.17 & ND & 6.30 & - & 40 & 2.92 & 21.56 & ND & 7.10 & - \\
\hline 50 & 3.28 & 83.17 & ND & 6.77 & - & 50 & 2.92 & 21.56 & ND & 7.12 & - \\
\hline 60 & 3.28 & 83.17 & ND & 7.07 & - & 60 & 2.92 & 21.56 & ND & 7.22 & - \\
\hline \multicolumn{6}{|c|}{ Experimental No.: DP21 } & \multicolumn{6}{|c|}{ Experimental No.: DP22 } \\
\hline $\begin{array}{l}\text { Time } \\
(\min )\end{array}$ & pH & $\begin{array}{l}\mathrm{As}(\mathrm{V}) \\
(\mathrm{mg} / \mathrm{L})\end{array}$ & $\begin{array}{l}\text { As(III) } \\
(\mathrm{mg} / \mathrm{L})\end{array}$ & $\begin{array}{c}\text { DO } \\
(\mathrm{mg} / \mathrm{L})\end{array}$ & $\begin{array}{c}\text { Eh } \\
(\mathrm{mV})\end{array}$ & $\begin{array}{l}\text { Time } \\
(\min )\end{array}$ & pH & $\begin{array}{l}\mathrm{As}(\mathrm{V}) \\
(\mathrm{mg} / \mathrm{L})\end{array}$ & $\begin{array}{l}\mathrm{As}(\mathrm{III}) \\
(\mathrm{mg} / \mathrm{L})\end{array}$ & $\begin{array}{c}\text { DO } \\
(\mathrm{mg} / \mathrm{L})\end{array}$ & $\begin{array}{c}\text { Eh } \\
(\mathrm{mV})\end{array}$ \\
\hline 0 & 3.22 & ND & 43.56 & 7.49 & - & 0 & 3.03 & ND & 63.81 & 7.72 & - \\
\hline 5 & 3.21 & 3.02 & 39.94 & 7.10 & - & 5 & 3.01 & 4.28 & 59.45 & 7.14 & - \\
\hline 10 & 3.18 & 10.84 & 32.97 & 6.47 & - & 10 & 2.98 & 14.01 & 51.58 & 6.34 & - \\
\hline 15 & 3.13 & 20.73 & 23.39 & 5.87 & - & 15 & 2.95 & 26.09 & 40.02 & 5.50 & - \\
\hline 20 & 3.09 & 33.31 & 10.89 & 5.24 & - & 20 & 2.92 & 42.33 & 24.81 & 4.65 & - \\
\hline 30 & 3.04 & 43.07 & ND & 6.43 & - & 30 & 2.85 & 65.18 & ND & 6.08 & - \\
\hline 40 & 3.04 & 43.07 & ND & 6.75 & - & 40 & 2.84 & 65.18 & ND & 6.86 & - \\
\hline 50 & 3.04 & 43.07 & ND & 6.86 & - & 50 & 2.84 & 65.18 & ND & 7.01 & - \\
\hline 60 & 3.04 & 43.07 & ND & 7.12 & - & 60 & 2.84 & 65.18 & ND & 7.13 & - \\
\hline
\end{tabular}




\begin{tabular}{|c|c|c|c|c|c|c|c|c|c|c|c|}
\hline \multicolumn{6}{|c|}{ Experimental No.: DP23 } & \multicolumn{6}{|c|}{ Experimental No.: DP24 } \\
\hline $\begin{array}{l}\text { Time } \\
\text { (min) }\end{array}$ & $\mathbf{p H}$ & $\begin{array}{l}\text { As(V) } \\
(\mathrm{mg} / \mathrm{L})\end{array}$ & $\begin{array}{l}\mathbf{A s}(\mathrm{III}) \\
(\mathrm{mg} / \mathrm{L})\end{array}$ & $\begin{array}{c}\text { DO } \\
\text { (mg/L) }\end{array}$ & $\begin{array}{l}\text { Eh } \\
(\mathrm{mV})\end{array}$ & $\begin{array}{l}\text { Time } \\
\text { (min) }\end{array}$ & $\mathrm{pH}$ & $\begin{array}{l}\text { As(V) } \\
(\mathrm{mg} / \mathrm{L})\end{array}$ & $\begin{array}{l}\text { As(III) } \\
\text { (mg/L) }\end{array}$ & $\begin{array}{c}\text { DO } \\
(\mathrm{mg} / \mathrm{L})\end{array}$ & $\begin{array}{c}\text { Eh } \\
(\mathrm{mV})\end{array}$ \\
\hline 0 & 3.06 & ND & 81.91 & 8.00 & - & 0 & 7.64 & ND & 98.13 & 8.22 & $\cdot$ \\
\hline 5 & 3.05 & 6.72 & 74.7 & 7.38 & - & 5 & 9.13 & 8.14 & 91.27 & 7.63 & - \\
\hline 10 & 3.03 & 16.48 & 66.87 & 6.44 & - & 10 & 8.17 & 20.17 & 79.03 & 5.44 & $\cdot$ \\
\hline 15 & 3.00 & 29.63 & 56.14 & 5.51 & - & 15 & 7.67 & 31.69 & 68.00 & 4.81 & - \\
\hline 20 & 2.96 & 46.95 & 39.83 & 4.55 & - & 30 & 5.45 & 80.65 & 22.13 & 1.86 & - \\
\hline 30 & 2.88 & 83.38 & ND & 3.34 & $\cdot$ & 40 & 4.84 & 94.17 & 5.26 & 0.86 & - \\
\hline 40 & 2.88 & 83.24 & ND & 6.79 & - & 60 & 4.34 & 99.47 & ND & 6.49 & - \\
\hline 50 & 2.88 & 83.03 & ND & 7.04 & - & & & & & & \\
\hline 60 & 2.88 & 83.03 & ND & 7.16 & - & & & & & & \\
\hline \multicolumn{6}{|c|}{ Experimental No.: DP25 } & \multicolumn{6}{|c|}{ Experimental No.: DP26 } \\
\hline $\begin{array}{l}\text { Time } \\
\text { (min) }\end{array}$ & pH & $\begin{array}{l}\mathrm{As}(\mathrm{V}) \\
(\mathrm{mg} / \mathrm{L})\end{array}$ & $\begin{array}{l}\text { As(III) } \\
\text { (mg/L) }\end{array}$ & $\begin{array}{c}\text { DO } \\
\text { (mg/L) }\end{array}$ & $\begin{array}{c}\text { Eh } \\
(\mathrm{mV})\end{array}$ & $\begin{array}{l}\text { Time } \\
(\min )\end{array}$ & pH & $\begin{array}{l}\mathbf{A s}(\mathrm{V}) \\
(\mathrm{mg} / \mathrm{L})\end{array}$ & $\begin{array}{l}\text { As(III) } \\
\text { (mg/L) }\end{array}$ & $\begin{array}{c}\text { DO } \\
(\mathrm{mg} / \mathrm{L})\end{array}$ & $\begin{array}{c}\text { Eh } \\
(\mathrm{mV})\end{array}$ \\
\hline 0 & 7.72 & ND & 99.75 & 8.18 & - & 0 & 7.70 & ND & 96.11 & 8.33 & - \\
\hline 5 & 7.92 & 27.40 & 73.09 & 0.78 & - & 5 & 5.02 & 6.38 & 89.42 & 7.02 & - \\
\hline 10 & 7.74 & 29.91 & 70.14 & 0.15 & - & 10 & 3.92 & 21.71 & 77.85 & 5.68 & - \\
\hline 15 & 7.55 & 36.58 & 63.14 & 0.16 & - & 15 & 3.56 & 35.62 & 63.45 & 4.32 & - \\
\hline 30 & 7.17 & 51.47 & 49.80 & 0.06 & - & 30 & 3.13 & 98.89 & 3.14 & 0.96 & - \\
\hline 40 & 4.12 & 60.09 & 41.38 & 0.66 & - & 40 & 3.13 & 98.89 & ND & 4.37 & - \\
\hline 60 & 3.52 & 71.00 & 28.08 & 2.47 & - & 60 & 3.13 & 98.89 & ND & 7.53 & - \\
\hline \multicolumn{12}{|c|}{ Experimental No.: DP27 } \\
\hline $\begin{array}{l}\text { Time } \\
(\min )\end{array}$ & $\mathrm{pH}$ & $\begin{array}{l}\mathrm{As}(\mathrm{V}) \\
(\mathrm{mg} / \mathrm{L})\end{array}$ & $\begin{array}{l}\mathbf{A s}(\mathrm{III}) \\
\text { (mg/L) }\end{array}$ & $\begin{array}{c}\text { DO } \\
(\mathrm{mg} / \mathrm{L})\end{array}$ & $\begin{array}{c}\text { Eh } \\
(\mathrm{mV})\end{array}$ & & & & & & \\
\hline 0 & 7.56 & ND & 97.30 & 8.10 & - & & & & & & \\
\hline 5 & 4.60 & 6.38 & 92.50 & 7.36 & - & & & & & & \\
\hline 10 & 3.54 & 20.18 & 80.38 & 5.48 & - & & & & & & \\
\hline 15 & 3.13 & 33.62 & 64.07 & 4.10 & - & & & & & & \\
\hline 30 & 3.12 & 98.53 & ND & 1.10 & - & & & & & & \\
\hline 40 & 3.12 & 98.14 & ND & 5.31 & - & & & & & & \\
\hline 60 & 3.13 & 98.14 & ND & 7.31 & - & & & & & & \\
\hline
\end{tabular}




\section{A.3: AOP with UV/ $\mathrm{H}_{2} \mathrm{O}_{2}$ in Batch Reactor}

\begin{tabular}{|c|c|c|c|c|c|c|c|c|c|c|c|}
\hline \multicolumn{6}{|c|}{ Experimental No.: AP01 } & \multicolumn{6}{|c|}{ Experimental No.: AP02 } \\
\hline $\begin{array}{l}\text { Time } \\
(\min )\end{array}$ & pH & $\begin{array}{l}A s(V) \\
(m g / L)\end{array}$ & $\begin{array}{l}\text { As(III) } \\
\text { (mg/L) }\end{array}$ & $\begin{array}{c}\text { DO } \\
\text { (mg/L) }\end{array}$ & $\begin{array}{c}\text { Eh } \\
(\mathrm{mV})\end{array}$ & $\begin{array}{l}\text { Time } \\
(\min )\end{array}$ & pH & $\begin{array}{l}\mathrm{As}(\mathrm{V}) \\
(\mathrm{mg} / \mathrm{L})\end{array}$ & $\begin{array}{l}\text { As(III) } \\
\text { (mg/L) }\end{array}$ & $\begin{array}{c}\text { DO } \\
(\mathrm{mg} / \mathrm{L})\end{array}$ & $\begin{array}{c}\text { Eh } \\
(\mathrm{mV})\end{array}$ \\
\hline 0 & 3.00 & ND & 98.10 & 7.73 & 610 & 0 & 3.01 & ND & 98.63 & 7.53 & 621 \\
\hline 3 & 2.93 & 22.48 & 76.09 & 4.82 & 636 & 3 & 2.92 & 24.63 & 73.65 & 4.04 & 636 \\
\hline 5 & 2.87 & 38.60 & 59.81 & 0.99 & 629 & 5 & 2.87 & 42.77 & 55.96 & 0.42 & 637 \\
\hline 8 & 2.83 & 52.96 & 45.69 & 0.22 & 622 & 8 & 2.82 & 58.86 & 39.58 & 0.25 & 629 \\
\hline 10 & 2.81 & 60.98 & 38.80 & 0.23 & 620 & 10 & 2.79 & 67.17 & 31.30 & 0.23 & 623 \\
\hline 15 & 2.78 & 68.65 & 30.78 & 0.24 & 617 & 15 & 2.77 & 76.48 & 22.77 & 0.22 & 621 \\
\hline 20 & 2.78 & 71.79 & 27.56 & 0.24 & 614 & 20 & 2.76 & 80.05 & 18.73 & 0.24 & 618 \\
\hline 30 & 2.77 & 74.93 & 24.33 & 0.24 & 611 & 30 & 2.75 & 84.63 & 14.38 & 0.25 & 623 \\
\hline 40 & 2.75 & 77.82 & 21.05 & 0.24 & 612 & 40 & 2.73 & 88.22 & 10.60 & 0.23 & 614 \\
\hline 50 & 2.74 & 81.24 & 18.02 & 0.24 & 610 & 50 & 2.72 & 92.81 & 6.40 & 0.24 & 618 \\
\hline 60 & 2.74 & 84.27 & 14.35 & 0.23 & 608 & 60 & 2.71 & 96.03 & 1.87 & 0.24 & 617 \\
\hline \multicolumn{6}{|c|}{ Experimental No.: AP03 } & \multicolumn{6}{|c|}{ Experimental No.: AP0 $4^{3}$} \\
\hline $\begin{array}{l}\text { Time } \\
(\min )\end{array}$ & pH & $\begin{array}{l}\mathrm{As}(\mathrm{V}) \\
(\mathrm{mg} / \mathrm{L})\end{array}$ & $\begin{array}{l}\text { As(III) } \\
(\mathrm{mg} / \mathrm{L})\end{array}$ & $\begin{array}{c}\text { DO } \\
(\mathrm{mg} / \mathrm{L})\end{array}$ & $\begin{array}{c}\text { Eh } \\
(\mathrm{mV})\end{array}$ & $\begin{array}{l}\text { Time } \\
\text { (min) }\end{array}$ & pH & $\begin{array}{l}\mathrm{As}(\mathrm{V}) \\
(\mathrm{mg} / \mathrm{L})\end{array}$ & $\begin{array}{l}\mathrm{As}(\mathrm{III}) \\
(\mathrm{mg} / \mathrm{L})\end{array}$ & $\begin{array}{c}\text { DO } \\
(\mathrm{mg} / \mathrm{L})\end{array}$ & $\begin{array}{c}\text { Eh } \\
(\mathrm{mV})\end{array}$ \\
\hline 0 & 3.01 & ND & 97.78 & 7.26 & 611 & 0 & 3.08 & ND & 94.65 & 7.70 & 613 \\
\hline 3 & 2.90 & 30.12 & 67.39 & 2.71 & 639 & 3 & 2.92 & 47.56 & 51.68 & 1.01 & 658 \\
\hline 5 & 2.84 & 51.57 & 45.57 & 0.31 & 628 & 5 & 2.91 & 72.52 & 26.89 & 0.24 & 658 \\
\hline 8 & 2.80 & 71.23 & 25.83 & 0.25 & 620 & 8 & 2.84 & 99.20 & ND & 0.94 & 651 \\
\hline 10 & 2.77 & 82.1 & 15.71 & 0.22 & 616 & 10 & 2.79 & 99.90 & ND & 5.00 & 651 \\
\hline 15 & 2.74 & 93.91 & 4.23 & 0.23 & 619 & 15 & 2.79 & 99.32 & ND & 8.75 & 644 \\
\hline 20 & 2.72 & 98.24 & ND & 0.24 & 628 & 20 & 2.78 & 98.74 & ND & 9.26 & 646 \\
\hline 30 & 2.71 & 98.63 & ND & 1.13 & 620 & 30 & 2.78 & 99.81 & ND & 9.15 & 640 \\
\hline \multicolumn{6}{|c|}{ Experimental No.: AP05 ${ }^{3}$} & \multicolumn{6}{|c|}{ Experimental No.: AP06 } \\
\hline $\begin{array}{l}\text { Time } \\
\text { (min) }\end{array}$ & $\mathrm{pH}$ & $\begin{array}{l}\text { As(V) } \\
(\mathrm{mg} / \mathrm{L})\end{array}$ & $\begin{array}{l}\text { As(III) } \\
(\mathrm{mg} / \mathrm{L})\end{array}$ & $\begin{array}{c}\text { DO } \\
(\mathrm{mg} / \mathrm{L})\end{array}$ & $\begin{array}{c}\text { Eh } \\
(\mathrm{mV})\end{array}$ & $\begin{array}{l}\text { Time } \\
(\min )\end{array}$ & $\mathrm{pH}$ & $\begin{array}{l}\text { As(V) } \\
(\mathrm{mg} / \mathrm{L})\end{array}$ & $\begin{array}{l}\text { As(III) } \\
\text { (mg/L) }\end{array}$ & $\begin{array}{c}\text { DO } \\
\text { (mg/L) }\end{array}$ & $\begin{array}{c}\text { Eh } \\
(\mathrm{mV})\end{array}$ \\
\hline 0 & 3.02 & ND & 99.17 & 7.29 & 618 & 0 & 3.14 & ND & 97.83 & 0.83 & 643 \\
\hline 3 & 2.87 & 92.53 & 7.23 & 0.83 & 668 & 3 & 3.06 & 43.85 & 56.32 & 0.31 & 653 \\
\hline 5 & 2.78 & 99.14 & ND & 0.22 & 657 & 5 & 2.93 & 67.58 & 33.51 & 0.68 & 670 \\
\hline 8 & 2.76 & 99.17 & ND & 7.16 & 656 & 8 & 2.90 & 90.47 & 6.11 & 0.23 & 665 \\
\hline 10 & 2.74 & 99.21 & ND & 13.09 & 646 & 10 & 2.88 & 97.93 & ND & 2.85 & 657 \\
\hline 15 & 2.74 & 99.48 & ND & 18.31 & 646 & 15 & 2.87 & 97.88 & ND & 2.67 & 650 \\
\hline 20 & 2.74 & 99.58 & ND & 17.87 & 646 & 30 & 2.86 & 97.72 & ND & 2.03 & 650 \\
\hline 30 & 2.74 & 99.42 & ND & 17.33 & 646 & 60 & 2.86 & 98.17 & ND & 1.92 & 646 \\
\hline
\end{tabular}

3: Sample analysis was further confirmed by HPLC-HG-AAS system. 


\begin{tabular}{|c|c|c|c|c|c|c|c|c|c|c|c|}
\hline \multicolumn{6}{|c|}{ Experimental No.: AP07 } & \multicolumn{6}{|c|}{ Experimental No.: AP08 } \\
\hline $\begin{array}{l}\text { Time } \\
(\min )\end{array}$ & pH & $\begin{array}{l}\text { As(V) } \\
(\mathrm{mg} / \mathrm{L})\end{array}$ & $\begin{array}{l}\text { As(III) } \\
(\mathrm{mg} / \mathrm{L})\end{array}$ & $\begin{array}{c}\text { DO } \\
(\mathrm{mg} / \mathrm{L})\end{array}$ & $\begin{array}{c}\text { Eh } \\
(\mathrm{mV})\end{array}$ & $\begin{array}{l}\text { Time } \\
(\min )\end{array}$ & pH & $\begin{array}{l}\mathrm{As}(\mathrm{V}) \\
(\mathrm{mg} / \mathrm{L})\end{array}$ & $\begin{array}{l}\mathrm{As}(\mathrm{III}) \\
\text { (mg/L) }\end{array}$ & $\begin{array}{c}\text { DO } \\
(\mathrm{mg} / \mathrm{L})\end{array}$ & $\begin{array}{c}\text { Eh } \\
(\mathrm{mV})\end{array}$ \\
\hline 0 & 3.08 & ND & 98.86 & 7.96 & 618 & 0 & 3.14 & ND & 95.27 & 0.95 & 620 \\
\hline 3 & 2.92 & 44.69 & 53.32 & 1.79 & 668 & 3 & 3.10 & 22.94 & 72.68 & 0.93 & 624 \\
\hline 5 & 2.84 & 72.12 & 26.32 & 0.26 & 657 & 5 & 3.00 & 46.78 & 56.74 & 0.94 & 623 \\
\hline 8 & 2.80 & 101.67 & ND & 2.94 & 656 & 8 & 2.98 & 52.63 & 47.17 & 0.92 & 624 \\
\hline 10 & 2.80 & 101.56 & ND & 8.91 & 646 & 10 & 2.98 & 55.65 & 44.97 & 0.95 & 622 \\
\hline 15 & 2.80 & 101.82 & ND & 12.07 & 646 & 15 & 2.98 & 57.65 & 43.11 & 0.22 & 602 \\
\hline 30 & 2.80 & 101.54 & ND & 7.63 & 646 & 30 & 2.98 & 58.48 & 42.49 & 0.22 & 603 \\
\hline \multirow[t]{2}{*}{60} & 2.80 & 101.99 & ND & 7.34 & 646 & 45 & 2.98 & 59.06 & 41.66 & 0.22 & 606 \\
\hline & & & & & & 60 & 2.97 & 60.08 & 40.92 & 0.22 & 607 \\
\hline \multicolumn{6}{|c|}{ Experimental No.: AP09 } & \multicolumn{6}{|c|}{ Experimental No.: AP10 } \\
\hline $\begin{array}{l}\text { Time } \\
\text { (min) }\end{array}$ & pH & $\begin{array}{l}\mathrm{As}(\mathrm{V}) \\
(\mathrm{mg} / \mathrm{L})\end{array}$ & $\begin{array}{l}\text { As(III) } \\
(\mathrm{mg} / \mathrm{L})\end{array}$ & $\begin{array}{c}\text { DO } \\
(\mathrm{mg} / \mathrm{L})\end{array}$ & $\begin{array}{c}\text { Eh } \\
(m V)\end{array}$ & $\begin{array}{l}\text { Time } \\
(\min )\end{array}$ & pH & $\begin{array}{l}\text { As(V) } \\
(\mathrm{mg} / \mathrm{L})\end{array}$ & $\begin{array}{l}\text { As(III) } \\
\text { (mg/L) }\end{array}$ & $\begin{array}{c}\text { DO } \\
(\mathrm{mg} / \mathrm{L})\end{array}$ & $\begin{array}{c}\text { Eh } \\
(m V)\end{array}$ \\
\hline 0 & 3.08 & ND & 97.45 & 7.87 & 612 & 0 & 3.19 & ND & 96.33 & 0.95 & 623 \\
\hline 3 & 2.95 & 28.60 & 72.01 & 3.44 & 663 & 3 & 3.12 & 12.26 & 84.36 & 0.93 & 637 \\
\hline 5 & 2.88 & 52.91 & 47.71 & 0.43 & 652 & 5 & 3.08 & 24.68 & 73.66 & 0.97 & 638 \\
\hline 8 & 2.82 & 86.11 & 14.43 & 0.28 & 642 & 8 & 3.08 & 27.19 & 71.42 & 0.94 & 639 \\
\hline 10 & 2.79 & 100.50 & ND & 2.10 & 646 & 10 & 3.07 & 31.08 & 69.29 & 0.97 & 637 \\
\hline 15 & 2.79 & 100.35 & ND & 7.78 & 633 & 15 & 3.07 & 31.76 & 68.42 & 0.22 & 629 \\
\hline 30 & 2.80 & 100.79 & ND & 7.65 & 628 & 30 & 3.07 & 32.73 & 67.27 & 0.22 & 620 \\
\hline \multirow[t]{2}{*}{60} & 2.80 & 100.84 & ND & 7.33 & 636 & 45 & 3.06 & 32.43 & 65.34 & 0.22 & 616 \\
\hline & & & & & & 60 & 3.05 & 35.68 & 64.55 & 0.22 & 608 \\
\hline \multicolumn{6}{|c|}{ Experimental No.: AP11 } & \multicolumn{6}{|c|}{ Experimental No.: AP12 } \\
\hline $\begin{array}{l}\text { Time } \\
(\mathrm{min})\end{array}$ & pH & $\begin{array}{l}\mathbf{A s}(\mathbf{V}) \\
(\mathrm{mg} / \mathrm{L})\end{array}$ & $\begin{array}{l}\text { As(III) } \\
(\mathrm{mg} / \mathrm{L})\end{array}$ & $\begin{array}{c}\text { DO } \\
\text { (mg/L) }\end{array}$ & $\begin{array}{c}\text { Eh } \\
(\mathrm{mV})\end{array}$ & $\begin{array}{l}\text { Time } \\
\text { (min) }\end{array}$ & $\mathbf{p H}$ & $\begin{array}{l}\mathbf{A s}(\mathbf{V}) \\
(\mathrm{mg} / \mathrm{L})\end{array}$ & $\begin{array}{l}\text { As(III) } \\
(\mathrm{mg} / \mathrm{L})\end{array}$ & $\begin{array}{c}\text { DO } \\
(\mathrm{mg} / \mathrm{L})\end{array}$ & $\begin{array}{c}\text { Eh } \\
(\mathrm{mV})\end{array}$ \\
\hline 0 & 3.07 & ND & 96.99 & 7.79 & 585 & 0 & 7.98 & ND & 101.80 & 0.81 & 318 \\
\hline 3 & 2.99 & 21.27 & 76.27 & 5.05 & 658 & 3 & 3.42 & 41.22 & 59.91 & 0.76 & 426 \\
\hline 5 & 2.94 & 35.23 & 61.38 & 2.91 & 651 & 5 & 3.27 & 82.59 & 19.05 & 0.91 & 600 \\
\hline 8 & 2.86 & 61.25 & 38.12 & 0.73 & 651 & 8 & 3.18 & 101.83 & ND & 0.94 & 612 \\
\hline 10 & 2.83 & 79.35 & 21.10 & 0.47 & 644 & 10 & 3.18 & 101.12 & ND & 2.97 & 592 \\
\hline 15 & 2.79 & 99.65 & ND & 3.27 & 646 & 15 & 3.17 & 101.69 & ND & 4.09 & 586 \\
\hline 30 & 2.80 & 100.34 & ND & 7.22 & 640 & 30 & 3.17 & 101.54 & ND & 4.26 & 583 \\
\hline \multirow[t]{2}{*}{60} & 2.78 & 99.91 & ND & 7.38 & 641 & 45 & 3.17 & 101.57 & ND & 4.17 & 582 \\
\hline & & & & & & 60 & 3.17 & 101.75 & ND & 4.03 & 581 \\
\hline
\end{tabular}




\begin{tabular}{|c|c|c|c|c|c|c|c|c|c|c|c|}
\hline \multicolumn{6}{|c|}{ Experimental No.: AP13 } & \multicolumn{6}{|c|}{ Experimental No.: AP14 } \\
\hline $\begin{array}{l}\text { Time } \\
\text { (min) }\end{array}$ & pH & $\begin{array}{l}\text { As(V) } \\
(\mathrm{mg} / \mathrm{L})\end{array}$ & $\begin{array}{l}\text { As(III) } \\
\text { (mg/L) }\end{array}$ & $\begin{array}{c}\mathrm{DO} \\
(\mathrm{mg} / \mathrm{L})\end{array}$ & $\begin{array}{c}\text { Eh } \\
(\mathrm{mV})\end{array}$ & $\begin{array}{l}\text { Time } \\
\text { (min) }\end{array}$ & $\mathrm{pH}$ & $\begin{array}{l}\text { As }(\mathbf{V}) \\
(\mathrm{mg} / \mathrm{L})\end{array}$ & $\begin{array}{l}\text { As(III) } \\
\text { (mg/L) }\end{array}$ & $\begin{array}{c}\text { DO } \\
\text { (mg/L) }\end{array}$ & $\begin{array}{c}\text { Eh } \\
(\mathrm{mV})\end{array}$ \\
\hline 0 & 9.97 & ND & 100.61 & 0.92 & 141 & 0 & 7.89 & ND & 95.26 & 7.99 & 354 \\
\hline 3 & 6.42 & 66.46 & 33.58 & 0.86 & 389 & 3 & 3.28 & 47.56 & 51.68 & 0.84 & 628 \\
\hline 5 & 4.87 & 97.14 & 3.12 & 0.94 & 439 & 5 & 3.10 & 77.16 & 21.32 & 0.23 & 619 \\
\hline 8 & 4.89 & 100.34 & ND & 3.13 & 429 & 8 & 3.06 & 99.81 & ND & 2.85 & 601 \\
\hline 10 & 4.92 & 100.21 & ND & 4.12 & 423 & 10 & 3.06 & 99.66 & ND & 6.27 & 592 \\
\hline 15 & 4.91 & 100.41 & ND & 4.07 & 423 & 15 & 3.07 & 98.09 & ND & 9.19 & 592 \\
\hline 30 & 4.92 & 100.39 & ND & 4.29 & 423 & 30 & 3.08 & 98.93 & ND & 9.10 & 592 \\
\hline 45 & 4.92 & 100.93 & ND & 3.75 & 420 & 60 & 3.08 & 98.42 & ND & 8.08 & 592 \\
\hline 60 & 4.92 & 100.49 & ND & 3.60 & 435 & & & & & & \\
\hline \multicolumn{6}{|c|}{ Experimental No.: AP15 } & \multicolumn{6}{|c|}{ Experimental No.: AP16 } \\
\hline $\begin{array}{l}\text { Time } \\
\text { (min) }\end{array}$ & $\mathrm{pH}$ & $\begin{array}{l}\text { As(V) } \\
(\mathrm{mg} / \mathrm{L})\end{array}$ & $\begin{array}{l}\text { As(III) } \\
\text { (mg/L) }\end{array}$ & $\begin{array}{c}\text { DO } \\
(\mathrm{mg} / \mathrm{L})\end{array}$ & $\begin{array}{c}\text { Eh } \\
(\mathrm{mV})\end{array}$ & $\begin{array}{l}\text { Time } \\
\text { (min) }\end{array}$ & pH & $\begin{array}{l}\text { As }(\mathbf{V}) \\
(\mathrm{mg} / \mathrm{L})\end{array}$ & $\begin{array}{l}\text { As(III) } \\
(\mathrm{mg} / \mathrm{L})\end{array}$ & $\begin{array}{c}\text { DO } \\
(\mathrm{mg} / \mathrm{L})\end{array}$ & $\begin{array}{c}\text { Eh } \\
(\mathrm{mV})\end{array}$ \\
\hline 0 & 9.84 & ND & 95.22 & 7.61 & 197 & 0 & 7.15 & ND & 98.42 & 7.95 & 342 \\
\hline 3 & 6.39 & 67.15 & 31.23 & 1.76 & 507 & 3 & 3.39 & 41.25 & 60.22 & 1.67 & 636 \\
\hline 5 & 4.31 & 98.17 & ND & 1.39 & 500 & 5 & 3.14 & 72.52 & 28.46 & 0.27 & 631 \\
\hline 8 & 4.30 & 98.42 & ND & 5.70 & 491 & 8 & 3.08 & 101.34 & ND & 4.49 & 615 \\
\hline 10 & 4.30 & 99.16 & ND & 7.51 & 482 & 10 & 3.08 & 101.93 & ND & 8.83 & 621 \\
\hline 15 & 4.31 & 98.43 & ND & 8.50 & 483 & 15 & 3.08 & 101.17 & ND & 11.54 & 620 \\
\hline 30 & 4.32 & 98.11 & ND & 8.42 & 481 & 30 & 3.08 & 101.38 & ND & 8.07 & 618 \\
\hline 60 & 4.33 & 97.98 & ND & 8.17 & 485 & 60 & 3.08 & 101.09 & ND & 7.32 & 616 \\
\hline \multicolumn{6}{|c|}{ Experimental No.: AP17 } & \multicolumn{6}{|c|}{ Experimental No.: AP18 } \\
\hline $\begin{array}{l}\text { Time } \\
\text { (min) }\end{array}$ & pH & $\begin{array}{l}\text { As(V) } \\
(\mathrm{mg} / \mathrm{L})\end{array}$ & $\begin{array}{l}\mathrm{As}(\mathrm{III}) \\
(\mathrm{mg} / \mathrm{L})\end{array}$ & $\begin{array}{c}\text { DO } \\
(\mathrm{mg} / \mathrm{L})\end{array}$ & $\begin{array}{c}\text { Eh } \\
(\mathrm{mV})\end{array}$ & $\begin{array}{l}\text { Time } \\
\text { (min) }\end{array}$ & pH & $\begin{array}{l}A s(V) \\
(m g / L)\end{array}$ & $\begin{array}{l}\text { As(III) } \\
(\mathrm{mg} / \mathrm{L})\end{array}$ & $\begin{array}{c}\text { DO } \\
\text { (mg/L) }\end{array}$ & $\begin{array}{c}\text { Eh } \\
(\mathrm{mV})\end{array}$ \\
\hline 0 & 9.89 & ND & 96.82 & 7.62 & 207 & 0 & 3.24 & ND & 19.36 & 7.95 & - \\
\hline 3 & 6.75 & 66.72 & 33.45 & 2.90 & 489 & 3 & 3.15 & 20.13 & ND & 5.20 & - \\
\hline 5 & 5.08 & 95.49 & 4.77 & 0.35 & 506 & 5 & 3.15 & 20.02 & ND & 6.28 & - \\
\hline 8 & 5.07 & 100.32 & ND & 6.83 & 486 & 8 & 3.14 & 19.84 & ND & 7.59 & - \\
\hline 10 & 5.09 & 100.76 & ND & 10.03 & 471 & 10 & 3.13 & 19.86 & ND & 8.11 & - \\
\hline 15 & 5.14 & 100.39 & ND & 10.43 & 477 & 15 & 3.12 & 19.94 & ND & 8.21 & - \\
\hline 30 & 5.14 & 99.66 & ND & 7.82 & 479 & 20 & 3.12 & 20.06 & ND & 8.07 & - \\
\hline 60 & 5.14 & 99.77 & ND & 7.27 & 481 & 30 & 3.11 & 19.98 & ND & 7.92 & - \\
\hline & & & & & & 60 & 3.11 & 19.98 & ND & 8.03 & - \\
\hline
\end{tabular}




\begin{tabular}{|c|c|c|c|c|c|c|c|c|c|c|c|}
\hline \multicolumn{6}{|c|}{ Experimental No.: AP19 } & \multicolumn{6}{|c|}{ Experimental No.: AP20 } \\
\hline $\begin{array}{l}\text { Time } \\
\text { (min) }\end{array}$ & pH & $\begin{array}{l}\text { As(V) } \\
(m g / L)\end{array}$ & $\begin{array}{l}\text { As(III) } \\
\text { (mg/L) }\end{array}$ & $\begin{array}{c}\text { DO } \\
\text { (mg/L) }\end{array}$ & $\begin{array}{c}\text { Eh } \\
(\mathrm{mV})\end{array}$ & $\begin{array}{l}\text { Time } \\
(\min )\end{array}$ & $\mathrm{pH}$ & $\begin{array}{l}\mathbf{A s}(\mathbf{V}) \\
(\mathrm{mg} / \mathrm{L})\end{array}$ & $\begin{array}{l}\text { As(III) } \\
(\mathrm{mg} / \mathrm{L})\end{array}$ & $\begin{array}{c}\text { DO } \\
(\mathrm{mg} / \mathrm{L})\end{array}$ & $\begin{array}{c}\text { Eh } \\
(\mathrm{mV})\end{array}$ \\
\hline 0 & 3.20 & ND & 40.26 & 8.35 & - & 0 & 3.24 & ND & 61.32 & 7.53 & - \\
\hline 5 & 3.15 & 32.68 & 7.23 & 2.52 & $\cdot$ & 3 & 3.15 & 44.83 & 22.03 & 1.50 & $\because$ \\
\hline 10 & 3.14 & 40.89 & ND & 1.34 & - & 5 & 3.15 & 62.38 & ND & 0.58 & - \\
\hline 15 & 3.13 & 40.86 & ND & 5.23 & - & 8 & 3.14 & 62.26 & ND & 4.87 & - \\
\hline 30 & 3.13 & 40.82 & ND & 7.29 & - & 10 & 3.12 & 62.24 & ND & 7.18 & - \\
\hline 40 & 3.13 & 40.76 & ND & 8.62 & $\cdot$ & 15 & 3.12 & 62.13 & ND & 8.50 & - \\
\hline 50 & 3.12 & 40.76 & ND & 8.54 & - & 20 & 3.11 & 62.13 & ND & 8.50 & - \\
\hline 60 & 3.12 & 40.76 & ND & 8.43 & - & 30 & 3.10 & 62.13 & ND & 8.06 & - \\
\hline 120 & 3.12 & 40.76 & ND & 8.43 & - & 60 & 3.10 & 62.13 & ND & 8.06 & - \\
\hline \multicolumn{6}{|c|}{ Experimental No.: AP21 } & \multicolumn{6}{|c|}{ Experimental No.: AP22 } \\
\hline $\begin{array}{l}\text { Time } \\
(\min )\end{array}$ & pH & $\begin{array}{l}\text { As(V) } \\
(\mathrm{mg} / \mathrm{L})\end{array}$ & $\begin{array}{l}\text { As(III) } \\
(\mathrm{mg} / \mathrm{L})\end{array}$ & $\begin{array}{c}\text { DO } \\
(\mathrm{mg} / \mathrm{L})\end{array}$ & $\begin{array}{c}\text { Eh } \\
(\mathrm{mV})\end{array}$ & $\begin{array}{l}\text { Time } \\
(\mathrm{min})\end{array}$ & $\mathrm{pH}$ & $\begin{array}{l}\mathrm{As}(\mathrm{V}) \\
(\mathrm{mg} / \mathrm{L})\end{array}$ & $\begin{array}{l}\text { As(III) } \\
\text { (mg/L) }\end{array}$ & $\begin{array}{c}\text { DO } \\
\text { (mg/L) }\end{array}$ & $\begin{array}{l}\text { Eh } \\
(\mathrm{mV})\end{array}$ \\
\hline 0 & 3.29 & ND & 80.77 & 7.96 & - & 0 & 7.28 & ND & 98.22 & 7.63 & - \\
\hline 3 & 3.05 & 51.12 & 30.55 & 1.34 & - & 3 & 5.93 & 72.14 & 28.51 & 1.15 & - \\
\hline 5 & 3.02 & 75.88 & 5.72 & 0.31 & - & 5 & 4.52 & 100.17 & ND & 1.74 & - \\
\hline 8 & 3.00 & 81.46 & ND & 3.15 & - & 8 & 4.49 & 99.87 & ND & 6.24 & - \\
\hline 10 & 2.99 & 81.43 & ND & 7.36 & - & 10 & 4.48 & 99.02 & ND & 8.14 & - \\
\hline 15 & 2.99 & 81.32 & ND & 10.21 & - & 15 & 4.49 & 99.04 & ND & 9.27 & - \\
\hline 20 & 2.99 & 81.58 & ND & 10.08 & - & 30 & 4.50 & 99.01 & ND & 9.34 & - \\
\hline 30 & 2.99 & 81.16 & ND & 8.74 & - & 60 & 4.51 & 99.15 & ND & 9.06 & - \\
\hline 60 & 2.99 & 81.16 & ND & 8.61 & - & & & & & & \\
\hline \multicolumn{6}{|c|}{ Experimental No.: AP23 } & \multicolumn{6}{|c|}{ Experimental No.: AP24 } \\
\hline $\begin{array}{l}\text { Time } \\
(\min )\end{array}$ & pH & $\begin{array}{l}\text { As(V) } \\
(\mathrm{mg} / \mathrm{L})\end{array}$ & $\begin{array}{l}\mathrm{As}(\mathrm{III}) \\
(\mathrm{mg} / \mathrm{L})\end{array}$ & $\begin{array}{c}\text { DO } \\
(\mathrm{mg} / \mathrm{L})\end{array}$ & $\begin{array}{c}\text { Eh } \\
(\mathrm{mV})\end{array}$ & $\begin{array}{l}\text { Time } \\
\text { (min) }\end{array}$ & pH & $\begin{array}{l}\operatorname{As}(\mathrm{V}) \\
(\mathrm{mg} / \mathrm{L})\end{array}$ & $\begin{array}{l}\text { As(III) } \\
\text { (mg/L) }\end{array}$ & $\begin{array}{c}\text { DO } \\
(\mathrm{mg} / \mathrm{L})\end{array}$ & $\begin{array}{c}\text { Eh } \\
(\mathrm{mV})\end{array}$ \\
\hline 0 & 7.46 & ND & 98.98 & 7.86 & - & 0 & 7.28 & ND & 97.71 & 8.22 & - \\
\hline 3 & 3.36 & 7.66 & 92.14 & 6.38 & - & 3 & 3.23 & 54.58 & 45.38 & 1.11 & $\cdot$ \\
\hline 5 & 3.31 & 11.45 & 88.40 & 5.33 & - & 5 & 3.08 & 79.47 & 20.66 & 0.24 & - \\
\hline 8 & 3.25 & 19.18 & 81.64 & 3.83 & - & 8 & 3.01 & 99.60 & ND & 2.18 & - \\
\hline 10 & 3.21 & 25.05 & 76.08 & 2.44 & - & 10 & 3.01 & 99.98 & ND & 6.70 & - \\
\hline 15 & 3.12 & 38.12 & 63.07 & 0.36 & - & 15 & 3.00 & 99.44 & ND & 10.52 & - \\
\hline 30 & 3.06 & 58.39 & 43.15 & 0.22 & - & 30 & 3.01 & 99.53 & ND & 10.89 & - \\
\hline 60 & 3.03 & 81.68 & 20.25 & 0.24 & - & 60 & 3.00 & 99.47 & ND & 10.75 & - \\
\hline
\end{tabular}




\begin{tabular}{cccccc}
\hline \multicolumn{6}{l}{ Experimental No.: AP25 } \\
$\begin{array}{ccccc}\text { Time } \\
(\mathrm{min})\end{array}$ & $\mathbf{p H}$ & $\begin{array}{c}\text { As(V) } \\
(\mathrm{mg} / \mathrm{L})\end{array}$ & $\begin{array}{c}\text { As(III) } \\
(\mathrm{mg} / \mathrm{L})\end{array}$ & $\begin{array}{c}\text { DO } \\
(\mathrm{mg} / \mathrm{L})\end{array}$ & $\begin{array}{c}\text { Eh } \\
(\mathrm{mV})\end{array}$ \\
\hline 0 & 7.25 & $\mathrm{ND}$ & 99.93 & 8.28 & 7.25 \\
3 & 3.30 & 51.17 & 48.98 & 1.50 & 3.30 \\
5 & 3.08 & 81.57 & 18.74 & 0.23 & 3.08 \\
8 & 3.01 & 99.60 & $\mathrm{ND}$ & 2.24 & 3.01 \\
10 & 3.01 & 99.81 & $\mathrm{ND}$ & 6.25 & 3.01 \\
15 & 3.00 & 99.55 & $\mathrm{ND}$ & 10.22 & 3.00 \\
30 & 3.00 & 99.81 & $\mathrm{ND}$ & 10.95 & 3.00 \\
60 & 2.99 & 99.67 & $\mathrm{ND}$ & 10.75 & 2.99 \\
\hline \hline
\end{tabular}

\section{B.1: Direct Photolysis in Recirculation Reactor:}

\begin{tabular}{|c|c|c|c|c|c|c|c|c|c|c|c|}
\hline \multicolumn{6}{|c|}{ Experimental No.: RD01 } & \multicolumn{6}{|c|}{ Experimental No.: RD02 } \\
\hline $\begin{array}{l}\text { Time } \\
\text { (min) }\end{array}$ & pH & $\begin{array}{l}\mathrm{As}(\mathrm{V}) \\
(\mathrm{mg} / \mathrm{L})\end{array}$ & $\begin{array}{l}\mathrm{As}(\mathrm{III}) \\
\text { (mg/L) }\end{array}$ & $\begin{array}{c}\text { DO } \\
(\mathrm{mg} / \mathrm{L})\end{array}$ & $\begin{array}{c}\text { Eh } \\
(\mathrm{mV})\end{array}$ & $\begin{array}{l}\text { Time } \\
(\min )\end{array}$ & $\mathbf{p H}$ & $\begin{array}{l}\mathrm{As}(\mathrm{V}) \\
(\mathrm{mg} / \mathrm{L})\end{array}$ & $\begin{array}{l}\text { As(III) } \\
\text { (mg/L) }\end{array}$ & $\begin{array}{c}\mathrm{DO} \\
(\mathrm{mg} / \mathrm{L})\end{array}$ & $\begin{array}{c}\text { Eh } \\
(\mathrm{mV})\end{array}$ \\
\hline 0 & 10.21 & ND & 96.93 & 8.14 & - & 0 & 10.19 & ND & 95.68 & 8.66 & - \\
\hline 5 & 10.09 & 3.63 & 93.91 & 7.25 & - & 5 & 10.08 & 3.99 & 92.10 & 8.41 & - \\
\hline 10 & 9.97 & 8.17 & 89.65 & 6.69 & - & 10 & 9.97 & 8.42 & 87.89 & 8.34 & - \\
\hline 15 & 9.84 & 12.72 & 85.90 & 6.41 & - & 15 & 9.84 & 13.13 & 83.73 & 8.52 & - \\
\hline 30 & 9.49 & 24.41 & 75.03 & 6.34 & - & 30 & 9.50 & 25.10 & 73.24 & 8.70 & - \\
\hline 40 & 9.24 & 31.55 & 68.37 & 6.39 & - & 40 & 9.24 & 31.62 & 67.06 & 8.72 & - \\
\hline 50 & 8.91 & 38.62 & 62.17 & 6.50 & - & 50 & 8.92 & 38.42 & 60.82 & 8.86 & - \\
\hline 60 & 8.27 & 45.56 & 55.22 & 6.52 & - & 60 & 8.34 & 45.09 & 54.88 & 8.99 & - \\
\hline \multicolumn{6}{|c|}{ Experimental No.: RD03 } & \multicolumn{6}{|c|}{ Experimental No.: RD04 } \\
\hline $\begin{array}{l}\text { Time } \\
(\min )\end{array}$ & $\mathrm{pH}$ & $\begin{array}{l}\mathbf{A s}(\mathbf{V}) \\
(\mathrm{mg} / \mathrm{L})\end{array}$ & $\begin{array}{l}\mathbf{A s}(\mathrm{III}) \\
(\mathrm{mg} / \mathrm{L})\end{array}$ & $\begin{array}{c}\text { DO } \\
(\mathrm{mg} / \mathrm{L})\end{array}$ & $\begin{array}{c}\text { Eh } \\
(\mathrm{mV})\end{array}$ & $\begin{array}{l}\text { Time } \\
\text { (min) }\end{array}$ & pH & $\begin{array}{l}A s(V) \\
(m g / L)\end{array}$ & $\begin{array}{l}\text { As(III) } \\
(\mathrm{mg} / \mathrm{L})\end{array}$ & $\begin{array}{c}\text { DO } \\
(\mathrm{mg} / \mathrm{L})\end{array}$ & $\begin{array}{c}\text { Eh } \\
(\mathrm{mV})\end{array}$ \\
\hline 0 & 10.05 & ND & 95.62 & 8.61 & - & 0 & 3.16 & ND & 96.09 & 8.19 & - \\
\hline 5 & 10.02 & 3.62 & 92.47 & 8.86 & - & 5 & 3.14 & 1.95 & 94.26 & 8.08 & - \\
\hline 10 & 9.91 & 8.36 & 88.11 & 8.71 & - & 10 & 3.13 & 5.89 & 90.60 & 8.10 & $\cdot$ \\
\hline 15 & 9.81 & 12.20 & 84.86 & 8.83 & - & 15 & 3.12 & 10.18 & 86.43 & 7.74 & - \\
\hline 30 & 9.49 & 23.15 & 75.17 & 8.77 & - & 30 & 3.04 & 30.27 & 68.04 & 7.42 & - \\
\hline 40 & 9.24 & 30.08 & 69.24 & 8.77 & - & 40 & 2.99 & 46.08 & 53.16 & 7.06 & - \\
\hline 50 & 8.91 & 36.88 & 62.72 & 8.81 & - & 50 & 2.95 & 65.13 & 34.19 & 7.21 & - \\
\hline 60 & 8.26 & 43.37 & 56.65 & 8.85 & - & 60 & 2.91 & 85.17 & 13.59 & 7.02 & - \\
\hline
\end{tabular}

Reproduced with permission of the copyright owner. Further reproduction prohibited without permission. 


\begin{tabular}{|c|c|c|c|c|c|c|c|c|c|c|c|}
\hline \multicolumn{6}{|c|}{ Experimental No.: RD05 } & \multicolumn{6}{|c|}{ Experimental No.: RD06 } \\
\hline $\begin{array}{l}\text { Time } \\
(\min )\end{array}$ & pH & $\begin{array}{l}\text { As(V) } \\
(\mathrm{mg} / \mathrm{L})\end{array}$ & $\begin{array}{l}\text { As(III) } \\
\text { (mg/L) }\end{array}$ & $\begin{array}{c}\text { DO } \\
\text { (mg/L) }\end{array}$ & $\begin{array}{c}\text { Eh } \\
(\mathrm{mV})\end{array}$ & $\begin{array}{l}\text { Time } \\
\text { (min) }\end{array}$ & pH & $\begin{array}{l}\text { As(V) } \\
(\mathrm{mg} / \mathrm{L})\end{array}$ & $\begin{array}{l}\text { As(III) } \\
(\mathrm{mg} / \mathrm{L})\end{array}$ & $\begin{array}{c}\text { DO } \\
(\mathrm{mg} / \mathrm{L})\end{array}$ & $\begin{array}{l}\text { Eh } \\
(\mathrm{mV})\end{array}$ \\
\hline 0 & 7.45 & ND & 96.29 & 8.24 & - & 0 & 10.35 & ND & 49.85 & 8.38 & - \\
\hline 5 & 5.13 & 3.43 & 93.26 & 8.11 & - & 5 & 9.90 & 2.29 & 47.14 & 8.42 & - \\
\hline 10 & 4.15 & 6.42 & 90.60 & 8.04 & - & 10 & 9.76 & 5.25 & 44.62 & 8.47 & - \\
\hline 15 & 3.25 & 8.41 & 88.43 & 7.89 & - & 15 & 9.56 & 8.18 & 41.60 & 8.53 & - \\
\hline 30 & 3.12 & 24.28 & 72.04 & 7.62 & - & 30 & 8.93 & 17.56 & 32.72 & 8.45 & - \\
\hline 40 & 3.11 & 36.08 & 60.73 & 7.41 & - & 40 & 7.85 & 22.65 & 28.06 & 8.34 & - \\
\hline 50 & 3.01 & 53.26 & 43.28 & 7.31 & - & 50 & 7.10 & 30.04 & 21.44 & 8.26 & - \\
\hline 60 & 3.00 & 71.17 & 26.42 & 7.19 & - & 60 & 6.61 & 38.13 & 11.81 & 8.26 & - \\
\hline \multicolumn{6}{|c|}{ Experimental No.: RD07 } & \multicolumn{6}{|c|}{ Experimental No.: RD08 } \\
\hline $\begin{array}{l}\text { Time } \\
\text { (min) }\end{array}$ & pH & $\begin{array}{c}\mathbf{A s}(\mathbf{V}) \\
(\mathrm{mg} / \mathrm{L})\end{array}$ & $\begin{array}{l}\mathbf{A s}(\mathrm{III}) \\
(\mathrm{mg} / \mathrm{L})\end{array}$ & $\begin{array}{c}\text { DO } \\
\text { (mg/L) }\end{array}$ & $\begin{array}{c}\text { Eh } \\
(\mathrm{mV})\end{array}$ & $\begin{array}{l}\text { Time } \\
(\min )\end{array}$ & pH & $\begin{array}{l}\mathbf{A s}(\mathbf{V}) \\
(\mathrm{mg} / \mathrm{L})\end{array}$ & $\begin{array}{l}\text { As }(\text { III) } \\
\text { (mg/L) }\end{array}$ & $\begin{array}{c}\text { DO } \\
\text { (mg/L) }\end{array}$ & $\begin{array}{c}\text { Eh } \\
(\mathrm{mV})\end{array}$ \\
\hline 0 & 7.46 & ND & 96.87 & 8.28 & - & 0 & 7.63 & ND & 98.99 & 8.26 & - \\
\hline 5 & 8.91 & 5.51 & 93.45 & 8.14 & - & 5 & 8.13 & 17.72 & 82.66 & 5.28 & - \\
\hline 10 & 8.64 & 8.30 & 88.53 & 8.06 & - & 10 & 7.93 & 25.75 & 74.31 & 2.13 & - \\
\hline 15 & 8.21 & 14.18 & 85.57 & 7.86 & - & 15 & 7.52 & 37.08 & 62.59 & 0.44 & - \\
\hline 20 & 7.45 & 18.02 & 80.88 & 7.69 & - & 20 & 6.53 & 48.46 & 51.26 & 4.18 & - \\
\hline 30 & 6.32 & 24.42 & 73.88 & 7.72 & - & 30 & 5.47 & 60.09 & 39.17 & 7.61 & - \\
\hline 40 & 5.53 & 39.39 & 62.51 & 7.68 & - & 40 & 4.22 & 71.83 & 28.33 & 7.74 & - \\
\hline 60 & 4.37 & 76.47 & 36.60 & 7.66 & - & 60 & 3.32 & 100.94 & ND & 7.66 & - \\
\hline \multicolumn{6}{|c|}{ Experimental No.: RD09 } & \multicolumn{6}{|c|}{ Experimental No.: RD10 } \\
\hline $\begin{array}{l}\text { Time } \\
\text { (min) }\end{array}$ & pH & $\begin{array}{c}\mathrm{As}(\mathrm{V}) \\
(\mathrm{mg} / \mathrm{L})\end{array}$ & $\begin{array}{l}\text { As(III) } \\
(\mathrm{mg} / \mathrm{L})\end{array}$ & $\begin{array}{c}\text { DO } \\
(\mathrm{mg} / \mathrm{L}) \\
\end{array}$ & $\begin{array}{c}\text { Eh } \\
(\mathrm{mV})\end{array}$ & $\begin{array}{l}\text { Time } \\
(\mathrm{min})\end{array}$ & pH & $\begin{array}{l}\mathrm{As}(\mathrm{V}) \\
(\mathrm{mg} / \mathrm{L})\end{array}$ & $\begin{array}{l}\text { As(III) } \\
\text { (mg/L) }\end{array}$ & $\begin{array}{c}\text { DO } \\
(\mathrm{mg} / \mathrm{L}) \\
\end{array}$ & $\begin{array}{c}\text { Eh } \\
(\mathrm{mV})\end{array}$ \\
\hline 0 & 7.16 & ND & 96.57 & 8.41 & - & 0 & 7.58 & ND & 96.63 & 8.33 & - \\
\hline 5 & 5.24 & 5.43 & 91.84 & 8.32 & $\cdot$ & 5 & 5.52 & 4.21 & 91.47 & 8.17 & $\cdot$ \\
\hline 10 & 4.33 & 9.62 & 87.68 & 8.11 & - & 10 & 4.33 & 8.64 & 87.46 & 8.00 & - \\
\hline 15 & 3.41 & 11.32 & 86.01 & 7.94 & $\cdot$ & 15 & 3.51 & 11.41 & 84.88 & 7.86 & - \\
\hline 30 & 3.32 & 16.65 & 80.45 & 7.71 & - & 20 & 3.41 & 18.84 & 77.52 & 7.61 & - \\
\hline 40 & 3.24 & 27.96 & 69.34 & 7.68 & - & 30 & 3.32 & 27.46 & 69.16 & 7.54 & - \\
\hline 50 & 3.17 & 38.73 & 58.17 & 7.44 & - & 40 & 3.19 & 39.87 & 57.27 & 7.21 & - \\
\hline 60 & 3.12 & 75.76 & 21.33 & 7.28 & - & 60 & 3.11 & 78.64 & 19.56 & 7.13 & - \\
\hline
\end{tabular}


B.2: AOP with $\mathrm{UV} / \mathrm{H}_{2} \mathrm{O}_{2}$ in Recirculation Reactor

\begin{tabular}{|c|c|c|c|c|c|c|c|c|c|c|c|}
\hline \multicolumn{6}{|c|}{ Experimental No.: RA01 } & \multicolumn{6}{|c|}{ Experimental No.: AA02 } \\
\hline $\begin{array}{l}\text { Time } \\
(\min )\end{array}$ & pH & $\begin{array}{l}\mathbf{A s}(\mathbf{V}) \\
(\mathrm{mg} / \mathrm{L})\end{array}$ & $\begin{array}{l}\text { As(III) } \\
(\mathrm{mg} / \mathrm{L})\end{array}$ & $\begin{array}{c}\text { DO } \\
(\mathrm{mg} / \mathrm{L})\end{array}$ & $\begin{array}{c}\text { Eh } \\
(\mathrm{mV})\end{array}$ & $\begin{array}{l}\text { Time } \\
\text { (min) }\end{array}$ & pH & $\begin{array}{l}\text { As(V) } \\
(\mathrm{mg} / \mathrm{L})\end{array}$ & $\begin{array}{l}\text { As(III) } \\
\text { (mg/L) }\end{array}$ & $\begin{array}{c}\text { DO } \\
(\mathrm{mg} / \mathrm{L})\end{array}$ & $\begin{array}{c}\text { Eh } \\
(\mathrm{mV})\end{array}$ \\
\hline 0 & 2.98 & ND & 96.99 & 8.23 & - & 0 & 3.15 & ND & 95.38 & 8.53 & - \\
\hline 3 & 2.93 & 16.27 & 81.27 & 5.34 & - & 3 & 3.05 & 34.20 & 62.87 & 5.26 & - \\
\hline 5 & 2.89 & 32.23 & 66.38 & 4.02 & - & 5 & 3.00 & 51.20 & 46.11 & 3.27 & - \\
\hline 8 & 2.85 & 55.25 & 43.12 & 3.33 & - & 8 & 2.94 & 72.83 & 25.28 & 1.59 & - \\
\hline 10 & 2.85 & 68.35 & 29.98 & 2.11 & - & 10 & 2.90 & 88.47 & 9.10 & 0.95 & - \\
\hline 15 & 2.85 & 79.65 & 19.10 & 0.59 & - & 15 & 2.87 & 98.26 & ND & 5.79 & - \\
\hline 20 & 2.87 & 89.34 & 9.16 & 1.92 & - & 20 & 2.87 & 98.92 & ND & 10.21 & - \\
\hline 30 & 2.86 & 98.91 & ND & 5.21 & - & 30 & 2.88 & 98.03 & ND & 9.81 & - \\
\hline 60 & 2.86 & 98.91 & ND & 7.86 & - & 60 & 2.87 & 98.03 & ND & 8.31 & - \\
\hline \multicolumn{6}{|c|}{ Experimental No.: RAO3 } & \multicolumn{6}{|c|}{ Experimental No.: RA04 } \\
\hline $\begin{array}{l}\text { Time } \\
(\min )\end{array}$ & pH & $\begin{array}{l}\mathrm{As}(\mathrm{V}) \\
(\mathrm{mg} / \mathrm{L})\end{array}$ & $\begin{array}{l}\text { As(III) } \\
\text { (mg/L) }\end{array}$ & $\begin{array}{c}\text { DO } \\
\text { (mg/L) }\end{array}$ & $\begin{array}{c}\text { Eh } \\
(\mathrm{mV})\end{array}$ & $\begin{array}{l}\text { Time } \\
\text { (min) }\end{array}$ & pH & $\begin{array}{l}\mathrm{As}(\mathrm{V}) \\
(\mathrm{mg} / \mathrm{L})\end{array}$ & $\begin{array}{l}\mathrm{As}(\mathrm{III}) \\
(\mathrm{mg} / \mathrm{L})\end{array}$ & $\begin{array}{c}\text { DO } \\
(\mathrm{mg} / \mathrm{L})\end{array}$ & $\begin{array}{c}\text { Eh } \\
(\mathrm{mV})\end{array}$ \\
\hline 0 & 2.94 & ND & 94.89 & 8.00 & - & 0 & 3.10 & ND & 95.25 & 8.42 & - \\
\hline 3 & 3.06 & 22.31 & 73.13 & 4.59 & - & 3 & 3.03 & 33.75 & 65.85 & 4.93 & - \\
\hline 5 & 3.00 & 43.51 & 53.93 & 1.63 & - & 5 & 2.99 & 48.73 & 50.87 & 1.98 & - \\
\hline 8 & 2.95 & 63.15 & 35.29 & 0.28 & - & 8 & 2.94 & 70.30 & 29.30 & 0.30 & - \\
\hline 10 & 2.91 & 79.29 & 20.19 & 0.27 & - & 10 & 2.92 & 82.98 & 16.62 & 0.25 & - \\
\hline 15 & 2.88 & 100.06 & ND & 1.99 & - & 15 & 2.89 & 99.89 & ND & 1.07 & - \\
\hline 20 & 2.88 & 99.06 & ND & 8.18 & - & 20 & 2.89 & 99.76 & ND & 6.95 & - \\
\hline 30 & 2.89 & 99.40 & ND & 10.44 & - & 30 & 2.91 & 99.37 & ND & 10.68 & - \\
\hline 60 & 2.90 & 99.40 & ND & 8.40 & - & 60 & 2.93 & 99.37 & ND & 8.43 & - \\
\hline \multicolumn{6}{|c|}{ Experimental No.: RA05 } & \multicolumn{6}{|c|}{ Experimental No.: RA06 } \\
\hline $\begin{array}{l}\text { Time } \\
\text { (min) }\end{array}$ & $\mathbf{p H}$ & $\begin{array}{l}\text { As(V) } \\
(m g / L)\end{array}$ & $\begin{array}{l}\text { As(III) } \\
(\mathrm{mg} / \mathrm{L})\end{array}$ & $\begin{array}{c}\text { DO } \\
(\mathrm{mg} / \mathrm{L})\end{array}$ & $\begin{array}{c}\text { Eh } \\
(\mathrm{mV})\end{array}$ & $\begin{array}{l}\text { Time } \\
(\min )\end{array}$ & $\mathbf{p H}$ & $\begin{array}{l}\text { As }(\mathrm{V}) \\
(\mathrm{mg} / \mathrm{L})\end{array}$ & $\begin{array}{l}\text { As(III) } \\
(\mathrm{mg} / \mathrm{L})\end{array}$ & $\begin{array}{c}\text { DO } \\
(\mathrm{mg} / \mathrm{L})\end{array}$ & $\begin{array}{c}\text { Eh } \\
(\mathrm{mV})\end{array}$ \\
\hline 0 & 7.33 & ND & 95.26 & 8.41 & - & 0 & 10.10 & ND & 96.41 & 8.28 & - \\
\hline 3 & 3.41 & 36.14 & 59.62 & 5.68 & - & 3 & 7.26 & 40.66 & 56.66 & 5.40 & - \\
\hline 5 & 3.22 & 52.71 & 43.23 & 3.41 & - & 5 & 6.68 & 65.00 & 33.32 & 3.86 & - \\
\hline 8 & 3.13 & 73.68 & 22.09 & 1.81 & - & 8 & 5.93 & 88.72 & 11.52 & 3.09 & $\cdot$ \\
\hline 10 & 3.06 & 90.26 & 6.14 & 0.92 & - & 10 & 5.22 & 100.49 & ND & 3.87 & - \\
\hline 15 & 3.02 & 98.44 & ND & 6.13 & - & 15 & 5.20 & 100.80 & ND & 8.93 & $\cdot$ \\
\hline 20 & 3.02 & 98.13 & ND & 9.78 & - & 20 & 5.20 & 100.91 & ND & 9.93 & - \\
\hline 30 & 3.00 & 98.07 & ND & 9.64 & - & 30 & 5.21 & 99.51 & ND & 8.83 & - \\
\hline 60 & 3.00 & 97.96 & ND & 8.43 & - & 60 & 5.22 & 99.51 & ND & 8.29 & - \\
\hline
\end{tabular}




\begin{tabular}{|c|c|c|c|c|c|c|c|c|c|c|c|}
\hline \multicolumn{6}{|c|}{ Experimental No.: RA07 } & \multicolumn{6}{|c|}{ Experimental No.: RA08 } \\
\hline $\begin{array}{l}\text { Time } \\
(\min )\end{array}$ & pH & $\begin{array}{l}\mathrm{As}(\mathrm{V}) \\
(\mathrm{mg} / \mathrm{L})\end{array}$ & $\begin{array}{l}\text { As(III) } \\
\text { (mg/L) }\end{array}$ & $\begin{array}{c}\text { DO } \\
\text { (mg/L) }\end{array}$ & $\begin{array}{c}\text { Eh } \\
(\mathrm{mV})\end{array}$ & $\begin{array}{l}\text { Time } \\
(\min )\end{array}$ & $\mathbf{p H}$ & $\begin{array}{l}\mathbf{A s}(\mathbf{V}) \\
(\mathrm{mg} / \mathrm{L})\end{array}$ & $\begin{array}{l}\text { As(III) } \\
(\mathrm{mg} / \mathrm{L})\end{array}$ & $\begin{array}{c}\text { DO } \\
(\mathrm{mg} / \mathrm{L})\end{array}$ & $\begin{array}{c}\text { Eh } \\
(\mathrm{mV})\end{array}$ \\
\hline 0 & 2.98 & ND & 50.54 & 8.16 & . & 0 & 7.83 & ND & 98.32 & 8.34 & - \\
\hline 3 & 2.93 & 20.23 & 30.59 & 5.34 & - & 3 & 6.11 & 42.66 & 57.10 & 5.15 & - \\
\hline 5 & 2.89 & 36.59 & 14.68 & 4.02 & - & 5 & 4.62 & 59.17 & 40.35 & 2.74 & - \\
\hline 8 & 2.85 & 46.91 & 4.48 & 3.33 & - & 8 & 4.58 & 82.13 & 18.16 & 1.24 & - \\
\hline 10 & 2.85 & 50.62 & ND & 5.11 & - & 10 & 4.51 & 100.12 & ND & 0.68 & - \\
\hline 15 & 2.85 & 49.64 & ND & 8.51 & - & 15 & 4.52 & 99.51 & ND & 7.27 & - \\
\hline 20 & 2.87 & 49.80 & ND & 8.92 & - & 30 & 4.51 & 99.48 & ND & 9.56 & - \\
\hline 30 & 2.86 & 49.84 & ND & 8.22 & - & 60 & 4.51 & 99.46 & ND & 9.43 & - \\
\hline 60 & 2.86 & 49.84 & ND & 8.20 & - & & & & & & \\
\hline \multicolumn{6}{|c|}{ Experimental No.: RA09 } & \multicolumn{6}{|c|}{ Experimental No.: RA10 } \\
\hline $\begin{array}{l}\text { Time } \\
(\min )\end{array}$ & pH & $\begin{array}{l}\mathrm{As}(\mathrm{V}) \\
(\mathrm{mg} / \mathrm{L})\end{array}$ & $\begin{array}{l}\text { As(III) } \\
\text { (mg/L) }\end{array}$ & $\begin{array}{c}\text { DO } \\
(\mathrm{mg} / \mathrm{L})\end{array}$ & $\begin{array}{c}\text { Eh } \\
(\mathrm{mV})\end{array}$ & $\begin{array}{l}\text { Time } \\
\text { (min) }\end{array}$ & pH & $\begin{array}{l}\mathrm{As}(\mathrm{V}) \\
(\mathrm{mg} / \mathrm{L})\end{array}$ & $\begin{array}{l}\text { As(III) } \\
\text { (mg/L) }\end{array}$ & $\begin{array}{c}\text { DO } \\
\text { (mg/L) }\end{array}$ & $\begin{array}{c}\text { Eh } \\
(\mathrm{mV})\end{array}$ \\
\hline 0 & 7.62 & ND & 98.17 & 8.19 & - & 0 & 7.41 & ND & 98.11 & 8.16 & - \\
\hline 5 & 3.63 & 13.63 & 86.63 & 7.25 & - & 5 & 3.49 & 37.75 & 62.51 & 5.48 & - \\
\hline 10 & 3.51 & 29.57 & 78.51 & 6.50 & - & 10 & 3.21 & 54.42 & 45.89 & 3.29 & - \\
\hline 15 & 3.42 & 45.22 & 64.93 & 6.66 & - & 15 & 3.16 & 76.68 & 23.37 & 1.94 & - \\
\hline 30 & 3.32 & 57.00 & 58.82 & 6.60 & - & 30 & 3.06 & 89.80 & 10.69 & 1.02 & - \\
\hline 40 & 3.29 & 71.14 & 49.60 & 6.50 & - & 40 & 3.05 & 100.35 & ND & 5.13 & - \\
\hline 50 & 3.24 & 78.40 & 40.14 & 6.44 & $=$ & 50 & 3.04 & 100.01 & ND & 9.46 & - \\
\hline 60 & 3.21 & 88.51 & 12.12 & 6.43 & - & 60 & 3.04 & 99.89 & ND & 9.21 & - \\
\hline
\end{tabular}

\begin{tabular}{cccccc}
\hline \hline \multicolumn{2}{c}{ Experimental No.: RA11 } & & & \\
\hline $\begin{array}{c}\text { Time } \\
(\mathrm{min})\end{array}$ & $\mathrm{pH}$ & $\begin{array}{c}\text { As(V) } \\
(\mathrm{mg} / \mathrm{L})\end{array}$ & $\begin{array}{c}\text { As(III) } \\
(\mathrm{mg} / \mathrm{L})\end{array}$ & $\begin{array}{c}\text { DO } \\
(\mathrm{mg} / \mathrm{L})\end{array}$ & $\begin{array}{c}\text { Eh } \\
(\mathrm{mV})\end{array}$ \\
\hline 0 & 7.59 & $\mathrm{ND}$ & 97.87 & 8.35 & - \\
5 & 3.62 & 39.14 & 61.68 & 5.87 & - \\
10 & 3.32 & 57.33 & 43.66 & 3.44 & - \\
15 & 3.21 & 77.61 & 22.86 & 1.76 & - \\
30 & 3.10 & 92.28 & 8.32 & 0.81 & - \\
40 & 3.10 & 100.14 & $\mathrm{ND}$ & 5.93 & - \\
50 & 3.07 & 99.87 & ND & 9.68 & - \\
60 & 3.07 & 99.65 & ND & 9.43 & - \\
\hline \hline
\end{tabular}

